University of Nebraska - Lincoln

DigitalCommons@University of Nebraska - Lincoln

September 2004

\title{
American Indian Treaties and the Supreme Court: A Guide to Treaty Citations from Opinions of the United States Supreme Court
}

Charles D. Bernholz

University of Nebraska-Lincoln, cbernholz2@unl.edu

Follow this and additional works at: https://digitalcommons.unl.edu/libraryscience

Part of the Library and Information Science Commons

Bernholz, Charles D., "American Indian Treaties and the Supreme Court: A Guide to Treaty Citations from Opinions of the United States Supreme Court" (2004). Faculty Publications, UNL Libraries. 11. https://digitalcommons.unl.edu/libraryscience/11

This Article is brought to you for free and open access by the Libraries at University of Nebraska-Lincoln at DigitalCommons@University of Nebraska - Lincoln. It has been accepted for inclusion in Faculty Publications, UNL Libraries by an authorized administrator of DigitalCommons@University of Nebraska - Lincoln. 


\title{
American Indian treaties and the Supreme Court: A guide to treaty citations from opinions of the United States Supreme Court
}

\author{
Charles D. Bernholz* \\ Love Memorial Library, University of Nebraska, Lincoln, NE 68588-4100, USA
}

Available online 17 January 2004

Scholarship is never done in isolation. It is always influenced by events and by people, sometimes in ways that are difficult to quantify. This article is dedicated with thanks to my friend Bruce Clark. His courage and quests for justice (Justice in Paradise, 1999b), as well as his writings (Indian Title in Canada, 1987; Native Liberty, Crown Sovereignty, 1990), have stimulated my interest in the tribes and in the Indian law of North America.

\begin{abstract}
This guide identifies those 307 United States Supreme Court opinions between 1799 and 2001 that cited one or more federally recognized American Indian treaty. In total, there are 1,325 citation entries to 209 of these 375 recognized instruments. Two tables present these data: one ordered by ratified treaty number and one by Court case title.

(C) 2003 Elsevier Inc. All rights reserved.
\end{abstract}

Keywords: American Indian treaties; Treaty citation; United States Supreme Court

The treaties drawn between the tribes and the United States were-and continue to be-important tools in federal Indian law. The American Indian Law Deskbook reinforces the history of litigation in this area with a large case table (Mazurek,

* Love Memorial Library, University of Nebraska, Lincoln, NE 68588-4100. Fax: +1-402-472-5131.

E-mail address: cbernholz2@unl.edu. 
Wrend, \& Smith, 1998, pp. 431-462). These actions frequently pivoted upon very old negotiated documents, and the recent Minnesota v. Mille Lacs Band of Chippewa Indians (526 U.S. 172 [1999]) decision - with its references to various treaty parameters - is a demonstration that these contracts are living legal instruments within the U.S. federal court system.

Section 8 of Article I of the U.S. Constitution pronounced, "Congress shall have the power...to regulate commerce with...the Indian tribes." This so-called Indian Commerce Clause has been interpreted by the Supreme Court to mean that "with the adoption of the Constitution, Indian relations became the exclusive providence of federal law" (County of Oneida v. Oneida Indian Nation, 470 U.S. 226, 234 [1985]). Indeed, this specific case before the Court concerned the Oneida Indian Nation's claim that their ancestors had conveyed to the State of New York in 1795 lands that had been reserved in a 1788 cession agreement with the State. ${ }^{1}$ This 1795 cession was alleged to be in violation of the second Intercourse Act that forbade land transfers from the tribes without federal approval (1 Stat. 329 [1793]).

Justice Powell, in delivering the Court's opinion, stated, "One would have thought that claims dating back for more than a century and a half would have been barred long ago. As our opinion indicates, however, neither petitioners nor we have found any applicable statute of limitations or other relevant legal basis for holding that the Oneidas' claims are barred or otherwise have been satisfied" (470 U.S. 226, 253 [1985]). He also remarked: "The canons of construction applicable in Indian law are rooted in the unique trust relationship between the United States and the Indians. Thus, it is well established that treaties should be construed liberally in favor of the Indians" (p. 247). Two enduring elements - the trust relationship and the treaties - thus provide a foundation for tribal-federal interactions, particularly before the Court.

Cohen (1942), Wilkinson (1987), Prucha (1994), and Wilkins (1997) have each commented on the interaction of treaties and the Supreme Court. Felix S. Cohen's Handbook of Federal Indian Law has served, for the last 60 years, as a fundamental resource for this area of law. ${ }^{2}$ At the very beginning of his publication, the focus was identified: "Our subject, therefore, cannot be defined in terms of the parties litigant appearing in any case. It must be defined rather in terms of the legal questions which are involved in the case. Where such questions turn upon rights, privileges, powers, or immunities of an Indian or an Indian tribe or an administrative agency set up to deal with Indian affairs, or where governing rules of law are affected by the fact that a place is under Indian ownership or devoted to Indian use, the case that presents such questions belongs within the confines of this study" (Cohen, 1942, p. 1).

A central element in his full discourse concerned tribal sovereignty, "the most basic principle of Indian law" (p. 122). Nathan R. Margold, the Solicitor for the Department of the Interior at that time, echoed this position in the Introduction to the Handbook. He cited Worcester v. Georgia (31 U.S. 515 [1832]) as a pivotal case 
before the Supreme Court that created a strong legal basis for inherent tribal sovereignty ( $\mathrm{p}$. $\mathrm{x}$ ). Cohen made extensive use of Worcester v. Georgia throughout the Handbook. He linked sovereignty to his presentation on the development of a trust relationship between the tribes and the federal government (pp. 169-173), and to the treaty-making process between 1789 and 1871 (pp. 33-66). The perceived, continuing importance of this relationship and of existing treaties was confirmed in the legislation that ended treaty making in 1871: "Provided, further, that nothing herein contained shall be construed to invalidate or impair the obligation of any treaty heretofore lawfully made and ratified with any such Indian nation or tribe" (16 Stat. 544, 566).

Charles F. Wilkinson declared that Indian law is a "time-warped field" because of "the tension between the old laws and the seemingly inexorable pressure of societal change" (Wilkinson, 1987, p. 13). As a signal of transition, he classified Williams v. Lee (358 U.S. 217 [1959]) as the onset of "the modern era of Federal Indian law" (p. 1) and constructed an assembly of 80 critical cases from the 1958 through the 1985 Supreme Court terms. ${ }^{3}$ All these cases illuminate the increased involvement by the Court in Indian concerns, and collectively expose "the task of reconciling nineteenth century laws with twentieth century society" (p. 13). County of Oneida $v$. Oneida Indian Nation was one of those chosen cases. Wilkinson described the decision in this action as "a fit monument of the tribes' continuing efforts to enforce solemn promises of another age" (p. 41). Those "solemn promises," Wilkinson concluded, form the foundation for today: "The field of Indian law rests mainly on the old treaties and treaty substitutes. To understand them, one must reach back to aboriginal sovereignty and forward to the epochal changes that have occurred since in law and civilization. But the inquiry usually returns to these unique documents and their unique promises" (p. 120). These documents continue to clarify the issues of tribal sovereignty, and the linkage to these instruments created by the tribes and the federal government is apparent. Tables 1 and 2 reveal that the County of Oneida v. Oneida Indian Nation opinion contains eight citations to five treaties.

In a substantial history of treaties with the tribes, Francis Paul Prucha devoted a chapter to treaties before the Court (Prucha, 1994, pp. 385-408). He remarked on four particularly important legal concerns during the last few decades: construing Indian treaties, tribal possessory and treaty rights to land, jurisdictional issues arising from reservation parameters in treaties, and gathering rights assured by these documents. Through the use of selected cases, Prucha determined that: "These Supreme Court readings of Indian treaties and of Congress's intent in regard to the rights they stipulated, while not uniformly favorable to the Indians, nevertheless helped significantly to provide an atmosphere in which claims for protection of Indian rights of whatever kind could flourish" (p. 408). Further, he observed that the treaties "have turned out, in the twentieth century, to be one of the principal bastions of protection for the lands, the political autonomy, and the hunting and fishing rights of presentday reservation Indians" (p. 385). 
David E. Wilkins's analysis of the decisions in 15 Indian rights cases before the Court is a recent demonstration of continued interest in this area. He considered the cumulative institutional, social, and historical pressures on the Court to be severe and determined "these decisions have not only had a tremendous, often devastating, impact on tribal sovereign status and aboriginal land title, but they have also contributed significantly to the confusion surrounding relationships between tribal governments and the U.S. government" (Wilkins, 1997, p. 3). He concluded that treaty negotiations ${ }^{4}$ with the federal government were one mechanism to adjust a tribe's sovereign power, but that such modifications affected inherent, not delegated, powers. ${ }^{5}$ Further, Wilkins reasoned that these opinions reveal a Supreme Court that has diminished, and therefore not confirmed, the tribes' rights derived from their inherent powers (p. 309).

Treaties, consequently, have served as important instruments to define the relationship between the federal government and the tribes. It is apparent that a major thrust of these documents conveyed land from, and/or guaranteed rights to, the tribes during the development of the United States. The Oneida, for example, participated in federal treaty negotiations, before and after the 1788 cession agreement with the State of New York cited in their presentation. The Treaty with the Six Nations, 1784 is an early example of their federal treaty activity (Kappler, 1971, pp. 5-6). In Minnesota v. Mille Lacs Band of Chippewa Indians (526 U.S. 172 [1999]), treaty rights formed the basis of the case brought by the band. ${ }^{6}$

An earlier compilation and subsequent update (Bernholz, 2001, 2002) identified, using the Department of State ratified treaty-numbering system, 81 recognized Indian treaties that had never been referenced in opinions at the federal court level. All the 374 ratified treaties in that formal numbering system-plus the never formally promulgated Treaty of Fort Laramie with the Sioux, etc., 1851 (Kappler, 1971, pp. 594-596)—were investigated. ${ }^{7}$ This contribution enumerates those 307 Supreme Court opinions between 1799 and 2001 that cited any remaining Indian treaties. In total, 209 of these 294 instruments may be found as part of the opinions of the Supreme Court. ${ }^{8}$ There are 1325 citation entries to an individual treaty, to a treaty article(s), or to an article section(s) in Table 1.

Cohen, in five reference tables and an index, ${ }^{9}$ assembled data through the middle of 1940 to present "the first comprehensive attempt to collect and systematize the basic materials of Federal Indian law" (1942, p. v). As one example from his "Annotated Table of Statutes and Treaties," he found three proceedings linked to ratified treaty number 8, the Treaty with the Delaware, 1778 (Kappler, 1971, pp. 3-5). ${ }^{10}$ Since the publication of this Handbook, additional cases have referred to this instrument. Table 1 of this article demonstrates that this document (or one of its specific articles) was cited in Cherokee Nation v. Georgia (30 U.S. 1 [1831]), ${ }^{11}$ Warren Trading Post Co. v. Arizona Tax Commission (380 U.S. 865 [1965]), and Oliphant v. Suquamish Indian Tribe (435 U.S. 191 [1978]). The opportunity therefore existed to update Cohen's compilation-while restricting it to only cases before the Supreme Court - and this is the basis of this contribution. There are 308 references, 
Table 1

Indian treaties, listed by Department of State ratified treaty number, which have been cited in the opinions of the U.S. Supreme Court

\begin{tabular}{|c|c|c|c|c|c|c|}
\hline $\begin{array}{l}\text { Ratified } \\
\text { treaty } \\
\text { number }\end{array}$ & $\begin{array}{l}\text { Signatory } \\
\text { tribe(s) }\end{array}$ & $\begin{array}{l}\text { Treaty } \\
\text { signing date }\end{array}$ & $\begin{array}{l}\text { Kappler } \\
\text { page } \\
\text { number }\end{array}$ & $\begin{array}{l}\text { Statutes at } \\
\text { Large or an } \\
\text { alternative } \\
\text { source }\end{array}$ & Case title & U.S. reports \\
\hline 7 & $\begin{array}{l}\text { Six Nations; } \\
\text { Shawnee; } \\
\text { Delaware; } \\
\text { Mingo }\end{array}$ & $\begin{array}{l}5 \text { November } \\
1768\end{array}$ & - & NY 8, 111 & Sims v. Irvine (1799) & $\begin{array}{l}3 \text { U.S. } \\
425,438\end{array}$ \\
\hline 7 & & $\begin{array}{l}5 \text { November } \\
1768\end{array}$ & - & NY 8, 111 & $\begin{array}{l}\text { Kinney v. Clark } \\
(1844)\end{array}$ & $\begin{array}{l}43 \text { U.S. } \\
76,87\end{array}$ \\
\hline 8 & Delaware & $\begin{array}{l}17 \text { September } \\
1778\end{array}$ & 3 & 7 Stat. 13 & $\begin{array}{l}\text { Cherokee Nation v. } \\
\text { Georgia (1831) }\end{array}$ & $\begin{array}{l}30 \text { U.S. } \\
1,65\end{array}$ \\
\hline 8 & & $\begin{array}{l}17 \text { September } \\
1778\end{array}$ & 3 & 7 Stat. 13 & $\begin{array}{l}\text { Worcester v. Georgia } \\
(1832)\end{array}$ & $\begin{array}{l}31 \text { U.S. } \\
515,549\end{array}$ \\
\hline 8 & & $\begin{array}{l}17 \text { September } \\
1778\end{array}$ & 3 & 7 Stat. 13 & $\begin{array}{l}\text { Warren Trading Post } \\
\text { Co. v. Arizona Tax } \\
\text { Commission }(1965)\end{array}$ & $\begin{array}{l}380 \text { U.S. } \\
685,687\end{array}$ \\
\hline 8 & & $\begin{array}{l}17 \text { September } \\
1778\end{array}$ & 3 & 7 Stat. 13 & $\begin{array}{l}\text { Oliphant } v . \\
\text { Suquamish Indian } \\
\text { Tribe (1978) }\end{array}$ & $\begin{array}{l}435 \text { U.S. } \\
191,199(4)\end{array}$ \\
\hline 8 & & $\begin{array}{l}17 \text { September } \\
1778\end{array}$ & 3 & 7 Stat. 13 & $\begin{array}{l}\text { Warren Trading Post } \\
\text { Co. v. Arizona Tax } \\
\text { Commission (1965) }\end{array}$ & $\begin{array}{l}380 \text { U.S. } \\
685,687(5)\end{array}$ \\
\hline 8 & & $\begin{array}{l}17 \text { September } \\
1778\end{array}$ & 3 & 7 Stat. 13 & $\begin{array}{l}\text { Cherokee Nation v. } \\
\text { Georgia (1831) }\end{array}$ & $\begin{array}{l}30 \text { U.S. } 1 \\
44(6)\end{array}$ \\
\hline 9 & Six Nations & $\begin{array}{l}22 \text { October } \\
1784\end{array}$ & 5 & 7 Stat. 15 & $\begin{array}{l}\text { New York Indians } \\
\text { (1867) }\end{array}$ & $\begin{array}{l}72 \text { U.S. } \\
761,762\end{array}$ \\
\hline 9 & & $\begin{array}{l}22 \text { October } \\
1784\end{array}$ & 5 & 7 Stat. 15 & $\begin{array}{l}\text { Federal Power } \\
\text { Commission v. } \\
\text { Tuscarora Indian } \\
\text { Nation (1960) }\end{array}$ & $\begin{array}{l}362 \text { U.S. } \\
99,121\end{array}$ \\
\hline 9 & & $\begin{array}{l}22 \text { October } \\
1784\end{array}$ & 5 & 7 Stat. 15 & $\begin{array}{l}\text { Oneida Indian Nation v. } \\
\text { County of Oneida } \\
\text { (1974) }\end{array}$ & $\begin{array}{l}414 \text { U.S. } \\
661,664\end{array}$ \\
\hline 9 & & $\begin{array}{l}22 \text { October } \\
1784\end{array}$ & 5 & 7 Stat. 15 & $\begin{array}{l}\text { County of Oneida } v . \\
\text { Oneida Indian Nation } \\
(1985)\end{array}$ & $\begin{array}{l}470 \text { U.S. } \\
226,234\end{array}$ \\
\hline 10 & $\begin{array}{l}\text { Wyandot; } \\
\text { Delaware; } \\
\text { Chippewa; } \\
\text { Ottawa }\end{array}$ & $\begin{array}{l}21 \text { January } \\
1785\end{array}$ & 6 & 7 Stat. 16 & $\begin{array}{l}\text { Jones v. Meehan } \\
\text { (1899) }\end{array}$ & $\begin{array}{l}175 \text { U.S. } \\
1,9(2)\end{array}$ \\
\hline 10 & & $\begin{array}{l}21 \text { January } \\
1785\end{array}$ & 6 & 7 Stat. 16 & $\begin{array}{l}\text { Kindred v. Union } \\
\text { Pacific Railroad Co. } \\
\text { (1912) }\end{array}$ & $\begin{array}{l}225 \text { U.S. } \\
582,589+\end{array}$ \\
\hline 11 & Cherokee & $\begin{array}{l}28 \text { November } \\
1785\end{array}$ & 8 & 7 Stat. 18 & $\begin{array}{l}\text { Cherokee Nation v. } \\
\text { Georgia (1831) }\end{array}$ & $\begin{array}{l}30 \text { U.S. } \\
1,4\end{array}$ \\
\hline
\end{tabular}


Table 1 (continued)

\begin{tabular}{|c|c|c|c|c|c|c|}
\hline $\begin{array}{l}\text { Ratified } \\
\text { treaty } \\
\text { number }\end{array}$ & $\begin{array}{l}\text { Signatory } \\
\text { tribe(s) }\end{array}$ & $\begin{array}{l}\text { Treaty } \\
\text { signing date }\end{array}$ & $\begin{array}{l}\text { Kappler } \\
\text { page } \\
\text { number }\end{array}$ & $\begin{array}{l}\text { Statutes at } \\
\text { Large or an } \\
\text { alternative } \\
\text { source }\end{array}$ & Case title & U.S. reports \\
\hline 11 & & $\begin{array}{l}28 \text { November } \\
1785\end{array}$ & 8 & 7 Stat. 18 & $\begin{array}{l}\text { Worcester v. Georgia } \\
(1832)\end{array}$ & $\begin{array}{l}31 \text { U.S. } \\
515,538\end{array}$ \\
\hline 11 & & $\begin{array}{l}28 \text { November } \\
1785\end{array}$ & 8 & 7 Stat. 18 & $\begin{array}{l}\text { Ex parte Crow Dog } \\
(1883)\end{array}$ & $\begin{array}{l}109 \text { U.S. } \\
556,568\end{array}$ \\
\hline 11 & & $\begin{array}{l}28 \text { November } \\
1785\end{array}$ & 8 & 7 Stat. 18 & $\begin{array}{l}\text { Cherokee Trust Funds } \\
\text { (1886) }\end{array}$ & $\begin{array}{l}117 \text { U.S. } \\
288,295\end{array}$ \\
\hline 11 & & $\begin{array}{l}28 \text { November } \\
1785\end{array}$ & 8 & 7 Stat. 18 & $\begin{array}{l}\text { Cherokee Nation v. } \\
\text { Southern Kansas } \\
\text { Railway Co. (1890) }\end{array}$ & $\begin{array}{l}135 \text { U.S. } \\
641,648\end{array}$ \\
\hline 11 & & $\begin{array}{l}28 \text { November } \\
1785\end{array}$ & 8 & 7 Stat. 18 & $\begin{array}{l}\text { United States v. Old } \\
\text { Settlers (1893) }\end{array}$ & $\begin{array}{l}148 \text { U.S. } \\
427,434\end{array}$ \\
\hline 11 & & $\begin{array}{l}28 \text { November } \\
1785\end{array}$ & 8 & 7 Stat. 18 & $\begin{array}{l}\text { Heckman v. United } \\
\text { States }(1912)\end{array}$ & $\begin{array}{l}224 \text { U.S. } \\
413,429\end{array}$ \\
\hline 11 & & $\begin{array}{l}28 \text { November } \\
1785\end{array}$ & 8 & 7 Stat. 18 & Williams v. Lee (1959) & $\begin{array}{l}358 \text { U.S. } \\
217,218\end{array}$ \\
\hline 11 & & $\begin{array}{l}28 \text { November } \\
1785\end{array}$ & 8 & 7 Stat. 18 & $\begin{array}{l}\text { Choctaw Nation v. } \\
\text { Oklahoma }(1970)\end{array}$ & $\begin{array}{l}397 \text { U.S. } \\
620,622\end{array}$ \\
\hline 11 & & $\begin{array}{l}28 \text { November } \\
1785\end{array}$ & 8 & 7 Stat. 18 & $\begin{array}{l}\text { Worcester v. Georgia } \\
(1832)\end{array}$ & $\begin{array}{l}31 \text { U.S. } \\
515,551(1)\end{array}$ \\
\hline 11 & & $\begin{array}{l}28 \text { November } \\
1785\end{array}$ & 8 & 7 Stat. 18 & $\begin{array}{l}\text { Worcester v. Georgia } \\
(1832)\end{array}$ & $\begin{array}{l}31 \text { U.S. } \\
515,551(2)\end{array}$ \\
\hline 11 & & $\begin{array}{l}28 \text { November } \\
1785\end{array}$ & 8 & 7 Stat. 18 & $\begin{array}{l}\text { Cherokee Nation v. } \\
\text { Georgia (1831) }\end{array}$ & $\begin{array}{l}30 \text { U.S. } 1 \\
38(3)\end{array}$ \\
\hline 11 & & $\begin{array}{l}28 \text { November } \\
1785\end{array}$ & 8 & 7 Stat. 18 & $\begin{array}{l}\text { Worcester v. Georgia } \\
(1832)\end{array}$ & $\begin{array}{l}31 \text { U.S. } \\
515,517(3)\end{array}$ \\
\hline 11 & & $\begin{array}{l}28 \text { November } \\
1785\end{array}$ & 8 & 7 Stat. 18 & $\begin{array}{l}\text { Cherokee Nation v. } \\
\text { Georgia }(1831)\end{array}$ & $\begin{array}{l}30 \text { U.S. } 1 \\
23(4)\end{array}$ \\
\hline 11 & & $\begin{array}{l}28 \text { November } \\
1785\end{array}$ & 8 & 7 Stat. 18 & $\begin{array}{l}\text { Worcester v. Georgia } \\
(1832)\end{array}$ & $\begin{array}{l}31 \text { U.S. } 515, \\
552(4)\end{array}$ \\
\hline 11 & & $\begin{array}{l}28 \text { November } \\
1785\end{array}$ & 8 & 7 Stat. 18 & $\begin{array}{l}\text { Lessee of Lattimer } v . \\
\text { Poteet }(1840)\end{array}$ & $\begin{array}{l}39 \text { U.S. } 4, \\
5(4)\end{array}$ \\
\hline 11 & & $\begin{array}{l}28 \text { November } \\
1785\end{array}$ & 8 & 7 Stat. 18 & $\begin{array}{l}\text { Kinney v. Clark } \\
(1844)\end{array}$ & $\begin{array}{l}43 \text { U.S. } \\
76,82(4)\end{array}$ \\
\hline 11 & & $\begin{array}{l}28 \text { November } \\
1785\end{array}$ & 8 & 7 Stat. 18 & $\begin{array}{l}\text { Jones v. Meehan } \\
\text { (1899) }\end{array}$ & $\begin{array}{l}175 \text { U.S. } \\
1,11(4)\end{array}$ \\
\hline 11 & & $\begin{array}{l}28 \text { November } \\
1785\end{array}$ & 8 & 7 Stat. 18 & $\begin{array}{l}\text { Cherokee Nation v. } \\
\text { Georgia }(1831)\end{array}$ & $\begin{array}{l}30 \text { U.S. } 1, \\
70(5)\end{array}$ \\
\hline 11 & & $\begin{array}{l}28 \text { November } \\
1785\end{array}$ & 8 & 7 Stat. 18 & $\begin{array}{l}\text { Worcester v. Georgia } \\
(1832)\end{array}$ & $\begin{array}{l}31 \text { U.S. } \\
515,553(5)\end{array}$ \\
\hline 11 & & $\begin{array}{l}28 \text { November } \\
1785\end{array}$ & 8 & 7 Stat. 18 & $\begin{array}{l}\text { Cherokee Nation v. } \\
\text { Georgia (1831) }\end{array}$ & $\begin{array}{l}30 \text { U.S. } 1 \\
61(6)\end{array}$ \\
\hline 11 & & $\begin{array}{l}28 \text { November } \\
1785\end{array}$ & 8 & 7 Stat. 18 & $\begin{array}{l}\text { Worcester v. Georgia } \\
(1832)\end{array}$ & $\begin{array}{l}31 \text { U.S. } \\
515,518(6)\end{array}$ \\
\hline
\end{tabular}


Table 1 (continued)

\begin{tabular}{|c|c|c|c|c|c|c|}
\hline $\begin{array}{l}\text { Ratified } \\
\text { treaty } \\
\text { number }\end{array}$ & $\begin{array}{l}\text { Signatory } \\
\text { tribe(s) }\end{array}$ & $\begin{array}{l}\text { Treaty } \\
\text { signing date }\end{array}$ & $\begin{array}{l}\text { Kappler } \\
\text { page } \\
\text { number }\end{array}$ & $\begin{array}{l}\text { Statutes at } \\
\text { Large or an } \\
\text { alternative } \\
\text { source }\end{array}$ & Case title & U.S. reports \\
\hline 11 & & $\begin{array}{l}28 \text { November } \\
1785\end{array}$ & 8 & 7 Stat. 18 & $\begin{array}{l}\text { Worcester v. Georgia } \\
(1832)\end{array}$ & $\begin{array}{l}31 \text { U.S. } \\
515,518(7)\end{array}$ \\
\hline 11 & & $\begin{array}{l}28 \text { November } \\
1785\end{array}$ & 8 & 7 Stat. 18 & $\begin{array}{l}\text { Cherokee Nation v. } \\
\text { Georgia (1831) }\end{array}$ & $\begin{array}{l}30 \text { U.S. } 1 \\
25(9)\end{array}$ \\
\hline 11 & & $\begin{array}{l}28 \text { November } \\
1785\end{array}$ & 8 & 7 Stat. 18 & $\begin{array}{l}\text { Cherokee Trust Funds } \\
\text { (1886) }\end{array}$ & $\begin{array}{l}117 \text { U.S. } \\
288,295(9)\end{array}$ \\
\hline 11 & & $\begin{array}{l}28 \text { November } \\
1785\end{array}$ & 8 & 7 Stat. 18 & $\begin{array}{l}\text { Cherokee Nation v. } \\
\text { Georgia (1831) }\end{array}$ & $\begin{array}{l}30 \text { U.S. } 1 \\
25(12)\end{array}$ \\
\hline 12 & Choctaw & $\begin{array}{l}3 \text { January } \\
1786\end{array}$ & 11 & 7 Stat. 21 & $\begin{array}{l}\text { Mullen v. United } \\
\text { States (1912) }\end{array}$ & $\begin{array}{l}224 \text { U.S. } \\
448,449\end{array}$ \\
\hline 12 & & $\begin{array}{l}3 \text { January } \\
1786\end{array}$ & 11 & 7 Stat. 21 & $\begin{array}{l}\text { Choctaw Nation v. } \\
\text { Oklahoma (1970) }\end{array}$ & $\begin{array}{l}397 \text { U.S. } \\
620,622\end{array}$ \\
\hline 12 & & $\begin{array}{l}3 \text { January } \\
1786\end{array}$ & 11 & 7 Stat. 21 & $\begin{array}{l}\text { United States v. John } \\
\text { (1978) }\end{array}$ & $\begin{array}{l}437 \text { U.S. } \\
634,638\end{array}$ \\
\hline 12 & & $\begin{array}{l}3 \text { January } \\
1786\end{array}$ & 11 & 7 Stat. 21 & $\begin{array}{l}\text { Kinney v. Clark } \\
\text { (1844) }\end{array}$ & $\begin{array}{l}43 \text { U.S. } \\
76,82(3)\end{array}$ \\
\hline 12 & & $\begin{array}{l}3 \text { January } \\
1786\end{array}$ & 11 & 7 Stat. 21 & $\begin{array}{l}\text { Menominee Tribe of } \\
\text { Indians } v \text {. United } \\
\text { States }(1968)\end{array}$ & $\begin{array}{l}391 \text { U.S. } \\
404,406(3)\end{array}$ \\
\hline 12 & & $\begin{array}{l}3 \text { January } \\
1786\end{array}$ & 11 & 7 Stat. 21 & $\begin{array}{l}\text { Oliphant } v . \\
\text { Suquamish Indian } \\
\text { Tribe (1978) }\end{array}$ & $\begin{array}{l}435 \text { U.S. } \\
191,198(4)\end{array}$ \\
\hline 13 & Chickasaw & $\begin{array}{l}10 \text { January } \\
1786\end{array}$ & 14 & 7 Stat. 24 & $\begin{array}{l}\text { Kinney v. Clark } \\
\text { (1844) }\end{array}$ & $\begin{array}{l}43 \text { U.S. 76, } \\
82(3)\end{array}$ \\
\hline 13 & & $\begin{array}{l}10 \text { January } \\
1786\end{array}$ & 14 & 7 Stat. 24 & $\begin{array}{l}\text { Kinney v. Clark } \\
\text { (1844) }\end{array}$ & $\begin{array}{l}43 \text { U.S. 76, } \\
83(4)\end{array}$ \\
\hline 14 & Shawnee & $\begin{array}{l}31 \text { January } \\
1786\end{array}$ & 16 & 7 Stat. 26 & $\begin{array}{l}\text { Oliphant } v . \\
\text { Suquamish Indian } \\
\text { Tribe (1978) }\end{array}$ & $\begin{array}{l}435 \text { U.S. } \\
191,198(3)\end{array}$ \\
\hline 14 & & $\begin{array}{l}31 \text { January } \\
1786\end{array}$ & 16 & 7 Stat. 26 & $\begin{array}{l}\text { Menominee Tribe of } \\
\text { Indians v. United } \\
\text { States }(1968)\end{array}$ & $\begin{array}{l}391 \text { U.S. } \\
404,407(6)\end{array}$ \\
\hline 15 & $\begin{array}{l}\text { Wyandot; } \\
\text { Delaware; } \\
\text { Ottawa; } \\
\text { Chippewa; } \\
\text { Potawatomi; } \\
\text { Sac }\end{array}$ & $\begin{array}{l}9 \text { January } \\
1789\end{array}$ & 18 & 7 Stat. 28 & $\begin{array}{l}\text { Kindred v. Union } \\
\text { Pacific Railroad Co. } \\
\text { (1912) }\end{array}$ & $\begin{array}{l}225 \text { U.S. } \\
582,589+\end{array}$ \\
\hline 15 & & $\begin{array}{l}9 \text { January } \\
1789\end{array}$ & 18 & 7 Stat. 28 & $\begin{array}{l}\text { Oklahoma Tax } \\
\text { Commission v. Sac } \\
\text { and Fox Nation } \\
\text { (1993) }\end{array}$ & $\begin{array}{l}508 \text { U.S. } \\
114,116+\end{array}$ \\
\hline 15 & & $\begin{array}{l}9 \text { January } \\
1789\end{array}$ & 18 & 7 Stat. 28 & $\begin{array}{l}\text { Jones v. Meehan } \\
\text { (1899) }\end{array}$ & $\begin{array}{l}175 \text { U.S. 1, } \\
9(3)\end{array}$ \\
\hline
\end{tabular}


Table 1 (continued)

\begin{tabular}{|c|c|c|c|c|c|c|}
\hline $\begin{array}{l}\text { Ratified } \\
\text { treaty } \\
\text { number }\end{array}$ & $\begin{array}{l}\text { Signatory } \\
\text { tribe(s) }\end{array}$ & $\begin{array}{l}\text { Treaty } \\
\text { signing date }\end{array}$ & $\begin{array}{l}\text { Kappler } \\
\text { page } \\
\text { number }\end{array}$ & $\begin{array}{l}\text { Statutes at } \\
\text { Large or an } \\
\text { alternative } \\
\text { source }\end{array}$ & Case title & U.S. reports \\
\hline 15 & & $\begin{array}{l}9 \text { January } \\
1789\end{array}$ & 18 & 7 Stat. 28 & $\begin{array}{l}\text { Menominee Tribe of } \\
\text { Indians v. United } \\
\text { States }(1968)\end{array}$ & $\begin{array}{l}391 \text { U.S. } \\
404,407(3)\end{array}$ \\
\hline 16 & Six Nations & $\begin{array}{l}9 \text { January } \\
1789\end{array}$ & 23 & 7 Stat. 33 & $\begin{array}{l}\text { New York Indians } \\
\text { (1867) }\end{array}$ & $\begin{array}{l}72 \text { U.S. } \\
761,762\end{array}$ \\
\hline 16 & & $\begin{array}{l}9 \text { January } \\
1789\end{array}$ & 23 & 7 Stat. 33 & $\begin{array}{l}\text { Federal Power } \\
\text { Commission v. } \\
\text { Tuscarora Indian } \\
\text { Nation (1960) }\end{array}$ & $\begin{array}{l}362 \text { U.S. } \\
99,121\end{array}$ \\
\hline 16 & & $\begin{array}{l}9 \text { January } \\
1789\end{array}$ & 23 & 7 Stat. 33 & $\begin{array}{l}\text { Oneida Indian Nation } v . \\
\text { County of Oneida } \\
(1974)\end{array}$ & $\begin{array}{l}414 \text { U.S. } \\
661,664\end{array}$ \\
\hline 16 & & $\begin{array}{l}9 \text { January } \\
1789\end{array}$ & 23 & 7 Stat. 33 & $\begin{array}{l}\text { County of Oneida } v . \\
\text { Oneida Indian Nation } \\
(1985)\end{array}$ & $\begin{array}{l}470 \text { U.S. } \\
226,234\end{array}$ \\
\hline 17 & Creek & $\begin{array}{l}7 \text { August } \\
1790\end{array}$ & 25 & 7 Stat. 35 & $\begin{array}{l}\text { Patterson v. Jenks } \\
\text { (1829) }\end{array}$ & $\begin{array}{l}27 \text { U.S. } \\
216,229(4)\end{array}$ \\
\hline 18 & Cherokee & 2 July 1791 & 29 & 7 Stat. 39 & $\begin{array}{l}\text { Preston v. Browder } \\
\text { (1816) }\end{array}$ & $\begin{array}{l}14 \text { U.S. } \\
115,116\end{array}$ \\
\hline 18 & & 2 July 1791 & 29 & 7 Stat. 39 & $\begin{array}{l}\text { Cherokee Nation v. } \\
\text { Georgia (1831) }\end{array}$ & $\begin{array}{l}30 \text { U.S. } \\
1,4\end{array}$ \\
\hline 18 & & 2 July 1791 & 29 & 7 Stat. 39 & $\begin{array}{l}\text { Worcester v. Georgia } \\
(1832)\end{array}$ & $\begin{array}{l}31 \text { U.S. } \\
515,519\end{array}$ \\
\hline 18 & & 2 July 1791 & 29 & 7 Stat. 39 & $\begin{array}{l}\text { Kinney v. Clark } \\
(1844)\end{array}$ & $\begin{array}{l}43 \text { U.S. } 97, \\
120\end{array}$ \\
\hline 18 & & 2 July 1791 & 29 & 7 Stat. 39 & $\begin{array}{l}\text { Cherokee Trust Funds } \\
\text { (1886) }\end{array}$ & $\begin{array}{l}117 \text { U.S. } \\
288,295\end{array}$ \\
\hline 18 & & 2 July 1791 & 29 & 7 Stat. 39 & $\begin{array}{l}\text { United States v. } \\
\text { Cherokee Nation } \\
\text { (1906) }\end{array}$ & $\begin{array}{l}202 \text { U.S. } \\
101,127\end{array}$ \\
\hline 18 & & 2 July 1791 & 29 & 7 Stat. 39 & $\begin{array}{l}\text { Heckman v. United } \\
\text { States (1912) }\end{array}$ & $\begin{array}{l}224 \text { U.S. } \\
413,429\end{array}$ \\
\hline 18 & & 2 July 1791 & 29 & 7 Stat. 39 & $\begin{array}{l}\text { Northwestern Bands } \\
\text { of Shoshone Indians v. } \\
\text { United States (1945) }\end{array}$ & $\begin{array}{l}324 \text { U.S. } \\
335,348\end{array}$ \\
\hline 18 & & 2 July 1791 & 29 & 7 Stat. 39 & Williams v. Lee (1959) & $\begin{array}{l}358 \text { U.S. } \\
217,218\end{array}$ \\
\hline 18 & & 2 July 1791 & 29 & 7 Stat. 39 & $\begin{array}{l}\text { Worcester v. Georgia } \\
(1832)\end{array}$ & $\begin{array}{l}31 \text { U.S. } \\
515,555(1)\end{array}$ \\
\hline 18 & & 2 July 1791 & 29 & 7 Stat. 39 & $\begin{array}{l}\text { Cherokee Trust Funds } \\
\text { (1886) }\end{array}$ & $\begin{array}{l}117 \text { U.S. } \\
288,295(1)\end{array}$ \\
\hline 18 & & 2 July 1791 & 29 & 7 Stat. 39 & $\begin{array}{l}\text { Cherokee Nation v. } \\
\text { Georgia (1831) }\end{array}$ & $\begin{array}{l}30 \text { U.S. 1, } \\
46(2)\end{array}$ \\
\hline
\end{tabular}


Table 1 (continued)

\begin{tabular}{|c|c|c|c|c|c|c|}
\hline $\begin{array}{l}\text { Ratified } \\
\text { treaty } \\
\text { number }\end{array}$ & $\begin{array}{l}\text { Signatory } \\
\text { tribe(s) }\end{array}$ & $\begin{array}{l}\text { Treaty } \\
\text { signing date }\end{array}$ & $\begin{array}{l}\text { Kappler } \\
\text { page } \\
\text { number }\end{array}$ & $\begin{array}{l}\text { Statutes at } \\
\text { Large or an } \\
\text { alternative } \\
\text { source }\end{array}$ & Case title & U.S. reports \\
\hline 18 & & 2 July 1791 & 29 & 7 Stat. 39 & $\begin{array}{l}\text { Worcester v. Georgia } \\
(1832)\end{array}$ & $\begin{array}{l}31 \text { U.S. } \\
515,555(2)\end{array}$ \\
\hline 18 & & 2 July 1791 & 29 & 7 Stat. 39 & $\begin{array}{l}\text { Worcester v. Georgia } \\
(1832)\end{array}$ & $\begin{array}{l}31 \text { U.S. } \\
515,555(3)\end{array}$ \\
\hline 18 & & 2 July 1791 & 29 & 7 Stat. 39 & $\begin{array}{l}\text { Cherokee Nation v. } \\
\text { Georgia (1831) }\end{array}$ & $\begin{array}{l}30 \text { U.S. } 1 \text {, } \\
70(4)\end{array}$ \\
\hline 18 & & 2 July 1791 & 29 & 7 Stat. 39 & $\begin{array}{l}\text { Worcester v. Georgia } \\
(1832)\end{array}$ & $\begin{array}{l}31 \text { U.S. } \\
515,555(4)\end{array}$ \\
\hline 18 & & 2 July 1791 & 29 & 7 Stat. 39 & $\begin{array}{l}\text { Lessee of Lattimer } v . \\
\text { Poteet }(1840)\end{array}$ & $\begin{array}{l}39 \text { U.S. } 4 \\
8(4)\end{array}$ \\
\hline 18 & & 2 July 1791 & 29 & 7 Stat. 39 & $\begin{array}{l}\text { Worcester v. Georgia } \\
(1832)\end{array}$ & $\begin{array}{l}31 \text { U.S. } \\
515,556(5)\end{array}$ \\
\hline 18 & & 2 July 1791 & 29 & 7 Stat. 39 & $\begin{array}{l}\text { Worcester v. Georgia } \\
\text { (1832) }\end{array}$ & $\begin{array}{l}31 \text { U.S. } \\
515,556(6)\end{array}$ \\
\hline 18 & & 2 July 1791 & 29 & 7 Stat. 39 & $\begin{array}{l}\text { Cherokee Nation v. } \\
\text { Georgia (1831) }\end{array}$ & $\begin{array}{l}30 \text { U.S. } 1 \text {, } \\
25(7)\end{array}$ \\
\hline 18 & & 2 July 1791 & 29 & 7 Stat. 39 & $\begin{array}{l}\text { Worcester v. Georgia } \\
(1832)\end{array}$ & $\begin{array}{l}31 \text { U.S. } \\
515,556(7)\end{array}$ \\
\hline 18 & & 2 July 1791 & 29 & 7 Stat. 39 & $\begin{array}{l}\text { Choctaw Nation v. } \\
\text { Oklahoma (1970) }\end{array}$ & $\begin{array}{l}397 \text { U.S. } \\
620,623(7)\end{array}$ \\
\hline 18 & & 2 July 1791 & 29 & 7 Stat. 39 & $\begin{array}{l}\text { Cherokee Nation v. } \\
\text { Georgia (1831) }\end{array}$ & $\begin{array}{l}30 \text { U.S. } 1 \\
70(8)\end{array}$ \\
\hline 18 & & 2 July 1791 & 29 & 7 Stat. 39 & $\begin{array}{l}\text { Worcester v. Georgia } \\
(1832)\end{array}$ & $\begin{array}{l}31 \text { U.S. } \\
515,556(8)\end{array}$ \\
\hline 18 & & 2 July 1791 & 29 & 7 Stat. 39 & $\begin{array}{l}\text { Worcester v. Georgia } \\
(1832)\end{array}$ & $\begin{array}{l}31 \text { U.S. } \\
515,556(9)\end{array}$ \\
\hline 18 & & 2 July 1791 & 29 & 7 Stat. 39 & $\begin{array}{l}\text { Cherokee Nation v. } \\
\text { Georgia (1831) }\end{array}$ & $\begin{array}{l}30 \text { U.S. } 1 \\
61(11)\end{array}$ \\
\hline 18 & & 2 July 1791 & 29 & 7 Stat. 39 & $\begin{array}{l}\text { Cherokee Nation v. } \\
\text { Georgia (1831) }\end{array}$ & $\begin{array}{l}30 \text { U.S. } 1 \\
5(14)\end{array}$ \\
\hline 18 & & 2 July 1791 & 29 & 7 Stat. 39 & $\begin{array}{l}\text { Cherokee Nation v. } \\
\text { Georgia (1831) }\end{array}$ & $\begin{array}{l}30 \text { U.S. } 1 \\
71(16)\end{array}$ \\
\hline 19 & Five Nations & 23 April 1792 & 1027 & $\begin{array}{l}\text { ASP: IA 1, } \\
232\end{array}$ & $\begin{array}{l}\text { Federal Power } \\
\text { Commission v. } \\
\text { Tuscarora Indian } \\
\text { Nation }(1960)\end{array}$ & $\begin{array}{l}362 \text { U.S. } \\
99,121\end{array}$ \\
\hline 20 & Cherokee & 26 June 1794 & 33 & 7 Stat. 43 & $\begin{array}{l}\text { Cherokee Nation v. } \\
\text { Georgia (1831) }\end{array}$ & $\begin{array}{l}30 \text { U.S. } \\
1,5\end{array}$ \\
\hline 20 & & 26 June 1794 & 33 & 7 Stat. 43 & $\begin{array}{l}\text { Worcester v. Georgia } \\
(1832)\end{array}$ & $\begin{array}{l}31 \text { U.S. } \\
515,538\end{array}$ \\
\hline 20 & & 26 June 1794 & 33 & 7 Stat. 43 & $\begin{array}{l}\text { Lessee of Lattimer } v . \\
\text { Poteet }(1840)\end{array}$ & $\begin{array}{l}39 \text { U.S. } \\
4,6\end{array}$ \\
\hline 20 & & 26 June 1794 & 33 & 7 Stat. 43 & $\begin{array}{l}\text { Cherokee Trust Funds } \\
\text { (1886) }\end{array}$ & $\begin{array}{l}117 \text { U.S. } \\
288,296\end{array}$ \\
\hline
\end{tabular}


Table 1 (continued)

\begin{tabular}{|c|c|c|c|c|c|c|}
\hline $\begin{array}{l}\text { Ratified } \\
\text { treaty } \\
\text { number }\end{array}$ & $\begin{array}{l}\text { Signatory } \\
\text { tribe(s) }\end{array}$ & $\begin{array}{l}\text { Treaty } \\
\text { signing date }\end{array}$ & $\begin{array}{l}\text { Kappler } \\
\text { page } \\
\text { number }\end{array}$ & $\begin{array}{l}\text { Statutes at } \\
\text { Large or an } \\
\text { alternative } \\
\text { source }\end{array}$ & Case title & U.S. reports \\
\hline 20 & & 26 June 1794 & 33 & 7 Stat. 43 & $\begin{array}{l}\text { Lessee of Lattimer } v . \\
\text { Poteet }(1840)\end{array}$ & $\begin{array}{l}39 \text { U.S. 4, } \\
6(2)\end{array}$ \\
\hline 21 & Six Nations & $\begin{array}{l}11 \text { November } \\
1794\end{array}$ & 34 & 7 Stat. 44 & $\begin{array}{l}\text { New York Indians } \\
(1867)\end{array}$ & $\begin{array}{l}72 \text { U.S. } \\
761,766\end{array}$ \\
\hline 21 & & $\begin{array}{l}11 \text { November } \\
1794\end{array}$ & 34 & 7 Stat. 44 & $\begin{array}{l}\text { Seneca Nation v. } \\
\text { Christy (1896) }\end{array}$ & $\begin{array}{l}162 \text { U.S. } \\
283,285\end{array}$ \\
\hline 21 & & $\begin{array}{l}11 \text { November } \\
1794\end{array}$ & 34 & 7 Stat. 44 & $\begin{array}{l}\text { Massachusetts v. New } \\
\text { York (1926) }\end{array}$ & $\begin{array}{l}271 \text { U.S. } \\
65,83\end{array}$ \\
\hline 21 & & $\begin{array}{l}11 \text { November } \\
1794\end{array}$ & 34 & 7 Stat. 44 & $\begin{array}{l}\text { New York ex rel. Ray v. } \\
\text { Martin }(1946)\end{array}$ & $\begin{array}{l}326 \text { U.S. } \\
496,500\end{array}$ \\
\hline 21 & & $\begin{array}{l}11 \text { November } \\
1794\end{array}$ & 34 & 7 Stat. 44 & $\begin{array}{l}\text { Federal Power } \\
\text { Commission v. } \\
\text { Tuscarora Indian } \\
\text { Nation (1960) }\end{array}$ & $\begin{array}{l}362 \text { U.S. } \\
99,121\end{array}$ \\
\hline 21 & & $\begin{array}{l}11 \text { November } \\
1794\end{array}$ & 34 & 7 Stat. 44 & $\begin{array}{l}\text { Oneida Indian Nation v. } \\
\text { County of Oneida } \\
(1974)\end{array}$ & $\begin{array}{l}414 \text { U.S. } \\
661,664\end{array}$ \\
\hline 21 & & $\begin{array}{l}11 \text { November } \\
1794\end{array}$ & 34 & 7 Stat. 44 & $\begin{array}{l}\text { County of Oneida } v . \\
\text { Oneida Indian Nation } \\
(1985)\end{array}$ & $\begin{array}{l}470 \text { U.S. } \\
226,234\end{array}$ \\
\hline 21 & & $\begin{array}{l}11 \text { November } \\
1794\end{array}$ & 34 & 7 Stat. 44 & $\begin{array}{l}\text { County of Oneida } v . \\
\text { Oneida Indian Nation } \\
(1985)\end{array}$ & $\begin{array}{l}470 \text { U.S. } \\
226,231(2)\end{array}$ \\
\hline 21 & & $\begin{array}{l}11 \text { November } \\
1794\end{array}$ & 34 & 7 Stat. 44 & $\begin{array}{l}\text { New York Indians } \\
(1867)\end{array}$ & $\begin{array}{l}72 \text { U.S. } \\
761,766(3)\end{array}$ \\
\hline 21 & & $\begin{array}{l}11 \text { November } \\
1794\end{array}$ & 34 & 7 Stat. 44 & $\begin{array}{l}\text { Massachusetts } v \text {. } \\
\text { New York (1926) }\end{array}$ & $\begin{array}{l}271 \text { U.S. } \\
65,83(3)\end{array}$ \\
\hline 21 & & $\begin{array}{l}11 \text { November } \\
1794\end{array}$ & 34 & 7 Stat. 44 & $\begin{array}{l}\text { Federal Power } \\
\text { Commission v. } \\
\text { Tuscarora Indian } \\
\text { Nation (1960) }\end{array}$ & $\begin{array}{l}362 \text { U.S. } \\
99,137(3)\end{array}$ \\
\hline 21 & & $\begin{array}{l}11 \text { November } \\
1794\end{array}$ & 34 & 7 Stat. 44 & $\begin{array}{l}\text { Federal Power } \\
\text { Commission v. } \\
\text { Tuscarora Indian } \\
\text { Nation (1960) }\end{array}$ & $\begin{array}{l}362 \text { U.S. } \\
99,122(6)\end{array}$ \\
\hline 21 & & $\begin{array}{l}11 \text { November } \\
1794\end{array}$ & 34 & 7 Stat. 44 & $\begin{array}{l}\text { New York ex rel. Ray } v \text {. } \\
\text { Martin }(1946)\end{array}$ & $\begin{array}{l}326 \text { U.S. } \\
496,497(7)\end{array}$ \\
\hline 21 & & $\begin{array}{l}11 \text { November } \\
1794\end{array}$ & 34 & 7 Stat. 44 & $\begin{array}{l}\text { County of Oneida } v . \\
\text { Oneida Indian Nation } \\
(1985)\end{array}$ & $\begin{array}{l}470 \text { U.S. } \\
226,247(7)\end{array}$ \\
\hline 22 & $\begin{array}{l}\text { Oneida; } \\
\text { Tuscarora; } \\
\text { Stockbridge }\end{array}$ & $\begin{array}{l}2 \text { December } \\
1794\end{array}$ & 37 & 7 Stat. 47 & $\begin{array}{l}\text { Federal Power } \\
\text { Commission v. } \\
\text { Tuscarora Indian } \\
\text { Nation (1960) }\end{array}$ & $\begin{array}{l}362 \text { U.S. } \\
99,137\end{array}$ \\
\hline
\end{tabular}


Table 1 (continued)

\begin{tabular}{|c|c|c|c|c|c|c|}
\hline $\begin{array}{l}\text { Ratified } \\
\text { treaty } \\
\text { number }\end{array}$ & $\begin{array}{l}\text { Signatory } \\
\text { tribe(s) }\end{array}$ & $\begin{array}{l}\text { Treaty } \\
\text { signing date }\end{array}$ & $\begin{array}{l}\text { Kappler } \\
\text { page } \\
\text { number }\end{array}$ & $\begin{array}{l}\text { Statutes at } \\
\text { Large or an } \\
\text { alternative } \\
\text { source }\end{array}$ & Case title & U.S. reports \\
\hline 23 & $\begin{array}{l}\text { Wyandot; } \\
\text { Delaware; } \\
\text { Shawnee; } \\
\text { Ottawa; } \\
\text { Chippewa; } \\
\text { Potawatomi; } \\
\text { Miami; Eel } \\
\text { River; Wea; } \\
\text { Kickapoo; } \\
\text { Piankashaw; } \\
\text { Kaskaskia }\end{array}$ & $\begin{array}{l}3 \text { August } \\
1795\end{array}$ & 39 & 7 Stat. 49 & $\begin{array}{l}\text { Reynolds v. M'Arthur } \\
\text { (1829) }\end{array}$ & $\begin{array}{l}27 \text { U.S. } \\
417,419\end{array}$ \\
\hline 23 & & $\begin{array}{l}3 \text { August } \\
1795\end{array}$ & 39 & 7 Stat. 49 & $\begin{array}{l}\text { United States v. } \\
\text { Arredondo (1832) }\end{array}$ & $\begin{array}{l}31 \text { U.S. } \\
691,712\end{array}$ \\
\hline 23 & & $\begin{array}{l}3 \text { August } \\
1795\end{array}$ & 39 & 7 Stat. 49 & $\begin{array}{l}\text { Kindred v. Union } \\
\text { Pacific Railroad Co. } \\
\text { (1912) }\end{array}$ & $\begin{array}{l}225 \text { U.S. } \\
582,589+\end{array}$ \\
\hline 23 & & $\begin{array}{l}3 \text { August } \\
1795\end{array}$ & 39 & 7 Stat. 49 & $\begin{array}{l}\text { Williams v. Chicago } \\
\text { (1917) }\end{array}$ & $\begin{array}{l}242 \text { U.S. } \\
434,434\end{array}$ \\
\hline 23 & & $\begin{array}{l}3 \text { August } \\
1795\end{array}$ & 39 & 7 Stat. 49 & $\begin{array}{l}\text { Chippewa Indians of } \\
\text { Minnesota v. United } \\
\text { States (1937) }\end{array}$ & $\begin{array}{l}301 \text { U.S. } \\
358,361\end{array}$ \\
\hline 23 & & $\begin{array}{l}3 \text { August } \\
1795\end{array}$ & 39 & 7 Stat. 49 & $\begin{array}{l}\text { Pam-To-Pee v. United } \\
\text { States (1893) }\end{array}$ & $\begin{array}{l}148 \text { U.S. } \\
691,698(4)\end{array}$ \\
\hline 23 & & $\begin{array}{l}3 \text { August } \\
1795\end{array}$ & 39 & 7 Stat. 49 & $\begin{array}{l}\text { Cherokee Nation v. } \\
\text { Blackfeather (1894) }\end{array}$ & $\begin{array}{l}155 \text { U.S. } \\
218,219(4)\end{array}$ \\
\hline 23 & & $\begin{array}{l}3 \text { August } \\
1795\end{array}$ & 39 & 7 Stat. 49 & $\begin{array}{l}\text { Jones v. Meehan } \\
\text { (1899) }\end{array}$ & $\begin{array}{l}175 \text { U.S. 1, } \\
9(4)\end{array}$ \\
\hline 23 & & $\begin{array}{l}3 \text { August } \\
1795\end{array}$ & 39 & 7 Stat. 49 & $\begin{array}{l}\text { Jones v. Meehan } \\
\text { (1899) }\end{array}$ & $\begin{array}{l}175 \text { U.S. 1, } \\
9(5)\end{array}$ \\
\hline 23 & & $\begin{array}{l}3 \text { August } \\
1795\end{array}$ & 39 & 7 Stat. 49 & $\begin{array}{l}\text { Menominee Tribe of } \\
\text { Indians v. United } \\
\text { States (1968) }\end{array}$ & $\begin{array}{l}391 \text { U.S. } \\
404,407(5)\end{array}$ \\
\hline 27 & Seneca & $\begin{array}{l}\text { 15 September } \\
1797\end{array}$ & 1027 & 7 Stat. 601 & $\begin{array}{l}\text { New York Indians } \\
\text { (1867) }\end{array}$ & $\begin{array}{l}72 \text { U.S. } \\
761,762\end{array}$ \\
\hline 27 & & $\begin{array}{l}15 \text { September } \\
1797\end{array}$ & 1027 & 7 Stat. 601 & $\begin{array}{l}\text { New York ex rel. } \\
\text { Kennedy v. Becker } \\
\text { (1916) }\end{array}$ & $\begin{array}{l}241 \text { U.S. } \\
556,560\end{array}$ \\
\hline 27 & & $\begin{array}{l}15 \text { September } \\
1797\end{array}$ & 1027 & 7 Stat. 601 & $\begin{array}{l}\text { Federal Power } \\
\text { Commission v. } \\
\text { Tuscarora Indian } \\
\text { Nation }(1960)\end{array}$ & $\begin{array}{l}362 \text { U.S. } \\
99,121\end{array}$ \\
\hline 27 & & $\begin{array}{l}15 \text { September } \\
1797\end{array}$ & 1027 & 7 Stat. 601 & $\begin{array}{l}\text { Minnesota v. Mille } \\
\text { Lacs Band of } \\
\text { Chippewa Indians } \\
\text { (1999) }\end{array}$ & $\begin{array}{l}526 \text { U.S. } \\
172,172\end{array}$ \\
\hline
\end{tabular}


Table 1 (continued)

\begin{tabular}{|c|c|c|c|c|c|c|}
\hline $\begin{array}{l}\text { Ratified } \\
\text { treaty } \\
\text { number }\end{array}$ & $\begin{array}{l}\text { Signatory } \\
\text { tribe(s) }\end{array}$ & $\begin{array}{l}\text { Treaty } \\
\text { signing date }\end{array}$ & $\begin{array}{l}\text { Kappler } \\
\text { page } \\
\text { number }\end{array}$ & $\begin{array}{l}\text { Statutes at } \\
\text { Large or an } \\
\text { alternative } \\
\text { source }\end{array}$ & Case title & U.S. reports \\
\hline 27 & & $\begin{array}{l}15 \text { September } \\
1797\end{array}$ & 1027 & 7 Stat. 601 & $\begin{array}{l}\text { Minnesota v. Mille } \\
\text { Lacs Band of } \\
\text { Chippewa Indians } \\
\text { (1999) }\end{array}$ & $\begin{array}{l}526 \text { U.S. } \\
172,224\end{array}$ \\
\hline 28 & Oneida & 1 June 1798 & - & $\begin{array}{l}\text { ASP: IA 1, } \\
641\end{array}$ & $\begin{array}{l}\text { County of Oneida v. } \\
\text { Oneida Indian Nation } \\
(1985)\end{array}$ & $\begin{array}{l}470 \text { U.S. } \\
226,246\end{array}$ \\
\hline 29 & Cherokee & $\begin{array}{l}2 \text { October } \\
1798\end{array}$ & 51 & 7 Stat. 62 & $\begin{array}{l}\text { Preston v. Browder } \\
\text { (1816) }\end{array}$ & $\begin{array}{l}14 \text { U.S. } \\
115,116\end{array}$ \\
\hline 29 & & $\begin{array}{l}2 \text { October } \\
1798\end{array}$ & 51 & 7 Stat. 62 & $\begin{array}{l}\text { Cherokee Nation v. } \\
\text { Georgia (1831) }\end{array}$ & $\begin{array}{l}30 \text { U.S. } \\
1,5\end{array}$ \\
\hline 29 & & $\begin{array}{l}2 \text { October } \\
1798\end{array}$ & 51 & 7 Stat. 62 & $\begin{array}{l}\text { Worcester v. Georgia } \\
\text { (1832) }\end{array}$ & $\begin{array}{l}31 \text { U.S. } \\
515,538\end{array}$ \\
\hline 29 & & $\begin{array}{l}2 \text { October } \\
1798\end{array}$ & 51 & 7 Stat. 62 & $\begin{array}{l}\text { Lessee of Lattimer } v . \\
\text { Poteet }(1840)\end{array}$ & $\begin{array}{l}39 \text { U.S. } \\
4,8\end{array}$ \\
\hline 29 & & $\begin{array}{l}2 \text { October } \\
1798\end{array}$ & 51 & 7 Stat. 62 & $\begin{array}{l}\text { Cherokee Trust Funds } \\
\text { (1886) }\end{array}$ & $\begin{array}{l}117 \text { U.S. } \\
288,296\end{array}$ \\
\hline 29 & & $\begin{array}{l}2 \text { October } \\
1798\end{array}$ & 51 & 7 Stat. 62 & $\begin{array}{l}\text { Cherokee Nation v. } \\
\text { Southern Kansas } \\
\text { Railway Co. (1890) }\end{array}$ & $\begin{array}{l}135 \text { U.S. } \\
641,654\end{array}$ \\
\hline 29 & & $\begin{array}{l}2 \text { October } \\
1798\end{array}$ & 51 & 7 Stat. 62 & $\begin{array}{l}\text { Choctaw Nation v. } \\
\text { Oklahoma (1970) }\end{array}$ & $\begin{array}{l}397 \text { U.S. } \\
620,623\end{array}$ \\
\hline 29 & & $\begin{array}{l}2 \text { October } \\
1798\end{array}$ & 51 & 7 Stat. 62 & $\begin{array}{l}\text { Lessee of Lattimer v. } \\
\text { Poteet }(1840)\end{array}$ & $\begin{array}{l}39 \text { U.S. } 4, \\
10(2)\end{array}$ \\
\hline 29 & & $\begin{array}{l}2 \text { October } \\
1798\end{array}$ & 51 & 7 Stat. 62 & $\begin{array}{l}\text { Lessee of Lattimer v. } \\
\text { Poteet }(1840)\end{array}$ & $\begin{array}{l}39 \text { U.S. } 4, \\
11(3)\end{array}$ \\
\hline 29 & & $\begin{array}{l}2 \text { October } \\
1798\end{array}$ & 51 & 7 Stat. 62 & $\begin{array}{l}\text { Lessee of Lattimer } v . \\
\text { Poteet }(1840)\end{array}$ & $\begin{array}{l}39 \text { U.S. } 4 \\
8(4)\end{array}$ \\
\hline 29 & & $\begin{array}{l}2 \text { October } \\
1798\end{array}$ & 51 & 7 Stat. 62 & $\begin{array}{l}\text { Lessee of Lattimer } v . \\
\text { Poteet }(1840)\end{array}$ & $\begin{array}{l}39 \text { U.S. } 4 \text {, } \\
9(5)\end{array}$ \\
\hline 31 & Choctaw & $\begin{array}{l}17 \text { December } \\
1801\end{array}$ & 56 & 7 Stat. 66 & $\begin{array}{l}\text { Choctaw Nation v. } \\
\text { Oklahoma (1970) }\end{array}$ & $\begin{array}{l}397 \text { U.S. } \\
620,623\end{array}$ \\
\hline 31 & & $\begin{array}{l}17 \text { December } \\
1801\end{array}$ & 56 & 7 Stat. 66 & $\begin{array}{l}\text { United States v. John } \\
\text { (1978) }\end{array}$ & $\begin{array}{l}437 \text { U.S. } \\
634,638\end{array}$ \\
\hline 32 & Creek & 16 June 1802 & 58 & 7 Stat. 68 & $\begin{array}{l}\text { Coffee v. Groover } \\
\text { (1887) }\end{array}$ & $\begin{array}{l}123 \text { U.S. } \\
1,14\end{array}$ \\
\hline 33 & Seneca & 30 June 1802 & 60 & 7 Stat. 70 & $\begin{array}{l}\text { New York Indians } \\
(1867)\end{array}$ & $\begin{array}{l}72 \text { U.S. } \\
761,762\end{array}$ \\
\hline 35 & Choctaw & $\begin{array}{l}17 \text { October } \\
1802\end{array}$ & 63 & 7 Stat. 73 & $\begin{array}{l}\text { United States v. John } \\
\text { (1978) }\end{array}$ & $\begin{array}{l}437 \text { U.S. } \\
634,638\end{array}$ \\
\hline 38 & $\begin{array}{l}\text { Kaskaskia; } \\
\text { Michigamea; } \\
\text { Cahokia; } \\
\text { Tamaroa }\end{array}$ & $\begin{array}{l}13 \text { August } \\
1803\end{array}$ & 67 & 7 Stat. 78 & $\begin{array}{l}\text { Wallace v. Jaffree } \\
\text { (1985) }\end{array}$ & $\begin{array}{l}472 \text { U.S. } \\
38,103\end{array}$ \\
\hline
\end{tabular}


Table 1 (continued)

\begin{tabular}{|c|c|c|c|c|c|c|}
\hline $\begin{array}{l}\text { Ratified } \\
\text { treaty } \\
\text { number }\end{array}$ & $\begin{array}{l}\text { Signatory } \\
\text { tribe(s) }\end{array}$ & $\begin{array}{l}\text { Treaty } \\
\text { signing date }\end{array}$ & $\begin{array}{l}\text { Kappler } \\
\text { page } \\
\text { number }\end{array}$ & $\begin{array}{l}\text { Statutes at } \\
\text { Large or an } \\
\text { alternative } \\
\text { source }\end{array}$ & Case title & U.S. reports \\
\hline 39 & Choctaw & $\begin{array}{l}31 \text { August } \\
1803\end{array}$ & 69 & 7 Stat. 80 & $\begin{array}{l}\text { United States v. John } \\
\text { (1978) }\end{array}$ & $\begin{array}{l}437 \text { U.S. } \\
634,638\end{array}$ \\
\hline 40 & Delaware & $\begin{array}{l}18 \text { August } \\
1804\end{array}$ & 70 & 7 Stat. 81 & $\begin{array}{l}\text { Cherokee Nation v. } \\
\text { Georgia (1831) }\end{array}$ & $\begin{array}{l}30 \text { U.S. } \\
1,65\end{array}$ \\
\hline 42 & Cherokee & $\begin{array}{l}24 \text { October } \\
1804\end{array}$ & 73 & 7 Stat. 228 & $\begin{array}{l}\text { Cherokee Nation v. } \\
\text { Georgia (1831) }\end{array}$ & $\begin{array}{l}30 \text { U.S. } \\
1,5\end{array}$ \\
\hline 42 & & $\begin{array}{l}24 \text { October } \\
1804\end{array}$ & 73 & 7 Stat. 228 & $\begin{array}{l}\text { Worcester v. Georgia } \\
(1832)\end{array}$ & $\begin{array}{l}31 \text { U.S. } \\
515,538\end{array}$ \\
\hline 43 & Sac and Fox & $\begin{array}{l}3 \text { November } \\
1804\end{array}$ & 74 & 7 Stat. 84 & $\begin{array}{l}\text { Marsh v. Brooks } \\
(1852)\end{array}$ & $\begin{array}{l}55 \text { U.S. } \\
513,522\end{array}$ \\
\hline 43 & & $\begin{array}{l}3 \text { November } \\
1804\end{array}$ & 74 & 7 Stat. 84 & $\begin{array}{l}\text { Sac Fox Indians of the } \\
\text { Mississippi in Iowa v. } \\
\text { Sac and Fox Indians } \\
\text { of the Mississippi in } \\
\text { Oklahoma (1911) }\end{array}$ & $\begin{array}{l}220 \text { U.S. } \\
481,484\end{array}$ \\
\hline 43 & & $\begin{array}{l}3 \text { November } \\
1804\end{array}$ & 74 & 7 Stat. 84 & $\begin{array}{l}\text { Oliphant } v . \\
\text { Suquamish Indian } \\
\text { Tribe }(1978)\end{array}$ & $\begin{array}{l}435 \text { U.S. } \\
191,198\end{array}$ \\
\hline 45 & $\begin{array}{l}\text { Wyandot; } \\
\text { Ottawa; } \\
\text { Chippewa; } \\
\text { Munsee; } \\
\text { Delaware; } \\
\text { Shawnee; } \\
\text { Potawatomi }\end{array}$ & 4 July 1805 & 77 & 7 Stat. 87 & $\begin{array}{l}\text { Chippewa Indians of } \\
\text { Minnesota v. United } \\
\text { States (1937) }\end{array}$ & $\begin{array}{l}301 \text { U.S. } \\
358,361\end{array}$ \\
\hline 48 & Cherokee & $\begin{array}{l}25 \text { October } \\
1805\end{array}$ & 82 & 7 Stat. 93 & $\begin{array}{l}\text { Cherokee Nation v. } \\
\text { Georgia (1831) }\end{array}$ & $\begin{array}{l}30 \text { U.S. } \\
1,5\end{array}$ \\
\hline 48 & & $\begin{array}{l}25 \text { October } \\
1805\end{array}$ & 82 & 7 Stat. 93 & $\begin{array}{l}\text { Worcester v. Georgia } \\
(1832)\end{array}$ & $\begin{array}{l}31 \text { U.S. } \\
515,538\end{array}$ \\
\hline 48 & & $\begin{array}{l}25 \text { October } \\
1805\end{array}$ & 82 & 7 Stat. 93 & $\begin{array}{l}\text { Cherokee Trust Funds } \\
\text { (1886) }\end{array}$ & $\begin{array}{l}117 \text { U.S. } \\
288,296\end{array}$ \\
\hline 48 & & $\begin{array}{l}25 \text { October } \\
1805\end{array}$ & 82 & 7 Stat. 93 & $\begin{array}{l}\text { Choctaw Nation v. } \\
\text { Oklahoma (1970) }\end{array}$ & $\begin{array}{l}397 \text { U.S. } \\
620,623\end{array}$ \\
\hline 48 & & $\begin{array}{l}25 \text { October } \\
1805\end{array}$ & 82 & 7 Stat. 93 & $\begin{array}{l}\text { Meigs v. M'Clung's } \\
\text { Lessee (1815) }\end{array}$ & $\begin{array}{l}13 \text { U.S. 11, } \\
11(2)\end{array}$ \\
\hline 49 & Cherokee & $\begin{array}{l}27 \text { October } \\
1805\end{array}$ & 84 & 7 Stat. 95 & $\begin{array}{l}\text { Cherokee Nation v. } \\
\text { Georgia (1831) }\end{array}$ & $\begin{array}{l}30 \text { U.S. } \\
1,5\end{array}$ \\
\hline 49 & & $\begin{array}{l}27 \text { October } \\
1805\end{array}$ & 84 & 7 Stat. 95 & $\begin{array}{l}\text { Worcester v. Georgia } \\
(1832)\end{array}$ & $\begin{array}{l}31 \text { U.S. } \\
515,538\end{array}$ \\
\hline 49 & & $\begin{array}{l}27 \text { October } \\
1805\end{array}$ & 84 & 7 Stat. 95 & $\begin{array}{l}\text { Cherokee Nation v. } \\
\text { Southern Kansas } \\
\text { Railway Co. (1890) }\end{array}$ & $\begin{array}{l}135 \text { U.S. } \\
641,654\end{array}$ \\
\hline 50 & Creek & $\begin{array}{l}14 \text { November } \\
1805\end{array}$ & 85 & 7 Stat. 96 & $\begin{array}{l}\text { Coffee v. Groover } \\
\text { (1887) }\end{array}$ & $\begin{array}{l}123 \text { U.S. } \\
1,15\end{array}$ \\
\hline
\end{tabular}


Table 1 (continued)

\begin{tabular}{|c|c|c|c|c|c|c|}
\hline $\begin{array}{l}\text { Ratified } \\
\text { treaty } \\
\text { number }\end{array}$ & $\begin{array}{l}\text { Signatory } \\
\text { tribe(s) }\end{array}$ & $\begin{array}{l}\text { Treaty } \\
\text { signing date }\end{array}$ & $\begin{array}{l}\text { Kappler } \\
\text { page } \\
\text { number }\end{array}$ & $\begin{array}{l}\text { Statutes at } \\
\text { Large or an } \\
\text { alternative } \\
\text { source }\end{array}$ & Case title & U.S. reports \\
\hline 51 & Choctaw & $\begin{array}{l}16 \text { November } \\
1805\end{array}$ & 87 & 7 Stat. 98 & $\begin{array}{l}\text { United States v. John } \\
\text { (1978) }\end{array}$ & $\begin{array}{l}437 \text { U.S. } \\
634,638\end{array}$ \\
\hline 53 & Cherokee & $\begin{array}{l}7 \text { January } \\
1806\end{array}$ & 90 & 7 Stat. 101 & $\begin{array}{l}\text { Cherokee Nation v. } \\
\text { Georgia }(1831)\end{array}$ & $\begin{array}{l}30 \text { U.S. } \\
1,5\end{array}$ \\
\hline 53 & & $\begin{array}{l}7 \text { January } \\
1806\end{array}$ & 90 & 7 Stat. 101 & $\begin{array}{l}\text { Worcester v. Georgia } \\
(1832)\end{array}$ & $\begin{array}{l}31 \text { U.S. } \\
515,538\end{array}$ \\
\hline 54 & $\begin{array}{l}\text { Ottawa; } \\
\text { Chippewa; } \\
\text { Wyandot; } \\
\text { Potawatomi }\end{array}$ & $\begin{array}{l}17 \text { November } \\
1807\end{array}$ & 92 & 7 Stat. 105 & $\begin{array}{l}\text { Chippewa Indians of } \\
\text { Minnesota } v \text {. United } \\
\text { States }(1937)\end{array}$ & $\begin{array}{l}301 \text { U.S. } \\
358,361\end{array}$ \\
\hline 55 & $\begin{array}{l}\text { Osage: Grand } \\
\text { and Little }\end{array}$ & $\begin{array}{l}10 \text { November } \\
1808\end{array}$ & 95 & 7 Stat. 107 & $\begin{array}{l}\text { Missouri v. Iowa } \\
(1849)\end{array}$ & $\begin{array}{l}48 \text { U.S. } \\
660,669\end{array}$ \\
\hline 55 & & $\begin{array}{l}10 \text { November } \\
1808\end{array}$ & 95 & 7 Stat. 107 & $\begin{array}{l}\text { Marsh v. Brooks } \\
(1852)\end{array}$ & $\begin{array}{l}55 \text { U.S. } \\
513,523\end{array}$ \\
\hline 55 & & $\begin{array}{l}10 \text { November } \\
1808\end{array}$ & 95 & 7 Stat. 107 & Hale v. Gaines (1860) & $\begin{array}{l}63 \text { U.S. } \\
144,148+\end{array}$ \\
\hline 57 & $\begin{array}{l}\text { Delaware; } \\
\text { Potawatomi; } \\
\text { Miami; Eel } \\
\text { River }\end{array}$ & $\begin{array}{l}30 \text { September } \\
1809\end{array}$ & 101 & 7 Stat. 113 & $\begin{array}{l}\text { Pam-To-Pee v. United } \\
\text { States (1893) }\end{array}$ & $\begin{array}{l}148 \text { U.S. } \\
691,698(3)\end{array}$ \\
\hline 61 & Creek & $\begin{array}{l}9 \text { August } \\
1814\end{array}$ & 107 & 7 Stat. 120 & $\begin{array}{l}\text { Minter v. Crommelin } \\
(1856)\end{array}$ & $\begin{array}{l}59 \text { U.S. } \\
87,87\end{array}$ \\
\hline 61 & & $\begin{array}{l}9 \text { August } \\
1814\end{array}$ & 107 & 7 Stat. 120 & $\begin{array}{l}\text { Coffee v. Groover } \\
(1887)\end{array}$ & $\begin{array}{l}123 \text { U.S. } \\
1,16\end{array}$ \\
\hline 71 & $\begin{array}{l}\text { Osage: Grand } \\
\text { and Little }\end{array}$ & $\begin{array}{l}12 \text { September } \\
1815\end{array}$ & 119 & 7 Stat. 133 & $\begin{array}{l}\text { Missouri v. Iowa } \\
(1849)\end{array}$ & $\begin{array}{l}48 \text { U.S. } \\
660,669\end{array}$ \\
\hline 76 & Cherokee & $\begin{array}{l}22 \text { March } \\
1816\end{array}$ & 124 & 7 Stat. 138 & $\begin{array}{l}\text { Cherokee Nation v. } \\
\text { Georgia (1831) }\end{array}$ & $\begin{array}{l}30 \text { U.S. } \\
1,5\end{array}$ \\
\hline 76 & & $\begin{array}{l}22 \text { March } \\
1816\end{array}$ & 124 & 7 Stat. 138 & $\begin{array}{l}\text { Worcester v. Georgia } \\
(1832)\end{array}$ & $\begin{array}{l}31 \text { U.S. } \\
515,538\end{array}$ \\
\hline 77 & Cherokee & $\begin{array}{l}22 \text { March } \\
1816\end{array}$ & 125 & 7 Stat. 139 & $\begin{array}{l}\text { Cherokee Nation v. } \\
\text { Georgia }(1831)\end{array}$ & $\begin{array}{l}30 \text { U.S. } \\
1,5\end{array}$ \\
\hline 77 & & $\begin{array}{l}22 \text { March } \\
1816\end{array}$ & 125 & 7 Stat. 139 & $\begin{array}{l}\text { Worcester v. Georgia } \\
(1832)\end{array}$ & $\begin{array}{l}31 \text { U.S. } \\
515,538\end{array}$ \\
\hline 83 & Cherokee & $\begin{array}{l}14 \text { September } \\
1816\end{array}$ & 133 & 7 Stat. 148 & $\begin{array}{l}\text { Worcester v. Georgia } \\
(1832)\end{array}$ & $\begin{array}{l}31 \text { U.S. } \\
515,538\end{array}$ \\
\hline 85 & Choctaw & $\begin{array}{l}24 \text { October } \\
1816\end{array}$ & 137 & 7 Stat. 152 & $\begin{array}{l}\text { United States v. } \\
\text { John }(1978)\end{array}$ & $\begin{array}{l}437 \text { U.S. } \\
634,638\end{array}$ \\
\hline 88 & Ponca & 25 June 1817 & 140 & 7 Stat. 155 & $\begin{array}{l}\text { Marsh v. Brooks } \\
(1850)\end{array}$ & $\begin{array}{l}49 \text { U.S. } \\
223,232\end{array}$ \\
\hline 89 & Cherokee & 8 July 1817 & 140 & 7 Stat. 156 & $\begin{array}{l}\text { Cherokee Nation v. } \\
\text { Georgia }(1831)\end{array}$ & $\begin{array}{l}30 \text { U.S. } \\
1,5\end{array}$ \\
\hline
\end{tabular}


Table 1 (continued)

\begin{tabular}{|c|c|c|c|c|c|c|}
\hline $\begin{array}{l}\text { Ratified } \\
\text { treaty } \\
\text { number }\end{array}$ & $\begin{array}{l}\text { Signatory } \\
\text { tribe(s) }\end{array}$ & $\begin{array}{l}\text { Treaty } \\
\text { signing date }\end{array}$ & $\begin{array}{l}\text { Kappler } \\
\text { page } \\
\text { number }\end{array}$ & $\begin{array}{l}\text { Statutes at } \\
\text { Large or an } \\
\text { alternative } \\
\text { source }\end{array}$ & Case title & U.S. reports \\
\hline 89 & & 8 July 1817 & 140 & 7 Stat. 156 & $\begin{array}{l}\text { Worcester v. Georgia } \\
(1832)\end{array}$ & $\begin{array}{l}31 \text { U.S. } \\
515,538\end{array}$ \\
\hline 89 & & 8 July 1817 & 140 & 7 Stat. 156 & $\begin{array}{l}\text { Henderson } v . \\
\text { Tennessee }(1850)\end{array}$ & $\begin{array}{l}51 \text { U.S. } \\
311,312\end{array}$ \\
\hline 89 & & 8 July 1817 & 140 & 7 Stat. 156 & Holden v. Joy (1872) & $\begin{array}{l}84 \text { U.S. } \\
211,240\end{array}$ \\
\hline 89 & & 8 July 1817 & 140 & 7 Stat. 156 & Elk v. Wilkins (1884) & $\begin{array}{l}112 \text { U.S. } \\
94,100\end{array}$ \\
\hline 89 & & 8 July 1817 & 140 & 7 Stat. 156 & $\begin{array}{l}\text { Cherokee Trust Funds } \\
\text { (1886) }\end{array}$ & $\begin{array}{l}117 \text { U.S. } \\
288,296\end{array}$ \\
\hline 89 & & 8 July 1817 & 140 & 7 Stat. 156 & $\begin{array}{l}\text { United States v. Old } \\
\text { Settlers (1893) }\end{array}$ & $\begin{array}{l}148 \text { U.S. } \\
427,436\end{array}$ \\
\hline 89 & & 8 July 1817 & 140 & 7 Stat. 156 & $\begin{array}{l}\text { United States v. } \\
\text { Cherokee Nation } \\
\text { (1906) }\end{array}$ & $\begin{array}{l}202 \text { U.S. } \\
101,107\end{array}$ \\
\hline 89 & & 8 July 1817 & 140 & 7 Stat. 156 & $\begin{array}{l}\text { Heckman v. United } \\
\text { States (1912) }\end{array}$ & $\begin{array}{l}224 \text { U.S. } \\
413,429\end{array}$ \\
\hline 89 & & 8 July 1817 & 140 & 7 Stat. 156 & $\begin{array}{l}\text { Cherokee Nation v. } \\
\text { United States (1926) }\end{array}$ & $\begin{array}{l}270 \text { U.S. } \\
476,480\end{array}$ \\
\hline 89 & & 8 July 1817 & 140 & 7 Stat. 156 & $\begin{array}{l}\text { Choctaw Nation v. } \\
\text { Oklahoma (1970) }\end{array}$ & $\begin{array}{l}397 \text { U.S. } \\
620,623\end{array}$ \\
\hline 89 & & 8 July 1817 & 140 & 7 Stat. 156 & $\begin{array}{l}\text { Cherokee Nation v. } \\
\text { Georgia (1831) }\end{array}$ & $\begin{array}{l}30 \text { U.S. } 1 \\
71(5)\end{array}$ \\
\hline 89 & & 8 July 1817 & 140 & 7 Stat. 156 & $\begin{array}{l}\text { Choctaw Nation v. } \\
\text { Oklahoma (1970) }\end{array}$ & $\begin{array}{l}397 \text { U.S. } \\
620,631(5)\end{array}$ \\
\hline 89 & & 8 July 1817 & 140 & 7 Stat. 156 & $\begin{array}{l}\text { Cherokee Nation v. } \\
\text { Georgia (1831) }\end{array}$ & $\begin{array}{l}30 \text { U.S. } 1, \\
66(8)\end{array}$ \\
\hline 89 & & 8 July 1817 & 140 & 7 Stat. 156 & $\begin{array}{l}\text { Henderson } v . \\
\text { Tennessee }(1850)\end{array}$ & $\begin{array}{l}51 \text { U.S. } \\
311,311(8)\end{array}$ \\
\hline 90 & $\begin{array}{l}\text { Wyandot; } \\
\text { Seneca; } \\
\text { Delaware; } \\
\text { Shawnee; } \\
\text { Potawatomi; } \\
\text { Ottawa; } \\
\text { Chippewa }\end{array}$ & $\begin{array}{l}29 \text { September } \\
1817\end{array}$ & 145 & 7 Stat. 160 & $\begin{array}{l}\text { Kindred v. Union } \\
\text { Pacific Railroad Co. } \\
\text { (1912) }\end{array}$ & $\begin{array}{l}225 \text { U.S. } \\
582,589+\end{array}$ \\
\hline 90 & & $\begin{array}{l}29 \text { September } \\
1817\end{array}$ & 145 & 7 Stat. 160 & $\begin{array}{l}\text { Cherokee Nation v. } \\
\text { Blackfeather (1894) }\end{array}$ & $\begin{array}{l}155 \text { U.S. } \\
218,219(4)\end{array}$ \\
\hline 90 & & $\begin{array}{l}29 \text { September } \\
1817\end{array}$ & 145 & 7 Stat. 160 & $\begin{array}{l}\text { Kansas Indians } \\
(1867)\end{array}$ & $\begin{array}{l}72 \text { U.S. } \\
737 \\
738(15)\end{array}$ \\
\hline 96 & Quapaw & $\begin{array}{l}24 \text { August } \\
1818\end{array}$ & 160 & 7 Stat. 176 & $\begin{array}{l}\text { Thredgill v. Pintard } \\
\text { (1851) }\end{array}$ & $\begin{array}{l}53 \text { U.S. } \\
24,37\end{array}$ \\
\hline 96 & & $\begin{array}{l}24 \text { August } \\
1818\end{array}$ & 160 & 7 Stat. 176 & $\begin{array}{l}\text { Cunningham v. Ashley } \\
\text { (1853) }\end{array}$ & $\begin{array}{l}55 \text { U.S. } \\
377,380\end{array}$ \\
\hline
\end{tabular}


Table 1 (continued)

\begin{tabular}{|c|c|c|c|c|c|c|}
\hline $\begin{array}{l}\text { Ratified } \\
\text { treaty } \\
\text { number }\end{array}$ & $\begin{array}{l}\text { Signatory } \\
\text { tribe(s) }\end{array}$ & $\begin{array}{l}\text { Treaty } \\
\text { signing date }\end{array}$ & $\begin{array}{l}\text { Kappler } \\
\text { page } \\
\text { number }\end{array}$ & $\begin{array}{l}\text { Statutes at } \\
\text { Large or an } \\
\text { alternative } \\
\text { source }\end{array}$ & Case title & U.S. reports \\
\hline 96 & & $\begin{array}{l}24 \text { August } \\
1818\end{array}$ & 160 & 7 Stat. 176 & $\begin{array}{l}\text { United States v. } \\
\text { Choctaw Nation } \\
(1900)\end{array}$ & $\begin{array}{l}179 \text { U.S. } \\
494,504(2)\end{array}$ \\
\hline 97 & $\begin{array}{l}\text { Wyandot; } \\
\text { Seneca; } \\
\text { Shawnee; } \\
\text { Ottawa }\end{array}$ & $\begin{array}{l}17 \text { September } \\
1818\end{array}$ & 162 & 7 Stat. 178 & $\begin{array}{l}\text { Kindred v. Union } \\
\text { Pacific Railroad Co. } \\
\text { (1912) }\end{array}$ & $\begin{array}{l}225 \text { U.S. } \\
582,589+\end{array}$ \\
\hline 101 & Potawatomi & $\begin{array}{l}2 \text { October } \\
1818\end{array}$ & 168 & 7 Stat. 185 & $\begin{array}{l}\text { Bowling and Miami } \\
\text { Investment Co. v. } \\
\text { United States (1914) }\end{array}$ & $\begin{array}{l}233 \text { U.S. } \\
528,529+\end{array}$ \\
\hline 101 & & $\begin{array}{l}2 \text { October } \\
1818\end{array}$ & 168 & 7 Stat. 185 & $\begin{array}{l}\text { Pam-To-Pee v. United } \\
\text { States (1893) }\end{array}$ & $\begin{array}{l}148 \text { U.S. } \\
691,698(3)\end{array}$ \\
\hline 103 & Delaware & $\begin{array}{l}3 \text { October } \\
1818\end{array}$ & 170 & 7 Stat. 188 & $\begin{array}{l}\text { United States v. } \\
\text { Stone }(1865)\end{array}$ & $\begin{array}{l}69 \text { U.S. } \\
525,525\end{array}$ \\
\hline 103 & & $\begin{array}{l}3 \text { October } \\
1818\end{array}$ & 170 & 7 Stat. 188 & $\begin{array}{l}\text { Kindred v. Union } \\
\text { Pacific Railroad Co. } \\
\text { (1912) }\end{array}$ & $\begin{array}{l}225 \text { U.S. } \\
582,589+\end{array}$ \\
\hline 103 & & $\begin{array}{l}3 \text { October } \\
1818\end{array}$ & 170 & 7 Stat. 188 & $\begin{array}{l}\text { Delaware Tribal } \\
\text { Business Committee v. } \\
\text { Weeks (1977) }\end{array}$ & $\begin{array}{l}430 \text { U.S. } \\
73,95\end{array}$ \\
\hline 105 & Chickasaw & $\begin{array}{l}19 \text { October } \\
1818\end{array}$ & 174 & 7 Stat. 192 & Clark v. Smith (1839) & $\begin{array}{l}38 \text { U.S. } \\
195,201\end{array}$ \\
\hline 105 & & $\begin{array}{l}19 \text { October } \\
1818\end{array}$ & 174 & 7 Stat. 192 & $\begin{array}{l}\text { Kinney v. Clark } \\
(1844)\end{array}$ & $\begin{array}{l}43 \text { U.S. } \\
76,83\end{array}$ \\
\hline 106 & Cherokee & $\begin{array}{l}27 \text { February } \\
1819\end{array}$ & 177 & 7 Stat. 195 & $\begin{array}{l}\text { Worcester v. Georgia } \\
(1832)\end{array}$ & $\begin{array}{l}31 \text { U.S. } \\
515,538\end{array}$ \\
\hline 106 & & $\begin{array}{l}27 \text { February } \\
1819\end{array}$ & 177 & 7 Stat. 195 & $\begin{array}{l}\text { Ladiga } v . \text { Roland } \\
(1844)\end{array}$ & $\begin{array}{l}43 \text { U.S. } \\
581,591\end{array}$ \\
\hline 106 & & $\begin{array}{l}27 \text { February } \\
1819\end{array}$ & 177 & 7 Stat. 195 & $\begin{array}{l}\text { Marsh v. Brooks } \\
(1850)\end{array}$ & $\begin{array}{l}49 \text { U.S. } \\
223,232\end{array}$ \\
\hline 106 & & $\begin{array}{l}27 \text { February } \\
1819\end{array}$ & 177 & 7 Stat. 195 & $\begin{array}{l}\text { Henderson } v \text {. } \\
\text { Tennessee }(1850)\end{array}$ & $\begin{array}{l}51 \text { U.S. } \\
311,312\end{array}$ \\
\hline 106 & & $\begin{array}{l}27 \text { February } \\
1819\end{array}$ & 177 & 7 Stat. 195 & Holden v. Joy (1872) & $\begin{array}{l}84 \text { U.S. } \\
211,212\end{array}$ \\
\hline 106 & & $\begin{array}{l}27 \text { February } \\
1819\end{array}$ & 177 & 7 Stat. 195 & $\begin{array}{l}\text { Cherokee Trust Funds } \\
\text { (1886) }\end{array}$ & $\begin{array}{l}117 \text { U.S. } \\
288,298\end{array}$ \\
\hline 106 & & $\begin{array}{l}27 \text { February } \\
1819\end{array}$ & 177 & 7 Stat. 195 & $\begin{array}{l}\text { United States v. Old } \\
\text { Settlers (1893) }\end{array}$ & $\begin{array}{l}148 \text { U.S. } \\
427,436\end{array}$ \\
\hline 106 & & $\begin{array}{l}27 \text { February } \\
1819\end{array}$ & 177 & 7 Stat. 195 & $\begin{array}{l}\text { United States v. } \\
\text { Cherokee Nation } \\
(1906)\end{array}$ & $\begin{array}{l}202 \text { U.S. } \\
101,107\end{array}$ \\
\hline 106 & & $\begin{array}{l}27 \text { February } \\
1819\end{array}$ & 177 & 7 Stat. 195 & $\begin{array}{l}\text { Heckman v. United } \\
\text { States (1912) }\end{array}$ & $\begin{array}{l}224 \text { U.S. } \\
413,429\end{array}$ \\
\hline
\end{tabular}


Table 1 (continued)

\begin{tabular}{|c|c|c|c|c|c|c|}
\hline $\begin{array}{l}\text { Ratified } \\
\text { treaty } \\
\text { number }\end{array}$ & $\begin{array}{l}\text { Signatory } \\
\text { tribe(s) }\end{array}$ & $\begin{array}{l}\text { Treaty } \\
\text { signing date }\end{array}$ & $\begin{array}{l}\text { Kappler } \\
\text { page } \\
\text { number }\end{array}$ & $\begin{array}{l}\text { Statutes at } \\
\text { Large or an } \\
\text { alternative } \\
\text { source }\end{array}$ & Case title & U.S. reports \\
\hline 106 & & $\begin{array}{l}27 \text { February } \\
1819\end{array}$ & 177 & 7 Stat. 195 & $\begin{array}{l}\text { Cherokee Nation v. } \\
\text { United States (1926) }\end{array}$ & $\begin{array}{l}270 \text { U.S. } \\
476,480\end{array}$ \\
\hline 106 & & $\begin{array}{l}27 \text { February } \\
1819\end{array}$ & 177 & 7 Stat. 195 & $\begin{array}{l}\text { Choctaw Nation v. } \\
\text { Oklahoma (1970) }\end{array}$ & $\begin{array}{l}397 \text { U.S. } \\
620,624\end{array}$ \\
\hline 106 & & $\begin{array}{l}27 \text { February } \\
1819\end{array}$ & 177 & 7 Stat. 195 & $\begin{array}{l}\text { Cherokee Nation v. } \\
\text { Georgia (1831) }\end{array}$ & $\begin{array}{l}30 \text { U.S. 1, } \\
5(\mathrm{P})\end{array}$ \\
\hline 106 & & $\begin{array}{l}27 \text { February } \\
1819\end{array}$ & 177 & 7 Stat. 195 & $\begin{array}{l}\text { Kinney v. Clark } \\
(1844)\end{array}$ & $\begin{array}{l}43 \text { U.S. 97, } \\
123(1)\end{array}$ \\
\hline 106 & & $\begin{array}{l}27 \text { February } \\
1819\end{array}$ & 177 & 7 Stat. 195 & $\begin{array}{l}\text { Cherokee Nation v. } \\
\text { Georgia (1831) }\end{array}$ & $\begin{array}{l}30 \text { U.S. } 1 \\
72(5)\end{array}$ \\
\hline 109 & Chippewa & $\begin{array}{l}\text { 24 September } \\
1819\end{array}$ & 185 & 7 Stat. 203 & $\begin{array}{l}\text { Wilbur v. United } \\
\text { States }(1930)\end{array}$ & $\begin{array}{l}281 \text { U.S. } \\
206,208\end{array}$ \\
\hline 109 & & $\begin{array}{l}\text { 24 September } \\
1819\end{array}$ & 185 & 7 Stat. 203 & $\begin{array}{l}\text { Francis } v . \\
\text { Francis }(1906)\end{array}$ & $\begin{array}{l}203 \text { U.S. } \\
233,237\end{array}$ \\
\hline 109 & & $\begin{array}{l}\text { 24 September } \\
1819\end{array}$ & 185 & 7 Stat. 203 & $\begin{array}{l}\text { Chippewa Indians of } \\
\text { Minnesota v. United } \\
\text { States (1937) }\end{array}$ & $\begin{array}{l}301 \text { U.S. } \\
358,361\end{array}$ \\
\hline 110 & Chippewa & 16 June 1820 & 187 & 7 Stat. 206 & $\begin{array}{l}\text { United States v. } \\
\text { Repentigny (1867) }\end{array}$ & $\begin{array}{l}72 \text { U.S. } \\
211,230\end{array}$ \\
\hline 110 & & 16 June 1820 & 187 & 7 Stat. 206 & $\begin{array}{l}\text { Spalding v. Chandler } \\
(1896)\end{array}$ & $\begin{array}{l}160 \text { U.S. } \\
394,394\end{array}$ \\
\hline 110 & & 16 June 1820 & 187 & 7 Stat. 206 & $\begin{array}{l}\text { Minnesota v. } \\
\text { Hitchcock (1902) }\end{array}$ & $\begin{array}{l}185 \text { U.S. } \\
373,390\end{array}$ \\
\hline 110 & & 16 June 1820 & 187 & 7 Stat. 206 & $\begin{array}{l}\text { Wilbur v. United } \\
\text { States (1930) }\end{array}$ & $\begin{array}{l}281 \text { U.S. } \\
206,208\end{array}$ \\
\hline 110 & & 16 June 1820 & 187 & 7 Stat. 206 & $\begin{array}{l}\text { Chippewa Indians of } \\
\text { Minnesota v. United } \\
\text { States (1937) }\end{array}$ & $\begin{array}{l}301 \text { U.S. } \\
358,361\end{array}$ \\
\hline 110 & & 16 June 1820 & 187 & 7 Stat. 206 & $\begin{array}{l}\text { Spalding v. Chandler } \\
(1896)\end{array}$ & $\begin{array}{l}160 \text { U.S. } \\
394,395(1)\end{array}$ \\
\hline 110 & & 16 June 1820 & 187 & 7 Stat. 206 & $\begin{array}{l}\text { Spalding v. Chandler } \\
(1896)\end{array}$ & $\begin{array}{l}160 \text { U.S. } \\
394,395(3)\end{array}$ \\
\hline 111 & $\begin{array}{l}\text { Ottawa; } \\
\text { Chippewa }\end{array}$ & 6 July 1820 & 188 & 7 Stat. 207 & $\begin{array}{l}\text { Chippewa Indians of } \\
\text { Minnesota v. United } \\
\text { States (1937) }\end{array}$ & $\begin{array}{l}301 \text { U.S. } \\
358,361\end{array}$ \\
\hline 115 & Choctaw & $\begin{array}{l}18 \text { October } \\
1820\end{array}$ & 191 & 7 Stat. 210 & Elk v. Wilkins (1884) & $\begin{array}{l}112 \text { U.S. } \\
94,100\end{array}$ \\
\hline 115 & & $\begin{array}{l}18 \text { October } \\
1820\end{array}$ & 191 & 7 Stat. 210 & $\begin{array}{l}\text { Choctaw Nation v. } \\
\text { United States (1886) }\end{array}$ & $\begin{array}{l}119 \text { U.S. } \\
1,36\end{array}$ \\
\hline 115 & & $\begin{array}{l}18 \text { October } \\
1820\end{array}$ & 191 & 7 Stat. 210 & $\begin{array}{l}\text { United States v. } \\
\text { Choctaw Nation } \\
\text { (1900) }\end{array}$ & $\begin{array}{l}179 \text { U.S. } \\
494,505\end{array}$ \\
\hline 115 & & $\begin{array}{l}18 \text { October } \\
1820\end{array}$ & 191 & 7 Stat. 210 & $\begin{array}{l}\text { Heckman v. United } \\
\text { States (1912) }\end{array}$ & $\begin{array}{l}224 \text { U.S. } \\
413,420+\end{array}$ \\
\hline
\end{tabular}


Table 1 (continued)

\begin{tabular}{|c|c|c|c|c|c|c|}
\hline $\begin{array}{l}\text { Ratified } \\
\text { treaty } \\
\text { number }\end{array}$ & $\begin{array}{l}\text { Signatory } \\
\text { tribe(s) }\end{array}$ & $\begin{array}{l}\text { Treaty } \\
\text { signing date }\end{array}$ & $\begin{array}{l}\text { Kappler } \\
\text { page } \\
\text { number }\end{array}$ & $\begin{array}{l}\text { Statutes at } \\
\text { Large or an } \\
\text { alternative } \\
\text { source }\end{array}$ & Case title & U.S. reports \\
\hline 115 & & $\begin{array}{l}18 \text { October } \\
1820\end{array}$ & 191 & 7 Stat. 210 & $\begin{array}{l}\text { Mullen v. United } \\
\text { States (1912) }\end{array}$ & $\begin{array}{l}224 \text { U.S. } \\
448,450\end{array}$ \\
\hline 115 & & $\begin{array}{l}18 \text { October } \\
1820\end{array}$ & 191 & 7 Stat. 210 & $\begin{array}{l}\text { United States v. John } \\
(1978)\end{array}$ & $\begin{array}{l}437 \text { U.S. } \\
634,639\end{array}$ \\
\hline 115 & & $\begin{array}{l}18 \text { October } \\
1820\end{array}$ & 191 & 7 Stat. 210 & $\begin{array}{l}\text { Choctaw Nation } v . \\
\text { United States }(1886)\end{array}$ & $\begin{array}{l}119 \text { U.S. } 1 \\
36(2)\end{array}$ \\
\hline 115 & & $\begin{array}{l}18 \text { October } \\
1820\end{array}$ & 191 & 7 Stat. 210 & $\begin{array}{l}\text { United States v. } \\
\text { Choctaw Nation } \\
(1900)\end{array}$ & $\begin{array}{l}179 \text { U.S. } \\
494,506(2)\end{array}$ \\
\hline 115 & & $\begin{array}{l}18 \text { October } \\
1820\end{array}$ & 191 & 7 Stat. 210 & $\begin{array}{l}\text { Fleming v. McCurtain } \\
\text { (1909) }\end{array}$ & $\begin{array}{l}215 \text { U.S. } \\
56,59(2)\end{array}$ \\
\hline 115 & & $\begin{array}{l}18 \text { October } \\
1820\end{array}$ & 191 & 7 Stat. 210 & $\begin{array}{l}\text { Choctaw Nation v. } \\
\text { Oklahoma }(1970)\end{array}$ & $\begin{array}{l}397 \text { U.S. } \\
620,629(2)\end{array}$ \\
\hline 115 & & $\begin{array}{l}18 \text { October } \\
1820\end{array}$ & 191 & 7 Stat. 210 & $\begin{array}{l}\text { Choctaw Nation } v . \\
\text { United States }(1886)\end{array}$ & $\begin{array}{l}119 \text { U.S. } 1, \\
10(4)\end{array}$ \\
\hline 117 & $\begin{array}{l}\text { Ottawa; } \\
\text { Chippewa; } \\
\text { Potawatomi }\end{array}$ & $\begin{array}{l}29 \text { August } \\
1821\end{array}$ & 198 & 7 Stat. 218 & $\begin{array}{l}\text { Chippewa Indians of } \\
\text { Minnesota } v \text {. United } \\
\text { States (1937) }\end{array}$ & $\begin{array}{l}301 \text { U.S. } \\
358,361\end{array}$ \\
\hline 117 & & $\begin{array}{l}29 \text { August } \\
1821\end{array}$ & 198 & 7 Stat. 218 & $\begin{array}{l}\text { Pam-To-Pee v. United } \\
\text { States (1893) }\end{array}$ & $\begin{array}{l}148 \text { U.S. } \\
691,698(4)\end{array}$ \\
\hline 121 & Sac and Fox & $\begin{array}{l}4 \text { August } \\
1824\end{array}$ & 207 & 7 Stat. 229 & $\begin{array}{l}\text { Missouri v. Iowa } \\
(1849)\end{array}$ & $\begin{array}{l}48 \text { U.S. } \\
660,670\end{array}$ \\
\hline 121 & & $\begin{array}{l}4 \text { August } \\
1824\end{array}$ & 207 & 7 Stat. 229 & $\begin{array}{l}\text { Marsh v. Brooks } \\
(1850)\end{array}$ & $\begin{array}{l}49 \text { U.S. } \\
223,223\end{array}$ \\
\hline 121 & & $\begin{array}{l}4 \text { August } \\
1824\end{array}$ & 207 & 7 Stat. 229 & $\begin{array}{l}\text { Webster v. Reid } \\
(1851)\end{array}$ & $\begin{array}{l}52 \text { U.S. } \\
437,437\end{array}$ \\
\hline 121 & & $\begin{array}{l}4 \text { August } \\
1824\end{array}$ & 207 & 7 Stat. 229 & $\begin{array}{l}\text { Marsh v. Brooks } \\
(1852)\end{array}$ & $\begin{array}{l}55 \text { U.S. } \\
513,514\end{array}$ \\
\hline 121 & & $\begin{array}{l}4 \text { August } \\
1824\end{array}$ & 207 & 7 Stat. 229 & $\begin{array}{l}\text { Coy v. Mason } \\
(1855)\end{array}$ & $\begin{array}{l}58 \text { U.S. } \\
580,580\end{array}$ \\
\hline 121 & & $\begin{array}{l}4 \text { August } \\
1824\end{array}$ & 207 & 7 Stat. 229 & $\begin{array}{l}\text { Barney v. Keokuk } \\
\text { (1877) }\end{array}$ & $\begin{array}{l}94 \text { U.S. } \\
324,326\end{array}$ \\
\hline 121 & & $\begin{array}{l}4 \text { August } \\
1824\end{array}$ & 207 & 7 Stat. 229 & $\begin{array}{l}\text { Missouri v. Iowa } \\
(1849)\end{array}$ & $\begin{array}{l}48 \text { U.S. } \\
660,670(1)\end{array}$ \\
\hline 121 & & $\begin{array}{l}4 \text { August } \\
1824\end{array}$ & 207 & 7 Stat. 229 & $\begin{array}{l}\text { Marsh v. Brooks } \\
(1850)\end{array}$ & $\begin{array}{l}49 \text { U.S. } \\
223,224(1)\end{array}$ \\
\hline 121 & & $\begin{array}{l}4 \text { August } \\
1824\end{array}$ & 207 & 7 Stat. 229 & $\begin{array}{l}\text { Webster v. Reid } \\
(1851)\end{array}$ & $\begin{array}{l}52 \text { U.S. } \\
437,437(1)\end{array}$ \\
\hline 121 & & $\begin{array}{l}4 \text { August } \\
1824\end{array}$ & 207 & 7 Stat. 229 & $\begin{array}{l}\text { Marsh v. Brooks } \\
(1852)\end{array}$ & $\begin{array}{l}55 \text { U.S. } \\
513,515(1)\end{array}$ \\
\hline 123 & Quapaw & $\begin{array}{l}15 \text { November } \\
1824\end{array}$ & 210 & 7 Stat. 232 & $\begin{array}{l}\text { Cunningham v. Ashley } \\
\text { (1853) }\end{array}$ & $\begin{array}{l}55 \text { U.S. } \\
377,380\end{array}$ \\
\hline 124 & Choctaw & $\begin{array}{l}20 \text { January } \\
1825\end{array}$ & 211 & 7 Stat. 234 & Elk v. Wilkins (1884) & $\begin{array}{l}112 \text { U.S. } \\
94,100\end{array}$ \\
\hline
\end{tabular}


Table 1 (continued)

\begin{tabular}{|c|c|c|c|c|c|c|}
\hline $\begin{array}{l}\text { Ratified } \\
\text { treaty } \\
\text { number }\end{array}$ & $\begin{array}{l}\text { Signatory } \\
\text { tribe(s) }\end{array}$ & $\begin{array}{l}\text { Treaty } \\
\text { signing date }\end{array}$ & $\begin{array}{l}\text { Kappler } \\
\text { page } \\
\text { number }\end{array}$ & $\begin{array}{l}\text { Statutes at } \\
\text { Large or an } \\
\text { alternative } \\
\text { source }\end{array}$ & Case title & U.S. reports \\
\hline 124 & & $\begin{array}{l}20 \text { January } \\
1825\end{array}$ & 211 & 7 Stat. 234 & $\begin{array}{l}\text { Choctaw Nation v. } \\
\text { United States (1886) }\end{array}$ & $\begin{array}{l}119 \text { U.S. } \\
1,36\end{array}$ \\
\hline 124 & & $\begin{array}{l}20 \text { January } \\
1825\end{array}$ & 211 & 7 Stat. 234 & $\begin{array}{l}\text { Choctaw Nation v. } \\
\text { Oklahoma (1970) }\end{array}$ & $\begin{array}{l}397 \text { U.S. } \\
620,624\end{array}$ \\
\hline 124 & & $\begin{array}{l}20 \text { January } \\
1825\end{array}$ & 211 & 7 Stat. 234 & $\begin{array}{l}\text { United States v. John } \\
\text { (1978) }\end{array}$ & $\begin{array}{l}437 \text { U.S. } \\
634,639\end{array}$ \\
\hline 124 & & $\begin{array}{l}20 \text { January } \\
1825\end{array}$ & 211 & 7 Stat. 234 & $\begin{array}{l}\text { Choctaw Nation v. } \\
\text { United States }(1886)\end{array}$ & $\begin{array}{l}119 \text { U.S. } \\
1,10(7)\end{array}$ \\
\hline 126 & $\begin{array}{l}\text { Osage: Grand } \\
\text { and Little }\end{array}$ & 2 June 1825 & 217 & 7 Stat. 240 & Holden v. Joy (1872) & $\begin{array}{l}84 \text { U.S. } \\
211,213\end{array}$ \\
\hline 126 & & 2 June 1825 & 217 & 7 Stat. 240 & $\begin{array}{l}\text { Leavenworth, } \\
\text { Lawrence and } \\
\text { Galveston Railroad } \\
\text { Co. v. United States } \\
(1876)\end{array}$ & $\begin{array}{l}92 \text { U.S. } \\
733,734\end{array}$ \\
\hline 126 & & 2 June 1825 & 217 & 7 Stat. 240 & $\begin{array}{l}\text { United States v. } \\
\text { McLaughlin (1888) }\end{array}$ & $\begin{array}{l}127 \text { U.S. } \\
428,452\end{array}$ \\
\hline 126 & & 2 June 1825 & 217 & 7 Stat. 240 & $\begin{array}{l}\text { Bardon v. Northern } \\
\text { Pacific Railroad Co. } \\
(1892)\end{array}$ & $\begin{array}{l}145 \text { U.S. } \\
535,540\end{array}$ \\
\hline 126 & & 2 June 1825 & 217 & 7 Stat. 240 & $\begin{array}{l}\text { Missouri, Kansas and } \\
\text { Texas Railway Co. v. } \\
\text { Roberts (1894) }\end{array}$ & $\begin{array}{l}152 \text { U.S. } \\
114,116\end{array}$ \\
\hline 126 & & 2 June 1825 & 217 & 7 Stat. 240 & Frost v. Wenie (1895) & $\begin{array}{l}157 \text { U.S. } \\
46,47\end{array}$ \\
\hline 126 & & 2 June 1825 & 217 & 7 Stat. 240 & $\begin{array}{l}\text { Leavenworth, } \\
\text { Lawrence and } \\
\text { Galveston Railroad } \\
\text { Co. v. United } \\
\text { States (1876) }\end{array}$ & $\begin{array}{l}92 \text { U.S. } \\
733,734(2)\end{array}$ \\
\hline 126 & & 2 June 1825 & 217 & 7 Stat. 240 & $\begin{array}{l}\text { Quick Bear v. Leupp } \\
\text { (1908) }\end{array}$ & $\begin{array}{l}210 \text { U.S. } \\
50,63(6)\end{array}$ \\
\hline 126 & & 2 June 1825 & 217 & 7 Stat. 240 & $\begin{array}{l}\text { Quick Bear v. Leupp } \\
\text { (1908) }\end{array}$ & $\begin{array}{l}210 \text { U.S. } \\
50,63(7)\end{array}$ \\
\hline 127 & Kansa & 3 June 1825 & 222 & 7 Stat. 244 & $\begin{array}{l}\text { Smith v. Stevens } \\
(1870)\end{array}$ & $\begin{array}{l}77 \text { U.S. } \\
321,321\end{array}$ \\
\hline 127 & & 3 June 1825 & 222 & 7 Stat. 244 & $\begin{array}{l}\text { Missouri v. Nebraska } \\
\text { (1904) }\end{array}$ & $\begin{array}{l}196 \text { U.S. } \\
23,26\end{array}$ \\
\hline 127 & & 3 June 1825 & 222 & 7 Stat. 244 & $\begin{array}{l}\text { Missouri v. Iowa } \\
\text { (1849) }\end{array}$ & $\begin{array}{l}48 \text { U.S. } \\
660,671(1)\end{array}$ \\
\hline 127 & & 3 June 1825 & 222 & 7 Stat. 244 & $\begin{array}{l}\text { Smith v. Stevens } \\
(1870)\end{array}$ & $\begin{array}{l}77 \text { U.S. } \\
321,321(6)\end{array}$ \\
\hline 127 & & 3 June 1825 & 222 & 7 Stat. 244 & $\begin{array}{l}\text { Jones v. Meehan } \\
\text { (1899) }\end{array}$ & $\begin{array}{l}175 \text { U.S. } \\
1,18(6)\end{array}$ \\
\hline
\end{tabular}


Table 1 (continued)

\begin{tabular}{|c|c|c|c|c|c|c|}
\hline $\begin{array}{l}\text { Ratified } \\
\text { treaty } \\
\text { number }\end{array}$ & $\begin{array}{l}\text { Signatory } \\
\text { tribe(s) }\end{array}$ & $\begin{array}{l}\text { Treaty } \\
\text { signing date }\end{array}$ & $\begin{array}{l}\text { Kappler } \\
\text { page } \\
\text { number }\end{array}$ & $\begin{array}{l}\text { Statutes at } \\
\text { Large or an } \\
\text { alternative } \\
\text { source }\end{array}$ & Case title & U.S. reports \\
\hline 127 & & 3 June 1825 & 222 & 7 Stat. 244 & $\begin{array}{l}\text { Smith v. Stevens } \\
(1870)\end{array}$ & $\begin{array}{l}77 \text { U.S. } \\
321 \\
322(11)\end{array}$ \\
\hline 127 & & 3 June 1825 & 222 & 7 Stat. 244 & $\begin{array}{l}\text { Jones v. Meehan } \\
(1899)\end{array}$ & $\begin{array}{l}175 \text { U.S. } 1 \\
18(11)\end{array}$ \\
\hline 139 & $\begin{array}{l}\text { Sioux; } \\
\text { Chippewa; } \\
\text { Sac and Fox; } \\
\text { Menominee; } \\
\text { Iowa; } \\
\text { Winnebago; } \\
\text { Ottawa; } \\
\text { Potawatomi }\end{array}$ & $\begin{array}{l}19 \text { August } \\
1825\end{array}$ & 250 & 7 Stat. 272 & $\begin{array}{l}\text { Beecher v. Wetherby } \\
(1877)\end{array}$ & $\begin{array}{l}95 \text { U.S. } \\
517,517\end{array}$ \\
\hline 139 & & $\begin{array}{l}19 \text { August } \\
1825\end{array}$ & 250 & 7 Stat. 272 & $\begin{array}{l}\text { Chippewa Indians of } \\
\text { Minnesota v. United } \\
\text { States }(1937)\end{array}$ & $\begin{array}{l}301 \text { U.S. } \\
358,361\end{array}$ \\
\hline 143 & Shawnee & $\begin{array}{l}7 \text { November } \\
1825\end{array}$ & 262 & 7 Stat. 284 & $\begin{array}{l}\text { Kansas Indians } \\
(1867)\end{array}$ & $\begin{array}{l}72 \text { U.S. } \\
737,738\end{array}$ \\
\hline 143 & & $\begin{array}{l}7 \text { November } \\
1825\end{array}$ & 262 & 7 Stat. 284 & $\begin{array}{l}\text { Walker v. Henshaw } \\
\text { (1873) }\end{array}$ & $\begin{array}{l}83 \text { U.S. } \\
436,442\end{array}$ \\
\hline 143 & & $\begin{array}{l}7 \text { November } \\
1825\end{array}$ & 262 & 7 Stat. 284 & $\begin{array}{l}\text { United States v. } \\
\text { Blackfeather (1894) }\end{array}$ & $\begin{array}{l}155 \text { U.S. } \\
180,186\end{array}$ \\
\hline 143 & & $\begin{array}{l}7 \text { November } \\
1825\end{array}$ & 262 & 7 Stat. 284 & $\begin{array}{l}\text { Metlakatla Indian } \\
\text { Community v. Egan } \\
\text { (1962) }\end{array}$ & $\begin{array}{l}369 \text { U.S. } \\
45,52\end{array}$ \\
\hline 143 & & $\begin{array}{l}7 \text { November } \\
1825\end{array}$ & 262 & 7 Stat. 284 & $\begin{array}{l}\text { United States v. } \\
\text { Blackfeather (1894) }\end{array}$ & $\begin{array}{l}155 \text { U.S. } \\
180,186(2)\end{array}$ \\
\hline 144 & Creek & $\begin{array}{l}24 \text { January } \\
1826\end{array}$ & 264 & 7 Stat. 286 & $\begin{array}{l}\text { Woodward v. De } \\
\text { Graffenried (1915) }\end{array}$ & $\begin{array}{l}238 \text { U.S. } \\
284,293(6)\end{array}$ \\
\hline 145 & Chippewa & $\begin{array}{l}5 \text { August } \\
1826\end{array}$ & 268 & 7 Stat. 290 & $\begin{array}{l}\text { Wilbur v. United } \\
\text { States }(1930)\end{array}$ & $\begin{array}{l}281 \text { U.S. } \\
206,208\end{array}$ \\
\hline 145 & & $\begin{array}{l}5 \text { August } \\
1826\end{array}$ & 268 & 7 Stat. 290 & $\begin{array}{l}\text { Chippewa Indians of } \\
\text { Minnesota v. United } \\
\text { States (1937) }\end{array}$ & $\begin{array}{l}301 \text { U.S. } \\
358,361\end{array}$ \\
\hline 146 & Potawatomi & $\begin{array}{l}16 \text { October } \\
1826\end{array}$ & 273 & 7 Stat. 295 & $\begin{array}{l}\text { Pam-To-Pee v. United } \\
\text { States }(1893)\end{array}$ & $\begin{array}{l}148 \text { U.S. } \\
691,698(3)\end{array}$ \\
\hline 148 & $\begin{array}{l}\text { Chippewa; } \\
\text { Menominee; } \\
\text { Winnebago }\end{array}$ & $\begin{array}{l}11 \text { August } \\
1827\end{array}$ & 281 & 7 Stat. 303 & $\begin{array}{l}\text { New York Indians v. } \\
\text { United States }(1898)\end{array}$ & $\begin{array}{l}170 \text { U.S. } \\
1,14\end{array}$ \\
\hline 148 & & $\begin{array}{l}11 \text { August } \\
1827\end{array}$ & 281 & 7 Stat. 303 & $\begin{array}{l}\text { Chippewa Indians of } \\
\text { Minnesota v. United } \\
\text { States (1937) }\end{array}$ & $\begin{array}{l}301 \text { U.S. } \\
358,361\end{array}$ \\
\hline 152 & $\begin{array}{l}\text { Cherokee: } \\
\text { Western }\end{array}$ & 6 May 1828 & 288 & 7 Stat. 311 & $\begin{array}{l}\text { Cherokee Nation v. } \\
\text { Georgia (1831) }\end{array}$ & $\begin{array}{l}30 \text { U.S. } \\
1,10\end{array}$ \\
\hline
\end{tabular}


Table 1 (continued)

\begin{tabular}{|c|c|c|c|c|c|c|}
\hline $\begin{array}{l}\text { Ratified } \\
\text { treaty } \\
\text { number }\end{array}$ & $\begin{array}{l}\text { Signatory } \\
\text { tribe(s) }\end{array}$ & $\begin{array}{l}\text { Treaty } \\
\text { signing date }\end{array}$ & $\begin{array}{l}\text { Kappler } \\
\text { page } \\
\text { number }\end{array}$ & $\begin{array}{l}\text { Statutes at } \\
\text { Large or an } \\
\text { alternative } \\
\text { source }\end{array}$ & Case title & U.S. reports \\
\hline 152 & & 6 May 1828 & 288 & 7 Stat. 311 & Holden v. Joy (1872) & $\begin{array}{l}84 \text { U.S. } \\
211,212\end{array}$ \\
\hline 152 & & 6 May 1828 & 288 & 7 Stat. 311 & $\begin{array}{l}\text { Cherokee Trust Funds } \\
\text { (1886) }\end{array}$ & $\begin{array}{l}117 \text { U.S. } \\
288,298\end{array}$ \\
\hline 152 & & 6 May 1828 & 288 & 7 Stat. 311 & $\begin{array}{l}\text { Cook v. United States } \\
\text { (1891) }\end{array}$ & $\begin{array}{l}138 \text { U.S. } \\
157,177\end{array}$ \\
\hline 152 & & 6 May 1828 & 288 & 7 Stat. 311 & $\begin{array}{l}\text { United States v. Old } \\
\text { Settlers }(1893)\end{array}$ & $\begin{array}{l}148 \text { U.S. } \\
427,429\end{array}$ \\
\hline 152 & & 6 May 1828 & 288 & 7 Stat. 311 & Thomas v. Gay (1898) & $\begin{array}{l}169 \text { U.S. } \\
264,268\end{array}$ \\
\hline 152 & & 6 May 1828 & 288 & 7 Stat. 311 & $\begin{array}{l}\text { United States v. } \\
\text { Cherokee Nation } \\
(1906)\end{array}$ & $\begin{array}{l}202 \text { U.S. } \\
101,104\end{array}$ \\
\hline 152 & & 6 May 1828 & 288 & 7 Stat. 311 & $\begin{array}{l}\text { Heckman v. United } \\
\text { States (1912) }\end{array}$ & $\begin{array}{l}224 \text { U.S. } \\
413,429\end{array}$ \\
\hline 152 & & 6 May 1828 & 288 & 7 Stat. 311 & $\begin{array}{l}\text { Cherokee Nation v. } \\
\text { United States (1926) }\end{array}$ & $\begin{array}{l}270 \text { U.S. } \\
476,480\end{array}$ \\
\hline 152 & & 6 May 1828 & 288 & 7 Stat. 311 & $\begin{array}{l}\text { Metlakatla Indian } \\
\text { Community v. Egan } \\
(1962)\end{array}$ & $\begin{array}{l}369 \text { U.S. } \\
45,52\end{array}$ \\
\hline 152 & & 6 May 1828 & 288 & 7 Stat. 311 & Kake v. Egan (1962) & $\begin{array}{l}369 \text { U.S. } \\
60,71\end{array}$ \\
\hline 152 & & 6 May 1828 & 288 & 7 Stat. 311 & $\begin{array}{l}\text { Choctaw Nation v. } \\
\text { Oklahoma (1970) }\end{array}$ & $\begin{array}{l}397 \text { U.S. } \\
620,624\end{array}$ \\
\hline 152 & & 6 May 1828 & 288 & 7 Stat. 311 & $\begin{array}{l}\text { Oklahoma v. } \\
\text { Arkansas (1985) }\end{array}$ & $\begin{array}{l}473 \text { U.S. } \\
610,611\end{array}$ \\
\hline 152 & & 6 May 1828 & 288 & 7 Stat. 311 & $\begin{array}{l}\text { Nevada v. Hicks } \\
\text { (2001) }\end{array}$ & $\begin{array}{l}533 \text { U.S. } \\
353,361\end{array}$ \\
\hline 152 & & 6 May 1828 & 288 & 7 Stat. 311 & $\begin{array}{l}\text { Arkansas v. } \\
\text { Mississippi (1919) }\end{array}$ & $\begin{array}{l}250 \text { U.S. } \\
39,42(1)\end{array}$ \\
\hline 152 & & 6 May 1828 & 288 & 7 Stat. 311 & $\begin{array}{l}\text { Witherspoon } v . \\
\text { Duncan (1867) }\end{array}$ & $\begin{array}{l}71 \text { U.S. } \\
210,211(2)\end{array}$ \\
\hline 152 & & 6 May 1828 & 288 & 7 Stat. 311 & $\begin{array}{l}\text { United States v. Old } \\
\text { Settlers (1893) }\end{array}$ & $\begin{array}{l}148 \text { U.S. } \\
427,436(2)\end{array}$ \\
\hline 152 & & 6 May 1828 & 288 & 7 Stat. 311 & $\begin{array}{l}\text { Cherokee Nation v. } \\
\text { Journeycake (1894) }\end{array}$ & $\begin{array}{l}155 \text { U.S. } \\
196,206(2)\end{array}$ \\
\hline 152 & & 6 May 1828 & 288 & 7 Stat. 311 & $\begin{array}{l}\text { Cherokee Nation v. } \\
\text { Hitchcock (1902) }\end{array}$ & $\begin{array}{l}187 \text { U.S. } \\
294,296(2)\end{array}$ \\
\hline 152 & & 6 May 1828 & 288 & 7 Stat. 311 & $\begin{array}{l}\text { United States v. Old } \\
\text { Settlers }(1893)\end{array}$ & $\begin{array}{l}148 \text { U.S. } \\
427,436(4)\end{array}$ \\
\hline 152 & & 6 May 1828 & 288 & 7 Stat. 311 & $\begin{array}{l}\text { United States v. Old } \\
\text { Settlers (1893) }\end{array}$ & $\begin{array}{l}148 \text { U.S. } \\
427,436(8)\end{array}$ \\
\hline 154 & Potawatomi & $\begin{array}{l}20 \text { September } \\
1828\end{array}$ & 294 & 7 Stat. 317 & $\begin{array}{l}\text { Pam-To-Pee v. United } \\
\text { States (1893) }\end{array}$ & $\begin{array}{l}148 \text { U.S. } \\
691,698(2)\end{array}$ \\
\hline
\end{tabular}


Table 1 (continued)

\begin{tabular}{|c|c|c|c|c|c|c|}
\hline $\begin{array}{l}\text { Ratified } \\
\text { treaty } \\
\text { number }\end{array}$ & $\begin{array}{l}\text { Signatory } \\
\text { tribe(s) }\end{array}$ & $\begin{array}{l}\text { Treaty } \\
\text { signing date }\end{array}$ & $\begin{array}{l}\text { Kappler } \\
\text { page } \\
\text { number }\end{array}$ & $\begin{array}{l}\text { Statutes at } \\
\text { Large or an } \\
\text { alternative } \\
\text { source }\end{array}$ & Case title & U.S. reports \\
\hline 155 & $\begin{array}{l}\text { Chippewa; } \\
\text { Ottawa; } \\
\text { Potawatomi }\end{array}$ & 29 July 1829 & 297 & 7 Stat. 320 & $\begin{array}{l}\text { Pam-To-Pee v. United } \\
\text { States (1893) }\end{array}$ & $\begin{array}{l}148 \text { U.S. } \\
691,697\end{array}$ \\
\hline 155 & & 29 July 1829 & 297 & 7 Stat. 320 & $\begin{array}{l}\text { Pam-To-Pee v. United } \\
\text { States (1902) }\end{array}$ & $\begin{array}{l}187 \text { U.S. } \\
371,386(2)\end{array}$ \\
\hline 155 & & 29 July 1829 & 297 & 7 Stat. 320 & $\begin{array}{l}\text { Pickering v. Lomax } \\
\text { (1892) }\end{array}$ & $\begin{array}{l}145 \text { U.S. } \\
310,310(4)\end{array}$ \\
\hline 155 & & 29 July 1829 & 297 & 7 Stat. 320 & $\begin{array}{l}\text { Lomax v. Pickering } \\
\text { (1899) }\end{array}$ & $\begin{array}{l}173 \text { U.S. } \\
26,27(4)\end{array}$ \\
\hline 155 & & 29 July 1829 & 297 & 7 Stat. 320 & $\begin{array}{l}\text { Jones v. Meehan } \\
\text { (1899) }\end{array}$ & $\begin{array}{l}175 \text { U.S. } 1 \\
21(4)\end{array}$ \\
\hline 158 & Delaware & $\begin{array}{l}24 \text { September } \\
1829\end{array}$ & 304 & 7 Stat. 327 & $\begin{array}{l}\text { United States v. } \\
\text { Stone }(1865)\end{array}$ & $\begin{array}{l}69 \text { U.S. } \\
525,536\end{array}$ \\
\hline 158 & & $\begin{array}{l}24 \text { September } \\
1829\end{array}$ & 304 & 7 Stat. 327 & $\begin{array}{l}\text { United States v. Union } \\
\text { Pacific Railway Co. } \\
\text { (1897) }\end{array}$ & $\begin{array}{l}168 \text { U.S. } \\
505,512\end{array}$ \\
\hline 158 & & $\begin{array}{l}24 \text { September } \\
1829\end{array}$ & 304 & 7 Stat. 327 & $\begin{array}{l}\text { Kindred v. Union } \\
\text { Pacific Railroad Co. } \\
\text { (1912) }\end{array}$ & $\begin{array}{l}225 \text { U.S. } \\
582,591\end{array}$ \\
\hline 158 & & $\begin{array}{l}24 \text { September } \\
1829\end{array}$ & 304 & 7 Stat. 327 & $\begin{array}{l}\text { Delaware Tribal } \\
\text { Business Committee v. } \\
\text { Weeks (1977) }\end{array}$ & $\begin{array}{l}430 \text { U.S. } \\
73,95\end{array}$ \\
\hline 159 & $\begin{array}{l}\text { Sac and Fox; } \\
\text { Sioux: } \\
\text { Mdewakanton, } \\
\text { Wahpeton, } \\
\text { Wahpekute } \\
\text { and Sisseton; } \\
\text { Omaha; } \\
\text { Iowa; Oto; } \\
\text { Missouri }\end{array}$ & 15 July 1830 & 305 & 7 Stat. 328 & $\begin{array}{l}\text { Missouri v. Iowa } \\
\text { (1849) }\end{array}$ & $\begin{array}{l}48 \text { U.S. } \\
660,671\end{array}$ \\
\hline 159 & & 15 July 1830 & 305 & 7 Stat. 328 & $\begin{array}{l}\text { Dubuque and Sioux } \\
\text { City Railroad Co. v. } \\
\text { Des Moines Valley } \\
\text { Railroad Co. (1883) }\end{array}$ & $\begin{array}{l}109 \text { U.S. } \\
329,331\end{array}$ \\
\hline 159 & & 15 July 1830 & 305 & 7 Stat. 328 & Felix v. Patrick (1892) & $\begin{array}{l}145 \text { U.S. } \\
317,317\end{array}$ \\
\hline 159 & & 15 July 1830 & 305 & 7 Stat. 328 & $\begin{array}{l}\text { Hegler v. Faulkner } \\
\text { (1894) }\end{array}$ & $\begin{array}{l}153 \text { U.S. } \\
109,111\end{array}$ \\
\hline 159 & & 15 July 1830 & 305 & 7 Stat. 328 & $\begin{array}{l}\text { Myrick v. Thompson } \\
\text { (1879) }\end{array}$ & $\begin{array}{l}99 \text { U.S. } \\
291,291(9)\end{array}$ \\
\hline 159 & & 15 July 1830 & 305 & 7 Stat. 328 & $\begin{array}{l}\text { Sloan v. United States } \\
(1904)\end{array}$ & $\begin{array}{l}193 \text { U.S. } \\
614,616(10)\end{array}$ \\
\hline
\end{tabular}


Table 1 (continued)

\begin{tabular}{|c|c|c|c|c|c|c|}
\hline $\begin{array}{l}\text { Ratified } \\
\text { treaty } \\
\text { number }\end{array}$ & $\begin{array}{l}\text { Signatory } \\
\text { tribe(s) }\end{array}$ & $\begin{array}{l}\text { Treaty } \\
\text { signing date }\end{array}$ & $\begin{array}{l}\text { Kappler } \\
\text { page } \\
\text { number }\end{array}$ & $\begin{array}{l}\text { Statutes at } \\
\text { Large or an } \\
\text { alternative } \\
\text { source }\end{array}$ & Case title & U.S. reports \\
\hline 160 & Choctaw & $\begin{array}{l}27 \text { September } \\
1830\end{array}$ & 310 & 7 Stat. 333 & Tyler v. Hand (1849) & $\begin{array}{l}48 \text { U.S. } \\
573,574\end{array}$ \\
\hline 160 & & $\begin{array}{l}27 \text { September } \\
1830\end{array}$ & 310 & 7 Stat. 333 & $\begin{array}{l}\text { Gaines v. Nicholson } \\
(1850)\end{array}$ & $\begin{array}{l}50 \text { U.S. } \\
356,363\end{array}$ \\
\hline 160 & & $\begin{array}{l}27 \text { September } \\
1830\end{array}$ & 310 & 7 Stat. 333 & Elk v. Wilkins (1884) & $\begin{array}{l}112 \text { U.S. } \\
94,100\end{array}$ \\
\hline 160 & & $\begin{array}{l}27 \text { September } \\
1830\end{array}$ & 310 & 7 Stat. 333 & $\begin{array}{l}\text { Choctaw Nation v. } \\
\text { United States (1886) }\end{array}$ & $\begin{array}{l}119 \text { U.S. } \\
1,2\end{array}$ \\
\hline 160 & & $\begin{array}{l}27 \text { September } \\
1830\end{array}$ & 310 & 7 Stat. 333 & $\begin{array}{l}\text { McKee v. Lamon } \\
\text { (1895) }\end{array}$ & $\begin{array}{l}159 \text { U.S. } \\
317,323\end{array}$ \\
\hline 160 & & $\begin{array}{l}27 \text { September } \\
1830\end{array}$ & 310 & 7 Stat. 333 & $\begin{array}{l}\text { Jones v. Meehan } \\
\text { (1899) }\end{array}$ & $\begin{array}{l}175 \text { U.S. } \\
1,13\end{array}$ \\
\hline 160 & & $\begin{array}{l}27 \text { September } \\
1830\end{array}$ & 310 & 7 Stat. 333 & $\begin{array}{l}\text { Ballinger v. United } \\
\text { States }(1910)\end{array}$ & $\begin{array}{l}216 \text { U.S. } \\
240,245\end{array}$ \\
\hline 160 & & $\begin{array}{l}27 \text { September } \\
1830\end{array}$ & 310 & 7 Stat. 333 & $\begin{array}{l}\text { Heckman v. United } \\
\text { States (1912) }\end{array}$ & $\begin{array}{l}224 \text { U.S. } \\
413,420+\end{array}$ \\
\hline 160 & & $\begin{array}{l}27 \text { September } \\
1830\end{array}$ & 310 & 7 Stat. 333 & $\begin{array}{l}\text { Mullen v. United } \\
\text { States (1912) }\end{array}$ & $\begin{array}{l}224 \text { U.S. } \\
448,450\end{array}$ \\
\hline 160 & & $\begin{array}{l}27 \text { September } \\
1830\end{array}$ & 310 & 7 Stat. 333 & $\begin{array}{l}\text { Johnson v. Riddle } \\
\text { (1916) }\end{array}$ & $\begin{array}{l}240 \text { U.S. } \\
467,475\end{array}$ \\
\hline 160 & & $\begin{array}{l}27 \text { September } \\
1830\end{array}$ & 310 & 7 Stat. 333 & $\begin{array}{l}\text { Winton v. Amos } \\
\text { (1921) }\end{array}$ & $\begin{array}{l}255 \text { U.S. } \\
373,377\end{array}$ \\
\hline 160 & & $\begin{array}{l}27 \text { September } \\
1830\end{array}$ & 310 & 7 Stat. 333 & $\begin{array}{l}\text { United States v. John } \\
\text { (1978) }\end{array}$ & $\begin{array}{l}437 \text { U.S. } \\
634,641\end{array}$ \\
\hline 160 & & $\begin{array}{l}27 \text { September } \\
1830\end{array}$ & 310 & 7 Stat. 333 & $\begin{array}{l}\text { United States v. Sioux } \\
\text { Nation of Indians } \\
(1980)\end{array}$ & $\begin{array}{l}448 \text { U.S. } \\
371,419\end{array}$ \\
\hline 160 & & $\begin{array}{l}27 \text { September } \\
1830\end{array}$ & 310 & 7 Stat. 333 & $\begin{array}{l}\text { Montana v. United } \\
\text { States }(1981)\end{array}$ & $\begin{array}{l}450 \text { U.S. } \\
544,556\end{array}$ \\
\hline 160 & & $\begin{array}{l}27 \text { September } \\
1830\end{array}$ & 310 & 7 Stat. 333 & $\begin{array}{l}\text { Oklahoma Tax } \\
\text { Commission v. } \\
\text { Chickasaw Nation } \\
(1995)\end{array}$ & $\begin{array}{l}515 \text { U.S. } \\
450,455\end{array}$ \\
\hline 160 & & $\begin{array}{l}27 \text { September } \\
1830\end{array}$ & 310 & 7 Stat. 333 & $\begin{array}{l}\text { United States v. John } \\
\text { (1978) }\end{array}$ & $\begin{array}{l}437 \text { U.S. } \\
634,641(\mathrm{P})\end{array}$ \\
\hline 160 & & $\begin{array}{l}27 \text { September } \\
1830\end{array}$ & 310 & 7 Stat. 333 & $\begin{array}{l}\text { United States v. } \\
\text { Choctaw Nation } \\
\text { (1900) }\end{array}$ & $\begin{array}{l}179 \text { U.S. } \\
494,508(2)\end{array}$ \\
\hline 160 & & $\begin{array}{l}27 \text { September } \\
1830\end{array}$ & 310 & 7 Stat. 333 & $\begin{array}{l}\text { Fleming v. McCurtain } \\
\text { (1909) }\end{array}$ & $\begin{array}{l}215 \text { U.S. } \\
56,57(2)\end{array}$ \\
\hline 160 & & $\begin{array}{l}27 \text { September } \\
1830\end{array}$ & 310 & 7 Stat. 333 & $\begin{array}{l}\text { Choctaw Nation v. } \\
\text { United States (1886) }\end{array}$ & $\begin{array}{l}119 \text { U.S. } \\
1,37(3)\end{array}$ \\
\hline 160 & & $\begin{array}{l}27 \text { September } \\
1830\end{array}$ & 310 & 7 Stat. 333 & $\begin{array}{l}\text { United States v. } \\
\text { Choctaw Nation } \\
(1900)\end{array}$ & $\begin{array}{l}179 \text { U.S. } \\
494,507(3)\end{array}$ \\
\hline
\end{tabular}


Table 1 (continued)

\begin{tabular}{|c|c|c|c|c|c|c|}
\hline $\begin{array}{l}\text { Ratified } \\
\text { treaty } \\
\text { number }\end{array}$ & $\begin{array}{l}\text { Signatory } \\
\text { tribe(s) }\end{array}$ & $\begin{array}{l}\text { Treaty } \\
\text { signing date }\end{array}$ & $\begin{array}{l}\text { Kappler } \\
\text { page } \\
\text { number }\end{array}$ & $\begin{array}{l}\text { Statutes at } \\
\text { Large or an } \\
\text { alternative } \\
\text { source }\end{array}$ & Case title & U.S. reports \\
\hline 160 & & $\begin{array}{l}27 \text { September } \\
1830\end{array}$ & 310 & 7 Stat. 333 & $\begin{array}{l}\text { Winton v. Amos } \\
\text { (1921) }\end{array}$ & $\begin{array}{l}255 \text { U.S. } \\
373,377(3)\end{array}$ \\
\hline 160 & & $\begin{array}{l}27 \text { September } \\
1830\end{array}$ & 310 & 7 Stat. 333 & $\begin{array}{l}\text { Atlantic and Pacific } \\
\text { Railroad Co. v. } \\
\text { Mingus (1897) }\end{array}$ & $\begin{array}{l}165 \text { U.S. } \\
413,436(4)\end{array}$ \\
\hline 160 & & $\begin{array}{l}27 \text { September } \\
1830\end{array}$ & 310 & 7 Stat. 333 & $\begin{array}{l}\text { United States v. } \\
\text { Choctaw Nation } \\
(1900)\end{array}$ & $\begin{array}{l}179 \text { U.S. } \\
494,507(4)\end{array}$ \\
\hline 160 & & $\begin{array}{l}27 \text { September } \\
1830\end{array}$ & 310 & 7 Stat. 333 & $\begin{array}{l}\text { Fleming v. McCurtain } \\
\text { (1909) }\end{array}$ & $\begin{array}{l}215 \text { U.S. } \\
56,60(4)\end{array}$ \\
\hline 160 & & $\begin{array}{l}27 \text { September } \\
1830\end{array}$ & 310 & 7 Stat. 333 & $\begin{array}{l}\text { Choctaw Nation v. } \\
\text { Oklahoma (1970) }\end{array}$ & $\begin{array}{l}397 \text { U.S. } \\
620,625(4)\end{array}$ \\
\hline 160 & & $\begin{array}{l}27 \text { September } \\
1830\end{array}$ & 310 & 7 Stat. 333 & $\begin{array}{l}\text { Oliphant } v . \\
\text { Suquamish Indian } \\
\text { Tribe (1978) }\end{array}$ & $\begin{array}{l}435 \text { U.S. } \\
191,197(4)\end{array}$ \\
\hline 160 & & $\begin{array}{l}27 \text { September } \\
1830\end{array}$ & 310 & 7 Stat. 333 & $\begin{array}{l}\text { Fleming v. McCurtain } \\
\text { (1909) }\end{array}$ & $\begin{array}{l}215 \text { U.S. } \\
56,60(5)\end{array}$ \\
\hline 160 & & $\begin{array}{l}27 \text { September } \\
1830\end{array}$ & 310 & 7 Stat. 333 & $\begin{array}{l}\text { Maney v. Porter } \\
(1845)\end{array}$ & $\begin{array}{l}45 \text { U.S. } 55, \\
55(14)\end{array}$ \\
\hline 160 & & $\begin{array}{l}27 \text { September } \\
1830\end{array}$ & 310 & 7 Stat. 333 & $\begin{array}{l}\text { Scott v. Sandford } \\
(1857)\end{array}$ & $\begin{array}{l}60 \text { U.S. } \\
393,586(14)\end{array}$ \\
\hline 160 & & $\begin{array}{l}27 \text { September } \\
1830\end{array}$ & 310 & 7 Stat. 333 & Wilson v. Wall (1867) & $\begin{array}{l}73 \text { U.S. } 83, \\
83(14)\end{array}$ \\
\hline 160 & & $\begin{array}{l}27 \text { September } \\
1830\end{array}$ & 310 & 7 Stat. 333 & $\begin{array}{l}\text { Choctaw Nation } v . \\
\text { United States }(1886)\end{array}$ & $\begin{array}{l}119 \text { U.S. } 1 \\
5(14)\end{array}$ \\
\hline 160 & & $\begin{array}{l}27 \text { September } \\
1830\end{array}$ & 310 & 7 Stat. 333 & $\begin{array}{l}\text { Boyd v. Nebraska } \\
\text { (1892) }\end{array}$ & $\begin{array}{l}143 \text { U.S. } \\
135,162(14)\end{array}$ \\
\hline 160 & & $\begin{array}{l}27 \text { September } \\
1830\end{array}$ & 310 & 7 Stat. 333 & $\begin{array}{l}\text { Stephens v. Cherokee } \\
\text { Nation (1899) }\end{array}$ & $\begin{array}{l}174 \text { U.S. } \\
445,463(14)\end{array}$ \\
\hline 160 & & $\begin{array}{l}27 \text { September } \\
1830\end{array}$ & 310 & 7 Stat. 333 & $\begin{array}{l}\text { Winton v. Amos } \\
\text { (1921) }\end{array}$ & $\begin{array}{l}255 \text { U.S. } \\
373,377(14)\end{array}$ \\
\hline 160 & & $\begin{array}{l}27 \text { September } \\
1830\end{array}$ & 310 & 7 Stat. 333 & $\begin{array}{l}\text { Choctaw Nation } v . \\
\text { United States }(1886)\end{array}$ & $\begin{array}{l}119 \text { U.S. } 1 \\
16(15)\end{array}$ \\
\hline 160 & & $\begin{array}{l}27 \text { September } \\
1830\end{array}$ & 310 & 7 Stat. 333 & $\begin{array}{l}\text { Choctaw Nation } v . \\
\text { United States }(1886)\end{array}$ & $\begin{array}{l}119 \text { U.S. } 1 \text {, } \\
7(16)\end{array}$ \\
\hline 160 & & $\begin{array}{l}27 \text { September } \\
1830\end{array}$ & 310 & 7 Stat. 333 & $\begin{array}{l}\text { Choctaw Nation } v . \\
\text { United States }(1886)\end{array}$ & $\begin{array}{l}119 \text { U.S. 1, } \\
11(18)\end{array}$ \\
\hline 160 & & $\begin{array}{l}27 \text { September } \\
1830\end{array}$ & 310 & 7 Stat. 333 & $\begin{array}{l}\text { Fleming v. McCurtain } \\
\text { (1909) }\end{array}$ & $\begin{array}{l}215 \text { U.S. } \\
56,61(18)\end{array}$ \\
\hline 160 & & $\begin{array}{l}27 \text { September } \\
1830\end{array}$ & 310 & 7 Stat. 333 & $\begin{array}{l}\text { Choctaw Nation v. } \\
\text { Oklahoma }(1970)\end{array}$ & $\begin{array}{l}397 \text { U.S. } \\
620,631(18)\end{array}$ \\
\hline 160 & & $\begin{array}{l}27 \text { September } \\
1830\end{array}$ & 310 & 7 Stat. 333 & Tyler v. Hand (1849) & $\begin{array}{l}48 \text { U.S. } \\
573,574(19)\end{array}$ \\
\hline
\end{tabular}


Table 1 (continued)

\begin{tabular}{|c|c|c|c|c|c|c|}
\hline $\begin{array}{l}\text { Ratified } \\
\text { treaty } \\
\text { number }\end{array}$ & $\begin{array}{l}\text { Signatory } \\
\text { tribe(s) }\end{array}$ & $\begin{array}{l}\text { Treaty } \\
\text { signing date }\end{array}$ & $\begin{array}{l}\text { Kappler } \\
\text { page } \\
\text { number }\end{array}$ & $\begin{array}{l}\text { Statutes at } \\
\text { Large or an } \\
\text { alternative } \\
\text { source }\end{array}$ & Case title & U.S. reports \\
\hline 160 & & $\begin{array}{l}27 \text { September } \\
1830\end{array}$ & 310 & 7 Stat. 333 & $\begin{array}{l}\text { Choctaw Nation v. } \\
\text { United States }(1886)\end{array}$ & $\begin{array}{l}119 \text { U.S. 1, } \\
7(19)\end{array}$ \\
\hline 160 & & $\begin{array}{l}27 \text { September } \\
1830\end{array}$ & 310 & 7 Stat. 333 & $\begin{array}{l}\text { Winton v. Amos } \\
\text { (1921) }\end{array}$ & $\begin{array}{l}255 \text { U.S. } \\
373,377(19)\end{array}$ \\
\hline 160 & & $\begin{array}{l}27 \text { September } \\
1830\end{array}$ & 310 & 7 Stat. 333 & $\begin{array}{l}\text { Choctaw Nation v. } \\
\text { United States }(1886)\end{array}$ & $\begin{array}{l}119 \text { U.S. 1, } \\
8(20)\end{array}$ \\
\hline 161 & Menominee & $\begin{array}{l}8 \text { February } \\
1831\end{array}$ & 319 & 7 Stat. 342 & $\begin{array}{l}\text { United States v. Cook } \\
\text { (1874) }\end{array}$ & $\begin{array}{l}86 \text { U.S. } \\
591,591\end{array}$ \\
\hline 161 & & $\begin{array}{l}8 \text { February } \\
1831\end{array}$ & 319 & 7 Stat. 342 & $\begin{array}{l}\text { Beecher v. Wetherby } \\
\text { (1877) }\end{array}$ & $\begin{array}{l}95 \text { U.S. } \\
517,518\end{array}$ \\
\hline 161 & & $\begin{array}{l}8 \text { February } \\
1831\end{array}$ & 319 & 7 Stat. 342 & $\begin{array}{l}\text { New York Indians v. } \\
\text { United States (1898) }\end{array}$ & $\begin{array}{l}170 \text { U.S. } \\
1,14\end{array}$ \\
\hline 161 & & $\begin{array}{l}8 \text { February } \\
1831\end{array}$ & 319 & 7 Stat. 342 & $\begin{array}{l}\text { Budzisz v. Illinois } \\
\text { Steel Co. (1898) }\end{array}$ & $\begin{array}{l}170 \text { U.S. } \\
41,42\end{array}$ \\
\hline 161 & & $\begin{array}{l}8 \text { February } \\
1831\end{array}$ & 319 & 7 Stat. 342 & $\begin{array}{l}\text { Minnesota v. } \\
\text { Hitchcock (1902) }\end{array}$ & $\begin{array}{l}185 \text { U.S. } \\
373,397\end{array}$ \\
\hline 161 & & $\begin{array}{l}8 \text { February } \\
1831\end{array}$ & 319 & 7 Stat. 342 & $\begin{array}{l}\text { United States v. Cook } \\
\text { (1874) }\end{array}$ & $\begin{array}{l}86 \text { U.S. } \\
591,591(1)\end{array}$ \\
\hline 161 & & $\begin{array}{l}8 \text { February } \\
1831\end{array}$ & 319 & 7 Stat. 342 & $\begin{array}{l}\text { New York Indians } v . \\
\text { United States (1898) }\end{array}$ & $\begin{array}{l}170 \text { U.S. } \\
1,8(1)\end{array}$ \\
\hline 162 & Seneca & $\begin{array}{l}28 \text { February } \\
1831\end{array}$ & 325 & 7 Stat. 348 & Libby v. Clark (1886) & $\begin{array}{l}118 \text { U.S. } \\
250,255+\end{array}$ \\
\hline 162 & & $\begin{array}{l}28 \text { February } \\
1831\end{array}$ & 325 & 7 Stat. 348 & $\begin{array}{l}\text { Francis v. Francis } \\
\text { (1906) }\end{array}$ & $\begin{array}{l}203 \text { U.S. } \\
233,235+\end{array}$ \\
\hline 164 & Shawnee & $\begin{array}{l}8 \text { August } \\
1831\end{array}$ & 331 & 7 Stat. 355 & $\begin{array}{l}\text { Kansas Indians } \\
(1867)\end{array}$ & $\begin{array}{l}72 \text { U.S. } \\
737,738\end{array}$ \\
\hline 164 & & $\begin{array}{l}8 \text { August } \\
1831\end{array}$ & 331 & 7 Stat. 355 & $\begin{array}{l}\text { Peoria Tribe of } \\
\text { Indians v. United } \\
\text { States }(1968)\end{array}$ & $\begin{array}{l}390 \text { U.S. } \\
468,471\end{array}$ \\
\hline 164 & & $\begin{array}{l}8 \text { August } \\
1831\end{array}$ & 331 & 7 Stat. 355 & $\begin{array}{l}\text { Nevada v. Hicks } \\
\text { (2001) }\end{array}$ & $\begin{array}{l}533 \text { U.S. } \\
353,363\end{array}$ \\
\hline 164 & & $\begin{array}{l}8 \text { August } \\
1831\end{array}$ & 331 & 7 Stat. 355 & $\begin{array}{l}\text { Walker v. Henshaw } \\
\text { (1873) }\end{array}$ & $\begin{array}{l}83 \text { U.S. } \\
436,442(2)\end{array}$ \\
\hline 164 & & $\begin{array}{l}8 \text { August } \\
1831\end{array}$ & 331 & 7 Stat. 355 & $\begin{array}{l}\text { United States v. } \\
\text { Blackfeather (1894) }\end{array}$ & $\begin{array}{l}155 \text { U.S. } \\
180,184(2)\end{array}$ \\
\hline 164 & & $\begin{array}{l}8 \text { August } \\
1831\end{array}$ & 331 & 7 Stat. 355 & $\begin{array}{l}\text { United States v. } \\
\text { Blackfeather (1894) }\end{array}$ & $\begin{array}{l}155 \text { U.S. } \\
180,184(4)\end{array}$ \\
\hline 164 & & $\begin{array}{l}8 \text { August } \\
1831\end{array}$ & 331 & 7 Stat. 355 & $\begin{array}{l}\text { United States v. } \\
\text { Blackfeather (1894) }\end{array}$ & $\begin{array}{l}155 \text { U.S. } \\
180,184(5)\end{array}$ \\
\hline 164 & & $\begin{array}{l}8 \text { August } \\
1831\end{array}$ & 331 & 7 Stat. 355 & $\begin{array}{l}\text { United States v. } \\
\text { Blackfeather (1894) }\end{array}$ & $\begin{array}{l}155 \text { U.S. } \\
180,180(7)\end{array}$ \\
\hline 164 & & $\begin{array}{l}8 \text { August } \\
1831\end{array}$ & 331 & 7 Stat. 355 & $\begin{array}{l}\text { Kansas Indians } \\
(1867)\end{array}$ & $\begin{array}{l}72 \text { U.S. } \\
737,739(10)\end{array}$ \\
\hline 164 & & $\begin{array}{l}8 \text { August } \\
1831\end{array}$ & 331 & 7 Stat. 355 & $\begin{array}{l}\text { Walker v. Henshaw } \\
\text { (1873) }\end{array}$ & $\begin{array}{l}83 \text { U.S. 436, } \\
437(10)\end{array}$ \\
\hline
\end{tabular}


Table 1 (continued)

\begin{tabular}{|c|c|c|c|c|c|c|}
\hline $\begin{array}{l}\text { Ratified } \\
\text { treaty } \\
\text { number }\end{array}$ & $\begin{array}{l}\text { Signatory } \\
\text { tribe(s) }\end{array}$ & $\begin{array}{l}\text { Treaty } \\
\text { signing date }\end{array}$ & $\begin{array}{l}\text { Kappler } \\
\text { page } \\
\text { number }\end{array}$ & $\begin{array}{l}\text { Statutes at } \\
\text { Large or an } \\
\text { alternative } \\
\text { source }\end{array}$ & Case title & U.S. reports \\
\hline 164 & & $\begin{array}{l}8 \text { August } \\
1831\end{array}$ & 331 & 7 Stat. 355 & $\begin{array}{l}\text { United States v. } \\
\text { Blackfeather (1894) }\end{array}$ & $\begin{array}{l}155 \text { U.S. } \\
180,183(11)\end{array}$ \\
\hline 164 & & $\begin{array}{l}8 \text { August } \\
1831\end{array}$ & 331 & 7 Stat. 355 & $\begin{array}{l}\text { United States } v . \\
\text { Blackfeather (1894) }\end{array}$ & $\begin{array}{l}155 \text { U.S. } \\
180,183(13)\end{array}$ \\
\hline 167 & Creek & $\begin{array}{l}24 \text { March } \\
1832\end{array}$ & 341 & 7 Stat. 366 & $\begin{array}{l}\text { Ladiga v. Roland } \\
\text { (1844) }\end{array}$ & $\begin{array}{l}43 \text { U.S. } \\
581,582(1)\end{array}$ \\
\hline 167 & & $\begin{array}{l}24 \text { March } \\
1832\end{array}$ & 341 & 7 Stat. 366 & $\begin{array}{l}\text { Ladiga v. Roland } \\
\text { (1844) }\end{array}$ & $\begin{array}{l}43 \text { U.S. } \\
581,581(2)\end{array}$ \\
\hline 167 & & $\begin{array}{l}24 \text { March } \\
1832\end{array}$ & 341 & 7 Stat. 366 & $\begin{array}{l}\text { Ladiga v. Roland } \\
(1844)\end{array}$ & $\begin{array}{l}43 \text { U.S. } \\
581,582(3)\end{array}$ \\
\hline 167 & & $\begin{array}{l}24 \text { March } \\
1832\end{array}$ & 341 & 7 Stat. 366 & $\begin{array}{l}\text { Ladiga v. Roland } \\
\text { (1844) }\end{array}$ & $\begin{array}{l}43 \text { U.S. } \\
581,583(4)\end{array}$ \\
\hline 167 & & $\begin{array}{l}24 \text { March } \\
1832\end{array}$ & 341 & 7 Stat. 366 & $\begin{array}{l}\text { Ladiga v. Roland } \\
\text { (1844) }\end{array}$ & $\begin{array}{l}43 \text { U.S. } \\
581,583(5)\end{array}$ \\
\hline 167 & & $\begin{array}{l}24 \text { March } \\
1832\end{array}$ & 341 & 7 Stat. 366 & $\begin{array}{l}\text { Ladiga v. Roland } \\
\text { (1844) }\end{array}$ & $\begin{array}{l}43 \text { U.S. } \\
581,583(6)\end{array}$ \\
\hline 167 & & $\begin{array}{l}24 \text { March } \\
1832\end{array}$ & 341 & 7 Stat. 366 & $\begin{array}{l}\text { Woodward v. De } \\
\text { Graffenried (1915) }\end{array}$ & $\begin{array}{l}238 \text { U.S. } \\
284,293(12)\end{array}$ \\
\hline 167 & & $\begin{array}{l}24 \text { March } \\
1832\end{array}$ & 341 & 7 Stat. 366 & $\begin{array}{l}\text { Noble v. Oklahoma } \\
\text { City (1936) }\end{array}$ & $\begin{array}{l}297 \text { U.S. } \\
481,482(12)\end{array}$ \\
\hline 167 & & $\begin{array}{l}24 \text { March } \\
1832\end{array}$ & 341 & 7 Stat. 366 & $\begin{array}{l}\text { Atlantic and Pacific } \\
\text { Railroad Co. v. } \\
\text { Mingus (1897) }\end{array}$ & $\begin{array}{l}165 \text { U.S. } \\
413,436(14)\end{array}$ \\
\hline 167 & & $\begin{array}{l}24 \text { March } \\
1832\end{array}$ & 341 & 7 Stat. 366 & $\begin{array}{l}\text { Woodward v. De } \\
\text { Graffenried (1915) }\end{array}$ & $\begin{array}{l}238 \text { U.S. } \\
284,293(14)\end{array}$ \\
\hline 167 & & $\begin{array}{l}24 \text { March } \\
1832\end{array}$ & 341 & 7 Stat. 366 & $\begin{array}{l}\text { Oklahoma Tax } \\
\text { Commission v. United } \\
\text { States (1943) }\end{array}$ & $\begin{array}{l}319 \text { U.S. } \\
598,616(14)\end{array}$ \\
\hline 167 & & $\begin{array}{l}24 \text { March } \\
1832\end{array}$ & 341 & 7 Stat. 366 & $\begin{array}{l}\text { Ladiga v. Roland } \\
\text { (1844) }\end{array}$ & $\begin{array}{l}43 \text { U.S. } \\
581,583(15)\end{array}$ \\
\hline 168 & Seminole & 9 May 1832 & 344 & 7 Stat. 368 & $\begin{array}{l}\text { Goat v. United States } \\
\text { (1912) }\end{array}$ & $\begin{array}{l}224 \text { U.S. } \\
458,461\end{array}$ \\
\hline 169 & Winnebago & $\begin{array}{l}15 \text { September } \\
1832\end{array}$ & 345 & 7 Stat. 370 & $\begin{array}{l}\text { Pumpelly v. Green } \\
\text { Bay Co. }(1872)\end{array}$ & $\begin{array}{l}80 \text { U.S. } \\
166,170\end{array}$ \\
\hline 172 & Potawatomi & $\begin{array}{l}20 \text { October } \\
1832\end{array}$ & 353 & 7 Stat. 378 & $\begin{array}{l}\text { Jones v. Meehan } \\
\text { (1899) }\end{array}$ & $\begin{array}{l}175 \text { U.S. } \\
1,12\end{array}$ \\
\hline 172 & & $\begin{array}{l}20 \text { October } \\
1832\end{array}$ & 353 & 7 Stat. 378 & $\begin{array}{l}\text { Pam-To-Pee v. United } \\
\text { States (1893) }\end{array}$ & $\begin{array}{l}148 \text { U.S. } \\
691,698(3)\end{array}$ \\
\hline 173 & Chickasaw & $\begin{array}{l}20 \text { October } \\
1832\end{array}$ & 356 & 7 Stat. 381 & $\begin{array}{l}\text { Ayres v. Carver } \\
(1855)\end{array}$ & $\begin{array}{l}58 \text { U.S. } \\
591,592\end{array}$ \\
\hline 173 & & $\begin{array}{l}20 \text { October } \\
1832\end{array}$ & 356 & 7 Stat. 381 & Best v. Polk (1873) & $\begin{array}{l}85 \text { U.S. } \\
112,112\end{array}$ \\
\hline
\end{tabular}


Table 1 (continued)

\begin{tabular}{|c|c|c|c|c|c|c|}
\hline $\begin{array}{l}\text { Ratified } \\
\text { treaty } \\
\text { number }\end{array}$ & $\begin{array}{l}\text { Signatory } \\
\text { tribe(s) }\end{array}$ & $\begin{array}{l}\text { Treaty } \\
\text { signing date }\end{array}$ & $\begin{array}{l}\text { Kappler } \\
\text { page } \\
\text { number }\end{array}$ & $\begin{array}{l}\text { Statutes at } \\
\text { Large or an } \\
\text { alternative } \\
\text { source }\end{array}$ & Case title & U.S. reports \\
\hline 173 & & $\begin{array}{l}20 \text { October } \\
1832\end{array}$ & 356 & 7 Stat. 381 & $\begin{array}{l}\text { United States v. } \\
\text { Nashville, } \\
\text { Chattanooga and St. } \\
\text { Louis Railway Co. } \\
(1886)\end{array}$ & $\begin{array}{l}118 \text { U.S. } \\
120,121\end{array}$ \\
\hline 173 & & $\begin{array}{l}20 \text { October } \\
1832\end{array}$ & 356 & 7 Stat. 381 & $\begin{array}{l}\text { United States v. } \\
\text { Choctaw Nation } \\
\text { (1904) }\end{array}$ & $\begin{array}{l}193 \text { U.S. } \\
115,116\end{array}$ \\
\hline 173 & & $\begin{array}{l}20 \text { October } \\
1832\end{array}$ & 356 & 7 Stat. 381 & $\begin{array}{l}\text { Papasan v. Allain } \\
\text { (1986) }\end{array}$ & $\begin{array}{l}478 \text { U.S. } \\
265,271+\end{array}$ \\
\hline 173 & & $\begin{array}{l}20 \text { October } \\
1832\end{array}$ & 356 & 7 Stat. 381 & $\begin{array}{l}\text { United States v. } \\
\text { Nashville, } \\
\text { Chattanooga and St. } \\
\text { Louis Railway Co. } \\
(1886)\end{array}$ & $\begin{array}{l}118 \text { U.S. } \\
120,120(1)\end{array}$ \\
\hline 173 & & $\begin{array}{l}20 \text { October } \\
1832\end{array}$ & 356 & 7 Stat. 381 & $\begin{array}{l}\text { United States v. } \\
\text { Nashville, } \\
\text { Chattanooga and St. } \\
\text { Louis Railway Co. } \\
(1886)\end{array}$ & $\begin{array}{l}118 \text { U.S. } \\
120,121(11)\end{array}$ \\
\hline 174 & Kickapoo & $\begin{array}{l}24 \text { October } \\
1832\end{array}$ & 365 & 7 Stat. 391 & $\begin{array}{l}\text { United States v. Reily } \\
\text { (1933) }\end{array}$ & $\begin{array}{l}290 \text { U.S. } \\
33,35\end{array}$ \\
\hline 174 & & $\begin{array}{l}24 \text { October } \\
1832\end{array}$ & 365 & 7 Stat. 391 & $\begin{array}{l}\text { United States v. } \\
\text { Oklahoma Gas and } \\
\text { Electric Co. }(1943)\end{array}$ & $\begin{array}{l}318 \text { U.S. } \\
206,215\end{array}$ \\
\hline 175 & Potawatomi & $\begin{array}{l}26 \text { October } \\
1832\end{array}$ & 367 & 7 Stat. 394 & $\begin{array}{l}\text { Verden v. Coleman } \\
\text { (1862) }\end{array}$ & $\begin{array}{l}66 \text { U.S. } \\
472,473\end{array}$ \\
\hline 175 & & $\begin{array}{l}26 \text { October } \\
1832\end{array}$ & 367 & 7 Stat. 394 & $\begin{array}{l}\text { Pam-To-Pee v. United } \\
\text { States (1893) }\end{array}$ & $\begin{array}{l}148 \text { U.S. } \\
691,698(3)\end{array}$ \\
\hline 177 & Potawatomi & $\begin{array}{l}27 \text { October } \\
1832\end{array}$ & 372 & 7 Stat. 399 & $\begin{array}{l}\text { Crews v. Burcham } \\
\text { (1862) }\end{array}$ & $\begin{array}{l}66 \text { U.S. } \\
352,352\end{array}$ \\
\hline 177 & & $\begin{array}{l}27 \text { October } \\
1832\end{array}$ & 372 & 7 Stat. 399 & $\begin{array}{l}\text { Mullen v. Pickens } \\
\text { (1919) }\end{array}$ & $\begin{array}{l}250 \text { U.S. } \\
590,594\end{array}$ \\
\hline 177 & & $\begin{array}{l}27 \text { October } \\
1832\end{array}$ & 372 & 7 Stat. 399 & $\begin{array}{l}\text { Jones v. Meehan } \\
\text { (1899) }\end{array}$ & $\begin{array}{l}175 \text { U.S. } 1 \\
15(1)\end{array}$ \\
\hline 177 & & $\begin{array}{l}27 \text { October } \\
1832\end{array}$ & 372 & 7 Stat. 399 & $\begin{array}{l}\text { Jones v. Meehan } \\
\text { (1899) }\end{array}$ & $\begin{array}{l}175 \text { U.S. } 1, \\
15(2)\end{array}$ \\
\hline 177 & & $\begin{array}{l}27 \text { October } \\
1832\end{array}$ & 372 & 7 Stat. 399 & $\begin{array}{l}\text { Doe ex. dem. Mann v. } \\
\text { Wilson (1860) }\end{array}$ & $\begin{array}{l}64 \text { U.S. } \\
457,457(3)\end{array}$ \\
\hline 177 & & $\begin{array}{l}27 \text { October } \\
1832\end{array}$ & 372 & 7 Stat. 399 & $\begin{array}{l}\text { Elwood v. Flannigan } \\
(1882)\end{array}$ & $\begin{array}{l}104 \text { U.S. } \\
562,563(3)\end{array}$ \\
\hline 177 & & $\begin{array}{l}27 \text { October } \\
1832\end{array}$ & 372 & 7 Stat. 399 & $\begin{array}{l}\text { Jones v. Meehan } \\
\text { (1899) }\end{array}$ & $\begin{array}{l}175 \text { U.S. } 1, \\
15(3)\end{array}$ \\
\hline
\end{tabular}


Table 1 (continued)

\begin{tabular}{|c|c|c|c|c|c|c|}
\hline $\begin{array}{l}\text { Ratified } \\
\text { treaty } \\
\text { number }\end{array}$ & $\begin{array}{l}\text { Signatory } \\
\text { tribe(s) }\end{array}$ & $\begin{array}{l}\text { Treaty } \\
\text { signing date }\end{array}$ & $\begin{array}{l}\text { Kappler } \\
\text { page } \\
\text { number }\end{array}$ & $\begin{array}{l}\text { Statutes at } \\
\text { large or an } \\
\text { alternative } \\
\text { source }\end{array}$ & Case title & U.S. reports \\
\hline 178 & $\begin{array}{l}\text { Kaskaskia; } \\
\text { Peoria; } \\
\text { Michigamea; } \\
\text { Cahokia; } \\
\text { Tamaroa }\end{array}$ & $\begin{array}{l}27 \text { October } \\
1832\end{array}$ & 376 & 7 Stat. 403 & $\begin{array}{l}\text { Bowling and Miami } \\
\text { Investment Co. v. } \\
\text { United States (1914) }\end{array}$ & $\begin{array}{l}233 \text { U.S. } \\
528,532\end{array}$ \\
\hline 179 & Menominee & $\begin{array}{l}27 \text { October } \\
1832\end{array}$ & 377 & 7 Stat. 405 & $\begin{array}{l}\text { Budzisz v. Illinois } \\
\text { Steel Co. (1898) }\end{array}$ & $\begin{array}{l}170 \text { U.S. } \\
41,42\end{array}$ \\
\hline 180 & $\begin{array}{l}\text { Piankashaw; } \\
\text { Wea }\end{array}$ & $\begin{array}{l}29 \text { October } \\
1832\end{array}$ & 382 & 7 Stat. 410 & $\begin{array}{l}\text { Bowling and Miami } \\
\text { Investment Co. v. } \\
\text { United States (1914) }\end{array}$ & $\begin{array}{l}233 \text { U.S. } \\
528,532\end{array}$ \\
\hline 182 & $\begin{array}{l}\text { Cherokee: } \\
\text { Western }\end{array}$ & $\begin{array}{l}14 \text { February } \\
1833\end{array}$ & 385 & 7 Stat. 414 & Holden v. Joy (1872) & $\begin{array}{l}84 \text { U.S. } \\
211,212\end{array}$ \\
\hline 182 & & $\begin{array}{l}14 \text { February } \\
1833\end{array}$ & 385 & 7 Stat. 414 & $\begin{array}{l}\text { Cherokee Trust Funds } \\
\text { (1886) }\end{array}$ & $\begin{array}{l}117 \text { U.S. } \\
288,299\end{array}$ \\
\hline 182 & & $\begin{array}{l}14 \text { February } \\
1833\end{array}$ & 385 & 7 Stat. 414 & $\begin{array}{l}\text { Cherokee Nation v. } \\
\text { Southern Kansas } \\
\text { Railway Co. (1890) }\end{array}$ & $\begin{array}{l}135 \text { U.S. } \\
641,648\end{array}$ \\
\hline 182 & & $\begin{array}{l}14 \text { February } \\
1833\end{array}$ & 385 & 7 Stat. 414 & $\begin{array}{l}\text { United States v. Old } \\
\text { Settlers (1893) }\end{array}$ & $\begin{array}{l}148 \text { U.S. } \\
427,429\end{array}$ \\
\hline 182 & & $\begin{array}{l}14 \text { February } \\
1833\end{array}$ & 385 & 7 Stat. 414 & $\begin{array}{l}\text { Cherokee Nation v. } \\
\text { Journeycake (1894) }\end{array}$ & $\begin{array}{l}155 \text { U.S. } \\
196,207\end{array}$ \\
\hline 182 & & $\begin{array}{l}14 \text { February } \\
1833\end{array}$ & 385 & 7 Stat. 414 & $\begin{array}{l}\text { Heckman v. United } \\
\text { States (1912) }\end{array}$ & $\begin{array}{l}224 \text { U.S. } \\
413,430\end{array}$ \\
\hline 182 & & $\begin{array}{l}14 \text { February } \\
1833\end{array}$ & 385 & 7 Stat. 414 & $\begin{array}{l}\text { Cherokee Nation v. } \\
\text { United States (1926) }\end{array}$ & $\begin{array}{l}270 \text { U.S. } \\
476,480\end{array}$ \\
\hline 182 & & $\begin{array}{l}14 \text { February } \\
1833\end{array}$ & 385 & 7 Stat. 414 & $\begin{array}{l}\text { Choctaw Nation v. } \\
\text { Oklahoma (1970) }\end{array}$ & $\begin{array}{l}397 \text { U.S. } \\
620,649\end{array}$ \\
\hline 182 & & $\begin{array}{l}14 \text { February } \\
1833\end{array}$ & 385 & 7 Stat. 414 & $\begin{array}{l}\text { Cherokee Nation v. } \\
\text { Hitchcock (1902) }\end{array}$ & $\begin{array}{l}187 \text { U.S. } \\
294,296(1)\end{array}$ \\
\hline 183 & Creek & $\begin{array}{l}14 \text { February } \\
1833\end{array}$ & 388 & 7 Stat. 417 & $\begin{array}{l}\text { Marchie Tiger v. } \\
\text { Western Investment } \\
\text { Co. (1911) }\end{array}$ & $\begin{array}{l}221 \text { U.S. } \\
286,299\end{array}$ \\
\hline 183 & & $\begin{array}{l}14 \text { February } \\
1833\end{array}$ & 388 & 7 Stat. 417 & $\begin{array}{l}\text { Heckman v. United } \\
\text { States (1912) }\end{array}$ & $\begin{array}{l}224 \text { U.S. } \\
413,420+\end{array}$ \\
\hline 183 & & $\begin{array}{l}14 \text { February } \\
1833\end{array}$ & 388 & 7 Stat. 417 & $\begin{array}{l}\text { Noble v. Oklahoma } \\
\text { City (1936) }\end{array}$ & $\begin{array}{l}297 \text { U.S. } \\
481,482\end{array}$ \\
\hline 183 & & $\begin{array}{l}14 \text { February } \\
1833\end{array}$ & 388 & 7 Stat. 417 & $\begin{array}{l}\text { United States v. Creek } \\
\text { Nation }(1935)\end{array}$ & $\begin{array}{l}295 \text { U.S. } \\
103,105(2)\end{array}$ \\
\hline 183 & & $\begin{array}{l}14 \text { February } \\
1833\end{array}$ & 388 & 7 Stat. 417 & $\begin{array}{l}\text { Woodward v. De } \\
\text { Graffenried (1915) }\end{array}$ & $\begin{array}{l}238 \text { U.S. } \\
284,293(3)\end{array}$ \\
\hline 183 & & $\begin{array}{l}14 \text { February } \\
1833\end{array}$ & 388 & 7 Stat. 417 & $\begin{array}{l}\text { United States v. Creek } \\
\text { Nation }(1935)\end{array}$ & $\begin{array}{l}295 \text { U.S. } \\
103,105(3)\end{array}$ \\
\hline 183 & & $\begin{array}{l}14 \text { February } \\
1833\end{array}$ & 388 & 7 Stat. 417 & $\begin{array}{l}\text { Goat v. United States } \\
\text { (1912) }\end{array}$ & $\begin{array}{l}224 \text { U.S. } \\
458,461(4)\end{array}$ \\
\hline
\end{tabular}


Table 1 (continued)

\begin{tabular}{|c|c|c|c|c|c|c|}
\hline $\begin{array}{l}\text { Ratified } \\
\text { treaty } \\
\text { number }\end{array}$ & $\begin{array}{l}\text { Signatory } \\
\text { tribe(s) }\end{array}$ & $\begin{array}{l}\text { Treaty } \\
\text { signing date }\end{array}$ & $\begin{array}{l}\text { Kappler } \\
\text { page } \\
\text { number }\end{array}$ & $\begin{array}{l}\text { Statutes at } \\
\text { Large or an } \\
\text { alternative } \\
\text { source }\end{array}$ & Case title & U.S. reports \\
\hline 185 & Seminole & $\begin{array}{l}28 \text { March } \\
1833\end{array}$ & 394 & 7 Stat. 423 & $\begin{array}{l}\text { Goat v. United States } \\
\text { (1912) }\end{array}$ & $\begin{array}{l}224 \text { U.S. } \\
458,461\end{array}$ \\
\hline 186 & Quapaw & 13 May 1833 & 395 & 7 Stat. 424 & $\begin{array}{l}\text { United States v. Noble } \\
\text { (1915) }\end{array}$ & $\begin{array}{l}237 \text { U.S. } \\
74,79\end{array}$ \\
\hline 189 & $\begin{array}{l}\text { Chippewa, } \\
\text { Ottawa, } \\
\text { Potawatomi }\end{array}$ & $\begin{array}{l}\text { 26 September } \\
1833\end{array}$ & 402 & 7 Stat. 431 & $\begin{array}{l}\text { Pam-To-Pee v. United } \\
\text { States (1893) }\end{array}$ & $\begin{array}{l}148 \text { U.S. } \\
691,691\end{array}$ \\
\hline 189 & & $\begin{array}{l}26 \text { September } \\
1833\end{array}$ & 402 & 7 Stat. 431 & $\begin{array}{l}\text { Pam-To-Pee v. United } \\
\text { States (1902) }\end{array}$ & $\begin{array}{l}187 \text { U.S. } \\
371,385(3)\end{array}$ \\
\hline 191 & Chickasaw & 24 May 1834 & 418 & 7 Stat. 450 & $\begin{array}{l}\text { Ayres v. Carver } \\
(1855)\end{array}$ & $\begin{array}{l}58 \text { U.S. } \\
591,592\end{array}$ \\
\hline 191 & & 24 May 1834 & 418 & 7 Stat. 450 & Best v. Polk (1873) & $\begin{array}{l}85 \text { U.S. } \\
112,112\end{array}$ \\
\hline 191 & & 24 May 1834 & 418 & 7 Stat. 450 & Doolan v. Carr (1888) & $\begin{array}{l}125 \text { U.S. } \\
618,629\end{array}$ \\
\hline 191 & & 24 May 1834 & 418 & 7 Stat. 450 & $\begin{array}{l}\text { Creek Nation v. } \\
\text { United States (1943) }\end{array}$ & $\begin{array}{l}318 \text { U.S. } \\
629,634(3)\end{array}$ \\
\hline 191 & & 24 May 1834 & 418 & 7 Stat. 450 & $\begin{array}{l}\text { Jones v. Meehan } \\
\text { (1899) }\end{array}$ & $\begin{array}{l}175 \text { U.S. } 1 \\
19(5)\end{array}$ \\
\hline 191 & & 24 May 1834 & 418 & 7 Stat. 450 & Best v. Polk (1873) & $\begin{array}{l}85 \text { U.S. } \\
112,113(6)\end{array}$ \\
\hline 191 & & 24 May 1834 & 418 & 7 Stat. 450 & $\begin{array}{l}\text { Jones v. Meehan } \\
\text { (1899) }\end{array}$ & $\begin{array}{l}175 \text { U.S. } 1 \text {, } \\
19(6)\end{array}$ \\
\hline 191 & & 24 May 1834 & 418 & 7 Stat. 450 & $\begin{array}{l}\text { United States v. } \\
\text { Nashville, } \\
\text { Chattanooga and St. } \\
\text { Louis Railway Co. } \\
(1886)\end{array}$ & $\begin{array}{l}118 \text { U.S. } \\
120,122(11)\end{array}$ \\
\hline 197 & Caddo & 1 July 1835 & 432 & 7 Stat. 470 & $\begin{array}{l}\text { United States v. } \\
\text { Brooks (1850) }\end{array}$ & $\begin{array}{l}51 \text { U.S. } \\
442,448\end{array}$ \\
\hline 197 & & 1 July 1835 & 432 & 7 Stat. 470 & $\begin{array}{l}\text { White v. Cannon } \\
\text { (1868) }\end{array}$ & $\begin{array}{l}73 \text { U.S. } \\
443,444\end{array}$ \\
\hline 197 & & 1 July 1835 & 432 & 7 Stat. 470 & $\begin{array}{l}\text { United States v. } \\
\text { Brooks (1850) }\end{array}$ & $\begin{array}{l}51 \text { U.S. } \\
442,459(1)\end{array}$ \\
\hline 198 & $\begin{array}{l}\text { Comanche; } \\
\text { Wichita; } \\
\text { Cherokee; } \\
\text { Muskogee; } \\
\text { Choctaw; } \\
\text { Osage; } \\
\text { Seneca; } \\
\text { Quapaw }\end{array}$ & $\begin{array}{l}24 \text { August } \\
1835\end{array}$ & 435 & 7 Stat. 474 & $\begin{array}{l}\text { Menominee Tribe of } \\
\text { Indians } v \text {. United } \\
\text { States }(1968)\end{array}$ & $\begin{array}{l}391 \text { U.S. } \\
404,407(4)\end{array}$ \\
\hline 199 & Cherokee & $\begin{array}{l}29 \text { December } \\
1835\end{array}$ & 439 & 7 Stat. 478 & $\begin{array}{l}\text { Ex parte Taylor } \\
(1852)\end{array}$ & $\begin{array}{l}55 \text { U.S. } \\
3,9\end{array}$ \\
\hline
\end{tabular}


Table 1 (continued)

\begin{tabular}{|c|c|c|c|c|c|c|}
\hline $\begin{array}{l}\text { Ratified } \\
\text { treaty } \\
\text { number }\end{array}$ & $\begin{array}{l}\text { Signatory } \\
\text { tribe(s) }\end{array}$ & $\begin{array}{l}\text { Treaty } \\
\text { signing date }\end{array}$ & $\begin{array}{l}\text { Kappler } \\
\text { page } \\
\text { number }\end{array}$ & $\begin{array}{l}\text { Statutes at } \\
\text { Large or an } \\
\text { alternative } \\
\text { source }\end{array}$ & Case title & U.S. reports \\
\hline 199 & & $\begin{array}{l}29 \text { December } \\
1835\end{array}$ & 439 & 7 Stat. 478 & Holden v. Joy (1872) & $\begin{array}{l}84 \text { U.S. } \\
211,213\end{array}$ \\
\hline 199 & & $\begin{array}{l}29 \text { December } \\
1835\end{array}$ & 439 & 7 Stat. 478 & Elk v. Wilkins (1884) & $\begin{array}{l}112 \text { U.S. } \\
94,100\end{array}$ \\
\hline 199 & & $\begin{array}{l}29 \text { December } \\
1835\end{array}$ & 439 & 7 Stat. 478 & $\begin{array}{l}\text { Cherokee Trust Funds } \\
\text { (1886) }\end{array}$ & $\begin{array}{l}117 \text { U.S. } \\
288,293\end{array}$ \\
\hline 199 & & $\begin{array}{l}29 \text { December } \\
1835\end{array}$ & 439 & 7 Stat. 478 & $\begin{array}{l}\text { Cherokee Nation v. } \\
\text { Southern Kansas } \\
\text { Railway Co. (1890) }\end{array}$ & $\begin{array}{l}135 \text { U.S. } \\
641,654\end{array}$ \\
\hline 199 & & $\begin{array}{l}29 \text { December } \\
1835\end{array}$ & 439 & 7 Stat. 478 & $\begin{array}{l}\text { United States } v . \\
\text { Old Settlers }(1893)\end{array}$ & $\begin{array}{l}148 \text { U.S. } \\
427,441\end{array}$ \\
\hline 199 & & $\begin{array}{l}29 \text { December } \\
1835\end{array}$ & 439 & 7 Stat. 478 & Thomas v. Gay (1898) & $\begin{array}{l}169 \text { U.S. } \\
264,268\end{array}$ \\
\hline 199 & & $\begin{array}{l}29 \text { December } \\
1835\end{array}$ & 439 & 7 Stat. 478 & $\begin{array}{l}\text { Cherokee Nation v. } \\
\text { Hitchcock (1902) }\end{array}$ & $\begin{array}{l}187 \text { U.S. } \\
294,295\end{array}$ \\
\hline 199 & & $\begin{array}{l}29 \text { December } \\
1835\end{array}$ & 439 & 7 Stat. 478 & $\begin{array}{l}\text { United States v. } \\
\text { Cherokee Nation } \\
\text { (1906) }\end{array}$ & $\begin{array}{l}202 \text { U.S. } \\
101,123\end{array}$ \\
\hline 199 & & $\begin{array}{l}29 \text { December } \\
1835\end{array}$ & 439 & 7 Stat. 478 & $\begin{array}{l}\text { In re Eastern } \\
\text { Cherokees (1911) }\end{array}$ & $\begin{array}{l}220 \text { U.S. } \\
83,85\end{array}$ \\
\hline 199 & & $\begin{array}{l}29 \text { December } \\
1835\end{array}$ & 439 & 7 Stat. 478 & $\begin{array}{l}\text { Heckman v. United } \\
\text { States (1912) }\end{array}$ & $\begin{array}{l}224 \text { U.S. } \\
413,430\end{array}$ \\
\hline 199 & & $\begin{array}{l}29 \text { December } \\
1835\end{array}$ & 439 & 7 Stat. 478 & $\begin{array}{l}\text { Cherokee Nation v. } \\
\text { United States (1926) }\end{array}$ & $\begin{array}{l}270 \text { U.S. } \\
476,480\end{array}$ \\
\hline 199 & & $\begin{array}{l}29 \text { December } \\
1835\end{array}$ & 439 & 7 Stat. 478 & $\begin{array}{l}\text { Choctaw Nation v. } \\
\text { Oklahoma }(1970)\end{array}$ & $\begin{array}{l}397 \text { U.S. } \\
620,649\end{array}$ \\
\hline 199 & & $\begin{array}{l}29 \text { December } \\
1835\end{array}$ & 439 & 7 Stat. 478 & Holden v. Joy (1872) & $\begin{array}{l}84 \text { U.S. } \\
211,213(1)\end{array}$ \\
\hline 199 & & $\begin{array}{l}29 \text { December } \\
1835\end{array}$ & 439 & 7 Stat. 478 & $\begin{array}{l}\text { United States v. Old } \\
\text { Settlers (1893) }\end{array}$ & $\begin{array}{l}148 \text { U.S. } \\
427,438(1)\end{array}$ \\
\hline 199 & & $\begin{array}{l}29 \text { December } \\
1835\end{array}$ & 439 & 7 Stat. 478 & $\begin{array}{l}\text { United States v. } \\
\text { Cherokee Nation } \\
\text { (1906) }\end{array}$ & $\begin{array}{l}202 \text { U.S. } \\
101,105(1)\end{array}$ \\
\hline 199 & & $\begin{array}{l}29 \text { December } \\
1835\end{array}$ & 439 & 7 Stat. 478 & Holden v. Joy (1872) & $\begin{array}{l}84 \text { U.S. } \\
211,211(2)\end{array}$ \\
\hline 199 & & $\begin{array}{l}29 \text { December } \\
1835\end{array}$ & 439 & 7 Stat. 478 & $\begin{array}{l}\text { Cherokee Trust Funds } \\
\text { (1886) }\end{array}$ & $\begin{array}{l}117 \text { U.S. } \\
288,301(2)\end{array}$ \\
\hline 199 & & $\begin{array}{l}29 \text { December } \\
1835\end{array}$ & 439 & 7 Stat. 478 & $\begin{array}{l}\text { United States v. Old } \\
\text { Settlers (1893) }\end{array}$ & $\begin{array}{l}148 \text { U.S. } \\
427,470(2)\end{array}$ \\
\hline 199 & & $\begin{array}{l}29 \text { December } \\
1835\end{array}$ & 439 & 7 Stat. 478 & $\begin{array}{l}\text { Cherokee Nation v. } \\
\text { Hitchcock (1902) }\end{array}$ & $\begin{array}{l}187 \text { U.S. } \\
294,296(2)\end{array}$ \\
\hline 199 & & $\begin{array}{l}29 \text { December } \\
1835\end{array}$ & 439 & 7 Stat. 478 & $\begin{array}{l}\text { Choctaw Nation v. } \\
\text { Oklahoma }(1970)\end{array}$ & $\begin{array}{l}397 \text { U.S. } \\
620,628(2)\end{array}$ \\
\hline
\end{tabular}


Table 1 (continued)

\begin{tabular}{|c|c|c|c|c|c|c|}
\hline $\begin{array}{l}\text { Ratified } \\
\text { treaty } \\
\text { number }\end{array}$ & $\begin{array}{l}\text { Signatory } \\
\text { tribe(s) }\end{array}$ & $\begin{array}{l}\text { Treaty } \\
\text { signing date }\end{array}$ & $\begin{array}{l}\text { Kappler } \\
\text { page } \\
\text { number }\end{array}$ & $\begin{array}{l}\text { Statutes at } \\
\text { Large or an } \\
\text { alternative } \\
\text { source }\end{array}$ & Case title & U.S. reports \\
\hline 199 & & $\begin{array}{l}29 \text { December } \\
1835\end{array}$ & 439 & 7 Stat. 478 & Holden v. Joy (1872) & $\begin{array}{l}84 \text { U.S. } \\
211,214(3)\end{array}$ \\
\hline 199 & & $\begin{array}{l}29 \text { December } \\
1835\end{array}$ & 439 & 7 Stat. 478 & $\begin{array}{l}\text { Cherokee Nation v. } \\
\text { Journeycake (1894) }\end{array}$ & $\begin{array}{l}155 \text { U.S. } \\
196,207(3)\end{array}$ \\
\hline 199 & & $\begin{array}{l}29 \text { December } \\
1835\end{array}$ & 439 & 7 Stat. 478 & $\begin{array}{l}\text { Cherokee Nation v. } \\
\text { Hitchcock (1902) }\end{array}$ & $\begin{array}{l}187 \text { U.S. } \\
294,296(3)\end{array}$ \\
\hline 199 & & $\begin{array}{l}29 \text { December } \\
1835\end{array}$ & 439 & 7 Stat. 478 & Holden v. Joy (1872) & $\begin{array}{l}84 \text { U.S. } \\
211,248(4)\end{array}$ \\
\hline 199 & & $\begin{array}{l}29 \text { December } \\
1835\end{array}$ & 439 & 7 Stat. 478 & $\begin{array}{l}\text { United States v. } \\
\text { Rogers }(1846)\end{array}$ & $\begin{array}{l}45 \text { U.S. } \\
567,567(5)\end{array}$ \\
\hline 199 & & $\begin{array}{l}29 \text { December } \\
1835\end{array}$ & 439 & 7 Stat. 478 & $\begin{array}{l}\text { United States use of } \\
\text { Mackey v. Coxe } \\
(1856)\end{array}$ & $\begin{array}{l}59 \text { U.S. } \\
100,102(5)\end{array}$ \\
\hline 199 & & $\begin{array}{l}29 \text { December } \\
1835\end{array}$ & 439 & 7 Stat. 478 & $\begin{array}{l}\text { Talton v. Mayes } \\
\text { (1896) }\end{array}$ & $\begin{array}{l}163 \text { U.S. } \\
376,380(5)\end{array}$ \\
\hline 199 & & $\begin{array}{l}29 \text { December } \\
1835\end{array}$ & 439 & 7 Stat. 478 & $\begin{array}{l}\text { Atlantic and Pacific } \\
\text { Railroad Co. v. } \\
\text { Mingus (1897) }\end{array}$ & $\begin{array}{l}165 \text { U.S. } \\
413,436(5)\end{array}$ \\
\hline 199 & & $\begin{array}{l}29 \text { December } \\
1835\end{array}$ & 439 & 7 Stat. 478 & $\begin{array}{l}\text { Stephens v. Cherokee } \\
\text { Nation (1899) }\end{array}$ & $\begin{array}{l}174 \text { U.S. } \\
445,484(5)\end{array}$ \\
\hline 199 & & $\begin{array}{l}29 \text { December } \\
1835\end{array}$ & 439 & 7 Stat. 478 & $\begin{array}{l}\text { Cherokee Nation v. } \\
\text { Hitchcock (1902) }\end{array}$ & $\begin{array}{l}187 \text { U.S. } \\
294,297(5)\end{array}$ \\
\hline 199 & & $\begin{array}{l}29 \text { December } \\
1835\end{array}$ & 439 & 7 Stat. 478 & $\begin{array}{l}\text { Cherokee } \\
\text { Intermarriage Cases } \\
\text { (1906) }\end{array}$ & $\begin{array}{l}203 \text { U.S. } \\
76,81(5)\end{array}$ \\
\hline 199 & & $\begin{array}{l}29 \text { December } \\
1835\end{array}$ & 439 & 7 Stat. 478 & $\begin{array}{l}\text { Merrion v. Jicarilla } \\
\text { Apache Tribe (1982) }\end{array}$ & $\begin{array}{l}455 \text { U.S. } \\
130,171(5)\end{array}$ \\
\hline 199 & & $\begin{array}{l}29 \text { December } \\
1835\end{array}$ & 439 & 7 Stat. 478 & $\begin{array}{l}\text { Nevada v. Hicks } \\
\text { (2001) }\end{array}$ & $\begin{array}{l}533 \text { U.S. } \\
353,382(5)\end{array}$ \\
\hline 199 & & $\begin{array}{l}29 \text { December } \\
1835\end{array}$ & 439 & 7 Stat. 478 & $\begin{array}{l}\text { Cherokee Trust Funds } \\
\text { (1886) }\end{array}$ & $\begin{array}{l}117 \text { U.S. } \\
288,301(8)\end{array}$ \\
\hline 199 & & $\begin{array}{l}29 \text { December } \\
1835\end{array}$ & 439 & 7 Stat. 478 & $\begin{array}{l}\text { United States v. Old } \\
\text { Settlers (1893) }\end{array}$ & $\begin{array}{l}148 \text { U.S. } \\
427,475(8)\end{array}$ \\
\hline 199 & & $\begin{array}{l}29 \text { December } \\
1835\end{array}$ & 439 & 7 Stat. 478 & $\begin{array}{l}\text { United States v. Old } \\
\text { Settlers }(1893)\end{array}$ & $\begin{array}{l}148 \text { U.S. } \\
427,477(10)\end{array}$ \\
\hline 199 & & $\begin{array}{l}29 \text { December } \\
1835\end{array}$ & 439 & 7 Stat. 478 & Holden v. Joy (1872) & $\begin{array}{l}84 \text { U.S. } \\
211,248(11)\end{array}$ \\
\hline 199 & & $\begin{array}{l}29 \text { December } \\
1835\end{array}$ & 439 & 7 Stat. 478 & $\begin{array}{l}\text { Scott v. Sandford } \\
(1857)\end{array}$ & $\begin{array}{l}60 \text { U.S. 393, } \\
586(12)\end{array}$ \\
\hline 199 & & $\begin{array}{l}29 \text { December } \\
1835\end{array}$ & 439 & 7 Stat. 478 & $\begin{array}{l}\text { Cherokee Trust Funds } \\
\text { (1886) }\end{array}$ & $\begin{array}{l}117 \text { U.S. } \\
288,302(12)\end{array}$ \\
\hline 199 & & $\begin{array}{l}29 \text { December } \\
1835\end{array}$ & 439 & 7 Stat. 478 & $\begin{array}{l}\text { Boyd v. Nebraska } \\
\text { (1892) }\end{array}$ & $\begin{array}{l}143 \text { U.S. } \\
135,162(12)\end{array}$ \\
\hline 199 & & $\begin{array}{l}29 \text { December } \\
1835\end{array}$ & 439 & 7 Stat. 478 & $\begin{array}{l}\text { United States v. Old } \\
\text { Settlers (1893) }\end{array}$ & $\begin{array}{l}148 \text { U.S. } \\
427,477(12)\end{array}$ \\
\hline
\end{tabular}


Table 1 (continued)

\begin{tabular}{|c|c|c|c|c|c|c|}
\hline $\begin{array}{l}\text { Ratified } \\
\text { treaty } \\
\text { number }\end{array}$ & $\begin{array}{l}\text { Signatory } \\
\text { tribe(s) }\end{array}$ & $\begin{array}{l}\text { Treaty } \\
\text { signing date }\end{array}$ & $\begin{array}{l}\text { Kappler } \\
\text { page } \\
\text { number }\end{array}$ & $\begin{array}{l}\text { Statutes at } \\
\text { Large or an } \\
\text { alternative } \\
\text { source }\end{array}$ & Case title & U.S. reports \\
\hline 199 & & $\begin{array}{l}29 \text { December } \\
1835\end{array}$ & 439 & 7 Stat. 478 & Holden v. Joy (1872) & $\begin{array}{l}84 \text { U.S. } \\
211,248(13)\end{array}$ \\
\hline 199 & & $\begin{array}{l}29 \text { December } \\
1835\end{array}$ & 439 & 7 Stat. 478 & $\begin{array}{l}\text { Cherokee Trust Funds } \\
\text { (1886) }\end{array}$ & $\begin{array}{l}117 \text { U.S. } \\
288,302(15)\end{array}$ \\
\hline 199 & & $\begin{array}{l}29 \text { December } \\
1835\end{array}$ & 439 & 7 Stat. 478 & $\begin{array}{l}\text { United States v. Old } \\
\text { Settlers (1893) }\end{array}$ & $\begin{array}{l}148 \text { U.S. } \\
427,472(15)\end{array}$ \\
\hline 199 & & $\begin{array}{l}29 \text { December } \\
1835\end{array}$ & 439 & 7 Stat. 478 & Holden v. Joy (1872) & $\begin{array}{l}84 \text { U.S. } \\
211,248(17)\end{array}$ \\
\hline 199 & & $\begin{array}{l}29 \text { December } \\
1835\end{array}$ & 439 & 7 Stat. 478 & Holden v. Joy (1872) & $\begin{array}{l}84 \text { U.S. } \\
211,248(18)\end{array}$ \\
\hline 201 & $\begin{array}{l}\text { Ottawa; } \\
\text { Chippewa }\end{array}$ & $\begin{array}{l}28 \mathrm{March} \\
1836\end{array}$ & 450 & 7 Stat. 491 & $\begin{array}{l}\text { Spalding v. Chandler } \\
(1896)\end{array}$ & $\begin{array}{l}160 \text { U.S. } \\
394,398\end{array}$ \\
\hline 207 & $\begin{array}{l}\text { Chippewa: } \\
\text { Swan Creek } \\
\text { and Black } \\
\text { River }\end{array}$ & 9 May 1836 & 461 & 7 Stat. 503 & $\begin{array}{l}\text { Chippewa Indians of } \\
\text { Minnesota } v \text {. United } \\
\text { States (1937) }\end{array}$ & $\begin{array}{l}301 \text { U.S. } \\
358,361\end{array}$ \\
\hline 211 & $\begin{array}{l}\text { Iowa; Sac: } \\
\text { Missouri; } \\
\text { Fox: } \\
\text { Missouri }\end{array}$ & $\begin{array}{l}17 \text { September } \\
1836\end{array}$ & 468 & 7 Stat. 511 & $\begin{array}{l}\text { Missouri v. Iowa } \\
(1849)\end{array}$ & $\begin{array}{l}48 \text { U.S. } \\
660,672\end{array}$ \\
\hline 211 & & $\begin{array}{l}17 \text { September } \\
1836\end{array}$ & 468 & 7 Stat. 511 & $\begin{array}{l}\text { Missouri v. Kansas } \\
\text { (1909) }\end{array}$ & $\begin{array}{l}213 \text { U.S. } \\
78,84\end{array}$ \\
\hline 211 & & $\begin{array}{l}17 \text { September } \\
1836\end{array}$ & 468 & 7 Stat. 511 & $\begin{array}{l}\text { Missouri v. Kansas } \\
\text { (1909) }\end{array}$ & $\begin{array}{l}213 \text { U.S. } \\
78,81(1)\end{array}$ \\
\hline 215 & Sac and Fox & $\begin{array}{l}27 \text { September } \\
1836\end{array}$ & 473 & 7 Stat. 516 & $\begin{array}{l}\text { Missouri v. Iowa } \\
(1849)\end{array}$ & $\begin{array}{l}48 \text { U.S. } \\
660,672\end{array}$ \\
\hline 217 & $\begin{array}{l}\text { Oto; } \\
\text { Missouri; } \\
\text { Omaha; } \\
\text { Sioux: } \\
\text { Yankton and } \\
\text { Santee }\end{array}$ & $\begin{array}{l}15 \text { October } \\
1836\end{array}$ & 479 & 7 Stat. 524 & $\begin{array}{l}\text { Missouri v. Iowa } \\
(1849)\end{array}$ & $\begin{array}{l}48 \text { U.S. } \\
660,672\end{array}$ \\
\hline 219 & $\begin{array}{l}\text { Chippewa: } \\
\text { Saginaw }\end{array}$ & $\begin{array}{l}\text { 14 January } \\
1837\end{array}$ & 482 & 7 Stat. 528 & $\begin{array}{l}\text { Chippewa Indians of } \\
\text { Minnesota v. United } \\
\text { States }(1937)\end{array}$ & $\begin{array}{l}301 \text { U.S. } \\
358,361\end{array}$ \\
\hline 219 & & $\begin{array}{l}\text { 14 January } \\
1837\end{array}$ & 482 & 7 Stat. 528 & $\begin{array}{l}\text { Minnesota v. Mille } \\
\text { Lacs Band of } \\
\text { Chippewa Indians } \\
\text { (1999) }\end{array}$ & $\begin{array}{l}526 \text { U.S. } \\
172,172(6)\end{array}$ \\
\hline 219 & & $\begin{array}{l}\text { 14 January } \\
1837\end{array}$ & 482 & 7 Stat. 528 & $\begin{array}{l}\text { Minnesota v. Mille } \\
\text { Lacs Band of } \\
\text { Chippewa Indians } \\
\text { (1999) }\end{array}$ & $\begin{array}{l}526 \text { U.S. } \\
172,189(6)\end{array}$ \\
\hline
\end{tabular}


Table 1 (continued)

\begin{tabular}{|c|c|c|c|c|c|c|}
\hline $\begin{array}{l}\text { Ratified } \\
\text { treaty } \\
\text { number }\end{array}$ & $\begin{array}{l}\text { Signatory } \\
\text { tribe(s) }\end{array}$ & $\begin{array}{l}\text { Treaty } \\
\text { signing date }\end{array}$ & $\begin{array}{l}\text { Kappler } \\
\text { page } \\
\text { number }\end{array}$ & $\begin{array}{l}\text { Statutes at } \\
\text { Large or an } \\
\text { alternative } \\
\text { source }\end{array}$ & Case title & U.S. reports \\
\hline 220 & $\begin{array}{l}\text { Choctaw; } \\
\text { Chickasaw }\end{array}$ & $\begin{array}{l}17 \text { January } \\
1837\end{array}$ & 486 & $\begin{array}{l}11 \text { Stat. } \\
573\end{array}$ & $\begin{array}{l}\text { United States v. } \\
\text { Choctaw Nation } \\
\text { (1900) }\end{array}$ & $\begin{array}{l}179 \text { U.S. } \\
494,509\end{array}$ \\
\hline 220 & & $\begin{array}{l}17 \text { January } \\
1837\end{array}$ & 486 & $\begin{array}{l}11 \text { Stat. } \\
573\end{array}$ & $\begin{array}{l}\text { Fleming v. McCurtain } \\
\text { (1909) }\end{array}$ & $\begin{array}{l}215 \text { U.S. } \\
56,58\end{array}$ \\
\hline 220 & & $\begin{array}{l}17 \text { January } \\
1837\end{array}$ & 486 & $\begin{array}{l}11 \text { Stat. } \\
573\end{array}$ & $\begin{array}{l}\text { Mullen v. United } \\
\text { States (1912) }\end{array}$ & $\begin{array}{l}224 \text { U.S. } \\
448,450\end{array}$ \\
\hline 220 & & $\begin{array}{l}17 \text { January } \\
1837\end{array}$ & 486 & $\begin{array}{l}11 \text { Stat. } \\
573\end{array}$ & $\begin{array}{l}\text { Johnson v. Riddle } \\
\text { (1916) }\end{array}$ & $\begin{array}{l}240 \text { U.S. } \\
467,475\end{array}$ \\
\hline 220 & & $\begin{array}{l}17 \text { January } \\
1837\end{array}$ & 486 & $\begin{array}{l}11 \text { Stat. } \\
573\end{array}$ & $\begin{array}{l}\text { Choctaw Nation v. } \\
\text { Oklahoma (1970) }\end{array}$ & $\begin{array}{l}397 \text { U.S. } \\
620,626+\end{array}$ \\
\hline 220 & & $\begin{array}{l}17 \text { January } \\
1837\end{array}$ & 486 & $\begin{array}{l}11 \text { Stat. } \\
573\end{array}$ & $\begin{array}{l}\text { Oklahoma Tax } \\
\text { Commission v. } \\
\text { Chickasaw Nation } \\
\text { (1995) }\end{array}$ & $\begin{array}{l}515 \text { U.S. } \\
450,465+\end{array}$ \\
\hline 221 & Potawatomi & $\begin{array}{l}11 \text { February } \\
1837\end{array}$ & 488 & 7 Stat. 532 & $\begin{array}{l}\text { Metlakatla Indian } \\
\text { Community v. Egan } \\
\text { (1962) }\end{array}$ & $\begin{array}{l}369 \text { U.S. } \\
45,52\end{array}$ \\
\hline 221 & & $\begin{array}{l}11 \text { February } \\
1837\end{array}$ & 488 & 7 Stat. 532 & $\begin{array}{l}\text { Minnesota v. Mille } \\
\text { Lacs Band of } \\
\text { Chippewa Indians } \\
\text { (1999) }\end{array}$ & $\begin{array}{l}526 \text { U.S. } \\
172,172(1)\end{array}$ \\
\hline 221 & & $\begin{array}{l}11 \text { February } \\
1837\end{array}$ & 488 & 7 Stat. 532 & $\begin{array}{l}\text { Minnesota v. Mille } \\
\text { Lacs Band of } \\
\text { Chippewa Indians } \\
\text { (1999) }\end{array}$ & $\begin{array}{l}526 \text { U.S. } \\
172,190(1)\end{array}$ \\
\hline 223 & Chippewa & 29 July 1837 & 491 & 7 Stat. 536 & $\begin{array}{l}\text { Wilbur v. United } \\
\text { States (1930) }\end{array}$ & $\begin{array}{l}281 \text { U.S. } \\
206,208\end{array}$ \\
\hline 223 & & 29 July 1837 & 491 & 7 Stat. 536 & $\begin{array}{l}\text { Minnesota v. Mille } \\
\text { Lacs Band of } \\
\text { Chippewa Indians } \\
\text { (1999) }\end{array}$ & $\begin{array}{l}526 \text { U.S. } \\
172,172\end{array}$ \\
\hline 223 & & 29 July 1837 & 491 & 7 Stat. 536 & $\begin{array}{l}\text { Minnesota v. Mille } \\
\text { Lacs Band of } \\
\text { Chippewa Indians } \\
\text { (1999) }\end{array}$ & $\begin{array}{l}526 \text { U.S. } \\
172,177\end{array}$ \\
\hline 223 & & 29 July 1837 & 491 & 7 Stat. 536 & $\begin{array}{l}\text { United States v. } \\
\text { Minnesota }(1926)\end{array}$ & $\begin{array}{l}270 \text { U.S. } \\
181,196(1)\end{array}$ \\
\hline 223 & & 29 July 1837 & 491 & 7 Stat. 536 & $\begin{array}{l}\text { Minnesota v. Mille } \\
\text { Lacs Band of } \\
\text { Chippewa Indians } \\
\text { (1999) }\end{array}$ & $\begin{array}{l}526 \text { U.S. } \\
172,172(1)\end{array}$ \\
\hline
\end{tabular}


Table 1 (continued)

\begin{tabular}{|c|c|c|c|c|c|c|}
\hline $\begin{array}{l}\text { Ratified } \\
\text { treaty } \\
\text { number }\end{array}$ & $\begin{array}{l}\text { Signatory } \\
\text { tribe(s) }\end{array}$ & $\begin{array}{l}\text { Treaty } \\
\text { signing date }\end{array}$ & $\begin{array}{l}\text { Kappler } \\
\text { page } \\
\text { number }\end{array}$ & $\begin{array}{l}\text { Statutes at } \\
\text { Large or an } \\
\text { alternative } \\
\text { source }\end{array}$ & Case title & U.S. reports \\
\hline 223 & & 29 July 1837 & 491 & 7 Stat. 536 & $\begin{array}{l}\text { Minnesota v. Mille } \\
\text { Lacs Band of } \\
\text { Chippewa Indians } \\
\text { (1999) }\end{array}$ & $\begin{array}{l}526 \text { U.S. } \\
172,176(1)\end{array}$ \\
\hline 223 & & 29 July 1837 & 491 & 7 Stat. 536 & $\begin{array}{l}\text { Minnesota v. Mille } \\
\text { Lacs Band of } \\
\text { Chippewa Indians } \\
\text { (1999) }\end{array}$ & $\begin{array}{l}526 \text { U.S. } \\
172,172(2)\end{array}$ \\
\hline 223 & & 29 July 1837 & 491 & 7 Stat. 536 & $\begin{array}{l}\text { Minnesota v. Mille } \\
\text { Lacs Band of } \\
\text { Chippewa Indians } \\
\text { (1999) }\end{array}$ & $\begin{array}{l}526 \text { U.S. } \\
172,185(2)\end{array}$ \\
\hline 223 & & 29 July 1837 & 491 & 7 Stat. 536 & $\begin{array}{l}\text { United States v. First } \\
\text { National Bank (1914) }\end{array}$ & $\begin{array}{l}234 \text { U.S. } \\
245,250(3)\end{array}$ \\
\hline 223 & & 29 July 1837 & 491 & 7 Stat. 536 & $\begin{array}{l}\text { Minnesota v. Mille } \\
\text { Lacs Band of } \\
\text { Chippewa Indians } \\
\text { (1999) }\end{array}$ & $\begin{array}{l}526 \text { U.S. } \\
172,172(3)\end{array}$ \\
\hline 223 & & 29 July 1837 & 491 & 7 Stat. 536 & $\begin{array}{l}\text { Minnesota v. Mille } \\
\text { Lacs Band of } \\
\text { Chippewa Indians } \\
\text { (1999) }\end{array}$ & $\begin{array}{l}526 \text { U.S. } \\
172,210(3)\end{array}$ \\
\hline 223 & & 29 July 1837 & 491 & 7 Stat. 536 & $\begin{array}{l}\text { Minnesota v. Mille } \\
\text { Lacs Band of } \\
\text { Chippewa Indians } \\
\text { (1999) }\end{array}$ & $\begin{array}{l}526 \text { U.S. } \\
172,172(4)\end{array}$ \\
\hline 223 & & 29 July 1837 & 491 & 7 Stat. 536 & $\begin{array}{l}\text { Minnesota v. Mille } \\
\text { Lacs Band of } \\
\text { Chippewa Indians } \\
\text { (1999) }\end{array}$ & $\begin{array}{l}526 \text { U.S. } \\
172,210(4)\end{array}$ \\
\hline 223 & & 29 July 1837 & 491 & 7 Stat. 536 & $\begin{array}{l}\text { Minnesota v. Mille } \\
\text { Lacs Band of } \\
\text { Chippewa Indians } \\
\text { (1999) }\end{array}$ & $\begin{array}{l}526 \text { U.S. } \\
172,172(5)\end{array}$ \\
\hline 223 & & 29 July 1837 & 491 & 7 Stat. 536 & $\begin{array}{l}\text { Minnesota v. Mille } \\
\text { Lacs Band of } \\
\text { Chippewa Indians } \\
\text { (1999) }\end{array}$ & $\begin{array}{l}526 \text { U.S. } \\
172,176(5)\end{array}$ \\
\hline 225 & Sac and Fox & $\begin{array}{l}21 \text { October } \\
1837\end{array}$ & 495 & 7 Stat. 540 & $\begin{array}{l}\text { Sac and Fox Indians } \\
\text { of the Mississippi in } \\
\text { Iowa v. Sac and Fox } \\
\text { Indians of the } \\
\text { Mississippi in } \\
\text { Oklahoma (1911) }\end{array}$ & $\begin{array}{l}220 \text { U.S. } \\
481,484\end{array}$ \\
\hline
\end{tabular}


Table 1 (continued)

\begin{tabular}{|c|c|c|c|c|c|c|}
\hline $\begin{array}{l}\text { Ratified } \\
\text { treaty } \\
\text { number }\end{array}$ & $\begin{array}{l}\text { Signatory } \\
\text { tribe(s) }\end{array}$ & $\begin{array}{l}\text { Treaty } \\
\text { signing date }\end{array}$ & $\begin{array}{l}\text { Kappler } \\
\text { page } \\
\text { number }\end{array}$ & $\begin{array}{l}\text { Statutes at } \\
\text { Large or an } \\
\text { alternative } \\
\text { source }\end{array}$ & Case title & U.S. reports \\
\hline 225 & & $\begin{array}{l}21 \text { October } \\
1837\end{array}$ & 495 & 7 Stat. 540 & $\begin{array}{l}\text { Minnesota v. Mille } \\
\text { Lacs Band of } \\
\text { Chippewa Indians } \\
\text { (1999) }\end{array}$ & $\begin{array}{l}526 \text { U.S. } \\
172,172\end{array}$ \\
\hline 225 & & $\begin{array}{l}21 \text { October } \\
1837\end{array}$ & 495 & 7 Stat. 540 & $\begin{array}{l}\text { Minnesota v. Mille } \\
\text { Lacs Band of } \\
\text { Chippewa Indians } \\
\text { (1999) }\end{array}$ & $\begin{array}{l}526 \text { U.S. } \\
172,190(1)\end{array}$ \\
\hline 225 & & $\begin{array}{l}21 \text { October } \\
1837\end{array}$ & 495 & 7 Stat. 540 & $\begin{array}{l}\text { Minnesota v. Mille } \\
\text { Lacs Band of } \\
\text { Chippewa Indians } \\
\text { (1999) }\end{array}$ & $\begin{array}{l}526 \text { U.S. } \\
172,172(2)\end{array}$ \\
\hline 225 & & $\begin{array}{l}21 \text { October } \\
1837\end{array}$ & 495 & 7 Stat. 540 & $\begin{array}{l}\text { Minnesota v. Mille } \\
\text { Lacs Band of } \\
\text { Chippewa Indians } \\
\text { (1999) }\end{array}$ & $\begin{array}{l}526 \text { U.S. } \\
172,196(2)\end{array}$ \\
\hline 227 & $\begin{array}{l}\text { Sac: } \\
\text { Missouri; } \\
\text { Fox: } \\
\text { Missouri }\end{array}$ & $\begin{array}{l}21 \text { October } \\
1837\end{array}$ & 497 & 7 Stat. 543 & $\begin{array}{l}\text { Minnesota v. Mille } \\
\text { Lacs Band of } \\
\text { Chippewa Indians } \\
\text { (1999) }\end{array}$ & $\begin{array}{l}526 \text { U.S. } \\
172 \\
196(2)+\end{array}$ \\
\hline 228 & Winnebago & $\begin{array}{l}1 \text { November } \\
1837\end{array}$ & 498 & 7 Stat. 544 & $\begin{array}{l}\text { Minnesota v. Mille } \\
\text { Lacs Band of } \\
\text { Chippewa Indians } \\
\text { (1999) }\end{array}$ & $\begin{array}{l}526 \text { U.S. } \\
172,172(3)\end{array}$ \\
\hline 228 & & $\begin{array}{l}1 \text { November } \\
1837\end{array}$ & 498 & 7 Stat. 544 & $\begin{array}{l}\text { Minnesota v. Mille } \\
\text { Lacs Band of } \\
\text { Chippewa Indians } \\
(1999)\end{array}$ & $\begin{array}{l}526 \text { U.S. } \\
172,190(3)\end{array}$ \\
\hline 230 & $\begin{array}{l}\text { New York } \\
\text { Indians }\end{array}$ & $\begin{array}{l}15 \text { January } \\
1838\end{array}$ & 502 & 7 Stat. 550 & $\begin{array}{l}\text { Fellows v. Blacksmith } \\
\text { (1857) }\end{array}$ & $\begin{array}{l}60 \text { U.S. } \\
366,366\end{array}$ \\
\hline 230 & & $\begin{array}{l}15 \text { January } \\
1838\end{array}$ & 502 & 7 Stat. 550 & $\begin{array}{l}\text { New York Indians v. } \\
\text { United States (1898) }\end{array}$ & $\begin{array}{l}170 \text { U.S. } \\
1,1\end{array}$ \\
\hline 230 & & $\begin{array}{l}15 \text { January } \\
1838\end{array}$ & 502 & 7 Stat. 550 & $\begin{array}{l}\text { United States v. New } \\
\text { York Indians (1899) }\end{array}$ & $\begin{array}{l}173 \text { U.S. } \\
464,468\end{array}$ \\
\hline 230 & & $\begin{array}{l}15 \text { January } \\
1838\end{array}$ & 502 & 7 Stat. 550 & $\begin{array}{l}\text { Federal Power } \\
\text { Commission v. } \\
\text { Tuscarora Indian } \\
\text { Nation (1960) }\end{array}$ & $\begin{array}{l}362 \text { U.S. } \\
99,137\end{array}$ \\
\hline 230 & & $\begin{array}{l}15 \text { January } \\
1838\end{array}$ & 502 & 7 Stat. 550 & $\begin{array}{l}\text { Metlakatla Indian } \\
\text { Community v. Egan } \\
\text { (1962) }\end{array}$ & $\begin{array}{l}369 \text { U.S. } \\
45,52\end{array}$ \\
\hline 230 & & $\begin{array}{l}15 \text { January } \\
1838\end{array}$ & 502 & 7 Stat. 550 & $\begin{array}{l}\text { County of Oneida v. } \\
\text { Oneida Indian Nation } \\
\text { (1985) }\end{array}$ & $\begin{array}{l}470 \text { U.S. } \\
226,272\end{array}$ \\
\hline
\end{tabular}


Table 1 (continued)

\begin{tabular}{|c|c|c|c|c|c|c|}
\hline $\begin{array}{l}\text { Ratified } \\
\text { treaty } \\
\text { number }\end{array}$ & $\begin{array}{l}\text { Signatory } \\
\text { tribe(s) }\end{array}$ & $\begin{array}{l}\text { Treaty } \\
\text { signing date }\end{array}$ & $\begin{array}{l}\text { Kappler } \\
\text { page } \\
\text { number }\end{array}$ & $\begin{array}{l}\text { Statutes at } \\
\text { Large or an } \\
\text { alternative } \\
\text { source }\end{array}$ & Case title & U.S. reports \\
\hline 230 & & $\begin{array}{l}15 \text { January } \\
1838\end{array}$ & 502 & 7 Stat. 550 & $\begin{array}{l}\text { New York Indians v. } \\
\text { United States (1898) }\end{array}$ & $\begin{array}{l}170 \text { U.S. } \\
1,15(1)\end{array}$ \\
\hline 230 & & $\begin{array}{l}15 \text { January } \\
1838\end{array}$ & 502 & 7 Stat. 550 & $\begin{array}{l}\text { New York Indians v. } \\
\text { United States }(1898)\end{array}$ & $\begin{array}{l}170 \text { U.S. } \\
1,15(2)\end{array}$ \\
\hline 230 & & $\begin{array}{l}15 \text { January } \\
1838\end{array}$ & 502 & 7 Stat. 550 & $\begin{array}{l}\text { United States v. New } \\
\text { York Indians (1899) }\end{array}$ & $\begin{array}{l}173 \text { U.S. } \\
484,468(2)\end{array}$ \\
\hline 230 & & $\begin{array}{l}15 \text { January } \\
1838\end{array}$ & 502 & 7 Stat. 550 & $\begin{array}{l}\text { Metlakatla Indian } \\
\text { Community v. Egan } \\
\text { (1962) }\end{array}$ & $\begin{array}{l}369 \text { U.S. } \\
45,52(2)\end{array}$ \\
\hline 230 & & $\begin{array}{l}15 \text { January } \\
1838\end{array}$ & 502 & 7 Stat. 550 & $\begin{array}{l}\text { County of Oneida } v . \\
\text { Oneida Indian Nation } \\
(1985)\end{array}$ & $\begin{array}{l}470 \text { U.S. } \\
226,270(2)\end{array}$ \\
\hline 230 & & $\begin{array}{l}15 \text { January } \\
1838\end{array}$ & 502 & 7 Stat. 550 & $\begin{array}{l}\text { New York Indians v. } \\
\text { United States }(1898)\end{array}$ & $\begin{array}{l}170 \text { U.S. } \\
1,9(3)\end{array}$ \\
\hline 230 & & $\begin{array}{l}15 \text { January } \\
1838\end{array}$ & 502 & 7 Stat. 550 & $\begin{array}{l}\text { New York Indians v. } \\
\text { United States }(1898)\end{array}$ & $\begin{array}{l}170 \text { U.S. } \\
1,9(4)\end{array}$ \\
\hline 230 & & $\begin{array}{l}15 \text { January } \\
1838\end{array}$ & 502 & 7 Stat. 550 & $\begin{array}{l}\text { New York Indians v. } \\
\text { United States (1898) }\end{array}$ & $\begin{array}{l}170 \text { U.S. } \\
1,9(5)\end{array}$ \\
\hline 230 & & $\begin{array}{l}15 \text { January } \\
1838\end{array}$ & 502 & 7 Stat. 550 & $\begin{array}{l}\text { New York Indians v. } \\
\text { United States }(1898)\end{array}$ & $\begin{array}{l}170 \text { U.S. } \\
1,9(6)\end{array}$ \\
\hline 230 & & $\begin{array}{l}15 \text { January } \\
1838\end{array}$ & 502 & 7 Stat. 550 & $\begin{array}{l}\text { New York Indians v. } \\
\text { United States }(1898)\end{array}$ & $\begin{array}{l}170 \text { U.S. } \\
1,9(9)\end{array}$ \\
\hline 230 & & $\begin{array}{l}15 \text { January } \\
1838\end{array}$ & 502 & 7 Stat. 550 & $\begin{array}{l}\text { Fellows v. Blacksmith } \\
(1857)\end{array}$ & $\begin{array}{l}60 \text { U.S. } \\
366,368(10)\end{array}$ \\
\hline 230 & & $\begin{array}{l}15 \text { January } \\
1838\end{array}$ & 502 & 7 Stat. 550 & $\begin{array}{l}\text { New York Indians } \\
\text { (1867) }\end{array}$ & $\begin{array}{l}72 \text { U.S. } \\
761,762(10)\end{array}$ \\
\hline 230 & & $\begin{array}{l}15 \text { January } \\
1838\end{array}$ & 502 & 7 Stat. 550 & $\begin{array}{l}\text { New York Indians v. } \\
\text { United States }(1898)\end{array}$ & $\begin{array}{l}170 \text { U.S. } \\
1,21(10)\end{array}$ \\
\hline 230 & & $\begin{array}{l}15 \text { January } \\
1838\end{array}$ & 502 & 7 Stat. 550 & $\begin{array}{l}\text { New York Indians v. } \\
\text { United States }(1898)\end{array}$ & $\begin{array}{l}170 \text { U.S. } \\
1,35(12)\end{array}$ \\
\hline 230 & & $\begin{array}{l}15 \text { January } \\
1838\end{array}$ & 502 & 7 Stat. 550 & $\begin{array}{l}\text { New York Indians v. } \\
\text { United States }(1898)\end{array}$ & $\begin{array}{l}170 \text { U.S. } \\
1,26(13)\end{array}$ \\
\hline 230 & & $\begin{array}{l}15 \text { January } \\
1838\end{array}$ & 502 & 7 Stat. 550 & $\begin{array}{l}\text { New York Indians v. } \\
\text { United States (1898) }\end{array}$ & $\begin{array}{l}170 \text { U.S. } \\
1,31(14)\end{array}$ \\
\hline 230 & & $\begin{array}{l}15 \text { January } \\
1838\end{array}$ & 502 & 7 Stat. 550 & $\begin{array}{l}\text { Federal Power } \\
\text { Commission v. } \\
\text { Tuscarora Indian } \\
\text { Nation (1960) }\end{array}$ & $\begin{array}{l}362 \text { U.S. } \\
99,135(14)\end{array}$ \\
\hline 230 & & $\begin{array}{l}15 \text { January } \\
1838\end{array}$ & 502 & 7 Stat. 550 & $\begin{array}{l}\text { Fellows v. Blacksmith } \\
(1857)\end{array}$ & $\begin{array}{l}60 \text { U.S. } \\
366,369(15)\end{array}$ \\
\hline 230 & & $\begin{array}{l}15 \text { January } \\
1838\end{array}$ & 502 & 7 Stat. 550 & $\begin{array}{l}\text { New York Indians v. } \\
\text { United States }(1898)\end{array}$ & $\begin{array}{l}170 \text { U.S. } \\
1,9(15)\end{array}$ \\
\hline
\end{tabular}


Table 1 (continued)

\begin{tabular}{|c|c|c|c|c|c|c|}
\hline $\begin{array}{l}\text { Ratified } \\
\text { treaty } \\
\text { number }\end{array}$ & $\begin{array}{l}\text { Signatory } \\
\text { tribe(s) }\end{array}$ & $\begin{array}{l}\text { Treaty } \\
\text { signing date }\end{array}$ & $\begin{array}{l}\text { Kappler } \\
\text { page } \\
\text { number }\end{array}$ & $\begin{array}{l}\text { Statutes at } \\
\text { Large or an } \\
\text { alternative } \\
\text { source }\end{array}$ & Case title & U.S. reports \\
\hline 232 & $\begin{array}{l}\text { Oneida: First } \\
\text { Christian and } \\
\text { Orchard }\end{array}$ & $\begin{array}{l}3 \text { February } \\
1838\end{array}$ & 517 & 7 Stat. 566 & $\begin{array}{l}\text { New York Indians v. } \\
\text { United States (1898) }\end{array}$ & $\begin{array}{l}170 \text { U.S. } \\
1,13\end{array}$ \\
\hline 240 & Wyandot & $\begin{array}{l}17 \text { March } \\
1842\end{array}$ & 534 & $\begin{array}{l}11 \text { Stat. } \\
581\end{array}$ & $\begin{array}{l}\text { Walker v. Henshaw } \\
\text { (1873) }\end{array}$ & $\begin{array}{l}83 \text { U.S. } \\
436,436\end{array}$ \\
\hline 240 & & $\begin{array}{l}17 \text { March } \\
1842\end{array}$ & 534 & $\begin{array}{l}11 \text { Stat. } \\
581\end{array}$ & $\begin{array}{l}\text { Walker v. Henshaw } \\
\text { (1873) }\end{array}$ & $\begin{array}{l}83 \text { U.S. } \\
436,437(14)\end{array}$ \\
\hline 241 & Seneca & 20 May 1842 & 537 & 7 Stat. 586 & $\begin{array}{l}\text { Fellows v. Blacksmith } \\
\text { (1857) }\end{array}$ & $\begin{array}{l}60 \text { U.S. } \\
366,366\end{array}$ \\
\hline 241 & & 20 May 1842 & 537 & 7 Stat. 586 & $\begin{array}{l}\text { New York ex rel. } \\
\text { Cutler v. Dibble (1859) }\end{array}$ & $\begin{array}{l}62 \text { U.S. } \\
366,369\end{array}$ \\
\hline 241 & & 20 May 1842 & 537 & 7 Stat. 586 & $\begin{array}{l}\text { New York Indians } \\
(1867)\end{array}$ & $\begin{array}{l}72 \text { U.S. } \\
761,762\end{array}$ \\
\hline 241 & & 20 May 1842 & 537 & 7 Stat. 586 & $\begin{array}{l}\text { New York Indians v. } \\
\text { United States (1898) }\end{array}$ & $\begin{array}{l}170 \text { U.S. } \\
1,11\end{array}$ \\
\hline 241 & & 20 May 1842 & 537 & 7 Stat. 586 & $\begin{array}{l}\text { Fellows v. Blacksmith } \\
\text { (1857) }\end{array}$ & $\begin{array}{l}60 \text { U.S. } \\
366,369(1)\end{array}$ \\
\hline 241 & & 20 May 1842 & 537 & 7 Stat. 586 & $\begin{array}{l}\text { Fellows v. Blacksmith } \\
(1857)\end{array}$ & $\begin{array}{l}60 \text { U.S. } \\
366,369(2)\end{array}$ \\
\hline 241 & & 20 May 1842 & 537 & 7 Stat. 586 & $\begin{array}{l}\text { Fellows v. Blacksmith } \\
\text { (1857) }\end{array}$ & $\begin{array}{l}60 \text { U.S. } \\
366,369(3)\end{array}$ \\
\hline 241 & & 20 May 1842 & 537 & 7 Stat. 586 & $\begin{array}{l}\text { Fellows v. Blacksmith } \\
\text { (1857) }\end{array}$ & $\begin{array}{l}60 \text { U.S. } \\
366,370(4)\end{array}$ \\
\hline 241 & & 20 May 1842 & 537 & 7 Stat. 586 & $\begin{array}{l}\text { Fellows v. Blacksmith } \\
\text { (1857) }\end{array}$ & $\begin{array}{l}60 \text { U.S. } \\
366,369(5)\end{array}$ \\
\hline 241 & & 20 May 1842 & 537 & 7 Stat. 586 & $\begin{array}{l}\text { Fellows v. Blacksmith } \\
\text { (1857) }\end{array}$ & $\begin{array}{l}60 \text { U.S. } \\
366,369(7)\end{array}$ \\
\hline 242 & $\begin{array}{l}\text { Chippewa: } \\
\text { Mississippi } \\
\text { Chippewa: } \\
\text { Lake } \\
\text { Superior }\end{array}$ & $\begin{array}{l}4 \text { October } \\
1842\end{array}$ & 542 & 7 Stat. 591 & $\begin{array}{l}\text { United States v. J.S. } \\
\text { Stearns Lumber Co. } \\
(1918)\end{array}$ & $\begin{array}{l}245 \text { U.S. } \\
436,436\end{array}$ \\
\hline 242 & & $\begin{array}{l}4 \text { October } \\
1842\end{array}$ & 542 & 7 Stat. 591 & $\begin{array}{l}\text { Wilbur v. United } \\
\text { States }(1930)\end{array}$ & $\begin{array}{l}281 \text { U.S. } \\
206,208\end{array}$ \\
\hline 242 & & $\begin{array}{l}4 \text { October } \\
1842\end{array}$ & 542 & 7 Stat. 591 & $\begin{array}{l}\text { Chippewa Indians of } \\
\text { Minnesota v. United } \\
\text { States (1937) }\end{array}$ & $\begin{array}{l}301 \text { U.S. } \\
358,361\end{array}$ \\
\hline 242 & & $\begin{array}{l}4 \text { October } \\
1842\end{array}$ & 542 & 7 Stat. 591 & $\begin{array}{l}\text { Minnesota v. Mille } \\
\text { Lacs Band of } \\
\text { Chippewa Indians } \\
\text { (1999) }\end{array}$ & $\begin{array}{l}526 \text { U.S. } \\
172,172\end{array}$ \\
\hline 242 & & $\begin{array}{l}4 \text { October } \\
1842\end{array}$ & 542 & 7 Stat. 591 & $\begin{array}{l}\text { Minnesota v. Mille } \\
\text { Lacs Band of } \\
\text { Chippewa Indians } \\
\text { (1999) }\end{array}$ & $\begin{array}{l}526 \text { U.S. } \\
172,177\end{array}$ \\
\hline
\end{tabular}


Table 1 (continued)

\begin{tabular}{|c|c|c|c|c|c|c|}
\hline $\begin{array}{l}\text { Ratified } \\
\text { treaty } \\
\text { number }\end{array}$ & $\begin{array}{l}\text { Signatory } \\
\text { tribe(s) }\end{array}$ & $\begin{array}{l}\text { Treaty } \\
\text { signing date }\end{array}$ & $\begin{array}{l}\text { Kappler } \\
\text { page } \\
\text { number }\end{array}$ & $\begin{array}{l}\text { Statutes at } \\
\text { Large or an } \\
\text { alternative } \\
\text { source }\end{array}$ & Case title & U.S. reports \\
\hline 242 & & $\begin{array}{l}4 \text { October } \\
1842\end{array}$ & 542 & 7 Stat. 591 & $\begin{array}{l}\text { United States } v . \\
\text { Thomas (1894) }\end{array}$ & $\begin{array}{l}151 \text { U.S. } \\
577,581(1)\end{array}$ \\
\hline 242 & & $\begin{array}{l}4 \text { October } \\
1842\end{array}$ & 542 & 7 Stat. 591 & $\begin{array}{l}\text { United States } v . \\
\text { Thomas (1894) }\end{array}$ & $\begin{array}{l}151 \text { U.S. } \\
577,582(2)\end{array}$ \\
\hline 242 & & $\begin{array}{l}4 \text { October } \\
1842\end{array}$ & 542 & 7 Stat. 591 & $\begin{array}{l}\text { Wisconsin v. } \\
\text { Hitchcock (1906) }\end{array}$ & $\begin{array}{l}201 \text { U.S. } \\
202,203(2)\end{array}$ \\
\hline 242 & & $\begin{array}{l}4 \text { October } \\
1842\end{array}$ & 542 & 7 Stat. 591 & $\begin{array}{l}\text { United States v. } \\
\text { Morrison (1916) }\end{array}$ & $\begin{array}{l}240 \text { U.S. } \\
192,207(2)\end{array}$ \\
\hline 242 & & $\begin{array}{l}4 \text { October } \\
1842\end{array}$ & 542 & 7 Stat. 591 & $\begin{array}{l}\text { Minnesota v. Mille } \\
\text { Lacs Band of } \\
\text { Chippewa Indians } \\
\text { (1999) }\end{array}$ & $\begin{array}{l}526 \text { U.S. } \\
172,172(2)\end{array}$ \\
\hline 242 & & $\begin{array}{l}4 \text { October } \\
1842\end{array}$ & 542 & 7 Stat. 591 & $\begin{array}{l}\text { Minnesota v. Mille } \\
\text { Lacs Band of } \\
\text { Chippewa Indians } \\
\text { (1999) }\end{array}$ & $\begin{array}{l}526 \text { U.S. } \\
172,177(2)\end{array}$ \\
\hline 242 & & $\begin{array}{l}4 \text { October } \\
1842\end{array}$ & 542 & 7 Stat. 591 & $\begin{array}{l}\text { Wisconsin v. } \\
\text { Hitchcock (1906) }\end{array}$ & $\begin{array}{l}201 \text { U.S. } \\
202,203(3)\end{array}$ \\
\hline 242 & & $\begin{array}{l}4 \text { October } \\
1842\end{array}$ & 542 & 7 Stat. 591 & $\begin{array}{l}\text { Wisconsin v. } \\
\text { Hitchcock (1906) }\end{array}$ & $\begin{array}{l}201 \text { U.S. } \\
202,203(4)\end{array}$ \\
\hline 242 & & $\begin{array}{l}4 \text { October } \\
1842\end{array}$ & 542 & 7 Stat. 591 & $\begin{array}{l}\text { United States v. First } \\
\text { National Bank (1914) }\end{array}$ & $\begin{array}{l}234 \text { U.S. } \\
245,250(4)\end{array}$ \\
\hline 242 & & $\begin{array}{l}4 \text { October } \\
1842\end{array}$ & 542 & 7 Stat. 591 & $\begin{array}{l}\text { United States v. } \\
\text { Thomas (1894) }\end{array}$ & $\begin{array}{l}151 \text { U.S. } \\
577,582(5)\end{array}$ \\
\hline 242 & & $\begin{array}{l}4 \text { October } \\
1842\end{array}$ & 542 & 7 Stat. 591 & $\begin{array}{l}\text { Minnesota v. Mille } \\
\text { Lacs Band of } \\
\text { Chippewa Indians } \\
\text { (1999) }\end{array}$ & $\begin{array}{l}526 \text { U.S. } \\
172,172(6)\end{array}$ \\
\hline 242 & & $\begin{array}{l}4 \text { October } \\
1842\end{array}$ & 542 & 7 Stat. 591 & $\begin{array}{l}\text { Minnesota v. Mille } \\
\text { Lacs Band of } \\
\text { Chippewa Indians } \\
\text { (1999) }\end{array}$ & $\begin{array}{l}526 \text { U.S. } \\
172,177(6)\end{array}$ \\
\hline 242 & & $\begin{array}{l}4 \text { October } \\
1842\end{array}$ & 542 & 7 Stat. 591 & $\begin{array}{l}\text { United States v. } \\
\text { Thomas (1894) }\end{array}$ & $\begin{array}{l}151 \text { U.S. } \\
577,582(7)\end{array}$ \\
\hline 243 & Sac and Fox & $\begin{array}{l}11 \text { October } \\
1842\end{array}$ & 546 & 7 Stat. 596 & $\begin{array}{l}\text { Pennock } v . \\
\text { Commissioners } \\
(1881)\end{array}$ & $\begin{array}{l}103 \text { U.S. } \\
44,45\end{array}$ \\
\hline 243 & & $\begin{array}{l}11 \text { October } \\
1842\end{array}$ & 546 & 7 Stat. 596 & $\begin{array}{l}\text { Sac and Fox Indians } \\
\text { of the Mississippi in } \\
\text { Iowa v. Sac and Fox } \\
\text { Indians of the } \\
\text { Mississippi in } \\
\text { Oklahoma (1911) }\end{array}$ & $\begin{array}{l}220 \text { U.S. } \\
481,482\end{array}$ \\
\hline
\end{tabular}


Table 1 (continued)

\begin{tabular}{|c|c|c|c|c|c|c|}
\hline $\begin{array}{l}\text { Ratified } \\
\text { treaty } \\
\text { number }\end{array}$ & $\begin{array}{l}\text { Signatory } \\
\text { tribe(s) }\end{array}$ & $\begin{array}{l}\text { Treaty } \\
\text { signing date }\end{array}$ & $\begin{array}{l}\text { Kappler } \\
\text { page } \\
\text { number }\end{array}$ & $\begin{array}{l}\text { Statutes at } \\
\text { Large or an } \\
\text { alternative } \\
\text { source }\end{array}$ & Case title & U.S. reports \\
\hline 243 & & $\begin{array}{l}11 \text { October } \\
1842\end{array}$ & 546 & 7 Stat. 596 & $\begin{array}{l}\text { Metlakatla Indian } \\
\text { Community v. Egan } \\
\text { (1962) }\end{array}$ & $\begin{array}{l}369 \text { U.S. } \\
45,52\end{array}$ \\
\hline 243 & & $\begin{array}{l}11 \text { October } \\
1842\end{array}$ & 546 & 7 Stat. 596 & $\begin{array}{l}\text { Pennock v. } \\
\text { Commissioners } \\
(1881)\end{array}$ & $\begin{array}{l}103 \text { U.S. } \\
44,45(2)+\end{array}$ \\
\hline 243 & & $\begin{array}{l}11 \text { October } \\
1842\end{array}$ & 546 & 7 Stat. 596 & $\begin{array}{l}\text { Sac and Fox Indians } \\
\text { of the Mississippi in } \\
\text { Iowa v. Sac and Fox } \\
\text { Indians of the } \\
\text { Mississippi in } \\
\text { Oklahoma (1911) }\end{array}$ & $\begin{array}{l}220 \text { U.S. } \\
481,487(4)\end{array}$ \\
\hline 244 & $\begin{array}{l}\text { Creek; } \\
\text { Seminole }\end{array}$ & $\begin{array}{l}\text { 4 January } \\
1845\end{array}$ & 550 & 9 Stat. 821 & $\begin{array}{l}\text { Goat v. United States } \\
\text { (1912) }\end{array}$ & $\begin{array}{l}224 \text { U.S. } \\
458,461\end{array}$ \\
\hline 247 & $\begin{array}{l}\text { Potawatomi; } \\
\text { Chippewa; } \\
\text { Ottawa }\end{array}$ & 5 June 1846 & 557 & 9 Stat. 853 & $\begin{array}{l}\text { Pam-To-Pee v. United } \\
\text { States (1893) }\end{array}$ & $\begin{array}{l}148 \text { U.S. } \\
691,698\end{array}$ \\
\hline 247 & & 5 June 1846 & 557 & 9 Stat. 853 & $\begin{array}{l}\text { Pam-To-Pee v. United } \\
\text { States (1902) }\end{array}$ & $\begin{array}{l}187 \text { U.S. } \\
371,386\end{array}$ \\
\hline 247 & & 5 June 1846 & 557 & 9 Stat. 853 & $\begin{array}{l}\text { Nadeau v. Union } \\
\text { Pacific Railroad Co. } \\
(1920)\end{array}$ & $\begin{array}{l}253 \text { U.S. } \\
442,442\end{array}$ \\
\hline 247 & & 5 June 1846 & 557 & 9 Stat. 853 & $\begin{array}{l}\text { Nadeau v. Union } \\
\text { Pacific Railroad Co. } \\
\text { (1920) }\end{array}$ & $\begin{array}{l}253 \text { U.S. } \\
442,444(4)\end{array}$ \\
\hline 248 & $\begin{array}{l}\text { Cherokee: } \\
\text { Western }\end{array}$ & $\begin{array}{l}6 \text { August } \\
1846\end{array}$ & 561 & 9 Stat. 871 & $\begin{array}{l}\text { Cherokee Trust Funds } \\
\text { (1886) }\end{array}$ & $\begin{array}{l}117 \text { U.S. } \\
288,306\end{array}$ \\
\hline 248 & & $\begin{array}{l}6 \text { August } \\
1846\end{array}$ & 561 & 9 Stat. 871 & $\begin{array}{l}\text { Cherokee Nation v. } \\
\text { Southern Kansas } \\
\text { Railway Co. (1890) }\end{array}$ & $\begin{array}{l}135 \text { U.S. } \\
641,654\end{array}$ \\
\hline 248 & & $\begin{array}{l}6 \text { August } \\
1846\end{array}$ & 561 & 9 Stat. 871 & $\begin{array}{l}\text { United States v. Old } \\
\text { Settlers }(1893)\end{array}$ & $\begin{array}{l}148 \text { U.S. } \\
427,445\end{array}$ \\
\hline 248 & & $\begin{array}{l}6 \text { August } \\
1846\end{array}$ & 561 & 9 Stat. 871 & $\begin{array}{l}\text { Stephens v. Cherokee } \\
\text { Nation (1899) }\end{array}$ & $\begin{array}{l}174 \text { U.S. } \\
445,450\end{array}$ \\
\hline 248 & & $\begin{array}{l}6 \text { August } \\
1846\end{array}$ & 561 & 9 Stat. 871 & $\begin{array}{l}\text { United States v. } \\
\text { Cherokee Nation } \\
\text { (1906) }\end{array}$ & $\begin{array}{l}202 \text { U.S. } \\
101,102\end{array}$ \\
\hline 248 & & $\begin{array}{l}6 \text { August } \\
1846\end{array}$ & 561 & 9 Stat. 871 & $\begin{array}{l}\text { In re Eastern } \\
\text { Cherokees (1911) }\end{array}$ & $\begin{array}{l}220 \text { U.S. } \\
83,85\end{array}$ \\
\hline 248 & & $\begin{array}{l}6 \text { August } \\
1846\end{array}$ & 561 & 9 Stat. 871 & $\begin{array}{l}\text { Heckman v. United } \\
\text { States (1912) }\end{array}$ & $\begin{array}{l}224 \text { U.S. } \\
413,431\end{array}$ \\
\hline 248 & & $\begin{array}{l}6 \text { August } \\
1846\end{array}$ & 561 & 9 Stat. 871 & $\begin{array}{l}\text { Cherokee Nation v. } \\
\text { United States (1926) }\end{array}$ & $\begin{array}{l}270 \text { U.S. } \\
476,479\end{array}$ \\
\hline 248 & & $\begin{array}{l}6 \text { August } \\
1846\end{array}$ & 561 & 9 Stat. 871 & $\begin{array}{l}\text { Cherokee Trust Funds } \\
(1886)\end{array}$ & $\begin{array}{l}117 \text { U.S. } \\
288,291(1)\end{array}$ \\
\hline
\end{tabular}


Table 1 (continued)

\begin{tabular}{|c|c|c|c|c|c|c|}
\hline $\begin{array}{l}\text { Ratified } \\
\text { treaty } \\
\text { number }\end{array}$ & $\begin{array}{l}\text { Signatory } \\
\text { tribe(s) }\end{array}$ & $\begin{array}{l}\text { Treaty } \\
\text { signing date }\end{array}$ & $\begin{array}{l}\text { Kappler } \\
\text { page } \\
\text { number }\end{array}$ & $\begin{array}{l}\text { Statutes at } \\
\text { Large or an } \\
\text { alternative } \\
\text { source }\end{array}$ & Case title & U.S. reports \\
\hline 248 & & $\begin{array}{l}6 \text { August } \\
1846\end{array}$ & 561 & 9 Stat. 871 & $\begin{array}{l}\text { Atlantic and Pacific } \\
\text { Railroad Co. v. } \\
\text { Mingus }(1897)\end{array}$ & $\begin{array}{l}165 \text { U.S. } \\
413,436(1)\end{array}$ \\
\hline 248 & & $\begin{array}{l}6 \text { August } \\
1846\end{array}$ & 561 & 9 Stat. 871 & $\begin{array}{l}\text { Stephens v. Cherokee } \\
\text { Nation (1899) }\end{array}$ & $\begin{array}{l}174 \text { U.S. } \\
445,485(1)\end{array}$ \\
\hline 248 & & $\begin{array}{l}6 \text { August } \\
1846\end{array}$ & 561 & 9 Stat. 871 & $\begin{array}{l}\text { Cherokee Nation v. } \\
\text { Hitchcock (1902) }\end{array}$ & $\begin{array}{l}187 \text { U.S. } \\
294,297(1)\end{array}$ \\
\hline 248 & & $\begin{array}{l}6 \text { August } \\
1846\end{array}$ & 561 & 9 Stat. 871 & $\begin{array}{l}\text { Cherokee } \\
\text { Intermarriage Cases } \\
(1906)\end{array}$ & $\begin{array}{l}203 \text { U.S. } \\
76,80(1)\end{array}$ \\
\hline 248 & & $\begin{array}{l}6 \text { August } \\
1846\end{array}$ & 561 & 9 Stat. 871 & $\begin{array}{l}\text { United States v. Old } \\
\text { Settlers (1893) }\end{array}$ & $\begin{array}{l}148 \text { U.S. } \\
427,445(3)\end{array}$ \\
\hline 248 & & $\begin{array}{l}6 \text { August } \\
1846\end{array}$ & 561 & 9 Stat. 871 & $\begin{array}{l}\text { Cherokee Trust Funds } \\
\text { (1886) }\end{array}$ & $\begin{array}{l}117 \text { U.S. } \\
288,291(4)\end{array}$ \\
\hline 248 & & $\begin{array}{l}6 \text { August } \\
1846\end{array}$ & 561 & 9 Stat. 871 & $\begin{array}{l}\text { United States v. Old } \\
\text { Settlers (1893) }\end{array}$ & $\begin{array}{l}148 \text { U.S. } \\
427,465(4)\end{array}$ \\
\hline 248 & & $\begin{array}{l}6 \text { August } \\
1846\end{array}$ & 561 & 9 Stat. 871 & $\begin{array}{l}\text { United States v. } \\
\text { Cherokee Nation } \\
\text { (1906) }\end{array}$ & $\begin{array}{l}202 \text { U.S. } \\
101,130(4)\end{array}$ \\
\hline 248 & & $\begin{array}{l}6 \text { August } \\
1846\end{array}$ & 561 & 9 Stat. 871 & $\begin{array}{l}\text { Cherokee } \\
\text { Intermarriage Cases } \\
\text { (1906) }\end{array}$ & $\begin{array}{l}203 \text { U.S. } \\
76,81(4)\end{array}$ \\
\hline 248 & & $\begin{array}{l}6 \text { August } \\
1846\end{array}$ & 561 & 9 Stat. 871 & $\begin{array}{l}\text { Kendall v. United } \\
\text { States }(1869)\end{array}$ & $\begin{array}{l}74 \text { U.S. } \\
113,114(5)\end{array}$ \\
\hline 248 & & $\begin{array}{l}6 \text { August } \\
1846\end{array}$ & 561 & 9 Stat. 871 & $\begin{array}{l}\text { United States v. Old } \\
\text { Settlers (1893) }\end{array}$ & $\begin{array}{l}148 \text { U.S. } \\
427,480(5)\end{array}$ \\
\hline 248 & & $\begin{array}{l}6 \text { August } \\
1846\end{array}$ & 561 & 9 Stat. 871 & Ball v. Halsell (1896) & $\begin{array}{l}161 \text { U.S. } \\
72,77(5)\end{array}$ \\
\hline 248 & & $\begin{array}{l}6 \text { August } \\
1846\end{array}$ & 561 & 9 Stat. 871 & $\begin{array}{l}\text { Cherokee Trust Funds } \\
\text { (1886) }\end{array}$ & $\begin{array}{l}117 \text { U.S. } \\
288,291(9)\end{array}$ \\
\hline 248 & & $\begin{array}{l}6 \text { August } \\
1846\end{array}$ & 561 & 9 Stat. 871 & $\begin{array}{l}\text { In re Eastern } \\
\text { Cherokees (1911) }\end{array}$ & $\begin{array}{l}220 \text { U.S. } \\
83,85(9)\end{array}$ \\
\hline 248 & & $\begin{array}{l}6 \text { August } \\
1846\end{array}$ & 561 & 9 Stat. 871 & $\begin{array}{l}\text { Cherokee Trust Funds } \\
\text { (1886) }\end{array}$ & $\begin{array}{l}117 \text { U.S. } \\
288,291(10)\end{array}$ \\
\hline 248 & & $\begin{array}{l}6 \text { August } \\
1846\end{array}$ & 561 & 9 Stat. 871 & $\begin{array}{l}\text { United States v. Old } \\
\text { Settlers (1893) }\end{array}$ & $\begin{array}{l}148 \text { U.S. } \\
427,451(11)\end{array}$ \\
\hline 248 & & $\begin{array}{l}6 \text { August } \\
1846\end{array}$ & 561 & 9 Stat. 871 & $\begin{array}{l}\text { United States v. } \\
\text { Cherokee Nation } \\
\text { (1906) }\end{array}$ & $\begin{array}{l}202 \text { U.S. } \\
101,101(11)\end{array}$ \\
\hline 249 & Winnebago & $\begin{array}{l}13 \text { October } \\
1846\end{array}$ & 565 & 9 Stat. 878 & $\begin{array}{l}\text { Minnesota v. Mille } \\
\text { Lacs Band of } \\
\text { Chippewa Indians } \\
\text { (1999) }\end{array}$ & $\begin{array}{l}526 \text { U.S. } \\
172,172\end{array}$ \\
\hline
\end{tabular}


Table 1 (continued)

\begin{tabular}{|c|c|c|c|c|c|c|}
\hline $\begin{array}{l}\text { Ratified } \\
\text { treaty } \\
\text { number }\end{array}$ & $\begin{array}{l}\text { Signatory } \\
\text { tribe(s) }\end{array}$ & $\begin{array}{l}\text { Treaty } \\
\text { signing date }\end{array}$ & $\begin{array}{l}\text { Kappler } \\
\text { page } \\
\text { number }\end{array}$ & $\begin{array}{l}\text { Statutes at } \\
\text { Large or an } \\
\text { alternative } \\
\text { source }\end{array}$ & Case title & U.S. reports \\
\hline 249 & & $\begin{array}{l}13 \text { October } \\
1846\end{array}$ & 565 & 9 Stat. 878 & $\begin{array}{l}\text { Minnesota v. Mille } \\
\text { Lacs Band of } \\
\text { Chippewa Indians } \\
\text { (1999) }\end{array}$ & $\begin{array}{l}526 \text { U.S. } \\
172,196\end{array}$ \\
\hline 249 & & $\begin{array}{l}13 \text { October } \\
1846\end{array}$ & 565 & 9 Stat. 878 & $\begin{array}{l}\text { Minnesota v. Mille } \\
\text { Lacs Band of } \\
\text { Chippewa Indians } \\
\text { (1999) }\end{array}$ & $\begin{array}{l}526 \text { U.S. } \\
172,196(4)+\end{array}$ \\
\hline 250 & $\begin{array}{l}\text { Chippewa: } \\
\text { Mississippi } \\
\text { Chippewa: } \\
\text { Lake } \\
\text { Superior }\end{array}$ & $\begin{array}{l}2 \text { August } \\
1847\end{array}$ & 567 & 9 Stat. 904 & $\begin{array}{l}\text { United States v. } \\
\text { Waller (1917) }\end{array}$ & $\begin{array}{l}243 \text { U.S. } \\
452,452+\end{array}$ \\
\hline 250 & & $\begin{array}{l}2 \text { August } \\
1847\end{array}$ & 567 & 9 Stat. 904 & $\begin{array}{l}\text { Chippewa Indians of } \\
\text { Minnesota v. United } \\
\text { States (1937) }\end{array}$ & $\begin{array}{l}301 \text { U.S. } \\
358,361\end{array}$ \\
\hline 250 & & $\begin{array}{l}2 \text { August } \\
1847\end{array}$ & 567 & 9 Stat. 904 & $\begin{array}{l}\text { United States v. First } \\
\text { National Bank (1914) }\end{array}$ & $\begin{array}{l}234 \text { U.S. } \\
245,250(4)\end{array}$ \\
\hline 251 & $\begin{array}{l}\text { Chippewa: } \\
\text { Pillager }\end{array}$ & $\begin{array}{l}21 \text { August } \\
1847\end{array}$ & 569 & 9 Stat. 908 & $\begin{array}{l}\text { Chippewa Indians of } \\
\text { Minnesota v. United } \\
\text { States (1937) }\end{array}$ & $\begin{array}{l}301 \text { U.S. } \\
358,361\end{array}$ \\
\hline 253 & Menominee & $\begin{array}{l}18 \text { October } \\
1848\end{array}$ & 572 & 9 Stat. 952 & $\begin{array}{l}\text { Beecher v. Wetherby } \\
\text { (1877) }\end{array}$ & $\begin{array}{l}95 \text { U.S. } \\
517,518\end{array}$ \\
\hline 253 & & $\begin{array}{l}18 \text { October } \\
1848\end{array}$ & 572 & 9 Stat. 952 & $\begin{array}{l}\text { Budzisz v. Illinois } \\
\text { Steel Co. (1898) }\end{array}$ & $\begin{array}{l}170 \text { U.S. } \\
41,42\end{array}$ \\
\hline 253 & & $\begin{array}{l}18 \text { October } \\
1848\end{array}$ & 572 & 9 Stat. 952 & $\begin{array}{l}\text { United States v. } \\
\text { Morrison (1916) }\end{array}$ & $\begin{array}{l}240 \text { U.S. } \\
192,206\end{array}$ \\
\hline 253 & & $\begin{array}{l}18 \text { October } \\
1848\end{array}$ & 572 & 9 Stat. 952 & $\begin{array}{l}\text { Wisconsin v. Lane } \\
\text { (1918) }\end{array}$ & $\begin{array}{l}245 \text { U.S. } \\
427,427\end{array}$ \\
\hline 253 & & $\begin{array}{l}18 \text { October } \\
1848\end{array}$ & 572 & 9 Stat. 952 & $\begin{array}{l}\text { Menominee Tribe of } \\
\text { Indians v. United } \\
\text { States }(1968)\end{array}$ & $\begin{array}{l}391 \text { U.S. } \\
404,411\end{array}$ \\
\hline 253 & & $\begin{array}{l}18 \text { October } \\
1848\end{array}$ & 572 & 9 Stat. 952 & $\begin{array}{l}\text { Minnesota v. } \\
\text { Hitchcock (1902) }\end{array}$ & $\begin{array}{l}185 \text { U.S. } \\
373,397(2)\end{array}$ \\
\hline 253 & & $\begin{array}{l}18 \text { October } \\
1848\end{array}$ & 572 & 9 Stat. 952 & $\begin{array}{l}\text { Quick Bear v. Leupp } \\
\text { (1908) }\end{array}$ & $\begin{array}{l}210 \text { U.S. } \\
50,62(5)\end{array}$ \\
\hline 253 & & $\begin{array}{l}18 \text { October } \\
1848\end{array}$ & 572 & 9 Stat. 952 & $\begin{array}{l}\text { Beecher v. Wetherby } \\
\text { (1877) }\end{array}$ & $\begin{array}{l}95 \text { U.S. } \\
517,518(8)\end{array}$ \\
\hline 254 & Stockbridge & $\begin{array}{l}24 \text { November } \\
1848\end{array}$ & 574 & 9 Stat. 955 & Elkv. Wilkins (1884) & $\begin{array}{l}112 \text { U.S. } \\
94,100\end{array}$ \\
\hline 254 & & $\begin{array}{l}24 \text { November } \\
1848\end{array}$ & 574 & 9 Stat. 955 & $\begin{array}{l}\text { New York Indians } v . \\
\text { United States }(1898)\end{array}$ & $\begin{array}{l}170 \text { U.S. } \\
1,12\end{array}$ \\
\hline 255 & Navajo & $\begin{array}{l}9 \text { September } \\
1849\end{array}$ & 583 & 9 Stat. 974 & $\begin{array}{l}\text { United States v. } \\
\text { Wheeler (1978) }\end{array}$ & $\begin{array}{l}435 \text { U.S. } \\
313,324\end{array}$ \\
\hline
\end{tabular}


Table 1 (continued)

\begin{tabular}{|c|c|c|c|c|c|c|}
\hline $\begin{array}{l}\text { Ratified } \\
\text { treaty } \\
\text { number }\end{array}$ & $\begin{array}{l}\text { Signatory } \\
\text { tribe(s) }\end{array}$ & $\begin{array}{l}\text { Treaty } \\
\text { signing date }\end{array}$ & $\begin{array}{l}\text { Kappler } \\
\text { page } \\
\text { number }\end{array}$ & $\begin{array}{l}\text { Statutes at } \\
\text { Large or an } \\
\text { alternative } \\
\text { source }\end{array}$ & Case title & U.S. reports \\
\hline 257 & Wyandot & 1 April 1850 & 587 & 9 Stat. 987 & $\begin{array}{l}\text { County of Yakima } v . \\
\text { Confederated Tribes } \\
\text { and Bands of the } \\
\text { Yakima Indian Nation } \\
\text { (1992) }\end{array}$ & $\begin{array}{l}502 \text { U.S. } \\
251,254(9)+\end{array}$ \\
\hline 258 & $\begin{array}{l}\text { Sioux: } \\
\text { Sisseton } \\
\text { and } \\
\text { Wahpeton }\end{array}$ & 23 July 1851 & 588 & $\begin{array}{l}10 \text { Stat. } \\
949\end{array}$ & $\begin{array}{l}\text { United States } v . \\
\text { Sisseton and } \\
\text { Wahpeton Bands of } \\
\text { Sioux Indians (1908) }\end{array}$ & $\begin{array}{l}208 \text { U.S. } \\
561,561\end{array}$ \\
\hline 258 & & 23 July 1851 & 588 & $\begin{array}{l}10 \text { Stat. } \\
949\end{array}$ & $\begin{array}{l}\text { Sisseton and } \\
\text { Wahpeton Bands of } \\
\text { Sioux Indians v. } \\
\text { United States (1928) }\end{array}$ & $\begin{array}{l}277 \text { U.S. } \\
424,428(3)\end{array}$ \\
\hline 259 & $\begin{array}{l}\text { Sioux: } \\
\text { Mdewakanton } \\
\text { and } \\
\text { Wahpekute }\end{array}$ & $\begin{array}{l}5 \text { August } \\
1851\end{array}$ & 591 & $\begin{array}{l}10 \text { Stat. } \\
954\end{array}$ & $\begin{array}{l}\text { Sisseton and } \\
\text { Wahpeton Bands of } \\
\text { Sioux Indians v. } \\
\text { United States (1928) }\end{array}$ & $\begin{array}{l}277 \text { U.S. } \\
424,428\end{array}$ \\
\hline 260 & Chickasaw & 22 June 1852 & 596 & $\begin{array}{l}10 \text { Stat. } \\
974\end{array}$ & $\begin{array}{l}\text { United States v. } \\
\text { Nashville, } \\
\text { Chattanooga and St. } \\
\text { Louis Railway Co. } \\
(1886)\end{array}$ & $\begin{array}{l}118 \text { U.S. } \\
120,122(2)\end{array}$ \\
\hline 260 & & 22 June 1852 & 596 & $\begin{array}{l}10 \text { Stat. } \\
974\end{array}$ & $\begin{array}{l}\text { United States v. } \\
\text { Nashville, } \\
\text { Chattanooga and St. } \\
\text { Louis Railway Co. } \\
\text { (1886) }\end{array}$ & $\begin{array}{l}118 \text { U.S. } \\
120,122(5)\end{array}$ \\
\hline 261 & $\begin{array}{l}\text { Apache: } \\
\text { Plains }\end{array}$ & 1 July 1852 & 598 & $\begin{array}{l}10 \text { Stat. } \\
979\end{array}$ & $\begin{array}{l}\text { United States v. Santa } \\
\text { Fe Pacific Railroad } \\
\text { Co. (1941) }\end{array}$ & $\begin{array}{l}314 \text { U.S. } \\
339,346\end{array}$ \\
\hline 261 & & 1 July 1852 & 598 & $\begin{array}{l}10 \text { Stat. } \\
979\end{array}$ & $\begin{array}{l}\text { Merrion v. Jicarilla } \\
\text { Apache Tribe (1982) }\end{array}$ & $\begin{array}{l}411 \text { U.S. } \\
145,150\end{array}$ \\
\hline 261 & & 1 July 1852 & 598 & $\begin{array}{l}10 \text { Stat. } \\
979\end{array}$ & $\begin{array}{l}\text { New Mexico v. } \\
\text { Mescalero Apache } \\
\text { Tribe (1983) }\end{array}$ & $\begin{array}{l}462 \text { U.S. } \\
324,337\end{array}$ \\
\hline 261 & & 1 July 1852 & 598 & $\begin{array}{l}10 \text { Stat. } \\
979\end{array}$ & $\begin{array}{l}\text { Merrion v. Jicarilla } \\
\text { Apache Tribe (1982) }\end{array}$ & $\begin{array}{l}411 \text { U.S. } \\
145,160(10)\end{array}$ \\
\hline 262 & $\begin{array}{l}\text { Comanche; } \\
\text { Kiowa; } \\
\text { Apache: } \\
\text { Plains }\end{array}$ & 27 July 1853 & 600 & $\begin{array}{l}10 \text { Stat. } \\
1013\end{array}$ & $\begin{array}{l}\text { Cook v. United States } \\
\text { (1891) }\end{array}$ & $\begin{array}{l}138 \text { U.S. } \\
157,175\end{array}$ \\
\hline 265 & $\begin{array}{l}\text { Oto and } \\
\text { Missouri }\end{array}$ & $\begin{array}{l}15 \text { March } \\
1854\end{array}$ & 608 & $\begin{array}{l}10 \text { Stat. } \\
1038\end{array}$ & $\begin{array}{l}\text { Oliphant } v . \\
\text { Suquamish Indian } \\
\text { Tribe (1978) }\end{array}$ & $\begin{array}{l}435 \text { U.S. } \\
191,207\end{array}$ \\
\hline
\end{tabular}


Table 1 (continued)

\begin{tabular}{|c|c|c|c|c|c|c|}
\hline $\begin{array}{l}\text { Ratified } \\
\text { treaty } \\
\text { number }\end{array}$ & $\begin{array}{l}\text { Signatory } \\
\text { tribe(s) }\end{array}$ & $\begin{array}{l}\text { Treaty } \\
\text { signing date }\end{array}$ & $\begin{array}{l}\text { Kappler } \\
\text { page } \\
\text { number }\end{array}$ & $\begin{array}{l}\text { Statutes at } \\
\text { Large or an } \\
\text { alternative } \\
\text { source }\end{array}$ & Case title & U.S. reports \\
\hline 266 & Omaha & $\begin{array}{l}16 \text { March } \\
1854\end{array}$ & 611 & $\begin{array}{l}10 \text { Stat. } \\
1043\end{array}$ & $\begin{array}{l}\text { United States } v . \\
\text { Omaha Tribe of } \\
\text { Indians }(1920)\end{array}$ & $\begin{array}{l}253 \text { U.S. } \\
275,276\end{array}$ \\
\hline 266 & & $\begin{array}{l}16 \text { March } \\
1854\end{array}$ & 611 & $\begin{array}{l}10 \text { Stat. } \\
1043\end{array}$ & $\begin{array}{l}\text { Chase v. United States } \\
\text { (1921) }\end{array}$ & $\begin{array}{l}256 \text { U.S. } \\
1,1\end{array}$ \\
\hline 266 & & $\begin{array}{l}\text { 16 March } \\
1854\end{array}$ & 611 & $\begin{array}{l}10 \text { Stat. } \\
1043\end{array}$ & $\begin{array}{l}\text { Gilpin v. United } \\
\text { States }(1921)\end{array}$ & $\begin{array}{l}256 \text { U.S. } \\
10,11\end{array}$ \\
\hline 266 & & $\begin{array}{l}16 \text { March } \\
1854\end{array}$ & 611 & $\begin{array}{l}10 \text { Stat. } \\
1043\end{array}$ & $\begin{array}{l}\text { Oliphant } v . \\
\text { Suquamish Indian } \\
\text { Tribe (1978) }\end{array}$ & $\begin{array}{l}435 \text { U.S. } \\
191,207\end{array}$ \\
\hline 266 & & $\begin{array}{l}16 \text { March } \\
1854\end{array}$ & 611 & $\begin{array}{l}10 \text { Stat. } \\
1043\end{array}$ & $\begin{array}{l}\text { Wilson v. Omaha } \\
\text { Indian Tribe (1979) }\end{array}$ & $\begin{array}{l}442 \text { U.S. } \\
653,658\end{array}$ \\
\hline 266 & & $\begin{array}{l}16 \text { March } \\
1854\end{array}$ & 611 & $\begin{array}{l}10 \text { Stat. } \\
1043\end{array}$ & $\begin{array}{l}\text { United States v. } \\
\text { Omaha Tribe of } \\
\text { Indians (1920) }\end{array}$ & $\begin{array}{l}253 \text { U.S. } \\
275,277(1)\end{array}$ \\
\hline 266 & & $\begin{array}{l}\text { 16 March } \\
1854\end{array}$ & 611 & $\begin{array}{l}10 \text { Stat. } \\
1043\end{array}$ & $\begin{array}{l}\text { Gilpin v. United } \\
\text { States }(1921)\end{array}$ & $\begin{array}{l}256 \text { U.S. } \\
1,6(1)\end{array}$ \\
\hline 266 & & $\begin{array}{l}16 \text { March } \\
1854\end{array}$ & 611 & $\begin{array}{l}10 \text { Stat. } \\
1043\end{array}$ & $\begin{array}{l}\text { United States v. } \\
\text { Omaha Tribe of } \\
\text { Indians }(1920)\end{array}$ & $\begin{array}{l}253 \text { U.S. } \\
275,277(4)\end{array}$ \\
\hline 266 & & $\begin{array}{l}16 \text { March } \\
1854\end{array}$ & 611 & $\begin{array}{l}10 \text { Stat. } \\
1043\end{array}$ & $\begin{array}{l}\text { United States v. } \\
\text { Omaha Tribe of } \\
\text { Indians }(1920)\end{array}$ & $\begin{array}{l}253 \text { U.S. } \\
275,278(5)\end{array}$ \\
\hline 266 & & $\begin{array}{l}16 \text { March } \\
1854\end{array}$ & 611 & $\begin{array}{l}10 \text { Stat. } \\
1043\end{array}$ & $\begin{array}{l}\text { Sloan v. United States } \\
\text { (1904) }\end{array}$ & $\begin{array}{l}193 \text { U.S. } \\
614,618(6)\end{array}$ \\
\hline 266 & & $\begin{array}{l}16 \text { March } \\
1854\end{array}$ & 611 & $\begin{array}{l}10 \text { Stat. } \\
1043\end{array}$ & $\begin{array}{l}\text { Goudy v. Meath } \\
\text { (1906) }\end{array}$ & $\begin{array}{l}203 \text { U.S. } \\
146,147(6)\end{array}$ \\
\hline 266 & & $\begin{array}{l}16 \text { March } \\
1854\end{array}$ & 611 & $\begin{array}{l}10 \text { Stat. } \\
1043\end{array}$ & $\begin{array}{l}\text { United States v. } \\
\text { Celestine (1909) }\end{array}$ & $\begin{array}{l}215 \text { U.S. } \\
278,278(6)\end{array}$ \\
\hline 266 & & $\begin{array}{l}16 \text { March } \\
1854\end{array}$ & 611 & $\begin{array}{l}10 \text { Stat. } \\
1043\end{array}$ & $\begin{array}{l}\text { United States v. } \\
\text { Sutton (1909) }\end{array}$ & $\begin{array}{l}215 \text { U.S. } \\
291,294(6)\end{array}$ \\
\hline 266 & & $\begin{array}{l}16 \text { March } \\
1854\end{array}$ & 611 & $\begin{array}{l}10 \text { Stat. } \\
1043\end{array}$ & $\begin{array}{l}\text { Jacobs v. Prichard } \\
\text { (1912) }\end{array}$ & $\begin{array}{l}223 \text { U.S. } \\
200,207(6)\end{array}$ \\
\hline 266 & & $\begin{array}{l}16 \text { March } \\
1854\end{array}$ & 611 & $\begin{array}{l}10 \text { Stat. } \\
1043\end{array}$ & $\begin{array}{l}\text { Gilpin v. United } \\
\text { States }(1921)\end{array}$ & $\begin{array}{l}256 \text { U.S. } \\
1,6(6)\end{array}$ \\
\hline 266 & & $\begin{array}{l}16 \text { March } \\
1854\end{array}$ & 611 & $\begin{array}{l}10 \text { Stat. } \\
1043\end{array}$ & $\begin{array}{l}\text { United States v. Payne } \\
\text { (1924) }\end{array}$ & $\begin{array}{l}264 \text { U.S. } \\
446,447(6)\end{array}$ \\
\hline 266 & & $\begin{array}{l}16 \text { March } \\
1854\end{array}$ & 611 & $\begin{array}{l}10 \text { Stat. } \\
1043\end{array}$ & $\begin{array}{l}\text { United States v. } \\
\text { Omaha Tribe of } \\
\text { Indians }(1920)\end{array}$ & $\begin{array}{l}253 \text { U.S. } \\
275,279(7)\end{array}$ \\
\hline 267 & Delaware & 6 May 1854 & 614 & $\begin{array}{l}10 \text { Stat. } \\
1048\end{array}$ & $\begin{array}{l}\text { United States v. Stone } \\
(1865)\end{array}$ & $\begin{array}{l}69 \text { U.S. } \\
525,525\end{array}$ \\
\hline 267 & & 6 May 1854 & 614 & $\begin{array}{l}10 \text { Stat. } \\
1048\end{array}$ & $\begin{array}{l}\text { United States v. } \\
\text { Brindle }(1884)\end{array}$ & $\begin{array}{l}110 \text { U.S. } \\
688,688\end{array}$ \\
\hline
\end{tabular}


Table 1 (continued)

\begin{tabular}{|c|c|c|c|c|c|c|}
\hline $\begin{array}{l}\text { Ratified } \\
\text { treaty } \\
\text { number }\end{array}$ & $\begin{array}{l}\text { Signatory } \\
\text { tribe(s) }\end{array}$ & $\begin{array}{l}\text { Treaty } \\
\text { signing date }\end{array}$ & $\begin{array}{l}\text { Kappler } \\
\text { page } \\
\text { number }\end{array}$ & $\begin{array}{l}\text { Statutes at } \\
\text { Large or an } \\
\text { alternative } \\
\text { source }\end{array}$ & Case title & U.S. reports \\
\hline 267 & & 6 May 1854 & 614 & $\begin{array}{l}10 \text { Stat. } \\
1048\end{array}$ & $\begin{array}{l}\text { United States v. Union } \\
\text { Pacific Railway Co. } \\
\text { (1897) }\end{array}$ & $\begin{array}{l}168 \text { U.S. } \\
505,512\end{array}$ \\
\hline 267 & & 6 May 1854 & 614 & $\begin{array}{l}10 \text { Stat. } \\
1048\end{array}$ & $\begin{array}{l}\text { Delaware Tribal } \\
\text { Business Committee v. } \\
\text { Weeks (1977) }\end{array}$ & $\begin{array}{l}430 \text { U.S. } \\
73,75\end{array}$ \\
\hline 267 & & 6 May 1854 & 614 & $\begin{array}{l}10 \text { Stat. } \\
1048\end{array}$ & $\begin{array}{l}\text { United States v. } \\
\text { Brindle (1884) }\end{array}$ & $\begin{array}{l}110 \text { U.S. } \\
688,690(1)\end{array}$ \\
\hline 267 & & 6 May 1854 & 614 & $\begin{array}{l}10 \text { Stat. } \\
1048\end{array}$ & $\begin{array}{l}\text { United States } v \text {. } \\
\text { Brindle (1884) }\end{array}$ & $\begin{array}{l}110 \text { U.S. } \\
688,690(2)\end{array}$ \\
\hline 267 & & 6 May 1854 & 614 & $\begin{array}{l}10 \text { Stat. } \\
1048\end{array}$ & $\begin{array}{l}\text { United States } v . \\
\text { Brindle }(1884)\end{array}$ & $\begin{array}{l}110 \text { U.S. } \\
688,690(3)\end{array}$ \\
\hline 267 & & 6 May 1854 & 614 & $\begin{array}{l}10 \text { Stat. } \\
1048\end{array}$ & $\begin{array}{l}\text { United States v. Union } \\
\text { Pacific Railway Co. } \\
\text { (1897) }\end{array}$ & $\begin{array}{l}168 \text { U.S. } \\
505,507(11)\end{array}$ \\
\hline 267 & & 6 May 1854 & 614 & $\begin{array}{l}10 \text { Stat. } \\
1048\end{array}$ & $\begin{array}{l}\text { Kindred v. Union } \\
\text { Pacific Railroad Co. } \\
\text { (1912) }\end{array}$ & $\begin{array}{l}225 \text { U.S. } \\
582,591(11)\end{array}$ \\
\hline 267 & & 6 May 1854 & 614 & $\begin{array}{l}10 \text { Stat. } \\
1048\end{array}$ & $\begin{array}{l}\text { United States v. Union } \\
\text { Pacific Railway Co. } \\
\text { (1897) }\end{array}$ & $\begin{array}{l}168 \text { U.S. } \\
505,507(12)\end{array}$ \\
\hline 267 & & 6 May 1854 & 614 & $\begin{array}{l}10 \text { Stat. } \\
1048\end{array}$ & $\begin{array}{l}\text { Kindred v. Union } \\
\text { Pacific Railroad Co. } \\
\text { (1912) }\end{array}$ & $\begin{array}{l}225 \text { U.S. } \\
582,591(12)\end{array}$ \\
\hline 268 & Shawnee & 10 May 1854 & 618 & $\begin{array}{l}10 \text { Stat. } \\
1053\end{array}$ & $\begin{array}{l}\text { Kansas Indians } \\
\text { (1867) }\end{array}$ & $\begin{array}{l}72 \text { U.S. } \\
737,753\end{array}$ \\
\hline 268 & & 10 May 1854 & 618 & $\begin{array}{l}10 \text { Stat. } \\
1053\end{array}$ & $\begin{array}{l}\text { Walker v. Henshaw } \\
\text { (1873) }\end{array}$ & $\begin{array}{l}83 \text { U.S. } \\
436,436\end{array}$ \\
\hline 268 & & 10 May 1854 & 618 & $\begin{array}{l}10 \text { Stat. } \\
1053\end{array}$ & $\begin{array}{l}\text { Cherokee Nation v. } \\
\text { Blackfeather (1894) }\end{array}$ & $\begin{array}{l}155 \text { U.S. } \\
218,220\end{array}$ \\
\hline 268 & & 10 May 1854 & 618 & $\begin{array}{l}10 \text { Stat. } \\
1053\end{array}$ & $\begin{array}{l}\text { Jones v. Meehan } \\
\text { (1899) }\end{array}$ & $\begin{array}{l}175 \text { U.S. } \\
1,30\end{array}$ \\
\hline 268 & & 10 May 1854 & 618 & $\begin{array}{l}10 \text { Stat. } \\
1053\end{array}$ & $\begin{array}{l}\text { Stearns v. Minnesota } \\
(1900)\end{array}$ & $\begin{array}{l}179 \text { U.S. } \\
223,249\end{array}$ \\
\hline 268 & & 10 May 1854 & 618 & $\begin{array}{l}10 \text { Stat. } \\
1053\end{array}$ & $\begin{array}{l}\text { Dunbar v. Green } \\
\text { (1905) }\end{array}$ & $\begin{array}{l}198 \text { U.S. } \\
166,166\end{array}$ \\
\hline 268 & & 10 May 1854 & 618 & $\begin{array}{l}10 \text { Stat. } \\
1053\end{array}$ & $\begin{array}{l}\text { Cherokee Nation v. } \\
\text { Blackfeather (1894) }\end{array}$ & $\begin{array}{l}155 \text { U.S. } \\
218,219(3)\end{array}$ \\
\hline 268 & & 10 May 1854 & 618 & $\begin{array}{l}10 \text { Stat. } \\
1053\end{array}$ & $\begin{array}{l}\text { Walker v. Henshaw } \\
\text { (1873) }\end{array}$ & $\begin{array}{l}83 \text { U.S. } \\
436,438(5)\end{array}$ \\
\hline 268 & & 10 May 1854 & 618 & $\begin{array}{l}10 \text { Stat. } \\
1053\end{array}$ & $\begin{array}{l}\text { United States v. } \\
\text { Blackfeather (1894) }\end{array}$ & $\begin{array}{l}155 \text { U.S. } \\
180,185(8)\end{array}$ \\
\hline 268 & & 10 May 1854 & 618 & $\begin{array}{l}10 \text { Stat. } \\
1053\end{array}$ & $\begin{array}{l}\text { Kansas Indians } \\
(1867)\end{array}$ & $\begin{array}{l}72 \text { U.S. } \\
737,740(11)\end{array}$ \\
\hline
\end{tabular}


Table 1 (continued)

\begin{tabular}{|c|c|c|c|c|c|c|}
\hline $\begin{array}{l}\text { Ratified } \\
\text { treaty } \\
\text { number }\end{array}$ & $\begin{array}{l}\text { Signatory } \\
\text { tribe(s) }\end{array}$ & $\begin{array}{l}\text { Treaty } \\
\text { signing date }\end{array}$ & $\begin{array}{l}\text { Kappler } \\
\text { page } \\
\text { number }\end{array}$ & $\begin{array}{l}\text { Statutes at } \\
\text { Large or an } \\
\text { alternative } \\
\text { source }\end{array}$ & Case title & U.S. reports \\
\hline 268 & & 10 May 1854 & 618 & $\begin{array}{l}10 \text { Stat. } \\
1053\end{array}$ & $\begin{array}{l}\text { Blackfeather v. United } \\
\text { States (1903) }\end{array}$ & $\begin{array}{l}190 \text { U.S. } \\
368,371(11)\end{array}$ \\
\hline 268 & & 10 May 1854 & 618 & $\begin{array}{l}10 \text { Stat. } \\
1053\end{array}$ & $\begin{array}{l}\text { Blackfeather v. United } \\
\text { States (1903) }\end{array}$ & $\begin{array}{l}190 \text { U.S. } \\
368,371(14)\end{array}$ \\
\hline 269 & Menominee & 12 May 1854 & 626 & $\begin{array}{l}10 \text { Stat. } \\
1064\end{array}$ & $\begin{array}{l}\text { Beecher v. Wetherby } \\
(1877)\end{array}$ & $\begin{array}{l}95 \text { U.S. } \\
517,518\end{array}$ \\
\hline 269 & & 12 May 1854 & 626 & $\begin{array}{l}10 \text { Stat. } \\
1064\end{array}$ & $\begin{array}{l}\text { United States v. } \\
\text { Morrison (1916) }\end{array}$ & $\begin{array}{l}240 \text { U.S. } \\
192,206\end{array}$ \\
\hline 269 & & 12 May 1854 & 626 & $\begin{array}{l}10 \text { Stat. } \\
1064\end{array}$ & $\begin{array}{l}\text { Wisconsin v. Lane } \\
\text { (1918) }\end{array}$ & $\begin{array}{l}245 \text { U.S. } \\
427,427\end{array}$ \\
\hline 269 & & 12 May 1854 & 626 & $\begin{array}{l}10 \text { Stat. } \\
1064\end{array}$ & $\begin{array}{l}\text { Wisconsin v. Lane } \\
\text { (1918) }\end{array}$ & $\begin{array}{l}245 \text { U.S. } \\
427,431+\end{array}$ \\
\hline 269 & & 12 May 1854 & 626 & $\begin{array}{l}10 \text { Stat. } \\
1064\end{array}$ & $\begin{array}{l}\text { Wisconsin v. Lane } \\
\text { (1918) }\end{array}$ & $\begin{array}{l}245 \text { U.S. } \\
427,434+\end{array}$ \\
\hline 269 & & 12 May 1854 & 626 & $\begin{array}{l}10 \text { Stat. } \\
1064\end{array}$ & $\begin{array}{l}\text { Menominee Tribe of } \\
\text { Indians v. United } \\
\text { States (1968) }\end{array}$ & $\begin{array}{l}391 \text { U.S. } \\
404,405\end{array}$ \\
\hline 269 & & 12 May 1854 & 626 & $\begin{array}{l}10 \text { Stat. } \\
1064\end{array}$ & $\begin{array}{l}\text { Minnesota v. } \\
\text { Hitchcock (1902) }\end{array}$ & $\begin{array}{l}185 \text { U.S. } \\
373,397(1)\end{array}$ \\
\hline 269 & & 12 May 1854 & 626 & $\begin{array}{l}10 \text { Stat. } \\
1064\end{array}$ & $\begin{array}{l}\text { Beecher v. Wetherby } \\
\text { (1877) }\end{array}$ & $\begin{array}{l}95 \text { U.S. } \\
517,519(2)\end{array}$ \\
\hline 272 & Kickapoo & 18 May 1854 & 634 & $\begin{array}{l}10 \text { Stat. } \\
1078\end{array}$ & $\begin{array}{l}\text { United States v. Reily } \\
\text { (1933) }\end{array}$ & $\begin{array}{l}290 \text { U.S. } \\
33,35\end{array}$ \\
\hline 272 & & 18 May 1854 & 634 & $\begin{array}{l}10 \text { Stat. } \\
1078\end{array}$ & $\begin{array}{l}\text { United States v. } \\
\text { Oklahoma Gas and } \\
\text { Electric Co. (1943) }\end{array}$ & $\begin{array}{l}318 \text { U.S. } \\
206,215\end{array}$ \\
\hline 273 & $\begin{array}{l}\text { Kaskaskia; } \\
\text { Peoria; } \\
\text { Piankashaw; } \\
\text { Wea }\end{array}$ & 30 May 1854 & 636 & $\begin{array}{l}10 \text { Stat. } \\
1082\end{array}$ & $\begin{array}{l}\text { Kansas Indians } \\
(1867)\end{array}$ & $\begin{array}{l}72 \text { U.S. } \\
737,755\end{array}$ \\
\hline 273 & & 30 May 1854 & 636 & $\begin{array}{l}10 \text { Stat. } \\
1082\end{array}$ & $\begin{array}{l}\text { United States v. } \\
\text { Brindle (1884) }\end{array}$ & $\begin{array}{l}110 \text { U.S. } \\
688,691\end{array}$ \\
\hline 273 & & 30 May 1854 & 636 & $\begin{array}{l}10 \text { Stat. } \\
1082\end{array}$ & $\begin{array}{l}\text { Lykins v. McGrath } \\
\text { (1902) }\end{array}$ & $\begin{array}{l}184 \text { U.S. } \\
169,169\end{array}$ \\
\hline 273 & & 30 May 1854 & 636 & $\begin{array}{l}10 \text { Stat. } \\
1082\end{array}$ & $\begin{array}{l}\text { Bowling and Miami } \\
\text { Investment Co. v. } \\
\text { United States (1914) }\end{array}$ & $\begin{array}{l}233 \text { U.S. } \\
528,532\end{array}$ \\
\hline 273 & & 30 May 1854 & 636 & $\begin{array}{l}10 \text { Stat. } \\
1082\end{array}$ & $\begin{array}{l}\text { Peoria Tribe of } \\
\text { Indians } v \text {. United } \\
\text { States }(1968)\end{array}$ & $\begin{array}{l}390 \text { U.S. } \\
468,469\end{array}$ \\
\hline 273 & & 30 May 1854 & 636 & $\begin{array}{l}10 \text { Stat. } \\
1082\end{array}$ & $\begin{array}{l}\text { United States v. } \\
\text { Brindle (1884) }\end{array}$ & $\begin{array}{l}110 \text { U.S. } \\
688,691(2)\end{array}$ \\
\hline 273 & & 30 May 1854 & 636 & $\begin{array}{l}10 \text { Stat. } \\
1082\end{array}$ & $\begin{array}{l}\text { Peoria Tribe of } \\
\text { Indians v. United } \\
\text { States (1968) }\end{array}$ & $\begin{array}{l}390 \text { U.S. } \\
468,469(4)\end{array}$ \\
\hline
\end{tabular}


Table 1 (continued)

\begin{tabular}{|c|c|c|c|c|c|c|}
\hline $\begin{array}{l}\text { Ratified } \\
\text { treaty } \\
\text { number }\end{array}$ & $\begin{array}{l}\text { Signatory } \\
\text { tribe(s) }\end{array}$ & $\begin{array}{l}\text { Treaty } \\
\text { signing date }\end{array}$ & $\begin{array}{l}\text { Kappler } \\
\text { page } \\
\text { number }\end{array}$ & $\begin{array}{l}\text { Statutes at } \\
\text { Large or an } \\
\text { alternative } \\
\text { source }\end{array}$ & Case title & U.S. reports \\
\hline 273 & & 30 May 1854 & 636 & $\begin{array}{l}10 \text { Stat. } \\
1082\end{array}$ & $\begin{array}{l}\text { Peoria Tribe of } \\
\text { Indians v. United } \\
\text { States }(1968)\end{array}$ & $\begin{array}{l}390 \text { U.S. } \\
468,469(7)\end{array}$ \\
\hline 273 & & 30 May 1854 & 636 & $\begin{array}{l}10 \text { Stat. } \\
1082\end{array}$ & $\begin{array}{l}\text { Kansas Indians } \\
(1867)\end{array}$ & $\begin{array}{l}72 \text { U.S. } \\
737,759(10)\end{array}$ \\
\hline 273 & & 30 May 1854 & 636 & $\begin{array}{l}10 \text { Stat. } \\
1082\end{array}$ & $\begin{array}{l}\text { Kansas Indians } \\
(1867)\end{array}$ & $\begin{array}{l}72 \text { U.S. } \\
737,759(11)\end{array}$ \\
\hline 274 & Miami & 5 June 1854 & 641 & $\begin{array}{l}10 \text { Stat. } \\
1093\end{array}$ & $\begin{array}{l}\text { Kansas Indians } \\
(1867)\end{array}$ & $\begin{array}{l}72 \text { U.S. } \\
737,748\end{array}$ \\
\hline 274 & & 5 June 1854 & 641 & $\begin{array}{l}10 \text { Stat. } \\
1093\end{array}$ & $\begin{array}{l}\text { Bowling and Miami } \\
\text { Investment Co. v. } \\
\text { United States (1914) }\end{array}$ & $\begin{array}{l}233 \text { U.S. } \\
528,531+\end{array}$ \\
\hline 274 & & 5 June 1854 & 641 & $\begin{array}{l}10 \text { Stat. } \\
1093\end{array}$ & $\begin{array}{l}\text { Kansas Indians } \\
(1867)\end{array}$ & $\begin{array}{l}72 \text { U.S. } \\
737,760(2)\end{array}$ \\
\hline 274 & & 5 June 1854 & 641 & $\begin{array}{l}10 \text { Stat. } \\
1093\end{array}$ & $\begin{array}{l}\text { Kansas Indians } \\
(1867)\end{array}$ & $\begin{array}{l}72 \text { U.S. } \\
737,741(9)\end{array}$ \\
\hline 274 & & 5 June 1854 & 641 & $\begin{array}{l}10 \text { Stat. } \\
1093\end{array}$ & $\begin{array}{l}\text { Kansas Indians } \\
(1867)\end{array}$ & $\begin{array}{l}72 \text { U.S. } \\
737,760(11)\end{array}$ \\
\hline 275 & $\begin{array}{l}\text { Chippewa: } \\
\text { Mississippi } \\
\text { Chippewa: Lake } \\
\text { Superior }\end{array}$ & $\begin{array}{l}30 \text { September } \\
1854\end{array}$ & 648 & $\begin{array}{l}10 \text { Stat. } \\
1109\end{array}$ & $\begin{array}{l}\text { United States v. } \\
\text { Thomas (1894) }\end{array}$ & $\begin{array}{l}151 \text { U.S. } \\
577,578\end{array}$ \\
\hline 275 & & $\begin{array}{l}30 \text { September } \\
1854\end{array}$ & 648 & $\begin{array}{l}10 \text { Stat. } \\
1109\end{array}$ & Fee v. Brown (1896) & $\begin{array}{l}162 \text { U.S. } \\
602,603\end{array}$ \\
\hline 275 & & $\begin{array}{l}30 \text { September } \\
1854\end{array}$ & 648 & $\begin{array}{l}10 \text { Stat. } \\
1109\end{array}$ & $\begin{array}{l}\text { United States v. First } \\
\text { National Bank (1914) }\end{array}$ & $\begin{array}{l}234 \text { U.S. } \\
245,249\end{array}$ \\
\hline 275 & & $\begin{array}{l}30 \text { September } \\
1854\end{array}$ & 648 & $\begin{array}{l}10 \text { Stat. } \\
1109\end{array}$ & $\begin{array}{l}\text { United States v. } \\
\text { Morrison (1916) }\end{array}$ & $\begin{array}{l}240 \text { U.S. } \\
192,208\end{array}$ \\
\hline 275 & & $\begin{array}{l}30 \text { September } \\
1854\end{array}$ & 648 & $\begin{array}{l}10 \text { Stat. } \\
1109\end{array}$ & $\begin{array}{l}\text { United States v. J.S. } \\
\text { Stearns Lumber Co. } \\
\text { (1918) }\end{array}$ & $\begin{array}{l}245 \text { U.S. } \\
436,436\end{array}$ \\
\hline 275 & & $\begin{array}{l}30 \text { September } \\
1854\end{array}$ & 648 & $\begin{array}{l}10 \text { Stat. } \\
1109\end{array}$ & $\begin{array}{l}\text { United States v. Holt } \\
\text { State Bank (1926) }\end{array}$ & $\begin{array}{l}270 \text { U.S. } \\
49,58\end{array}$ \\
\hline 275 & & $\begin{array}{l}30 \text { September } \\
1854\end{array}$ & 648 & $\begin{array}{l}10 \text { Stat. } \\
1109\end{array}$ & $\begin{array}{l}\text { Chippewa Indians of } \\
\text { Minnesota v. United } \\
\text { States }(1937)\end{array}$ & $\begin{array}{l}301 \text { U.S. } \\
358,361\end{array}$ \\
\hline 275 & & $\begin{array}{l}30 \text { September } \\
1854\end{array}$ & 648 & $\begin{array}{l}10 \text { Stat. } \\
1109\end{array}$ & $\begin{array}{l}\text { Minnesota v. United } \\
\text { States (1939) }\end{array}$ & $\begin{array}{l}305 \text { U.S. } \\
382,383\end{array}$ \\
\hline 275 & & $\begin{array}{l}30 \text { September } \\
1854\end{array}$ & 648 & $\begin{array}{l}10 \text { Stat. } \\
1109\end{array}$ & $\begin{array}{l}\text { Montana v. United } \\
\text { States }(1981)\end{array}$ & $\begin{array}{l}450 \text { U.S. } \\
544,552+\end{array}$ \\
\hline 275 & & $\begin{array}{l}30 \text { September } \\
1854\end{array}$ & 648 & $\begin{array}{l}10 \text { Stat. } \\
1109\end{array}$ & $\begin{array}{l}\text { Minnesota v. Mille } \\
\text { Lacs Band of } \\
\text { Chippewa Indians } \\
\text { (1999) }\end{array}$ & $\begin{array}{l}526 \text { U.S. } \\
172,172\end{array}$ \\
\hline
\end{tabular}


Table 1 (continued)

\begin{tabular}{|c|c|c|c|c|c|c|}
\hline $\begin{array}{l}\text { Ratified } \\
\text { treaty } \\
\text { number }\end{array}$ & $\begin{array}{l}\text { Signatory } \\
\text { tribe(s) }\end{array}$ & $\begin{array}{l}\text { Treaty } \\
\text { signing date }\end{array}$ & $\begin{array}{l}\text { Kappler } \\
\text { page } \\
\text { number }\end{array}$ & $\begin{array}{l}\text { Statutes at } \\
\text { Large or an } \\
\text { alternative } \\
\text { source }\end{array}$ & Case title & U.S. reports \\
\hline 275 & & $\begin{array}{l}30 \text { September } \\
1854\end{array}$ & 648 & $\begin{array}{l}10 \text { Stat. } \\
1109\end{array}$ & $\begin{array}{l}\text { Minnesota v. Mille } \\
\text { Lacs Band of } \\
\text { Chippewa Indians } \\
\text { (1999) }\end{array}$ & $\begin{array}{l}526 \text { U.S. } \\
172,183\end{array}$ \\
\hline 275 & & $\begin{array}{l}30 \text { September } \\
1854\end{array}$ & 648 & $\begin{array}{l}10 \text { Stat. } \\
1109\end{array}$ & Fee v. Brown (1896) & $\begin{array}{l}162 \text { U.S. } \\
602,606(1)\end{array}$ \\
\hline 275 & & $\begin{array}{l}30 \text { September } \\
1854\end{array}$ & 648 & $\begin{array}{l}10 \text { Stat. } \\
1109\end{array}$ & $\begin{array}{l}\text { Wisconsin v. } \\
\text { Hitchcock (1906) }\end{array}$ & $\begin{array}{l}201 \text { U.S. } \\
202,204(1)\end{array}$ \\
\hline 275 & & $\begin{array}{l}30 \text { September } \\
1854\end{array}$ & 648 & $\begin{array}{l}10 \text { Stat. } \\
1109\end{array}$ & Fee v. Brown (1896) & $\begin{array}{l}162 \text { U.S. } \\
602,606(2)\end{array}$ \\
\hline 275 & & $\begin{array}{l}30 \text { September } \\
1854\end{array}$ & 648 & $\begin{array}{l}10 \text { Stat. } \\
1109\end{array}$ & $\begin{array}{l}\text { Wisconsin v. } \\
\text { Hitchcock (1906) }\end{array}$ & $\begin{array}{l}201 \text { U.S. } \\
202,204(2)\end{array}$ \\
\hline 275 & & $\begin{array}{l}30 \text { September } \\
1854\end{array}$ & 648 & $\begin{array}{l}10 \text { Stat. } \\
1109\end{array}$ & $\begin{array}{l}\text { Minnesota v. Mille } \\
\text { Lacs Band of } \\
\text { Chippewa Indians } \\
\text { (1999) }\end{array}$ & $\begin{array}{l}526 \text { U.S. } \\
172,172(2)\end{array}$ \\
\hline 275 & & $\begin{array}{l}30 \text { September } \\
1854\end{array}$ & 648 & $\begin{array}{l}10 \text { Stat. } \\
1109\end{array}$ & $\begin{array}{l}\text { Minnesota v. Mille } \\
\text { Lacs Band of } \\
\text { Chippewa Indians } \\
\text { (1999) }\end{array}$ & $\begin{array}{l}526 \text { U.S. } \\
172,184(2)\end{array}$ \\
\hline 275 & & $\begin{array}{l}30 \text { September } \\
1854\end{array}$ & 648 & $\begin{array}{l}10 \text { Stat. } \\
1109\end{array}$ & Fee v. Brown (1896) & $\begin{array}{l}162 \text { U.S. } 602 \\
606(2.1-2.6)\end{array}$ \\
\hline 275 & & $\begin{array}{l}30 \text { September } \\
1854\end{array}$ & 648 & $\begin{array}{l}10 \text { Stat. } \\
1109\end{array}$ & $\begin{array}{l}\text { Pigeon River } \\
\text { Improvement, Slide } \\
\text { and Boom Co. v. } \\
\text { Charles W. Cox, Ltd. } \\
(1934)\end{array}$ & $\begin{array}{l}291 \text { U.S. } \\
138,151(2.5)\end{array}$ \\
\hline 275 & & $\begin{array}{l}30 \text { September } \\
1854\end{array}$ & 648 & $\begin{array}{l}10 \text { Stat. } \\
1109\end{array}$ & $\begin{array}{l}\text { Prentice v. Stearns } \\
\text { (1885) }\end{array}$ & $\begin{array}{l}113 \text { U.S. } \\
435,436(2.6)\end{array}$ \\
\hline 275 & & $\begin{array}{l}30 \text { September } \\
1854\end{array}$ & 648 & $\begin{array}{l}10 \text { Stat. } \\
1109\end{array}$ & $\begin{array}{l}\text { Prentice v. Northern } \\
\text { Pacific Railroad Co. } \\
\text { (1894) }\end{array}$ & $\begin{array}{l}154 \text { U.S. } \\
163,164(2.6)\end{array}$ \\
\hline 275 & & $\begin{array}{l}30 \text { September } \\
1854\end{array}$ & 648 & $\begin{array}{l}10 \text { Stat. } \\
1109\end{array}$ & Fee v. Brown (1896) & $\begin{array}{l}162 \text { U.S. } \\
602,607(3)\end{array}$ \\
\hline 275 & & $\begin{array}{l}30 \text { September } \\
1854\end{array}$ & 648 & $\begin{array}{l}10 \text { Stat. } \\
1109\end{array}$ & $\begin{array}{l}\text { Wisconsin v. } \\
\text { Hitchcock (1906) }\end{array}$ & $\begin{array}{l}201 \text { U.S. } \\
202,205(3)\end{array}$ \\
\hline 275 & & $\begin{array}{l}30 \text { September } \\
1854\end{array}$ & 648 & $\begin{array}{l}10 \text { Stat. } \\
1109\end{array}$ & $\begin{array}{l}\text { Starr v. Campbell } \\
\text { (1908) }\end{array}$ & $\begin{array}{l}208 \text { U.S. } \\
527,527(3)\end{array}$ \\
\hline 275 & & $\begin{array}{l}30 \text { September } \\
1854\end{array}$ & 648 & $\begin{array}{l}10 \text { Stat. } \\
1109\end{array}$ & $\begin{array}{l}\text { United States v. J.S. } \\
\text { Stearns Lumber Co. } \\
(1918)\end{array}$ & $\begin{array}{l}245 \text { U.S. } \\
436,438(3)\end{array}$ \\
\hline 275 & & $\begin{array}{l}30 \text { September } \\
1854\end{array}$ & 648 & $\begin{array}{l}10 \text { Stat. } \\
1109\end{array}$ & $\begin{array}{l}\text { Minnesota v. United } \\
\text { States (1939) }\end{array}$ & $\begin{array}{l}305 \text { U.S. } \\
382,385(3)\end{array}$ \\
\hline 275 & & $\begin{array}{l}30 \text { September } \\
1854\end{array}$ & 648 & $\begin{array}{l}10 \text { Stat. } \\
1109\end{array}$ & Fee v. Brown (1896) & $\begin{array}{l}162 \text { U.S. } \\
602,609(7)\end{array}$ \\
\hline
\end{tabular}


Table 1 (continued)

\begin{tabular}{|c|c|c|c|c|c|c|}
\hline $\begin{array}{l}\text { Ratified } \\
\text { treaty } \\
\text { number }\end{array}$ & $\begin{array}{l}\text { Signatory } \\
\text { tribe(s) }\end{array}$ & $\begin{array}{l}\text { Treaty } \\
\text { signing date }\end{array}$ & $\begin{array}{l}\text { Kappler } \\
\text { page } \\
\text { number }\end{array}$ & $\begin{array}{l}\text { Statutes at } \\
\text { Large or an } \\
\text { alternative } \\
\text { source }\end{array}$ & Case title & U.S. reports \\
\hline 275 & & $\begin{array}{l}30 \text { September } \\
1854\end{array}$ & 648 & $\begin{array}{l}10 \text { Stat. } \\
1109\end{array}$ & $\begin{array}{l}\text { Minnesota v. Mille } \\
\text { Lacs Band of } \\
\text { Chippewa Indians } \\
\text { (1999) }\end{array}$ & $\begin{array}{l}526 \text { U.S. } \\
172,172(11)\end{array}$ \\
\hline 275 & & $\begin{array}{l}30 \text { September } \\
1854\end{array}$ & 648 & $\begin{array}{l}10 \text { Stat. } \\
1109\end{array}$ & $\begin{array}{l}\text { Minnesota v. Mille } \\
\text { Lacs Band of } \\
\text { Chippewa Indians } \\
\text { (1999) }\end{array}$ & $\begin{array}{l}526 \text { U.S. } \\
172,184(11)\end{array}$ \\
\hline 281 & $\begin{array}{l}\text { Nisqually; } \\
\text { Puyallup; } \\
\text { Steilacoom; } \\
\text { Squaxin; } \\
\text { Homamish; } \\
\text { Stehchass; } \\
\text { Tapeeksin; } \\
\text { Squiaitl; } \\
\text { Sahewamish }\end{array}$ & $\begin{array}{l}26 \text { December } \\
1854\end{array}$ & 661 & $\begin{array}{l}10 \text { Stat. } \\
1132\end{array}$ & $\begin{array}{l}\text { Goudy v. Meath } \\
\text { (1906) }\end{array}$ & $\begin{array}{l}203 \text { U.S. } \\
146,146\end{array}$ \\
\hline 281 & & $\begin{array}{l}26 \text { December } \\
1854\end{array}$ & 661 & $\begin{array}{l}10 \text { Stat. } \\
1132\end{array}$ & $\begin{array}{l}\text { United States v. } \\
\text { Celestine (1909) }\end{array}$ & $\begin{array}{l}215 \text { U.S. } \\
278,287\end{array}$ \\
\hline 281 & & $\begin{array}{l}26 \text { December } \\
1854\end{array}$ & 661 & $\begin{array}{l}10 \text { Stat. } \\
1132\end{array}$ & $\begin{array}{l}\text { Puyallup Tribe v. } \\
\text { Dept. of Game (1968) }\end{array}$ & $\begin{array}{l}391 \text { U.S. } \\
392,393\end{array}$ \\
\hline 281 & & $\begin{array}{l}26 \text { December } \\
1854\end{array}$ & 661 & $\begin{array}{l}10 \text { Stat. } \\
1132\end{array}$ & $\begin{array}{l}\text { Dept. of Game v. } \\
\text { Puyallup Tribe (1973) }\end{array}$ & $\begin{array}{l}414 \text { U.S. } \\
44,45\end{array}$ \\
\hline 281 & & $\begin{array}{l}26 \text { December } \\
1854\end{array}$ & 661 & $\begin{array}{l}10 \text { Stat. } \\
1132\end{array}$ & $\begin{array}{l}\text { Puyallup Tribe, Inc. v. } \\
\text { Dept. of Game (1977) }\end{array}$ & $\begin{array}{l}433 \text { U.S. } \\
165,174\end{array}$ \\
\hline 281 & & $\begin{array}{l}26 \text { December } \\
1854\end{array}$ & 661 & $\begin{array}{l}10 \text { Stat. } \\
1132\end{array}$ & $\begin{array}{l}\text { Puyallup Tribe v. } \\
\text { Dept. of Game (1968) }\end{array}$ & $\begin{array}{l}391 \text { U.S. } \\
392,394(2)\end{array}$ \\
\hline 281 & & $\begin{array}{l}26 \text { December } \\
1854\end{array}$ & 661 & $\begin{array}{l}10 \text { Stat. } \\
1132\end{array}$ & $\begin{array}{l}\text { Puyallup Tribe, Inc. v. } \\
\text { Dept. of Game (1977) }\end{array}$ & $\begin{array}{l}433 \text { U.S. } \\
165,174(2)\end{array}$ \\
\hline 281 & & $\begin{array}{l}26 \text { December } \\
1854\end{array}$ & 661 & $\begin{array}{l}10 \text { Stat. } \\
1132\end{array}$ & $\begin{array}{l}\text { Montana v. United } \\
\text { States }(1981)\end{array}$ & $\begin{array}{l}450 \text { U.S. } \\
544,561(2)\end{array}$ \\
\hline 281 & & $\begin{array}{l}26 \text { December } \\
1854\end{array}$ & 661 & $\begin{array}{l}10 \text { Stat. } \\
1132\end{array}$ & $\begin{array}{l}\text { Puyallup Tribe v. } \\
\text { Dept. of Game (1968) }\end{array}$ & $\begin{array}{l}391 \text { U.S. } \\
392,392(3)\end{array}$ \\
\hline 281 & & $\begin{array}{l}26 \text { December } \\
1854\end{array}$ & 661 & $\begin{array}{l}10 \text { Stat. } \\
1132\end{array}$ & $\begin{array}{l}\text { Puyallup Tribe, Inc. v. } \\
\text { Dept. of Game (1977) }\end{array}$ & $\begin{array}{l}433 \text { U.S. } \\
165,167(3)\end{array}$ \\
\hline 281 & & $\begin{array}{l}26 \text { December } \\
1854\end{array}$ & 661 & $\begin{array}{l}10 \text { Stat. } \\
1132\end{array}$ & $\begin{array}{l}\text { Washington v. } \\
\text { Washington State } \\
\text { Commercial } \\
\text { Passenger Fishing } \\
\text { Vessel Association } \\
(1979)\end{array}$ & $\begin{array}{l}443 \text { U.S. } \\
658,674(3)\end{array}$ \\
\hline 281 & & $\begin{array}{l}26 \text { December } \\
1854\end{array}$ & 661 & $\begin{array}{l}10 \text { Stat. } \\
1132\end{array}$ & $\begin{array}{l}\text { Montana v. United } \\
\text { States }(1981)\end{array}$ & $\begin{array}{l}450 \text { U.S. } \\
544,561(3)\end{array}$ \\
\hline
\end{tabular}


Table 1 (continued)

\begin{tabular}{|c|c|c|c|c|c|c|}
\hline $\begin{array}{l}\text { Ratified } \\
\text { treaty } \\
\text { number }\end{array}$ & $\begin{array}{l}\text { Signatory } \\
\text { tribe(s) }\end{array}$ & $\begin{array}{l}\text { Treaty } \\
\text { signing date }\end{array}$ & $\begin{array}{l}\text { Kappler } \\
\text { page } \\
\text { number }\end{array}$ & $\begin{array}{l}\text { Statutes at } \\
\text { Large or an } \\
\text { alternative } \\
\text { source }\end{array}$ & Case title & U.S. reports \\
\hline 281 & & $\begin{array}{l}26 \text { December } \\
1854\end{array}$ & 661 & $\begin{array}{l}10 \text { Stat. } \\
1132\end{array}$ & $\begin{array}{l}\text { Puyallup Tribe v. } \\
\text { Dept. of Game (1968) }\end{array}$ & $\begin{array}{l}391 \text { U.S. } \\
392,394(6)\end{array}$ \\
\hline 281 & & $\begin{array}{l}26 \text { December } \\
1854\end{array}$ & 661 & $\begin{array}{l}10 \text { Stat. } \\
1132\end{array}$ & $\begin{array}{l}\text { Washington } v . \\
\text { Washington State } \\
\text { Commercial } \\
\text { Passenger Fishing } \\
\text { Vessel Association } \\
(1979)\end{array}$ & $\begin{array}{l}443 \text { U.S. } \\
658,697(13)\end{array}$ \\
\hline 282 & $\begin{array}{l}\text { Kalapuya; } \\
\text { Molala; } \\
\text { Tumwater; } \\
\text { Clackamas }\end{array}$ & $\begin{array}{l}22 \text { January } \\
1855\end{array}$ & 665 & $\begin{array}{l}10 \text { Stat. } \\
1143\end{array}$ & $\begin{array}{l}\text { United States v. Texas } \\
\text { (1896) }\end{array}$ & $\begin{array}{l}162 \text { U.S. } \\
1,66\end{array}$ \\
\hline 283 & $\begin{array}{l}\text { Duwamish; } \\
\text { Suquamish; } \\
\text { Stkehlmish; } \\
\text { Sammamish; } \\
\text { Smulkamish; } \\
\text { Skopamish; } \\
\text { Stkamish; } \\
\text { Snoqualmie; } \\
\text { Skykomish; } \\
\text { Kwehtlamamish; } \\
\text { Staktalijamish; } \\
\text { Stillaguamish; } \\
\text { Snohomish; } \\
\text { Skagit; } \\
\text { Kikiallus; } \\
\text { Swinomish; } \\
\text { Squinamish; } \\
\text { Sauk-Suiattle; } \\
\text { Nuwhaha; } \\
\text { Nookachamps; } \\
\text { Mesekwegwils; } \\
\text { Choba }\end{array}$ & $\begin{array}{l}22 \text { January } \\
1855\end{array}$ & 669 & $\begin{array}{l}12 \text { Stat. } \\
927\end{array}$ & $\begin{array}{l}\text { Oliphant } v . \\
\text { Suquamish Indian } \\
\text { Tribe (1978) }\end{array}$ & $\begin{array}{l}435 \text { U.S. } \\
191,192\end{array}$ \\
\hline 283 & & $\begin{array}{l}22 \text { January } \\
1855\end{array}$ & 669 & $\begin{array}{l}12 \text { Stat. } \\
927\end{array}$ & $\begin{array}{l}\text { Washington } v . \\
\text { Washington State } \\
\text { Commercial } \\
\text { Passenger Fishing } \\
\text { Vessel Association } \\
(1979)\end{array}$ & $\begin{array}{l}443 \text { U.S. } \\
658,662\end{array}$ \\
\hline 283 & & $\begin{array}{l}22 \text { January } \\
1855\end{array}$ & 669 & $\begin{array}{l}12 \text { Stat. } \\
927\end{array}$ & $\begin{array}{l}\text { Washington } v \text {. } \\
\text { Confederated Tribes } \\
\text { of the Colville Indian } \\
\text { Reservation (1980) }\end{array}$ & $\begin{array}{l}447 \text { U.S. } \\
134,143\end{array}$ \\
\hline
\end{tabular}


Table 1 (continued)

\begin{tabular}{|c|c|c|c|c|c|c|}
\hline $\begin{array}{l}\text { Ratified } \\
\text { treaty } \\
\text { number }\end{array}$ & $\begin{array}{l}\text { Signatory } \\
\text { tribe(s) }\end{array}$ & $\begin{array}{l}\text { Treaty } \\
\text { signing date }\end{array}$ & $\begin{array}{l}\text { Kappler } \\
\text { page } \\
\text { number }\end{array}$ & $\begin{array}{l}\text { Statutes at } \\
\text { Large or an } \\
\text { alternative } \\
\text { source }\end{array}$ & Case title & U.S. reports \\
\hline 283 & & $\begin{array}{l}22 \text { January } \\
1855\end{array}$ & 669 & $\begin{array}{l}12 \text { Stat. } \\
927\end{array}$ & $\begin{array}{l}\text { United States v. } \\
\text { Celestine (1909) }\end{array}$ & $\begin{array}{l}215 \text { U.S. } \\
278,285(3)\end{array}$ \\
\hline 283 & & $\begin{array}{l}22 \text { January } \\
1855\end{array}$ & 669 & $\begin{array}{l}12 \text { Stat. } \\
927\end{array}$ & $\begin{array}{l}\text { United States v. } \\
\text { Celestine (1909) }\end{array}$ & $\begin{array}{l}215 \text { U.S. } \\
278,286(7)\end{array}$ \\
\hline 283 & & $\begin{array}{l}22 \text { January } \\
1855\end{array}$ & 669 & $\begin{array}{l}12 \text { Stat. } \\
927\end{array}$ & $\begin{array}{l}\text { Oliphant } v . \\
\text { Suquamish Indian } \\
\text { Tribe }(1978)\end{array}$ & $\begin{array}{l}435 \text { U.S. } \\
191,206(9)\end{array}$ \\
\hline 284 & $\begin{array}{l}\text { Clallam; } \\
\text { Skokomish; } \\
\text { Chemakum }\end{array}$ & $\begin{array}{l}26 \text { January } \\
1855\end{array}$ & 674 & $\begin{array}{l}12 \text { Stat. } \\
933\end{array}$ & $\begin{array}{l}\text { Washington v. } \\
\text { Washington State } \\
\text { Commercial } \\
\text { Passenger Fishing } \\
\text { Vessel Association } \\
\text { (1979) }\end{array}$ & $\begin{array}{l}443 \text { U.S. } \\
658,662\end{array}$ \\
\hline 285 & Wyandot & $\begin{array}{l}31 \text { January } \\
1855\end{array}$ & 677 & $\begin{array}{l}10 \text { Stat. } \\
1159\end{array}$ & $\begin{array}{l}\text { Walker v. Henshaw } \\
\text { (1873) }\end{array}$ & $\begin{array}{l}83 \text { U.S. } \\
436,436\end{array}$ \\
\hline 285 & & $\begin{array}{l}31 \text { January } \\
1855\end{array}$ & 677 & $\begin{array}{l}10 \text { Stat. } \\
1159\end{array}$ & Elk v. Wilkins (1884) & $\begin{array}{l}112 \text { U.S. } \\
94,100\end{array}$ \\
\hline 285 & & $\begin{array}{l}31 \text { January } \\
1855\end{array}$ & 677 & $\begin{array}{l}10 \text { Stat. } \\
1159\end{array}$ & $\begin{array}{l}\text { Goudy v. Meath } \\
\text { (1906) }\end{array}$ & $\begin{array}{l}203 \text { U.S. } \\
146,149\end{array}$ \\
\hline 285 & & $\begin{array}{l}31 \text { January } \\
1855\end{array}$ & 677 & $\begin{array}{l}10 \text { Stat. } \\
1159\end{array}$ & $\begin{array}{l}\text { Schrimpscher v. } \\
\text { Stockton (1902) }\end{array}$ & $\begin{array}{l}183 \text { U.S. } \\
290,296(1)\end{array}$ \\
\hline 285 & & $\begin{array}{l}31 \text { January } \\
1855\end{array}$ & 677 & $\begin{array}{l}10 \text { Stat. } \\
1159\end{array}$ & $\begin{array}{l}\text { Conley v. Ballinger } \\
(1910)\end{array}$ & $\begin{array}{l}216 \text { U.S. } \\
84,88(1)\end{array}$ \\
\hline 285 & & $\begin{array}{l}31 \text { January } \\
1855\end{array}$ & 677 & $\begin{array}{l}10 \text { Stat. } \\
1159\end{array}$ & $\begin{array}{l}\text { Schrimpscher } v . \\
\text { Stockton (1902) }\end{array}$ & $\begin{array}{l}183 \text { U.S. } \\
290,292(2)\end{array}$ \\
\hline 285 & & $\begin{array}{l}31 \text { January } \\
1855\end{array}$ & 677 & $\begin{array}{l}10 \text { Stat. } \\
1159\end{array}$ & $\begin{array}{l}\text { Conley v. Ballinger } \\
(1910)\end{array}$ & $\begin{array}{l}216 \text { U.S. } \\
84,88(2)\end{array}$ \\
\hline 285 & & $\begin{array}{l}31 \text { January } \\
1855\end{array}$ & 677 & $\begin{array}{l}10 \text { Stat. } \\
1159\end{array}$ & $\begin{array}{l}\text { Schrimpscher } v . \\
\text { Stockton }(1902)\end{array}$ & $\begin{array}{l}183 \text { U.S. } \\
290,292(3)\end{array}$ \\
\hline 285 & & $\begin{array}{l}31 \text { January } \\
1855\end{array}$ & 677 & $\begin{array}{l}10 \text { Stat. } \\
1159\end{array}$ & $\begin{array}{l}\text { Schrimpscher } v . \\
\text { Stockton }(1902)\end{array}$ & $\begin{array}{l}183 \text { U.S. } \\
290,291(4)\end{array}$ \\
\hline 285 & & $\begin{array}{l}31 \text { January } \\
1855\end{array}$ & 677 & $\begin{array}{l}10 \text { Stat. } \\
1159\end{array}$ & $\begin{array}{l}\text { Walker v. Henshaw } \\
\text { (1873) }\end{array}$ & $\begin{array}{l}83 \text { U.S. } \\
436,439(9)\end{array}$ \\
\hline 286 & Makah & $\begin{array}{l}31 \text { January } \\
1855\end{array}$ & 682 & $\begin{array}{l}12 \text { Stat. } \\
939\end{array}$ & $\begin{array}{l}\text { Washington v. } \\
\text { Washington State } \\
\text { Commercial } \\
\text { Passenger Fishing } \\
\text { Vessel Association } \\
(1979)\end{array}$ & $\begin{array}{l}443 \text { U.S. } \\
658,662\end{array}$ \\
\hline 286 & & $\begin{array}{l}31 \text { January } \\
1855\end{array}$ & 682 & $\begin{array}{l}12 \text { Stat. } \\
939\end{array}$ & $\begin{array}{l}\text { Washington v. } \\
\text { Confederated Tribes } \\
\text { of the Colville Indian } \\
\text { Reservation (1980) }\end{array}$ & $\begin{array}{l}447 \text { U.S. } \\
134,143\end{array}$ \\
\hline
\end{tabular}


Table 1 (continued)

\begin{tabular}{|c|c|c|c|c|c|c|}
\hline $\begin{array}{l}\text { Ratified } \\
\text { treaty } \\
\text { number }\end{array}$ & $\begin{array}{l}\text { Signatory } \\
\text { tribe(s) }\end{array}$ & $\begin{array}{l}\text { Treaty } \\
\text { signing date }\end{array}$ & $\begin{array}{l}\text { Kappler } \\
\text { page } \\
\text { number }\end{array}$ & $\begin{array}{l}\text { Statutes at } \\
\text { Large or an } \\
\text { alternative } \\
\text { source }\end{array}$ & Case title & U.S. reports \\
\hline 287 & $\begin{array}{l}\text { Chippewa: } \\
\text { Mississippi, } \\
\text { Pillager and } \\
\text { Lake } \\
\text { Winnibigoshish }\end{array}$ & $\begin{array}{l}22 \text { February } \\
1855\end{array}$ & 685 & $\begin{array}{l}10 \text { Stat. } \\
1165\end{array}$ & $\begin{array}{l}\text { United States } v . \\
\text { Forty-three Gallons } \\
\text { of Whiskey (1876) }\end{array}$ & $\begin{array}{l}93 \text { U.S. } \\
188,192+\end{array}$ \\
\hline 287 & & $\begin{array}{l}22 \text { February } \\
1855\end{array}$ & 685 & $\begin{array}{l}10 \text { Stat. } \\
1165\end{array}$ & $\begin{array}{l}\text { United States v. Mille } \\
\text { Lac Band of } \\
\text { Chippewa Indians } \\
\text { (1913) }\end{array}$ & $\begin{array}{l}229 \text { U.S. } \\
498,499\end{array}$ \\
\hline 287 & & $\begin{array}{l}22 \text { February } \\
1855\end{array}$ & 685 & $\begin{array}{l}10 \text { Stat. } \\
1165\end{array}$ & $\begin{array}{l}\text { Johnson v. Gearlds } \\
\text { (1914) }\end{array}$ & $\begin{array}{l}234 \text { U.S. } \\
422,426\end{array}$ \\
\hline 287 & & $\begin{array}{l}22 \text { February } \\
1855\end{array}$ & 685 & $\begin{array}{l}10 \text { Stat. } \\
1165\end{array}$ & $\begin{array}{l}\text { United States v. Holt } \\
\text { State Bank (1926) }\end{array}$ & $\begin{array}{l}270 \text { U.S. } \\
49,58\end{array}$ \\
\hline 287 & & $\begin{array}{l}22 \text { February } \\
1855\end{array}$ & 685 & $\begin{array}{l}10 \text { Stat. } \\
1165\end{array}$ & $\begin{array}{l}\text { United States v. } \\
\text { Minnesota }(1926)\end{array}$ & $\begin{array}{l}270 \text { U.S. } \\
181,196\end{array}$ \\
\hline 287 & & $\begin{array}{l}22 \text { February } \\
1855\end{array}$ & 685 & $\begin{array}{l}10 \text { Stat. } \\
1165\end{array}$ & $\begin{array}{l}\text { Wilbur v. United } \\
\text { States }(1930)\end{array}$ & $\begin{array}{l}281 \text { U.S. } \\
206,208\end{array}$ \\
\hline 287 & & $\begin{array}{l}22 \text { February } \\
1855\end{array}$ & 685 & $\begin{array}{l}10 \text { Stat. } \\
1165\end{array}$ & $\begin{array}{l}\text { Chippewa Indians of } \\
\text { Minnesota v. United } \\
\text { States (1937) }\end{array}$ & $\begin{array}{l}301 \text { U.S. } \\
358,361\end{array}$ \\
\hline 287 & & $\begin{array}{l}22 \text { February } \\
1855\end{array}$ & 685 & $\begin{array}{l}10 \text { Stat. } \\
1165\end{array}$ & $\begin{array}{l}\text { Bryan v. Itasca } \\
\text { County (1976) }\end{array}$ & $\begin{array}{l}426 \text { U.S. } \\
373,375\end{array}$ \\
\hline 287 & & $\begin{array}{l}22 \text { February } \\
1855\end{array}$ & 685 & $\begin{array}{l}10 \text { Stat. } \\
1165\end{array}$ & $\begin{array}{l}\text { Montana v. United } \\
\text { States (1981) }\end{array}$ & $\begin{array}{l}450 \text { U.S. } \\
544,552\end{array}$ \\
\hline 287 & & $\begin{array}{l}22 \text { February } \\
1855\end{array}$ & 685 & $\begin{array}{l}10 \text { Stat. } \\
1165\end{array}$ & $\begin{array}{l}\text { Minnesota v. Mille } \\
\text { Lacs Band of } \\
\text { Chippewa Indians } \\
\text { (1999) }\end{array}$ & $\begin{array}{l}526 \text { U.S. } \\
172,172\end{array}$ \\
\hline 287 & & $\begin{array}{l}22 \text { February } \\
1855\end{array}$ & 685 & $\begin{array}{l}10 \text { Stat. } \\
1165\end{array}$ & $\begin{array}{l}\text { Minnesota v. Mille } \\
\text { Lacs Band of } \\
\text { Chippewa Indians } \\
\text { (1999) }\end{array}$ & $\begin{array}{l}526 \text { U.S. } \\
172,195\end{array}$ \\
\hline 287 & & $\begin{array}{l}22 \text { February } \\
1855\end{array}$ & 685 & $\begin{array}{l}10 \text { Stat. } \\
1165\end{array}$ & $\begin{array}{l}\text { Johnson v. Gearlds } \\
\text { (1914) }\end{array}$ & $\begin{array}{l}234 \text { U.S. } \\
422,425(1)\end{array}$ \\
\hline 287 & & $\begin{array}{l}22 \text { February } \\
1855\end{array}$ & 685 & $\begin{array}{l}10 \text { Stat. } \\
1165\end{array}$ & $\begin{array}{l}\text { United States v. } \\
\text { Minnesota }(1926)\end{array}$ & $\begin{array}{l}270 \text { U.S. } \\
181,196(1)\end{array}$ \\
\hline 287 & & $\begin{array}{l}22 \text { February } \\
1855\end{array}$ & 685 & $\begin{array}{l}10 \text { Stat. } \\
1165\end{array}$ & $\begin{array}{l}\text { Minnesota v. Mille } \\
\text { Lacs Band of } \\
\text { Chippewa Indians } \\
\text { (1999) }\end{array}$ & $\begin{array}{l}526 \text { U.S. } \\
172,172(1)\end{array}$ \\
\hline 287 & & $\begin{array}{l}22 \text { February } \\
1855\end{array}$ & 685 & $\begin{array}{l}10 \text { Stat. } \\
1165\end{array}$ & $\begin{array}{l}\text { Minnesota v. Mille } \\
\text { Lacs Band of } \\
\text { Chippewa Indians } \\
\text { (1999) }\end{array}$ & $\begin{array}{l}526 \text { U.S. } \\
172,184(1)\end{array}$ \\
\hline
\end{tabular}


Table 1 (continued)

\begin{tabular}{|c|c|c|c|c|c|c|}
\hline $\begin{array}{l}\text { Ratified } \\
\text { treaty } \\
\text { number }\end{array}$ & $\begin{array}{l}\text { Signatory } \\
\text { tribe(s) }\end{array}$ & $\begin{array}{l}\text { Treaty } \\
\text { signing date }\end{array}$ & $\begin{array}{l}\text { Kappler } \\
\text { page } \\
\text { number }\end{array}$ & $\begin{array}{l}\text { Statutes at } \\
\text { Large or an } \\
\text { alternative } \\
\text { source }\end{array}$ & Case title & U.S. reports \\
\hline 287 & & $\begin{array}{l}22 \text { February } \\
1855\end{array}$ & 685 & $\begin{array}{l}10 \text { Stat. } \\
1165\end{array}$ & $\begin{array}{l}\text { Johnson v. Gearlds } \\
\text { (1914) }\end{array}$ & $\begin{array}{l}234 \text { U.S. } \\
422,425(2)\end{array}$ \\
\hline 287 & & $\begin{array}{l}22 \text { February } \\
1855\end{array}$ & 685 & $\begin{array}{l}10 \text { Stat. } \\
1165\end{array}$ & $\begin{array}{l}\text { United States v. } \\
\text { Minnesota }(1926)\end{array}$ & $\begin{array}{l}270 \text { U.S. } \\
181,196(2)\end{array}$ \\
\hline 287 & & $\begin{array}{l}22 \text { February } \\
1855\end{array}$ & 685 & $\begin{array}{l}10 \text { Stat. } \\
1165\end{array}$ & $\begin{array}{l}\text { United States v. First } \\
\text { National Bank (1914) }\end{array}$ & $\begin{array}{l}234 \text { U.S. } \\
245,250(6)\end{array}$ \\
\hline 287 & & $\begin{array}{l}22 \text { February } \\
1855\end{array}$ & 685 & $\begin{array}{l}10 \text { Stat. } \\
1165\end{array}$ & $\begin{array}{l}\text { Johnson v. Gearlds } \\
\text { (1914) }\end{array}$ & $\begin{array}{l}234 \text { U.S. } \\
422,422(7)\end{array}$ \\
\hline 287 & & $\begin{array}{l}22 \text { February } \\
1855\end{array}$ & 685 & $\begin{array}{l}10 \text { Stat. } \\
1165\end{array}$ & $\begin{array}{l}\text { Minnesota v. Mille } \\
\text { Lacs Band of } \\
\text { Chippewa Indians } \\
\text { (1999) }\end{array}$ & $\begin{array}{l}526 \text { U.S. } \\
172,184(11)\end{array}$ \\
\hline 288 & Winnebago & $\begin{array}{l}27 \text { February } \\
1855\end{array}$ & 690 & $\begin{array}{l}10 \text { Stat. } \\
1172\end{array}$ & $\begin{array}{l}\text { Johnson v. Gearlds } \\
\text { (1914) }\end{array}$ & $\begin{array}{l}234 \text { U.S. } \\
422,436(8)\end{array}$ \\
\hline 289 & $\begin{array}{l}\text { Walla Walla; } \\
\text { Cayuse; } \\
\text { Umatilla }\end{array}$ & 9 June 1855 & 694 & $\begin{array}{l}12 \text { Stat. } \\
945\end{array}$ & $\begin{array}{l}H y-Y u-T s e-M i l-K i n v . \\
\text { Smith }(1904)\end{array}$ & $\begin{array}{l}194 \text { U.S. } \\
401,402\end{array}$ \\
\hline 290 & $\begin{array}{l}\text { Yakima; } \\
\text { Palouse; } \\
\text { Pisquouse; } \\
\text { Wenatchee; } \\
\text { Klikitat; } \\
\text { Klinquit; } \\
\text { Kowwassayee; } \\
\text { Liaywas; Skin; } \\
\text { Wishram; } \\
\text { Shyiks; } \\
\text { Ochechotes; } \\
\text { Kahmiltpah; } \\
\text { Seapcat }\end{array}$ & 9 June 1855 & 698 & $\begin{array}{l}12 \text { Stat. } \\
951\end{array}$ & $\begin{array}{l}\text { United States v. } \\
\text { Winans (1905) }\end{array}$ & $\begin{array}{l}198 \text { U.S. } \\
371,371\end{array}$ \\
\hline 290 & & 9 June 1855 & 698 & $\begin{array}{l}12 \text { Stat. } \\
951\end{array}$ & $\begin{array}{l}\text { Northern Pacific } \\
\text { Railway Co. v. United } \\
\text { States (1913) }\end{array}$ & $\begin{array}{l}227 \text { U.S. } \\
355,355\end{array}$ \\
\hline 290 & & 9 June 1855 & 698 & $\begin{array}{l}12 \text { Stat. } \\
951\end{array}$ & $\begin{array}{l}\text { New York ex rel. } \\
\text { Kennedy v. Becker } \\
(1916)\end{array}$ & $\begin{array}{l}241 \text { U.S. } \\
556,564\end{array}$ \\
\hline 290 & & 9 June 1855 & 698 & $\begin{array}{l}12 \text { Stat. } \\
951\end{array}$ & $\begin{array}{l}\text { Seufert Bros. Co. v. } \\
\text { United States (1919) }\end{array}$ & $\begin{array}{l}249 \text { U.S. } \\
194,195\end{array}$ \\
\hline 290 & & 9 June 1855 & 698 & $\begin{array}{l}12 \text { Stat. } \\
951\end{array}$ & $\begin{array}{l}\text { Tulee v. Washington } \\
\text { (1942) }\end{array}$ & $\begin{array}{l}315 \text { U.S. } \\
681,683\end{array}$ \\
\hline 290 & & 9 June 1855 & 698 & $\begin{array}{l}12 \text { Stat. } \\
951\end{array}$ & $\begin{array}{l}\text { Puyallup Tribe v. } \\
\text { Dept. of Game (1968) }\end{array}$ & $\begin{array}{l}391 \text { U.S. } \\
392,399\end{array}$ \\
\hline
\end{tabular}


Table 1 (continued)

\begin{tabular}{|c|c|c|c|c|c|c|}
\hline $\begin{array}{l}\text { Ratified } \\
\text { treaty } \\
\text { number }\end{array}$ & $\begin{array}{l}\text { Signatory } \\
\text { tribe(s) }\end{array}$ & $\begin{array}{l}\text { Treaty } \\
\text { signing date }\end{array}$ & $\begin{array}{l}\text { Kappler } \\
\text { page } \\
\text { number }\end{array}$ & $\begin{array}{l}\text { Statutes at } \\
\text { Large or an } \\
\text { alternative } \\
\text { source }\end{array}$ & Case title & U.S. reports \\
\hline 290 & & 9 June 1855 & 698 & $\begin{array}{l}12 \text { Stat. } \\
951\end{array}$ & $\begin{array}{l}\text { Washington } v \text {. } \\
\text { Confederated Bands } \\
\text { and Tribes of the } \\
\text { Yakima Indian Nation } \\
\text { (1979) }\end{array}$ & $\begin{array}{l}439 \text { U.S. } \\
463,469\end{array}$ \\
\hline 290 & & 9 June 1855 & 698 & $\begin{array}{l}12 \text { Stat. } \\
951\end{array}$ & $\begin{array}{l}\text { Washington v. } \\
\text { Washington State } \\
\text { Commercial } \\
\text { Passenger Fishing } \\
\text { Vessel Association } \\
(1979)\end{array}$ & $\begin{array}{l}443 \text { U.S. } \\
658,662\end{array}$ \\
\hline 290 & & 9 June 1855 & 698 & $\begin{array}{l}12 \text { Stat. } \\
951\end{array}$ & $\begin{array}{l}\text { Washington } v . \\
\text { Confederated Tribes } \\
\text { of the Colville Indian } \\
\text { Reservation (1980) }\end{array}$ & $\begin{array}{l}447 \text { U.S. } \\
134,144\end{array}$ \\
\hline 290 & & 9 June 1855 & 698 & $\begin{array}{l}12 \text { Stat. } \\
951\end{array}$ & $\begin{array}{l}\text { Oregon Dept. of Fish } \\
\text { and Wildlife v. } \\
\text { Klamath Indian Tribe } \\
\text { (1985) }\end{array}$ & $\begin{array}{l}473 \text { U.S. } \\
753,769\end{array}$ \\
\hline 290 & & 9 June 1855 & 698 & $\begin{array}{l}12 \text { Stat. } \\
951\end{array}$ & $\begin{array}{l}\text { Brendale v. } \\
\text { Confederated Tribes } \\
\text { and Bands of the } \\
\text { Yakima Indian Nation } \\
\text { (1989) }\end{array}$ & $\begin{array}{l}492 \text { U.S. } \\
408,414\end{array}$ \\
\hline 290 & & 9 June 1855 & 698 & $\begin{array}{l}12 \text { Stat. } \\
951\end{array}$ & $\begin{array}{l}\text { County of Yakima v. } \\
\text { Confederated Tribes } \\
\text { and Bands of the } \\
\text { Yakima Indian Nation } \\
\text { (1992) }\end{array}$ & $\begin{array}{l}502 \text { U.S. } \\
251,256+\end{array}$ \\
\hline 290 & & 9 June 1855 & 698 & $\begin{array}{l}12 \text { Stat. } \\
951\end{array}$ & $\begin{array}{l}\text { Atkinson Trading Co. } \\
\text { v. Shirley (2001) }\end{array}$ & $\begin{array}{l}532 \text { U.S. } \\
645,658\end{array}$ \\
\hline 290 & & 9 June 1855 & 698 & $\begin{array}{l}12 \text { Stat. } \\
951\end{array}$ & $\begin{array}{l}\text { Idaho v. United States } \\
\text { (2001) }\end{array}$ & $\begin{array}{l}533 \text { U.S. } \\
262,274\end{array}$ \\
\hline 290 & & 9 June 1855 & 698 & $\begin{array}{l}12 \text { Stat. } \\
951\end{array}$ & $\begin{array}{l}\text { United States v. } \\
\text { Winans (1905) }\end{array}$ & $\begin{array}{l}198 \text { U.S. } \\
371,377(1)\end{array}$ \\
\hline 290 & & 9 June 1855 & 698 & $\begin{array}{l}12 \text { Stat. } \\
951\end{array}$ & $\begin{array}{l}\text { Northern Pacific } \\
\text { Railway Co. v. United } \\
\text { States (1913) }\end{array}$ & $\begin{array}{l}227 \text { U.S. } \\
355,356(1)\end{array}$ \\
\hline 290 & & 9 June 1855 & 698 & $\begin{array}{l}12 \text { Stat. } \\
951\end{array}$ & $\begin{array}{l}\text { United States v. } \\
\text { Winans }(1905)\end{array}$ & $\begin{array}{l}198 \text { U.S. } \\
371,377(2)\end{array}$ \\
\hline 290 & & 9 June 1855 & 698 & $\begin{array}{l}12 \text { Stat. } \\
951\end{array}$ & $\begin{array}{l}\text { United States v. } \\
\text { Sutton (1909) }\end{array}$ & $\begin{array}{l}215 \text { U.S. } \\
291,293(2)\end{array}$ \\
\hline 290 & & 9 June 1855 & 698 & $\begin{array}{l}12 \text { Stat. } \\
951\end{array}$ & $\begin{array}{l}\text { Northern Pacific } \\
\text { Railway Co. v. United } \\
\text { States (1913) }\end{array}$ & $\begin{array}{l}227 \text { U.S. } \\
355,356(2)\end{array}$ \\
\hline
\end{tabular}


Table 1 (continued)

\begin{tabular}{|c|c|c|c|c|c|c|}
\hline $\begin{array}{l}\text { Ratified } \\
\text { treaty } \\
\text { number }\end{array}$ & $\begin{array}{l}\text { Signatory } \\
\text { tribe(s) }\end{array}$ & $\begin{array}{l}\text { Treaty } \\
\text { signing date }\end{array}$ & $\begin{array}{l}\text { Kappler } \\
\text { page } \\
\text { number }\end{array}$ & $\begin{array}{l}\text { Statutes at } \\
\text { Large or an } \\
\text { alternative } \\
\text { source }\end{array}$ & Case title & U.S. reports \\
\hline 290 & & 9 June 1855 & 698 & $\begin{array}{l}12 \text { Stat. } \\
951\end{array}$ & $\begin{array}{l}\text { United States v. } \\
\text { Winans (1905) }\end{array}$ & $\begin{array}{l}198 \text { U.S. } \\
371,378(3)\end{array}$ \\
\hline 290 & & 9 June 1855 & 698 & $\begin{array}{l}12 \text { Stat. } \\
951\end{array}$ & $\begin{array}{l}\text { Seufert Bros. Co. v. } \\
\text { United States (1919) }\end{array}$ & $\begin{array}{l}249 \text { U.S. } \\
194,194(3)\end{array}$ \\
\hline 290 & & 9 June 1855 & 698 & $\begin{array}{l}12 \text { Stat. } \\
951\end{array}$ & $\begin{array}{l}\text { Tulee v. Washington } \\
\text { (1942) }\end{array}$ & $\begin{array}{l}315 \text { U.S. } \\
681,683(3)\end{array}$ \\
\hline 290 & & 9 June 1855 & 698 & $\begin{array}{l}12 \text { Stat. } \\
951\end{array}$ & $\begin{array}{l}\text { Minnesota v. Mille } \\
\text { Lacs Band of } \\
\text { Chippewa Indians } \\
\text { (1999) }\end{array}$ & $\begin{array}{l}526 \text { U.S. } \\
172,172(3)\end{array}$ \\
\hline 290 & & 9 June 1855 & 698 & $\begin{array}{l}12 \text { Stat. } \\
951\end{array}$ & $\begin{array}{l}\text { Minnesota v. Mille } \\
\text { Lacs Band of } \\
\text { Chippewa Indians } \\
\text { (1999) }\end{array}$ & $\begin{array}{l}526 \text { U.S. } \\
172,223(3)\end{array}$ \\
\hline 290 & & 9 June 1855 & 698 & $\begin{array}{l}12 \text { Stat. } \\
951\end{array}$ & $\begin{array}{l}\text { United States v. } \\
\text { Sutton (1909) }\end{array}$ & $\begin{array}{l}215 \text { U.S. } \\
291,294(4)\end{array}$ \\
\hline 290 & & 9 June 1855 & 698 & $\begin{array}{l}12 \text { Stat. } \\
951\end{array}$ & $\begin{array}{l}\text { United States v. } \\
\text { Winans (1905) }\end{array}$ & $\begin{array}{l}198 \text { U.S. } \\
371,378(10)\end{array}$ \\
\hline 291 & Nez Perce & 11 June 1855 & 702 & $\begin{array}{l}12 \text { Stat. } \\
957\end{array}$ & $\begin{array}{l}\text { Robinson v. Caldwell } \\
\text { (1897) }\end{array}$ & $\begin{array}{l}165 \text { U.S. } \\
359,359\end{array}$ \\
\hline 292 & $\begin{array}{l}\text { Choctaw; } \\
\text { Chickasaw }\end{array}$ & 22 June 1855 & 706 & $\begin{array}{l}11 \text { Stat. } \\
611\end{array}$ & $\begin{array}{l}\text { Choctaw Nation } v . \\
\text { United States (1886) }\end{array}$ & 119 U.S. 1, 1 \\
\hline 292 & & 22 June 1855 & 706 & $\begin{array}{l}11 \text { Stat. } \\
611\end{array}$ & $\begin{array}{l}\text { Gilfillian v. McKee } \\
\text { (1895) }\end{array}$ & $\begin{array}{l}159 \text { U.S. } \\
303,307\end{array}$ \\
\hline 292 & & 22 June 1855 & 706 & $\begin{array}{l}11 \text { Stat. } \\
611\end{array}$ & $\begin{array}{l}\text { McKee v. Lamon } \\
(1895)\end{array}$ & $\begin{array}{l}159 \text { U.S. } \\
317,323\end{array}$ \\
\hline 292 & & 22 June 1855 & 706 & $\begin{array}{l}11 \text { Stat. } \\
611\end{array}$ & $\begin{array}{l}\text { United States v. Texas } \\
(1896)\end{array}$ & $\begin{array}{l}162 \text { U.S. } \\
1,63\end{array}$ \\
\hline 292 & & 22 June 1855 & 706 & $\begin{array}{l}11 \text { Stat. } \\
611\end{array}$ & $\begin{array}{l}\text { United States v. } \\
\text { Choctaw Nation } \\
(1900)\end{array}$ & $\begin{array}{l}179 \text { U.S. } \\
494,518\end{array}$ \\
\hline 292 & & 22 June 1855 & 706 & $\begin{array}{l}11 \text { Stat. } \\
611\end{array}$ & $\begin{array}{l}\text { United States v. } \\
\text { Choctaw Nation } \\
(1904)\end{array}$ & $\begin{array}{l}193 \text { U.S. } \\
115,116\end{array}$ \\
\hline 292 & & 22 June 1855 & 706 & $\begin{array}{l}11 \text { Stat. } \\
611\end{array}$ & $\begin{array}{l}\text { Fleming v. McCurtain } \\
\text { (1909) }\end{array}$ & $\begin{array}{l}215 \text { U.S. } \\
56,62\end{array}$ \\
\hline 292 & & 22 June 1855 & 706 & $\begin{array}{l}11 \text { Stat. } \\
611\end{array}$ & $\begin{array}{l}\text { Heckman v. United } \\
\text { States (1912) }\end{array}$ & $\begin{array}{l}224 \text { U.S. } \\
413,420+\end{array}$ \\
\hline 292 & & 22 June 1855 & 706 & $\begin{array}{l}11 \text { Stat. } \\
611\end{array}$ & $\begin{array}{l}\text { Mullen v. United } \\
\text { States (1912) }\end{array}$ & $\begin{array}{l}224 \text { U.S. } \\
448,451\end{array}$ \\
\hline 292 & & 22 June 1855 & 706 & $\begin{array}{l}11 \text { Stat. } \\
611\end{array}$ & $\begin{array}{l}\text { Johnson v. Riddle } \\
\text { (1916) }\end{array}$ & $\begin{array}{l}240 \text { U.S. } \\
467,475\end{array}$ \\
\hline
\end{tabular}


Table 1 (continued)

\begin{tabular}{|c|c|c|c|c|c|c|}
\hline $\begin{array}{l}\text { Ratified } \\
\text { treaty } \\
\text { number }\end{array}$ & $\begin{array}{l}\text { Signatory } \\
\text { tribe(s) }\end{array}$ & $\begin{array}{l}\text { Treaty } \\
\text { signing date }\end{array}$ & $\begin{array}{l}\text { Kappler } \\
\text { page } \\
\text { number }\end{array}$ & $\begin{array}{l}\text { Statutes at } \\
\text { Large or an } \\
\text { alternative } \\
\text { source }\end{array}$ & Case title & U.S. reports \\
\hline 292 & & 22 June 1855 & 706 & $\begin{array}{l}11 \text { Stat. } \\
611\end{array}$ & $\begin{array}{l}\text { Heirs of Garland v. } \\
\text { Choctaw Nation } \\
\text { (1921) }\end{array}$ & $\begin{array}{l}256 \text { U.S. } \\
439,443\end{array}$ \\
\hline 292 & & 22 June 1855 & 706 & $\begin{array}{l}11 \text { Stat. } \\
611\end{array}$ & $\begin{array}{l}\text { Oklahoma v. Texas } \\
\text { (1926) }\end{array}$ & $\begin{array}{l}272 \text { U.S. } \\
21,26+\end{array}$ \\
\hline 292 & & 22 June 1855 & 706 & $\begin{array}{l}11 \text { Stat. } \\
611\end{array}$ & $\begin{array}{l}\text { Klamath and Moadoc } \\
\text { Tribes of Indians v. } \\
\text { United States }(1935)\end{array}$ & $\begin{array}{l}296 \text { U.S. } \\
244,251\end{array}$ \\
\hline 292 & & 22 June 1855 & 706 & $\begin{array}{l}11 \text { Stat. } \\
611\end{array}$ & $\begin{array}{l}\text { Noble v. Oklahoma } \\
\text { City (1936) }\end{array}$ & $\begin{array}{l}297 \text { U.S. } \\
481,483\end{array}$ \\
\hline 292 & & 22 June 1855 & 706 & $\begin{array}{l}11 \text { Stat. } \\
611\end{array}$ & $\begin{array}{l}\text { Choctaw Nation v. } \\
\text { Oklahoma (1970) }\end{array}$ & $\begin{array}{l}397 \text { U.S. } \\
620,626\end{array}$ \\
\hline 292 & & 22 June 1855 & 706 & $\begin{array}{l}11 \text { Stat. } \\
611\end{array}$ & $\begin{array}{l}\text { United States v. } \\
\text { John (1978) }\end{array}$ & $\begin{array}{l}437 \text { U.S. } \\
634,642\end{array}$ \\
\hline 292 & & 22 June 1855 & 706 & $\begin{array}{l}11 \text { Stat. } \\
611\end{array}$ & $\begin{array}{l}\text { United States v. } \\
\text { Choctaw Nation } \\
(1900)\end{array}$ & $\begin{array}{l}179 \text { U.S. } \\
494,519(1)\end{array}$ \\
\hline 292 & & 22 June 1855 & 706 & $\begin{array}{l}11 \text { Stat. } \\
611\end{array}$ & $\begin{array}{l}\text { Oklahoma v. Texas } \\
\text { (1926) }\end{array}$ & $\begin{array}{l}272 \text { U.S. } \\
21,26(1)\end{array}$ \\
\hline 292 & & 22 June 1855 & 706 & $\begin{array}{l}11 \text { Stat. } \\
611\end{array}$ & $\begin{array}{l}\text { United States v. } \\
\text { Choctaw Nation } \\
(1900)\end{array}$ & $\begin{array}{l}179 \text { U.S. } \\
494,520(2)\end{array}$ \\
\hline 292 & & 22 June 1855 & 706 & $\begin{array}{l}11 \text { Stat. } \\
611\end{array}$ & $\begin{array}{l}\text { United States v. } \\
\text { Choctaw Nation } \\
(1900)\end{array}$ & $\begin{array}{l}179 \text { U.S. } \\
494,520(3)\end{array}$ \\
\hline 292 & & 22 June 1855 & 706 & $\begin{array}{l}11 \text { Stat. } \\
611\end{array}$ & $\begin{array}{l}\text { United States v. } \\
\text { Choctaw Nation } \\
(1900)\end{array}$ & $\begin{array}{l}179 \text { U.S. } \\
494,520(4)\end{array}$ \\
\hline 292 & & 22 June 1855 & 706 & $\begin{array}{l}11 \text { Stat. } \\
611\end{array}$ & $\begin{array}{l}\text { United States v. } \\
\text { Choctaw Nation } \\
(1900)\end{array}$ & $\begin{array}{l}179 \text { U.S. } \\
494,520(5)\end{array}$ \\
\hline 292 & & 22 June 1855 & 706 & $\begin{array}{l}11 \text { Stat. } \\
611\end{array}$ & $\begin{array}{l}\text { United States v. } \\
\text { Choctaw Nation } \\
(1900)\end{array}$ & $\begin{array}{l}179 \text { U.S. } \\
494,520(6)\end{array}$ \\
\hline 292 & & 22 June 1855 & 706 & $\begin{array}{l}11 \text { Stat. } \\
611\end{array}$ & Roff v. Burney (1897) & $\begin{array}{l}168 \text { U.S. } \\
218,220(7)\end{array}$ \\
\hline 292 & & 22 June 1855 & 706 & $\begin{array}{l}11 \text { Stat. } \\
611\end{array}$ & $\begin{array}{l}\text { United States v. } \\
\text { Choctaw Nation } \\
(1900)\end{array}$ & $\begin{array}{l}179 \text { U.S. } \\
494,520(7)\end{array}$ \\
\hline 292 & & 22 June 1855 & 706 & $\begin{array}{l}11 \text { Stat. } \\
611\end{array}$ & $\begin{array}{l}\text { Morris v. Hitchcock } \\
\text { (1904) }\end{array}$ & $\begin{array}{l}194 \text { U.S. } \\
384,389(7)\end{array}$ \\
\hline 292 & & 22 June 1855 & 706 & $\begin{array}{l}11 \text { Stat. } \\
611\end{array}$ & $\begin{array}{l}\text { Merrion v. Jicarilla } \\
\text { Apache Tribe (1982) }\end{array}$ & $\begin{array}{l}455 \text { U.S. } \\
130,171(7)\end{array}$ \\
\hline 292 & & 22 June 1855 & 706 & $\begin{array}{l}11 \text { Stat. } \\
611\end{array}$ & $\begin{array}{l}\text { Nevada v. Hicks } \\
\text { (2001) }\end{array}$ & $\begin{array}{l}533 \text { U.S. } \\
353,382(7)\end{array}$ \\
\hline
\end{tabular}


Table 1 (continued)

\begin{tabular}{|c|c|c|c|c|c|c|}
\hline $\begin{array}{l}\text { Ratified } \\
\text { treaty } \\
\text { number }\end{array}$ & $\begin{array}{l}\text { Signatory } \\
\text { tribe(s) }\end{array}$ & $\begin{array}{l}\text { Treaty } \\
\text { signing date }\end{array}$ & $\begin{array}{l}\text { Kappler } \\
\text { page } \\
\text { number }\end{array}$ & $\begin{array}{l}\text { Statutes at } \\
\text { Large or an } \\
\text { alternative } \\
\text { source }\end{array}$ & Case title & U.S. reports \\
\hline 292 & & 22 June 1855 & 706 & $\begin{array}{l}11 \text { Stat. } \\
611\end{array}$ & $\begin{array}{l}\text { United States v. } \\
\text { Choctaw Nation } \\
(1900)\end{array}$ & $\begin{array}{l}179 \text { U.S. } \\
494,520(8)\end{array}$ \\
\hline 292 & & 22 June 1855 & 706 & $\begin{array}{l}11 \text { Stat. } \\
611\end{array}$ & $\begin{array}{l}\text { United States v. } \\
\text { Choctaw Nation } \\
(1900)\end{array}$ & $\begin{array}{l}179 \text { U.S. } \\
494,520(9)\end{array}$ \\
\hline 292 & & 22 June 1855 & 706 & $\begin{array}{l}11 \text { Stat. } \\
611\end{array}$ & $\begin{array}{l}\text { United States v. } \\
\text { Choctaw Nation } \\
(1900)\end{array}$ & $\begin{array}{l}179 \text { U.S. } \\
494,520(10)\end{array}$ \\
\hline 292 & & 22 June 1855 & 706 & $\begin{array}{l}11 \text { Stat. } \\
611\end{array}$ & $\begin{array}{l}\text { Choctaw Nation v. } \\
\text { United States (1886) }\end{array}$ & $\begin{array}{l}119 \text { U.S. } \\
1,43(11)\end{array}$ \\
\hline 292 & & 22 June 1855 & 706 & $\begin{array}{l}11 \text { Stat. } \\
611\end{array}$ & $\begin{array}{l}\text { Choctaw Nation v. } \\
\text { United States }(1886)\end{array}$ & $\begin{array}{l}119 \text { U.S. } \\
1,22(12)\end{array}$ \\
\hline 292 & & 22 June 1855 & 706 & $\begin{array}{l}11 \text { Stat. } \\
611\end{array}$ & $\begin{array}{l}\text { Choctaw Nation } v . \\
\text { United States }(1886)\end{array}$ & $\begin{array}{l}119 \text { U.S. } \\
1,34(13)\end{array}$ \\
\hline 292 & & 22 June 1855 & 706 & $\begin{array}{l}11 \text { Stat. } \\
611\end{array}$ & $\begin{array}{l}\text { Choctaw Nation } v . \\
\text { United States }(1886)\end{array}$ & $\begin{array}{l}119 \text { U.S. } \\
1,13(14)\end{array}$ \\
\hline 292 & & 22 June 1855 & 706 & $\begin{array}{l}11 \text { Stat. } \\
611\end{array}$ & $\begin{array}{l}\text { Morris v. Hitchcock } \\
\text { (1904) }\end{array}$ & $\begin{array}{l}194 \text { U.S. } \\
\text { 384, 389(14) }\end{array}$ \\
\hline 293 & $\begin{array}{l}\text { Walla Walla; } \\
\text { Wasco }\end{array}$ & 25 June 1855 & 714 & $\begin{array}{l}12 \text { Stat. } \\
963\end{array}$ & $\begin{array}{l}\text { Seufert Bros. Co. v. } \\
\text { United States (1919) }\end{array}$ & $\begin{array}{l}249 \text { U.S. } \\
194,196\end{array}$ \\
\hline 293 & & 25 June 1855 & 714 & $\begin{array}{l}12 \text { Stat. } \\
963\end{array}$ & $\begin{array}{l}\text { Federal Power } \\
\text { Commission v. } \\
\text { Oregon }(1955)\end{array}$ & $\begin{array}{l}349 \text { U.S. } \\
435,438\end{array}$ \\
\hline 293 & & 25 June 1855 & 714 & $\begin{array}{l}12 \text { Stat. } \\
963\end{array}$ & $\begin{array}{l}\text { Federal Power } \\
\text { Commission v. } \\
\text { Oregon (1955) }\end{array}$ & $\begin{array}{l}349 \text { U.S. } \\
435,438(1)\end{array}$ \\
\hline 294 & $\begin{array}{l}\text { Quinault; } \\
\text { Quileute }\end{array}$ & $\begin{array}{l}1 \text { July } 1855, \\
25 \text { January } \\
1856\end{array}$ & 719 & $\begin{array}{l}12 \text { Stat. } \\
971\end{array}$ & $\begin{array}{l}\text { United States v. } \\
\text { Payne (1924) }\end{array}$ & $\begin{array}{l}264 \text { U.S. } \\
446,446\end{array}$ \\
\hline 294 & & $\begin{array}{l}1 \text { July } 1855, \\
25 \text { January } \\
1856\end{array}$ & 719 & $\begin{array}{l}12 \text { Stat. } \\
971\end{array}$ & $\begin{array}{l}\text { Halbert v. United } \\
\text { States }(1931)\end{array}$ & $\begin{array}{l}283 \text { U.S. } \\
753,756\end{array}$ \\
\hline 294 & & $\begin{array}{l}1 \text { July } 1855, \\
25 \text { January } \\
1856\end{array}$ & 719 & $\begin{array}{l}12 \text { Stat. } \\
971\end{array}$ & $\begin{array}{l}\text { Squire v. Capoeman } \\
(1956)\end{array}$ & $\begin{array}{l}351 \text { U.S. } \\
1,1\end{array}$ \\
\hline 294 & & $\begin{array}{l}1 \text { July } 1855, \\
25 \text { January } \\
1856\end{array}$ & 719 & $\begin{array}{l}12 \text { Stat. } \\
971\end{array}$ & $\begin{array}{l}\text { Metlakatla Indian } \\
\text { Community v. Egan } \\
\text { (1962) }\end{array}$ & $\begin{array}{l}369 \text { U.S. } \\
45,52\end{array}$ \\
\hline
\end{tabular}


Table 1 (continued)

\begin{tabular}{|c|c|c|c|c|c|c|}
\hline $\begin{array}{l}\text { Ratified } \\
\text { treaty } \\
\text { number }\end{array}$ & $\begin{array}{l}\text { Signatory } \\
\text { tribe(s) }\end{array}$ & $\begin{array}{l}\text { Treaty } \\
\text { signing date }\end{array}$ & $\begin{array}{l}\text { Kappler } \\
\text { page } \\
\text { number }\end{array}$ & $\begin{array}{l}\text { Statutes at } \\
\text { Large or an } \\
\text { alternative } \\
\text { source }\end{array}$ & Case title & U.S. reports \\
\hline 294 & & $\begin{array}{l}1 \text { July } 1855, \\
25 \text { January } \\
1856\end{array}$ & 719 & $\begin{array}{l}12 \text { Stat. } \\
971\end{array}$ & $\begin{array}{l}\text { Washington } v . \\
\text { Washington State } \\
\text { Commercial } \\
\text { Passenger Fishing } \\
\text { Vessel Association } \\
(1979)\end{array}$ & $\begin{array}{l}443 \text { U.S. } \\
658,662\end{array}$ \\
\hline 294 & & $\begin{array}{l}1 \text { July } 1855 \text {, } \\
25 \text { January } \\
1856\end{array}$ & 719 & $\begin{array}{l}12 \text { Stat. } \\
971\end{array}$ & $\begin{array}{l}\text { United States v. } \\
\text { Mitchell (1980) }\end{array}$ & $\begin{array}{l}445 \text { U.S. } \\
535,546\end{array}$ \\
\hline 294 & & $\begin{array}{l}1 \text { July } 1855 \text {, } \\
25 \text { January } \\
1856\end{array}$ & 719 & $\begin{array}{l}12 \text { Stat. } \\
971\end{array}$ & $\begin{array}{l}\text { United States v. } \\
\text { Mitchell (1983) }\end{array}$ & $\begin{array}{l}463 \text { U.S. } \\
206,208\end{array}$ \\
\hline 294 & & $\begin{array}{l}1 \text { July } 1855 \text {, } \\
25 \text { January } \\
1856\end{array}$ & 719 & $\begin{array}{l}12 \text { Stat. } \\
971\end{array}$ & $\begin{array}{l}\text { United States v. Payne } \\
\text { (1924) }\end{array}$ & $\begin{array}{l}264 \text { U.S. } \\
446,447(2)\end{array}$ \\
\hline 294 & & $\begin{array}{l}1 \text { July } 1855, \\
25 \text { January } \\
1856\end{array}$ & 719 & $\begin{array}{l}12 \text { Stat. } \\
971\end{array}$ & $\begin{array}{l}\text { Squire v. Capoeman } \\
\text { (1956) }\end{array}$ & $\begin{array}{l}351 \text { U.S. } \\
1,3(2)\end{array}$ \\
\hline 294 & & $\begin{array}{l}\text { 1 July } 1855 \text {, } \\
25 \text { January } \\
1856\end{array}$ & 719 & $\begin{array}{l}12 \text { Stat. } \\
971\end{array}$ & $\begin{array}{l}\text { United States v. Payne } \\
\text { (1924) }\end{array}$ & $\begin{array}{l}264 \text { U.S. } \\
446,447(5)\end{array}$ \\
\hline 294 & & $\begin{array}{l}1 \text { July } 1855 \text {, } \\
25 \text { January } \\
1856\end{array}$ & 719 & $\begin{array}{l}12 \text { Stat. } \\
971\end{array}$ & $\begin{array}{l}\text { United States v. Payne } \\
\text { (1924) }\end{array}$ & $\begin{array}{l}264 \text { U.S. } \\
446,447(6)\end{array}$ \\
\hline 295 & $\begin{array}{l}\text { Flathead; } \\
\text { Kutenai; } \\
\text { Upper Pend } \\
\text { d'Oreille }\end{array}$ & 16 July 1855 & 722 & $\begin{array}{l}12 \text { Stat. } \\
975\end{array}$ & $\begin{array}{l}\text { Clairmont v. United } \\
\text { States (1912) }\end{array}$ & $\begin{array}{l}225 \text { U.S. } \\
551,555\end{array}$ \\
\hline 295 & & 16 July 1855 & 722 & $\begin{array}{l}12 \text { Stat. } \\
975\end{array}$ & $\begin{array}{l}\text { Moe v. Confederated } \\
\text { Salish and Kootenai } \\
\text { Tribes of Flathead } \\
\text { Reservation (1976) }\end{array}$ & $\begin{array}{l}425 \text { U.S. } \\
463,474\end{array}$ \\
\hline 295 & & 16 July 1855 & 722 & $\begin{array}{l}12 \text { Stat. } \\
975\end{array}$ & $\begin{array}{l}\text { Pronovost } v . \text { United } \\
\text { States (1914) }\end{array}$ & $\begin{array}{l}232 \text { U.S. } \\
487,489(2)\end{array}$ \\
\hline 297 & $\begin{array}{l}\text { Chippewa: } \\
\text { Sault Ste. } \\
\text { Marie }\end{array}$ & $\begin{array}{l}2 \text { August } \\
1855\end{array}$ & 732 & $\begin{array}{l}11 \text { Stat. } \\
631\end{array}$ & $\begin{array}{l}\text { Spalding v. Chandler } \\
\text { (1896) }\end{array}$ & $\begin{array}{l}160 \text { U.S. } \\
394,395\end{array}$ \\
\hline 297 & & $\begin{array}{l}2 \text { August } \\
1855\end{array}$ & 732 & $\begin{array}{l}11 \text { Stat. } \\
631\end{array}$ & $\begin{array}{l}\text { Minnesota v. Mille } \\
\text { Lacs Band of } \\
\text { Chippewa Indians } \\
(1999)\end{array}$ & $\begin{array}{l}526 \text { U.S. } \\
172,172\end{array}$ \\
\hline 297 & & $\begin{array}{l}2 \text { August } \\
1855\end{array}$ & 732 & $\begin{array}{l}11 \text { Stat. } \\
631\end{array}$ & $\begin{array}{l}\text { Minnesota v. Mille } \\
\text { Lacs Band of } \\
\text { Chippewa Indians } \\
\text { (1999) }\end{array}$ & $\begin{array}{l}526 \text { U.S. } \\
172,195\end{array}$ \\
\hline
\end{tabular}


Table 1 (continued)

\begin{tabular}{|c|c|c|c|c|c|c|}
\hline $\begin{array}{l}\text { Ratified } \\
\text { treaty } \\
\text { number }\end{array}$ & $\begin{array}{l}\text { Signatory } \\
\text { tribe(s) }\end{array}$ & $\begin{array}{l}\text { Treaty } \\
\text { signing date }\end{array}$ & $\begin{array}{l}\text { Kappler } \\
\text { page } \\
\text { number }\end{array}$ & $\begin{array}{l}\text { Statutes at } \\
\text { Large or an } \\
\text { alternative } \\
\text { source }\end{array}$ & Case title & U.S. reports \\
\hline 297 & & $\begin{array}{l}2 \text { August } \\
1855\end{array}$ & 732 & $\begin{array}{l}11 \text { Stat. } \\
631\end{array}$ & $\begin{array}{l}\text { Minnesota v. Mille } \\
\text { Lacs Band of } \\
\text { Chippewa Indians } \\
\text { (1999) }\end{array}$ & $\begin{array}{l}526 \text { U.S. } \\
172,195(1)+\end{array}$ \\
\hline 298 & $\begin{array}{l}\text { Chippewa: } \\
\text { Saginaw, } \\
\text { Swan Creek } \\
\text { and Black } \\
\text { River }\end{array}$ & $\begin{array}{l}2 \text { August } \\
1855\end{array}$ & 733 & $\begin{array}{l}11 \text { Stat. } \\
633\end{array}$ & $\begin{array}{l}\text { United States v. } \\
\text { Holliday (1866) }\end{array}$ & $\begin{array}{l}70 \text { U.S. } \\
407,409\end{array}$ \\
\hline 299 & $\begin{array}{l}\text { Blackfeet: } \\
\text { Piegan and } \\
\text { Blood; Gros } \\
\text { Ventre; } \\
\text { Flathead; } \\
\text { Upper Pend } \\
\text { d'Oreille; } \\
\text { Kutenai; } \\
\text { Nez Perce }\end{array}$ & $\begin{array}{l}17 \text { October } \\
1855\end{array}$ & 736 & $\begin{array}{l}11 \text { Stat. } \\
657\end{array}$ & $\begin{array}{l}\text { British-American Oil } \\
\text { Producing Co. v. } \\
\text { Board of Equalization } \\
\text { (1936) }\end{array}$ & $\begin{array}{l}299 \text { U.S. } \\
159,162\end{array}$ \\
\hline 299 & & $\begin{array}{l}17 \text { October } \\
1855\end{array}$ & 736 & $\begin{array}{l}11 \text { Stat. } \\
657\end{array}$ & $\begin{array}{l}\text { United States v. } \\
\text { Northern Pacific } \\
\text { Railway Co. (1940) }\end{array}$ & $\begin{array}{l}311 \text { U.S. } \\
317,347\end{array}$ \\
\hline 301 & $\begin{array}{l}\text { Stockbridge; } \\
\text { Munsee }\end{array}$ & $\begin{array}{l}5 \text { February } \\
1856\end{array}$ & 742 & $\begin{array}{l}11 \text { Stat. } \\
663\end{array}$ & Elk v. Wilkins (1884) & $\begin{array}{l}112 \text { U.S. } \\
94,100\end{array}$ \\
\hline 301 & & $\begin{array}{l}5 \text { February } \\
1856\end{array}$ & 742 & $\begin{array}{l}11 \text { Stat. } \\
663\end{array}$ & $\begin{array}{l}\text { New York Indians } v . \\
\text { United States }(1898)\end{array}$ & $\begin{array}{l}170 \text { U.S. } \\
1,12\end{array}$ \\
\hline 301 & & $\begin{array}{l}5 \text { February } \\
1856\end{array}$ & 742 & $\begin{array}{l}11 \text { Stat. } \\
663\end{array}$ & $\begin{array}{l}\text { United States v. Paine } \\
\text { Lumber Co. (1907) }\end{array}$ & $\begin{array}{l}206 \text { U.S. } \\
467,467\end{array}$ \\
\hline 301 & & $\begin{array}{l}5 \text { February } \\
1856\end{array}$ & 742 & $\begin{array}{l}11 \text { Stat. } \\
663\end{array}$ & $\begin{array}{l}\text { United States v. } \\
\text { Morrison }(1916)\end{array}$ & $\begin{array}{l}240 \text { U.S. } \\
192,206\end{array}$ \\
\hline 301 & & $\begin{array}{l}5 \text { February } \\
1856\end{array}$ & 742 & $\begin{array}{l}11 \text { Stat. } \\
663\end{array}$ & $\begin{array}{l}\text { United States v. Paine } \\
\text { Lumber Co. (1907) }\end{array}$ & $\begin{array}{l}206 \text { U.S. } \\
467,471(11)\end{array}$ \\
\hline 302 & Menominee & $\begin{array}{l}11 \text { February } \\
1856\end{array}$ & 755 & $\begin{array}{l}11 \text { Stat. } \\
679\end{array}$ & $\begin{array}{l}\text { New York Indians v. } \\
\text { United States (1898) }\end{array}$ & $\begin{array}{l}170 \text { U.S. } \\
1,12\end{array}$ \\
\hline 303 & $\begin{array}{l}\text { Creek; } \\
\text { Seminole }\end{array}$ & $\begin{array}{l}7 \text { August } \\
1856\end{array}$ & 756 & $\begin{array}{l}11 \text { Stat. } \\
699\end{array}$ & $\begin{array}{l}\text { Heckman v. United } \\
\text { States (1912) }\end{array}$ & $\begin{array}{l}224 \text { U.S. } \\
413,420+\end{array}$ \\
\hline 303 & & $\begin{array}{l}7 \text { August } \\
1856\end{array}$ & 756 & $\begin{array}{l}11 \text { Stat. } \\
699\end{array}$ & $\begin{array}{l}\text { Goat v. United States } \\
\text { (1912) }\end{array}$ & $\begin{array}{l}224 \text { U.S. } \\
458,461\end{array}$ \\
\hline 303 & & $\begin{array}{l}7 \text { August } \\
1856\end{array}$ & 756 & $\begin{array}{l}11 \text { Stat. } \\
699\end{array}$ & $\begin{array}{l}\text { Noble v. Oklahoma } \\
\text { City (1936) }\end{array}$ & $\begin{array}{l}297 \text { U.S. } \\
481,482\end{array}$ \\
\hline 303 & & $\begin{array}{l}7 \text { August } \\
1856\end{array}$ & 756 & $\begin{array}{l}11 \text { Stat. } \\
699\end{array}$ & $\begin{array}{l}\text { Noble v. Oklahoma } \\
\text { City (1936) }\end{array}$ & $\begin{array}{l}297 \text { U.S. } \\
481,482(2)\end{array}$ \\
\hline 303 & & $\begin{array}{l}7 \text { August } \\
1856\end{array}$ & 756 & $\begin{array}{l}11 \text { Stat. } \\
699\end{array}$ & $\begin{array}{l}\text { Woodward v. De } \\
\text { Graffenried (1915) }\end{array}$ & $\begin{array}{l}238 \text { U.S. } \\
284,294(4)\end{array}$ \\
\hline
\end{tabular}


Table 1 (continued)

\begin{tabular}{|c|c|c|c|c|c|c|}
\hline $\begin{array}{l}\text { Ratified } \\
\text { treaty } \\
\text { number }\end{array}$ & $\begin{array}{l}\text { Signatory } \\
\text { tribe(s) }\end{array}$ & $\begin{array}{l}\text { Treaty } \\
\text { signing date }\end{array}$ & $\begin{array}{l}\text { Kappler } \\
\text { page } \\
\text { number }\end{array}$ & $\begin{array}{l}\text { Statutes at } \\
\text { Large or an } \\
\text { alternative } \\
\text { source }\end{array}$ & Case title & U.S. reports \\
\hline 303 & & $\begin{array}{l}7 \text { August } \\
1856\end{array}$ & 756 & $\begin{array}{l}11 \text { Stat. } \\
699\end{array}$ & $\begin{array}{l}\text { Oklahoma Tax } \\
\text { Commission v. United } \\
\text { States (1943) }\end{array}$ & $\begin{array}{l}319 \text { U.S. } \\
598,616(4)\end{array}$ \\
\hline 303 & & $\begin{array}{l}7 \text { August } \\
1856\end{array}$ & 756 & $\begin{array}{l}11 \text { Stat. } \\
699\end{array}$ & $\begin{array}{l}\text { United States v. } \\
\text { Seminole Nation } \\
\text { (1937) }\end{array}$ & $\begin{array}{l}299 \text { U.S. } \\
417,425(8)\end{array}$ \\
\hline 303 & & $\begin{array}{l}7 \text { August } \\
1856\end{array}$ & 756 & $\begin{array}{l}11 \text { Stat. } \\
699\end{array}$ & $\begin{array}{l}\text { Seminole Nation v. } \\
\text { United States (1942) }\end{array}$ & $\begin{array}{l}316 \text { U.S. } \\
286,286(8)\end{array}$ \\
\hline 303 & & $\begin{array}{l}7 \text { August } \\
1856\end{array}$ & 756 & $\begin{array}{l}11 \text { Stat. } \\
699\end{array}$ & $\begin{array}{l}\text { Woodward v. De } \\
\text { Graffenried (1915) }\end{array}$ & $\begin{array}{l}238 \text { U.S. } \\
284,294(15)\end{array}$ \\
\hline 303 & & $\begin{array}{l}7 \text { August } \\
1856\end{array}$ & 756 & $\begin{array}{l}11 \text { Stat. } \\
699\end{array}$ & $\begin{array}{l}\text { Merrion v. Jicarilla } \\
\text { Apache Tribe (1982) }\end{array}$ & $\begin{array}{l}455 \text { U.S. } \\
130,171(15)\end{array}$ \\
\hline 303 & & $\begin{array}{l}7 \text { August } \\
1856\end{array}$ & 756 & $\begin{array}{l}11 \text { Stat. } \\
699\end{array}$ & $\begin{array}{l}\text { Nevada v. Hicks } \\
\text { (2001) }\end{array}$ & $\begin{array}{l}533 \text { U.S. } \\
353,382(15)\end{array}$ \\
\hline 305 & $\begin{array}{l}\text { Seneca: } \\
\text { Tonawanda }\end{array}$ & $\begin{array}{l}5 \text { November } \\
1857\end{array}$ & 767 & $\begin{array}{l}11 \text { Stat. } \\
735,12 \\
\text { Stat. } 991\end{array}$ & $\begin{array}{l}\text { New York Indians v. } \\
\text { United States (1898) }\end{array}$ & $\begin{array}{l}170 \text { U.S. } \\
1,30\end{array}$ \\
\hline 307 & $\begin{array}{l}\text { Sioux: } \\
\text { Yankton }\end{array}$ & 19 April 1858 & 776 & $\begin{array}{l}11 \text { Stat. } \\
743\end{array}$ & $\begin{array}{l}\text { United States } v . \\
\text { Carpenter }(1884)\end{array}$ & $\begin{array}{l}111 \text { U.S. } \\
347,347\end{array}$ \\
\hline 307 & & 19 April 1858 & 776 & $\begin{array}{l}11 \text { Stat. } \\
743\end{array}$ & $\begin{array}{l}\text { Perrin v. United } \\
\text { States (1914) }\end{array}$ & $\begin{array}{l}232 \text { U.S. } \\
478,480\end{array}$ \\
\hline 307 & & 19 April 1858 & 776 & $\begin{array}{l}11 \text { Stat. } \\
743\end{array}$ & $\begin{array}{l}\text { Johnson v. Gearlds } \\
\text { (1914) }\end{array}$ & $\begin{array}{l}234 \text { U.S. } \\
422,445\end{array}$ \\
\hline 307 & & 19 April 1858 & 776 & $\begin{array}{l}11 \text { Stat. } \\
743\end{array}$ & $\begin{array}{l}\text { Yankton Sioux Tribe v. } \\
\text { United States (1926) }\end{array}$ & $\begin{array}{l}272 \text { U.S. } \\
351,351\end{array}$ \\
\hline 307 & & 19 April 1858 & 776 & $\begin{array}{l}11 \text { Stat. } \\
743\end{array}$ & $\begin{array}{l}\text { United States v. Dion } \\
\text { (1986) }\end{array}$ & $\begin{array}{l}476 \text { U.S. } \\
734,737\end{array}$ \\
\hline 307 & & 19 April 1858 & 776 & $\begin{array}{l}11 \text { Stat. } \\
743\end{array}$ & $\begin{array}{l}\text { South Dakota v. } \\
\text { Yankton Sioux Tribe } \\
\text { (1998) }\end{array}$ & $\begin{array}{l}522 \text { U.S. } \\
329,334\end{array}$ \\
\hline 307 & & 19 April 1858 & 776 & $\begin{array}{l}11 \text { Stat. } \\
743\end{array}$ & $\begin{array}{l}\text { South Dakota v. } \\
\text { Yankton Sioux Tribe } \\
\text { (1998) }\end{array}$ & $\begin{array}{l}522 \text { U.S. } \\
329,334(1)\end{array}$ \\
\hline 307 & & 19 April 1858 & 776 & $\begin{array}{l}11 \text { Stat. } \\
743\end{array}$ & $\begin{array}{l}\text { South Dakota v. } \\
\text { Yankton Sioux Tribe } \\
\text { (1998) }\end{array}$ & $\begin{array}{l}522 \text { U.S. } \\
329,334(4)\end{array}$ \\
\hline 307 & & 19 April 1858 & 776 & $\begin{array}{l}11 \text { Stat. } \\
743\end{array}$ & $\begin{array}{l}\text { Yankton Sioux Tribe v. } \\
\text { United States (1926) }\end{array}$ & $\begin{array}{l}272 \text { U.S. } \\
351,353(8)\end{array}$ \\
\hline 307 & & 19 April 1858 & 776 & $\begin{array}{l}11 \text { Stat. } \\
743\end{array}$ & $\begin{array}{l}\text { South Dakota v. } \\
\text { Yankton Sioux Tribe } \\
\text { (1998) }\end{array}$ & $\begin{array}{l}522 \text { U.S. } \\
329,334(10)\end{array}$ \\
\hline 307 & & 19 April 1858 & 776 & $\begin{array}{l}11 \text { Stat. } \\
743\end{array}$ & $\begin{array}{l}\text { South Dakota v. } \\
\text { Yankton Sioux Tribe } \\
\text { (1998) }\end{array}$ & $\begin{array}{l}522 \text { U.S. } \\
329,334(11)\end{array}$ \\
\hline
\end{tabular}


Table 1 (continued)

\begin{tabular}{|c|c|c|c|c|c|c|}
\hline $\begin{array}{l}\text { Ratified } \\
\text { treaty } \\
\text { number }\end{array}$ & $\begin{array}{l}\text { Signatory } \\
\text { tribe(s) }\end{array}$ & $\begin{array}{l}\text { Treaty } \\
\text { signing date }\end{array}$ & $\begin{array}{l}\text { Kappler } \\
\text { page } \\
\text { number }\end{array}$ & $\begin{array}{l}\text { Statutes at } \\
\text { Large or an } \\
\text { alternative } \\
\text { source }\end{array}$ & Case title & U.S. reports \\
\hline 307 & & 19 April 1858 & 776 & $\begin{array}{l}11 \text { Stat. } \\
743\end{array}$ & $\begin{array}{l}\text { Perrin v. United } \\
\text { States }(1914)\end{array}$ & $\begin{array}{l}232 \text { U.S. } \\
478,479(17)\end{array}$ \\
\hline 308 & $\begin{array}{l}\text { Sioux: } \\
\text { Mdewakanton } \\
\text { and Wahpekute }\end{array}$ & 19 June 1858 & 781 & $\begin{array}{l}12 \text { Stat. } \\
1031\end{array}$ & $\begin{array}{l}\text { Sisseton and } \\
\text { Wahpeton Bands of } \\
\text { Sioux Indians v. } \\
\text { United States (1928) }\end{array}$ & $\begin{array}{l}277 \text { U.S. } \\
424,429\end{array}$ \\
\hline 309 & $\begin{array}{l}\text { Sioux: } \\
\text { Sisseton and } \\
\text { Wahpeton }\end{array}$ & 19 June 1858 & 785 & $\begin{array}{l}12 \text { Stat. } \\
1037\end{array}$ & $\begin{array}{l}\text { United States v. } \\
\text { Sisseton and } \\
\text { Wahpeton Bands of } \\
\text { Sioux Indians (1908) }\end{array}$ & $\begin{array}{l}208 \text { U.S. } \\
561,566(6)\end{array}$ \\
\hline 312 & Sac and Fox & $\begin{array}{l}1 \text { October } \\
1859\end{array}$ & 796 & $\begin{array}{l}15 \text { Stat. } \\
467\end{array}$ & $\begin{array}{l}\text { Pennock v. } \\
\text { Commissioners } \\
(1881)\end{array}$ & $\begin{array}{l}103 \text { U.S. } \\
44,45\end{array}$ \\
\hline 312 & & $\begin{array}{l}1 \text { October } \\
1859\end{array}$ & 796 & $\begin{array}{l}15 \text { Stat. } \\
467\end{array}$ & $\begin{array}{l}\text { Sac and Fox Indians } \\
\text { of the Mississippi in } \\
\text { Iowa v. Sac and Fox } \\
\text { Indians of the } \\
\text { Mississippi in } \\
\text { Oklahoma (1911) }\end{array}$ & $\begin{array}{l}220 \text { U.S. } \\
481,482\end{array}$ \\
\hline 312 & & $\begin{array}{l}1 \text { October } \\
1859\end{array}$ & 796 & $\begin{array}{l}15 \text { Stat. } \\
467\end{array}$ & $\begin{array}{l}\text { Sac and Fox Indians } \\
\text { of the Mississippi in } \\
\text { Iowa v. Sac and Fox } \\
\text { Indians of the } \\
\text { Mississippi in } \\
\text { Oklahoma (1911) }\end{array}$ & $\begin{array}{l}220 \text { U.S. } \\
481,485(6)\end{array}$ \\
\hline 312 & & $\begin{array}{l}1 \text { October } \\
1859\end{array}$ & 796 & $\begin{array}{l}15 \text { Stat. } \\
467\end{array}$ & $\begin{array}{l}\text { Sac and Fox Indians } \\
\text { of the Mississippi in } \\
\text { Iowa v. Sac and Fox } \\
\text { Indians of the } \\
\text { Mississippi in } \\
\text { Oklahoma (1911) }\end{array}$ & $\begin{array}{l}220 \text { U.S. } \\
481,484(7)\end{array}$ \\
\hline 312 & & $\begin{array}{l}1 \text { October } \\
1859\end{array}$ & 796 & $\begin{array}{l}15 \text { Stat. } \\
467\end{array}$ & $\begin{array}{l}\text { Pennock v. } \\
\text { Commissioners } \\
(1881)\end{array}$ & $\begin{array}{l}103 \text { U.S. } \\
44,46(10)\end{array}$ \\
\hline 314 & Delaware & 30 May 1860 & 803 & $\begin{array}{l}12 \text { Stat. } \\
1129\end{array}$ & $\begin{array}{l}\text { United States v. Stone } \\
(1865)\end{array}$ & $\begin{array}{l}69 \text { U.S. } \\
525,525\end{array}$ \\
\hline 314 & & 30 May 1860 & 803 & $\begin{array}{l}12 \text { Stat. } \\
1129\end{array}$ & $\begin{array}{l}\text { United States v. Union } \\
\text { Pacific Railway Co. } \\
\text { (1897) }\end{array}$ & $\begin{array}{l}168 \text { U.S. } \\
505,512\end{array}$ \\
\hline 314 & & 30 May 1860 & 803 & $\begin{array}{l}12 \text { Stat. } \\
1129\end{array}$ & $\begin{array}{l}\text { Kindred v. Union } \\
\text { Pacific Railroad Co. } \\
\text { (1912) }\end{array}$ & $\begin{array}{l}225 \text { U.S. } \\
582,583\end{array}$ \\
\hline
\end{tabular}


Table 1 (continued)

\begin{tabular}{|c|c|c|c|c|c|c|}
\hline $\begin{array}{l}\text { Ratified } \\
\text { treaty } \\
\text { number }\end{array}$ & $\begin{array}{l}\text { Signatory } \\
\text { tribe(s) }\end{array}$ & $\begin{array}{l}\text { Treaty } \\
\text { signing date }\end{array}$ & $\begin{array}{l}\text { Kappler } \\
\text { page } \\
\text { number }\end{array}$ & $\begin{array}{l}\text { Statutes at } \\
\text { Large or an } \\
\text { alternative } \\
\text { source }\end{array}$ & Case title & U.S. reports \\
\hline 314 & & 30 May 1860 & 803 & $\begin{array}{l}12 \text { Stat. } \\
1129\end{array}$ & $\begin{array}{l}\text { United States v. Union } \\
\text { Pacific Railway Co. } \\
\text { (1897) }\end{array}$ & $\begin{array}{l}168 \text { U.S. } \\
505,506(2)\end{array}$ \\
\hline 314 & & 30 May 1860 & 803 & $\begin{array}{l}12 \text { Stat. } \\
1129\end{array}$ & $\begin{array}{l}\text { United States v. Union } \\
\text { Pacific Railway Co. } \\
\text { (1897) }\end{array}$ & $\begin{array}{l}168 \text { U.S. } \\
505,506(3)\end{array}$ \\
\hline 314 & & 30 May 1860 & 803 & $\begin{array}{l}12 \text { Stat. } \\
1129\end{array}$ & $\begin{array}{l}\text { Kindred v. Union } \\
\text { Pacific Railroad Co. } \\
\text { (1912) }\end{array}$ & $\begin{array}{l}225 \text { U.S. } \\
582,591(3)\end{array}$ \\
\hline 314 & & 30 May 1860 & 803 & $\begin{array}{l}12 \text { Stat. } \\
1129\end{array}$ & $\begin{array}{l}\text { Delaware Tribal } \\
\text { Business Committee v. } \\
\text { Weeks (1977) }\end{array}$ & $\begin{array}{l}430 \text { U.S. } \\
73,76(4)\end{array}$ \\
\hline 317 & Delaware & 2 July 1861 & 814 & $\begin{array}{l}12 \text { Stat. } \\
1177\end{array}$ & $\begin{array}{l}\text { United States v. Union } \\
\text { Pacific Railway Co. } \\
\text { (1897) }\end{array}$ & $\begin{array}{l}168 \text { U.S. } \\
505,508\end{array}$ \\
\hline 318 & Potawatomi & $\begin{array}{l}15 \text { November } \\
1861\end{array}$ & 824 & $\begin{array}{l}12 \text { Stat. } \\
1191\end{array}$ & Elk v. Wilkins (1884) & $\begin{array}{l}112 \text { U.S. } \\
94,100\end{array}$ \\
\hline 318 & & $\begin{array}{l}15 \text { November } \\
1861\end{array}$ & 824 & $\begin{array}{l}12 \text { Stat. } \\
1191\end{array}$ & In re Heff (1905) & $\begin{array}{l}197 \text { U.S. } \\
488,501\end{array}$ \\
\hline 318 & & $\begin{array}{l}15 \text { November } \\
1861\end{array}$ & 824 & $\begin{array}{l}12 \text { Stat. } \\
1191\end{array}$ & $\begin{array}{l}\text { United States v. Chase } \\
\text { (1917) }\end{array}$ & $\begin{array}{l}245 \text { U.S. } \\
89,95\end{array}$ \\
\hline 318 & & $\begin{array}{l}15 \text { November } \\
1861\end{array}$ & 824 & $\begin{array}{l}12 \text { Stat. } \\
1191\end{array}$ & $\begin{array}{l}\text { Nadeau v. Union } \\
\text { Pacific Railroad Co. } \\
(1920)\end{array}$ & $\begin{array}{l}253 \text { U.S. } \\
442,442\end{array}$ \\
\hline 318 & & $\begin{array}{l}15 \text { November } \\
1861\end{array}$ & 824 & $\begin{array}{l}12 \text { Stat. } \\
1191\end{array}$ & $\begin{array}{l}\text { Board of County } \\
\text { Commissioners v. } \\
\text { United States (1939) }\end{array}$ & $\begin{array}{l}308 \text { U.S. } \\
343,348\end{array}$ \\
\hline 318 & & $\begin{array}{l}15 \text { November } \\
1861\end{array}$ & 824 & $\begin{array}{l}12 \text { Stat. } \\
1191\end{array}$ & $\begin{array}{l}\text { Nadeau v. Union } \\
\text { Pacific Railroad Co. } \\
(1920)\end{array}$ & $\begin{array}{l}253 \text { U.S. } \\
442,445(5)\end{array}$ \\
\hline 320 & $\begin{array}{l}\text { Ottawa: } \\
\text { Blanchard's } \\
\text { Fork; Ottawa: } \\
\text { Roche de } \\
\text { Boeuf }\end{array}$ & 24 June 1862 & 830 & $\begin{array}{l}12 \text { Stat. } \\
1237\end{array}$ & Elk v. Wilkins (1884) & $\begin{array}{l}112 \text { U.S. } \\
94,100\end{array}$ \\
\hline 320 & & 24 June 1862 & 830 & $\begin{array}{l}12 \text { Stat. } \\
1237\end{array}$ & Libby v. Clark (1886) & $\begin{array}{l}118 \text { U.S. } \\
250,251\end{array}$ \\
\hline 320 & & 24 June 1862 & 830 & $\begin{array}{l}12 \text { Stat. } \\
1237\end{array}$ & $\begin{array}{l}\text { Wiggan v. Conolly } \\
\text { (1896) }\end{array}$ & $\begin{array}{l}163 \text { U.S. } \\
56,56\end{array}$ \\
\hline 320 & & 24 June 1862 & 830 & $\begin{array}{l}12 \text { Stat. } \\
1237\end{array}$ & Libby v. Clark (1886) & $\begin{array}{l}118 \text { U.S. } \\
250,254(1)\end{array}$ \\
\hline 320 & & 24 June 1862 & 830 & $\begin{array}{l}12 \text { Stat. } \\
1237\end{array}$ & $\begin{array}{l}\text { Wiggan v. Conolly } \\
\text { (1896) }\end{array}$ & $\begin{array}{l}163 \text { U.S. } \\
56,56(1)\end{array}$ \\
\hline 320 & & 24 June 1862 & 830 & $\begin{array}{l}12 \text { Stat. } \\
1237\end{array}$ & Libby v. Clark (1886) & $\begin{array}{l}118 \text { U.S. } \\
250,250(3)\end{array}$ \\
\hline
\end{tabular}


Table 1 (continued)

\begin{tabular}{|c|c|c|c|c|c|c|}
\hline $\begin{array}{l}\text { Ratified } \\
\text { treaty } \\
\text { number }\end{array}$ & $\begin{array}{l}\text { Signatory } \\
\text { tribe(s) }\end{array}$ & $\begin{array}{l}\text { Treaty } \\
\text { signing date }\end{array}$ & $\begin{array}{l}\text { Kappler } \\
\text { page } \\
\text { number }\end{array}$ & $\begin{array}{l}\text { Statutes at } \\
\text { Large or an } \\
\text { alternative } \\
\text { source }\end{array}$ & Case title & U.S. reports \\
\hline 320 & & 24 June 1862 & 830 & $\begin{array}{l}12 \text { Stat. } \\
1237\end{array}$ & $\begin{array}{l}\text { Jones v. Meehan } \\
\text { (1899) }\end{array}$ & $\begin{array}{l}175 \text { U.S. } \\
1,20(3)\end{array}$ \\
\hline 320 & & 24 June 1862 & 830 & $\begin{array}{l}12 \text { Stat. } \\
1237\end{array}$ & Libby v. Clark (1886) & $\begin{array}{l}118 \text { U.S. } \\
250,250(7)\end{array}$ \\
\hline 320 & & 24 June 1862 & 830 & $\begin{array}{l}12 \text { Stat. } \\
1237\end{array}$ & $\begin{array}{l}\text { Wiggan v. Conolly } \\
\text { (1896) }\end{array}$ & $\begin{array}{l}163 \text { U.S. } \\
56,57(7)\end{array}$ \\
\hline 320 & & 24 June 1862 & 830 & $\begin{array}{l}12 \text { Stat. } \\
1237\end{array}$ & $\begin{array}{l}\text { Jones v. Meehan } \\
(1899)\end{array}$ & $\begin{array}{l}175 \text { U.S. } \\
1,21(7)\end{array}$ \\
\hline 321 & Kickapoo & 28 June 1862 & 835 & $\begin{array}{l}13 \text { Stat. } \\
623\end{array}$ & Elk v. Wilkins (1884) & $\begin{array}{l}112 \text { U.S. } \\
94,100\end{array}$ \\
\hline 321 & & 28 June 1862 & 835 & $\begin{array}{l}13 \text { Stat. } \\
623\end{array}$ & $\begin{array}{l}\text { United States v. Reily } \\
\text { (1933) }\end{array}$ & $\begin{array}{l}290 \text { U.S. } \\
33,35\end{array}$ \\
\hline 321 & & 28 June 1862 & 835 & $\begin{array}{l}13 \text { Stat. } \\
623\end{array}$ & $\begin{array}{l}\text { United States v. } \\
\text { Oklahoma Gas and } \\
\text { Electric Co. (1943) }\end{array}$ & $\begin{array}{l}318 \text { U.S. } \\
206,215\end{array}$ \\
\hline 321 & & 28 June 1862 & 835 & $\begin{array}{l}13 \text { Stat. } \\
623\end{array}$ & In re Heff (1905) & $\begin{array}{l}197 \text { U.S. } \\
488,500(3)\end{array}$ \\
\hline 321 & & 28 June 1862 & 835 & $\begin{array}{l}13 \text { Stat. } \\
623\end{array}$ & $\begin{array}{l}\text { United States v. Reily } \\
\text { (1933) }\end{array}$ & $\begin{array}{l}290 \text { U.S. } \\
33,35(10)\end{array}$ \\
\hline 322 & $\begin{array}{l}\text { Chippewa: } \\
\text { Mississippi, } \\
\text { Pillager and } \\
\text { Lake } \\
\text { Winnibigoshish }\end{array}$ & $\begin{array}{l}11 \text { March } \\
1863\end{array}$ & 839 & $\begin{array}{l}12 \text { Stat. } \\
1249\end{array}$ & $\begin{array}{l}\text { Wilbur v. United } \\
\text { States }(1930)\end{array}$ & $\begin{array}{l}281 \text { U.S. } \\
206,208\end{array}$ \\
\hline 322 & & $\begin{array}{l}11 \text { March } \\
1863\end{array}$ & 839 & $\begin{array}{l}12 \text { Stat. } \\
1249\end{array}$ & $\begin{array}{l}\text { United States v. Mille } \\
\text { Lac Band of } \\
\text { Chippewa Indians } \\
\text { (1913) }\end{array}$ & $\begin{array}{l}229 \text { U.S. } \\
498,500(1)\end{array}$ \\
\hline 322 & & $\begin{array}{l}11 \text { March } \\
1863\end{array}$ & 839 & $\begin{array}{l}12 \text { Stat. } \\
1249\end{array}$ & $\begin{array}{l}\text { Johnson v. Gearlds } \\
\text { (1914) }\end{array}$ & $\begin{array}{l}234 \text { U.S. } \\
422,427(1)\end{array}$ \\
\hline 322 & & $\begin{array}{l}11 \text { March } \\
1863\end{array}$ & 839 & $\begin{array}{l}12 \text { Stat. } \\
1249\end{array}$ & $\begin{array}{l}\text { United States } v . \\
\text { Minnesota }(1926)\end{array}$ & $\begin{array}{l}270 \text { U.S. } \\
181,197(1)\end{array}$ \\
\hline 322 & & $\begin{array}{l}11 \text { March } \\
1863\end{array}$ & 839 & $\begin{array}{l}12 \text { Stat. } \\
1249\end{array}$ & $\begin{array}{l}\text { United States v. Mille } \\
\text { Lac Band of } \\
\text { Chippewa Indians } \\
\text { (1913) }\end{array}$ & $\begin{array}{l}229 \text { U.S. } \\
498,499(2)\end{array}$ \\
\hline 322 & & $\begin{array}{l}11 \text { March } \\
1863\end{array}$ & 839 & $\begin{array}{l}12 \text { Stat. } \\
1249\end{array}$ & $\begin{array}{l}\text { United States v. } \\
\text { Minnesota }(1926)\end{array}$ & $\begin{array}{l}270 \text { U.S. } \\
181,197(2)\end{array}$ \\
\hline 322 & & $\begin{array}{l}11 \text { March } \\
1863\end{array}$ & 839 & $\begin{array}{l}12 \text { Stat. } \\
1249\end{array}$ & $\begin{array}{l}\text { United States v. Mille } \\
\text { Lac Band of } \\
\text { Chippewa Indians } \\
\text { (1913) }\end{array}$ & $\begin{array}{l}229 \text { U.S. } \\
498,501(4)\end{array}$ \\
\hline
\end{tabular}


Table 1 (continued)

\begin{tabular}{|c|c|c|c|c|c|c|}
\hline $\begin{array}{l}\text { Ratified } \\
\text { treaty } \\
\text { number }\end{array}$ & $\begin{array}{l}\text { Signatory } \\
\text { tribe(s) }\end{array}$ & $\begin{array}{l}\text { Treaty } \\
\text { signing date }\end{array}$ & $\begin{array}{l}\text { Kappler } \\
\text { page } \\
\text { number }\end{array}$ & $\begin{array}{l}\text { Statutes at } \\
\text { Large or an } \\
\text { alternative } \\
\text { source }\end{array}$ & Case title & U.S. reports \\
\hline 322 & & $\begin{array}{l}11 \text { March } \\
1863\end{array}$ & 839 & $\begin{array}{l}12 \text { Stat. } \\
1249\end{array}$ & $\begin{array}{l}\text { United States v. Mille } \\
\text { Lac Band of } \\
\text { Chippewa Indians } \\
\text { (1913) }\end{array}$ & $\begin{array}{l}229 \text { U.S. } \\
498,501(12)\end{array}$ \\
\hline 322 & & $\begin{array}{l}11 \text { March } \\
1863\end{array}$ & 839 & $\begin{array}{l}12 \text { Stat. } \\
1249\end{array}$ & $\begin{array}{l}\text { United States v. } \\
\text { Minnesota (1926) }\end{array}$ & $\begin{array}{l}270 \text { U.S. } \\
181,197(12)\end{array}$ \\
\hline 324 & $\begin{array}{l}\text { Shoshone: } \\
\text { Eastern }\end{array}$ & 2 July 1863 & 848 & $\begin{array}{l}18 \text { Stat. } \\
685\end{array}$ & $\begin{array}{l}\text { United States v. } \\
\text { Shoshone Tribe of } \\
\text { Indians (1938) }\end{array}$ & $\begin{array}{l}304 \text { U.S. } \\
111,113\end{array}$ \\
\hline 324 & & 2 July 1863 & 848 & $\begin{array}{l}18 \text { Stat. } \\
685\end{array}$ & $\begin{array}{l}\text { Northwestern Bands } \\
\text { of Shoshone Indians v. } \\
\text { United States (1945) }\end{array}$ & $\begin{array}{l}324 \text { U.S. } \\
335,342\end{array}$ \\
\hline 324 & & 2 July 1863 & 848 & $\begin{array}{l}18 \text { Stat. } \\
685\end{array}$ & $\begin{array}{l}\text { United States v. Alcea } \\
\text { Band of Tillamooks } \\
\text { (1946) }\end{array}$ & $\begin{array}{l}329 \text { U.S. } \\
40,50\end{array}$ \\
\hline 324 & & 2 July 1863 & 848 & $\begin{array}{l}18 \text { Stat. } \\
685\end{array}$ & $\begin{array}{l}\text { Northwestern Bands } \\
\text { of Shoshone Indians v. } \\
\text { United States (1945) }\end{array}$ & $\begin{array}{l}324 \text { U.S. } \\
335,342(2)\end{array}$ \\
\hline 324 & & 2 July 1863 & 848 & $\begin{array}{l}18 \text { Stat. } \\
685\end{array}$ & $\begin{array}{l}\text { Northwestern Bands } \\
\text { of Shoshone Indians v. } \\
\text { United States (1945) }\end{array}$ & $\begin{array}{l}324 \text { U.S. } \\
335,342(3)\end{array}$ \\
\hline 324 & & 2 July 1863 & 848 & $\begin{array}{l}18 \text { Stat. } \\
685\end{array}$ & $\begin{array}{l}\text { Northwestern Bands } \\
\text { of Shoshone Indians v. } \\
\text { United States (1945) }\end{array}$ & $\begin{array}{l}324 \text { U.S. } \\
335,342(4)\end{array}$ \\
\hline 325 & $\begin{array}{l}\text { Shoshone: } \\
\text { Northwestern }\end{array}$ & 30 July 1863 & 850 & $\begin{array}{l}13 \text { Stat. } \\
663\end{array}$ & $\begin{array}{l}\text { Northwestern Bands } \\
\text { of Shoshone Indians v. } \\
\text { United States (1945) }\end{array}$ & $\begin{array}{l}324 \text { U.S. } \\
335,342\end{array}$ \\
\hline 325 & & 30 July 1863 & 850 & $\begin{array}{l}13 \text { Stat. } \\
663\end{array}$ & $\begin{array}{l}\text { Northwestern Bands } \\
\text { of Shoshone Indians v. } \\
\text { United States (1945) }\end{array}$ & $\begin{array}{l}324 \text { U.S. } \\
335,343(1)\end{array}$ \\
\hline 325 & & 30 July 1863 & 850 & $\begin{array}{l}13 \text { Stat. } \\
663\end{array}$ & $\begin{array}{l}\text { Northwestern Bands } \\
\text { of Shoshone Indians v. } \\
\text { United States (1945) }\end{array}$ & $\begin{array}{l}324 \text { U.S. } \\
335,344(2)\end{array}$ \\
\hline 325 & & 30 July 1863 & 850 & $\begin{array}{l}13 \text { Stat. } \\
663\end{array}$ & $\begin{array}{l}\text { Northwestern Bands } \\
\text { of Shoshone Indians v. } \\
\text { United States (1945) }\end{array}$ & $\begin{array}{l}324 \text { U.S. } \\
335,344(3)\end{array}$ \\
\hline 325 & & 30 July 1863 & 850 & $\begin{array}{l}13 \text { Stat. } \\
663\end{array}$ & $\begin{array}{l}\text { Northwestern Bands } \\
\text { of Shoshone Indians v. } \\
\text { United States (1945) }\end{array}$ & $\begin{array}{l}324 \text { U.S. } \\
335,344(4)\end{array}$ \\
\hline 326 & $\begin{array}{l}\text { Shoshone: } \\
\text { Western }\end{array}$ & $\begin{array}{l}1 \text { October } \\
1863\end{array}$ & 851 & $\begin{array}{l}18 \text { Stat. } \\
689\end{array}$ & $\begin{array}{l}\text { Northwestern Bands } \\
\text { of Shoshone Indians v. } \\
\text { United States (1945) }\end{array}$ & $\begin{array}{l}324 \text { U.S. } \\
335,342\end{array}$ \\
\hline 327 & $\begin{array}{l}\text { Chippewa: } \\
\text { Red Lake and } \\
\text { Pembina }\end{array}$ & $\begin{array}{l}2 \text { October } \\
1863\end{array}$ & 853 & $\begin{array}{l}13 \text { Stat. } \\
667\end{array}$ & $\begin{array}{l}\text { United States v. } \\
\text { Forty-three Gallons } \\
\text { of Whiskey (1876) }\end{array}$ & $\begin{array}{l}93 \text { U.S. } \\
188,189\end{array}$ \\
\hline
\end{tabular}


Table 1 (continued)

\begin{tabular}{|c|c|c|c|c|c|c|}
\hline $\begin{array}{l}\text { Ratified } \\
\text { treaty } \\
\text { number }\end{array}$ & $\begin{array}{l}\text { Signatory } \\
\text { tribe(s) }\end{array}$ & $\begin{array}{l}\text { Treaty } \\
\text { signing date }\end{array}$ & $\begin{array}{l}\text { Kappler } \\
\text { page } \\
\text { number }\end{array}$ & $\begin{array}{l}\text { Statutes at } \\
\text { Large or an } \\
\text { alternative } \\
\text { source }\end{array}$ & Case title & U.S. reports \\
\hline 327 & & $\begin{array}{l}2 \text { October } \\
1863\end{array}$ & 853 & $\begin{array}{l}13 \text { Stat. } \\
667\end{array}$ & $\begin{array}{l}\text { Minnesota } v . \\
\text { Hitchcock (1902) }\end{array}$ & $\begin{array}{l}185 \text { U.S. } \\
373,376\end{array}$ \\
\hline 327 & & $\begin{array}{l}2 \text { October } \\
1863\end{array}$ & 853 & $\begin{array}{l}13 \text { Stat. } \\
667\end{array}$ & $\begin{array}{l}\text { Dick v. United States } \\
\text { (1908) }\end{array}$ & $\begin{array}{l}208 \text { U.S. } \\
340,355\end{array}$ \\
\hline 327 & & $\begin{array}{l}2 \text { October } \\
1863\end{array}$ & 853 & $\begin{array}{l}13 \text { Stat. } \\
667\end{array}$ & $\begin{array}{l}\text { Mullen v. Pickens } \\
\text { (1919) }\end{array}$ & $\begin{array}{l}250 \text { U.S. } \\
590,594\end{array}$ \\
\hline 327 & & $\begin{array}{l}2 \text { October } \\
1863\end{array}$ & 853 & $\begin{array}{l}13 \text { Stat. } \\
667\end{array}$ & $\begin{array}{l}\text { United States v. Holt } \\
\text { State Bank (1926) }\end{array}$ & $\begin{array}{l}270 \text { U.S. } \\
49,58\end{array}$ \\
\hline 327 & & $\begin{array}{l}2 \text { October } \\
1863\end{array}$ & 853 & $\begin{array}{l}13 \text { Stat. } \\
667\end{array}$ & $\begin{array}{l}\text { Wilbur v. United } \\
\text { States }(1930)\end{array}$ & $\begin{array}{l}281 \text { U.S. } \\
206,208\end{array}$ \\
\hline 327 & & $\begin{array}{l}2 \text { October } \\
1863\end{array}$ & 853 & $\begin{array}{l}13 \text { Stat. } \\
667\end{array}$ & $\begin{array}{l}\text { Chippewa Indians of } \\
\text { Minnesota v. United } \\
\text { States (1937) }\end{array}$ & $\begin{array}{l}301 \text { U.S. } \\
358,361\end{array}$ \\
\hline 327 & & $\begin{array}{l}2 \text { October } \\
1863\end{array}$ & 853 & $\begin{array}{l}13 \text { Stat. } \\
667\end{array}$ & $\begin{array}{l}\text { Jones v. Meehan } \\
\text { (1899) }\end{array}$ & $\begin{array}{l}175 \text { U.S. } \\
1,3(2)\end{array}$ \\
\hline 327 & & $\begin{array}{l}2 \text { October } \\
1863\end{array}$ & 853 & $\begin{array}{l}13 \text { Stat. } \\
667\end{array}$ & $\begin{array}{l}\text { Jones v. Meehan } \\
(1899)\end{array}$ & $\begin{array}{l}175 \text { U.S. } \\
1,3(3)\end{array}$ \\
\hline 327 & & $\begin{array}{l}2 \text { October } \\
1863\end{array}$ & 853 & $\begin{array}{l}13 \text { Stat. } \\
667\end{array}$ & $\begin{array}{l}\text { Jones v. Meehan } \\
\text { (1899) }\end{array}$ & $\begin{array}{l}175 \text { U.S. } \\
1,3(5)\end{array}$ \\
\hline 327 & & $\begin{array}{l}2 \text { October } \\
1863\end{array}$ & 853 & $\begin{array}{l}13 \text { Stat. } \\
667\end{array}$ & $\begin{array}{l}\text { Chippewa Indians of } \\
\text { Minnesota v. United } \\
\text { States (1937) }\end{array}$ & $\begin{array}{l}301 \text { U.S. } \\
358,373(6)\end{array}$ \\
\hline 327 & & $\begin{array}{l}2 \text { October } \\
1863\end{array}$ & 853 & $\begin{array}{l}13 \text { Stat. } \\
667\end{array}$ & $\begin{array}{l}\text { United States v. } \\
\text { Forty-three Gallons } \\
\text { of Whiskey (1876) }\end{array}$ & $\begin{array}{l}93 \text { U.S. } \\
188,189(7)\end{array}$ \\
\hline 327 & & $\begin{array}{l}2 \text { October } \\
1863\end{array}$ & 853 & $\begin{array}{l}13 \text { Stat. } \\
667\end{array}$ & $\begin{array}{l}\text { United States v. } \\
\text { Forty-three Gallons } \\
\text { of Whiskey (1883) }\end{array}$ & $\begin{array}{l}108 \text { U.S. } \\
491,491(7)\end{array}$ \\
\hline 327 & & $\begin{array}{l}2 \text { October } \\
1863\end{array}$ & 853 & $\begin{array}{l}13 \text { Stat. } \\
667\end{array}$ & $\begin{array}{l}\text { Dick v. United States } \\
\text { (1908) }\end{array}$ & $\begin{array}{l}208 \text { U.S. } \\
340,355(7)\end{array}$ \\
\hline 327 & & $\begin{array}{l}2 \text { October } \\
1863\end{array}$ & 853 & $\begin{array}{l}13 \text { Stat. } \\
667\end{array}$ & $\begin{array}{l}\text { Perrin v. United } \\
\text { States (1914) }\end{array}$ & $\begin{array}{l}232 \text { U.S. } \\
478,483(7)\end{array}$ \\
\hline 327 & & $\begin{array}{l}2 \text { October } \\
1863\end{array}$ & 853 & $\begin{array}{l}13 \text { Stat. } \\
667\end{array}$ & $\begin{array}{l}\text { Jones v. Meehan } \\
\text { (1899) }\end{array}$ & $\begin{array}{l}175 \text { U.S. } \\
1,3(8)\end{array}$ \\
\hline 327 & & $\begin{array}{l}2 \text { October } \\
1863\end{array}$ & 853 & $\begin{array}{l}13 \text { Stat. } \\
667\end{array}$ & $\begin{array}{l}\text { Jones v. Meehan } \\
(1899)\end{array}$ & $\begin{array}{l}175 \text { U.S. } \\
1,2(9)\end{array}$ \\
\hline 328 & $\begin{array}{l}\text { Ute: } \\
\text { Tabeguache }\end{array}$ & $\begin{array}{l}7 \text { October } \\
1863\end{array}$ & 856 & $\begin{array}{l}13 \text { Stat. } \\
673\end{array}$ & $\begin{array}{l}\text { United States v. Santa } \\
\text { Fe Pacific Railroad } \\
\text { Co. }(1941)\end{array}$ & $\begin{array}{l}314 \text { U.S. } \\
339,346\end{array}$ \\
\hline 328 & & $\begin{array}{l}7 \text { October } \\
1863\end{array}$ & 856 & $\begin{array}{l}13 \text { Stat. } \\
673\end{array}$ & $\begin{array}{l}\text { United States v. } \\
\text { Southern Ute Tribe } \\
\text { (1971) }\end{array}$ & $\begin{array}{l}402 \text { U.S. } \\
159,162\end{array}$ \\
\hline 328 & & $\begin{array}{l}7 \text { October } \\
1863\end{array}$ & 856 & $\begin{array}{l}13 \text { Stat. } \\
673\end{array}$ & $\begin{array}{l}\text { Thurston v. United } \\
\text { States (1914) }\end{array}$ & $\begin{array}{l}232 \text { U.S. } \\
469,477(6)\end{array}$ \\
\hline
\end{tabular}


Table 1 (continued)

\begin{tabular}{|c|c|c|c|c|c|c|}
\hline $\begin{array}{l}\text { Ratified } \\
\text { treaty } \\
\text { number }\end{array}$ & $\begin{array}{l}\text { Signatory } \\
\text { tribe(s) }\end{array}$ & $\begin{array}{l}\text { Treaty } \\
\text { signing date }\end{array}$ & $\begin{array}{l}\text { Kappler } \\
\text { page } \\
\text { number }\end{array}$ & $\begin{array}{l}\text { Statutes at } \\
\text { Large or an } \\
\text { alternative } \\
\text { source }\end{array}$ & Case title & U.S. reports \\
\hline 328 & & $\begin{array}{l}7 \text { October } \\
1863\end{array}$ & 856 & $\begin{array}{l}13 \text { Stat. } \\
673\end{array}$ & $\begin{array}{l}\text { Oliphant } v . \\
\text { Suquamish Indian } \\
\text { Tribe (1978) }\end{array}$ & $\begin{array}{l}435 \text { U.S. } \\
191,199(6)\end{array}$ \\
\hline 329 & $\begin{array}{l}\text { Shoshone: } \\
\text { Gosiute }\end{array}$ & $\begin{array}{l}12 \text { October } \\
1863\end{array}$ & 859 & $\begin{array}{l}13 \text { Stat. } \\
681\end{array}$ & $\begin{array}{l}\text { Northwestern Bands } \\
\text { of Shoshone Indians v. } \\
\text { United States (1945) }\end{array}$ & $\begin{array}{l}324 \text { U.S. } \\
335,342\end{array}$ \\
\hline 330 & $\begin{array}{l}\text { Chippewa: } \\
\text { Red Lake and } \\
\text { Pembina }\end{array}$ & 12 April 1864 & 861 & $\begin{array}{l}13 \text { Stat. } \\
689\end{array}$ & $\begin{array}{l}\text { Chippewa Indians of } \\
\text { Minnesota v. United } \\
\text { States (1937) }\end{array}$ & $\begin{array}{l}301 \text { U.S. } \\
358,361\end{array}$ \\
\hline 331 & $\begin{array}{l}\text { Chippewa: } \\
\text { Mississippi, } \\
\text { Pillager and } \\
\text { Lake } \\
\text { Winnibigoshish }\end{array}$ & 7 May 1864 & 862 & $\begin{array}{l}13 \text { Stat. } \\
693\end{array}$ & $\begin{array}{l}\text { Jones v. Meehan } \\
\text { (1899) }\end{array}$ & $\begin{array}{l}175 \text { U.S. } \\
1,29\end{array}$ \\
\hline 331 & & 7 May 1864 & 862 & $\begin{array}{l}13 \text { Stat. } \\
693\end{array}$ & $\begin{array}{l}\text { United States v. Mille } \\
\text { Lac Band of } \\
\text { Chippewa Indians } \\
\text { (1913) }\end{array}$ & $\begin{array}{l}229 \text { U.S. } \\
498,499\end{array}$ \\
\hline 331 & & 7 May 1864 & 862 & $\begin{array}{l}13 \text { Stat. } \\
693\end{array}$ & $\begin{array}{l}\text { United States v. } \\
\text { Minnesota }(1926)\end{array}$ & $\begin{array}{l}270 \text { U.S. } \\
181,197\end{array}$ \\
\hline 331 & & 7 May 1864 & 862 & $\begin{array}{l}13 \text { Stat. } \\
693\end{array}$ & $\begin{array}{l}\text { Wilbur v. United } \\
\text { States (1930) }\end{array}$ & $\begin{array}{l}281 \text { U.S. } \\
206,208\end{array}$ \\
\hline 331 & & 7 May 1864 & 862 & $\begin{array}{l}13 \text { Stat. } \\
693\end{array}$ & $\begin{array}{l}\text { Chippewa Indians of } \\
\text { Minnesota v. United } \\
\text { States (1937) }\end{array}$ & $\begin{array}{l}301 \text { U.S. } \\
358,361\end{array}$ \\
\hline 331 & & 7 May 1864 & 862 & $\begin{array}{l}13 \text { Stat. } \\
693\end{array}$ & $\begin{array}{l}\text { United States v. Mille } \\
\text { Lac Band of } \\
\text { Chippewa Indians } \\
\text { (1913) }\end{array}$ & $\begin{array}{l}229 \text { U.S. } \\
498,499(1)\end{array}$ \\
\hline 331 & & 7 May 1864 & 862 & $\begin{array}{l}13 \text { Stat. } \\
693\end{array}$ & $\begin{array}{l}\text { Johnson v. Gearlds } \\
\text { (1914) }\end{array}$ & $\begin{array}{l}234 \text { U.S. } \\
422,422(1)\end{array}$ \\
\hline 331 & & 7 May 1864 & 862 & $\begin{array}{l}13 \text { Stat. } \\
693\end{array}$ & $\begin{array}{l}\text { United States v. } \\
\text { Minnesota (1926) }\end{array}$ & $\begin{array}{l}270 \text { U.S. } \\
181,198(1)\end{array}$ \\
\hline 331 & & 7 May 1864 & 862 & $\begin{array}{l}13 \text { Stat. } \\
693\end{array}$ & $\begin{array}{l}\text { United States v. Mille } \\
\text { Lac Band of } \\
\text { Chippewa Indians } \\
\text { (1913) }\end{array}$ & $\begin{array}{l}229 \text { U.S. } \\
498,501(2)\end{array}$ \\
\hline 331 & & 7 May 1864 & 862 & $\begin{array}{l}13 \text { Stat. } \\
693\end{array}$ & $\begin{array}{l}\text { United States v. } \\
\text { Minnesota }(1926)\end{array}$ & $\begin{array}{l}270 \text { U.S. } \\
181,197(2)\end{array}$ \\
\hline 331 & & 7 May 1864 & 862 & $\begin{array}{l}13 \text { Stat. } \\
693\end{array}$ & $\begin{array}{l}\text { United States v. Mille } \\
\text { Lac Band of } \\
\text { Chippewa Indians } \\
\text { (1913) }\end{array}$ & $\begin{array}{l}229 \text { U.S. } \\
498,502(12)\end{array}$ \\
\hline
\end{tabular}


Table 1 (continued)

\begin{tabular}{|c|c|c|c|c|c|c|}
\hline $\begin{array}{l}\text { Ratified } \\
\text { treaty } \\
\text { number }\end{array}$ & $\begin{array}{l}\text { Signatory } \\
\text { tribe(s) }\end{array}$ & $\begin{array}{l}\text { Treaty } \\
\text { signing date }\end{array}$ & $\begin{array}{l}\text { Kappler } \\
\text { page } \\
\text { number }\end{array}$ & $\begin{array}{l}\text { Statutes at } \\
\text { Large or an } \\
\text { alternative } \\
\text { source }\end{array}$ & Case title & U.S. reports \\
\hline 332 & $\begin{array}{l}\text { Klamath; } \\
\text { Modoc; Paiute: } \\
\text { Yahooskin }\end{array}$ & $\begin{array}{l}14 \text { October } \\
1864\end{array}$ & 865 & $\begin{array}{l}16 \text { Stat. } \\
707\end{array}$ & $\begin{array}{l}\text { Oregon v. Hitchcock } \\
(1906)\end{array}$ & $\begin{array}{l}202 \text { U.S. } \\
60,62\end{array}$ \\
\hline 332 & & $\begin{array}{l}14 \text { October } \\
1864\end{array}$ & 865 & $\begin{array}{l}16 \text { Stat. } \\
707\end{array}$ & $\begin{array}{l}\text { Klamath and Moadoc } \\
\text { Tribes of Indians v. } \\
\text { United States }(1935)\end{array}$ & $\begin{array}{l}296 \text { U.S. } \\
244,246\end{array}$ \\
\hline 332 & & $\begin{array}{l}14 \text { October } \\
1864\end{array}$ & 865 & $\begin{array}{l}16 \text { Stat. } \\
707\end{array}$ & $\begin{array}{l}\text { United States v. } \\
\text { Klamath and Moadoc } \\
\text { Tribes }(1938)\end{array}$ & $\begin{array}{l}304 \text { U.S. } \\
119,121\end{array}$ \\
\hline 332 & & $\begin{array}{l}14 \text { October } \\
1864\end{array}$ & 865 & $\begin{array}{l}16 \text { Stat. } \\
707\end{array}$ & $\begin{array}{l}\text { United States v. } \\
\text { Algoma Lumber Co. } \\
\text { (1939) }\end{array}$ & $\begin{array}{l}305 \text { U.S. } \\
415,415\end{array}$ \\
\hline 332 & & $\begin{array}{l}14 \text { October } \\
1864\end{array}$ & 865 & $\begin{array}{l}16 \text { Stat. } \\
707\end{array}$ & $\begin{array}{l}\text { Tee-Hit-Ton Indians v. } \\
\text { United States (1955) }\end{array}$ & $\begin{array}{l}348 \text { U.S. } \\
272,282\end{array}$ \\
\hline 332 & & $\begin{array}{l}14 \text { October } \\
1864\end{array}$ & 865 & $\begin{array}{l}16 \text { Stat. } \\
707\end{array}$ & $\begin{array}{l}\text { Oregon Dept. of Fish } \\
\text { and Wildlife } v . \\
\text { Klamath Indian Tribe } \\
(1985)\end{array}$ & $\begin{array}{l}473 \text { U.S. } \\
753,755\end{array}$ \\
\hline 332 & & $\begin{array}{l}14 \text { October } \\
1864\end{array}$ & 865 & $\begin{array}{l}16 \text { Stat. } \\
707\end{array}$ & $\begin{array}{l}\text { Minnesota v. Mille } \\
\text { Lacs Band of } \\
\text { Chippewa Indians } \\
\text { (1999) }\end{array}$ & $\begin{array}{l}526 \text { U.S. } \\
172,172\end{array}$ \\
\hline 332 & & $\begin{array}{l}14 \text { October } \\
1864\end{array}$ & 865 & $\begin{array}{l}16 \text { Stat. } \\
707\end{array}$ & $\begin{array}{l}\text { Minnesota v. Mille } \\
\text { Lacs Band of } \\
\text { Chippewa Indians } \\
\text { (1999) }\end{array}$ & $\begin{array}{l}526 \text { U.S. } \\
172,200\end{array}$ \\
\hline 332 & & $\begin{array}{l}14 \text { October } \\
1864\end{array}$ & 865 & $\begin{array}{l}16 \text { Stat. } \\
707\end{array}$ & $\begin{array}{l}\text { Klamath and Moadoc } \\
\text { Tribes of Indians v. } \\
\text { United States }(1935)\end{array}$ & $\begin{array}{l}296 \text { U.S. } \\
244,246(1)\end{array}$ \\
\hline 334 & Omaha & 6 March 1865 & 872 & $\begin{array}{l}14 \text { Stat. } \\
667\end{array}$ & $\begin{array}{l}\text { Chase v. United States } \\
\text { (1921) }\end{array}$ & $\begin{array}{l}256 \text { U.S. } \\
1,1\end{array}$ \\
\hline 334 & & 6 March 1865 & 872 & $\begin{array}{l}14 \text { Stat. } \\
667\end{array}$ & $\begin{array}{l}\text { Gilpin v. United } \\
\text { States }(1921)\end{array}$ & $\begin{array}{l}256 \text { U.S. } \\
10,11\end{array}$ \\
\hline 334 & & 6 March 1865 & 872 & $\begin{array}{l}14 \text { Stat. } \\
667\end{array}$ & Rice v. Olson (1945) & $\begin{array}{l}324 \text { U.S. } \\
786,790+\end{array}$ \\
\hline 334 & & 6 March 1865 & 872 & $\begin{array}{l}14 \text { Stat. } \\
667\end{array}$ & $\begin{array}{l}\text { Wilson v. Omaha } \\
\text { Indian Tribe (1979) }\end{array}$ & $\begin{array}{l}442 \text { U.S. } \\
653,659\end{array}$ \\
\hline 334 & & 6 March 1865 & 872 & $\begin{array}{l}14 \text { Stat. } \\
667\end{array}$ & $\begin{array}{l}\text { United States } v . \\
\text { Omaha Tribe of } \\
\text { Indians (1920) }\end{array}$ & $\begin{array}{l}253 \text { U.S. } \\
275,279(2)\end{array}$ \\
\hline 334 & & 6 March 1865 & 872 & $\begin{array}{l}14 \text { Stat. } \\
667\end{array}$ & $\begin{array}{l}\text { Sloan v. United States } \\
\text { (1904) }\end{array}$ & $\begin{array}{l}193 \text { U.S. } \\
614,616(4)\end{array}$ \\
\hline 334 & & 6 March 1865 & 872 & $\begin{array}{l}14 \text { Stat. } \\
667\end{array}$ & $\begin{array}{l}\text { United States v. Chase } \\
\text { (1917) }\end{array}$ & $\begin{array}{l}245 \text { U.S. } \\
89,89(4)\end{array}$ \\
\hline
\end{tabular}


Table 1 (continued)

\begin{tabular}{|c|c|c|c|c|c|c|}
\hline $\begin{array}{l}\text { Ratified } \\
\text { treaty } \\
\text { number }\end{array}$ & $\begin{array}{l}\text { Signatory } \\
\text { tribe(s) }\end{array}$ & $\begin{array}{l}\text { Treaty } \\
\text { signing date }\end{array}$ & $\begin{array}{l}\text { Kappler } \\
\text { page } \\
\text { number }\end{array}$ & $\begin{array}{l}\text { Statutes at } \\
\text { Large or an } \\
\text { alternative } \\
\text { source }\end{array}$ & Case title & U.S. reports \\
\hline 334 & & 6 March 1865 & 872 & $\begin{array}{l}14 \text { Stat. } \\
667\end{array}$ & $\begin{array}{l}\text { Gilpin v. United } \\
\text { States }(1921)\end{array}$ & $\begin{array}{l}256 \text { U.S. } \\
1,7(4)\end{array}$ \\
\hline 335 & Winnebago & 8 March 1865 & 874 & $\begin{array}{l}14 \text { Stat. } \\
671\end{array}$ & Rice v. Olson (1945) & $\begin{array}{l}324 \text { U.S. } \\
786,790\end{array}$ \\
\hline 338 & $\begin{array}{l}\text { Osage: Grand } \\
\text { and Little }\end{array}$ & $\begin{array}{l}29 \text { September } \\
1865\end{array}$ & 878 & $\begin{array}{l}14 \text { Stat. } \\
687\end{array}$ & $\begin{array}{l}\text { Leavenworth, } \\
\text { Lawrence and } \\
\text { Galveston Railroad } \\
\text { Co. v. United States } \\
(1876)\end{array}$ & $\begin{array}{l}92 \text { U.S. } \\
733,734\end{array}$ \\
\hline 338 & & $\begin{array}{l}29 \text { September } \\
1865\end{array}$ & 878 & $\begin{array}{l}14 \text { Stat. } \\
687\end{array}$ & $\begin{array}{l}\text { Leavenworth, } \\
\text { Lawrence and } \\
\text { Galveston Railroad } \\
\text { Co. v. United States } \\
(1876)\end{array}$ & $\begin{array}{l}92 \text { U.S. } \\
733,760\end{array}$ \\
\hline 338 & & $\begin{array}{l}29 \text { September } \\
1865\end{array}$ & 878 & $\begin{array}{l}14 \text { Stat. } \\
687\end{array}$ & $\begin{array}{l}\text { Missouri, Kansas and } \\
\text { Texas Railway Co. v. } \\
\text { Roberts (1894) }\end{array}$ & $\begin{array}{l}152 \text { U.S. } \\
114,116\end{array}$ \\
\hline 338 & & $\begin{array}{l}29 \text { September } \\
1865\end{array}$ & 878 & $\begin{array}{l}14 \text { Stat. } \\
687\end{array}$ & Frost v. Wenie (1895) & $\begin{array}{l}157 \text { U.S. } \\
46,49\end{array}$ \\
\hline 338 & & $\begin{array}{l}29 \text { September } \\
1865\end{array}$ & 878 & $\begin{array}{l}14 \text { Stat. } \\
687\end{array}$ & $\begin{array}{l}\text { Missouri, Kansas and } \\
\text { Texas Railway Co. v. } \\
\text { Cook (1896) }\end{array}$ & $\begin{array}{l}163 \text { U.S. } \\
491,492\end{array}$ \\
\hline 338 & & $\begin{array}{l}29 \text { September } \\
1865\end{array}$ & 878 & $\begin{array}{l}14 \text { Stat. } \\
687\end{array}$ & Thomas v. Gay (1898) & $\begin{array}{l}169 \text { U.S. } \\
264,269\end{array}$ \\
\hline 338 & & $\begin{array}{l}29 \text { September } \\
1865\end{array}$ & 878 & $\begin{array}{l}14 \text { Stat. } \\
687\end{array}$ & Frost v. Wenie (1895) & $\begin{array}{l}157 \text { U.S. } \\
46,49(1)\end{array}$ \\
\hline 338 & & $\begin{array}{l}29 \text { September } \\
1865\end{array}$ & 878 & $\begin{array}{l}14 \text { Stat. } \\
687\end{array}$ & $\begin{array}{l}\text { Stewart v. United } \\
\text { States (1907) }\end{array}$ & $\begin{array}{l}206 \text { U.S. } \\
185,187(1)\end{array}$ \\
\hline 338 & & $\begin{array}{l}29 \text { September } \\
1865\end{array}$ & 878 & $\begin{array}{l}14 \text { Stat. } \\
687\end{array}$ & $\begin{array}{l}\text { Leavenworth, } \\
\text { Lawrence and } \\
\text { Galveston Railroad } \\
\text { Co. v. United States } \\
(1876)\end{array}$ & $\begin{array}{l}92 \text { U.S. } \\
733,737(2)\end{array}$ \\
\hline 338 & & $\begin{array}{l}29 \text { September } \\
1865\end{array}$ & 878 & $\begin{array}{l}14 \text { Stat. } \\
687\end{array}$ & Frost v. Wenie (1895) & $\begin{array}{l}157 \text { U.S. } \\
46,50(2)\end{array}$ \\
\hline 338 & & $\begin{array}{l}29 \text { September } \\
1865\end{array}$ & 878 & $\begin{array}{l}14 \text { Stat. } \\
687\end{array}$ & $\begin{array}{l}\text { Stewart v. United } \\
\text { States (1907) }\end{array}$ & $\begin{array}{l}206 \text { U.S. } \\
185,187(2)\end{array}$ \\
\hline 338 & & $\begin{array}{l}29 \text { September } \\
1865\end{array}$ & 878 & $\begin{array}{l}14 \text { Stat. } \\
687\end{array}$ & $\begin{array}{l}\text { Quick Bear v. } \\
\text { Leupp (1908) }\end{array}$ & $\begin{array}{l}210 \text { U.S. } \\
50,62(2)\end{array}$ \\
\hline 338 & & $\begin{array}{l}29 \text { September } \\
1865\end{array}$ & 878 & $\begin{array}{l}14 \text { Stat. } \\
687\end{array}$ & $\begin{array}{l}\text { West v. Oklahoma Tax } \\
\text { Commission (1948) }\end{array}$ & $\begin{array}{l}334 \text { U.S. } \\
717,721(2)\end{array}$ \\
\hline 338 & & $\begin{array}{l}29 \text { September } \\
1865\end{array}$ & 878 & $\begin{array}{l}14 \text { Stat. } \\
687\end{array}$ & $\begin{array}{l}\text { Stewart v. United } \\
\text { States (1907) }\end{array}$ & $\begin{array}{l}206 \text { U.S. } \\
185,188(13)\end{array}$ \\
\hline 338 & & $\begin{array}{l}29 \text { September } \\
1865\end{array}$ & 878 & $\begin{array}{l}14 \text { Stat. } \\
687\end{array}$ & Frost v. Wenie (1895) & $\begin{array}{l}157 \text { U.S. } \\
46,49(16)\end{array}$ \\
\hline
\end{tabular}


Table 1 (continued)

\begin{tabular}{|c|c|c|c|c|c|c|}
\hline $\begin{array}{l}\text { Ratified } \\
\text { treaty } \\
\text { number }\end{array}$ & $\begin{array}{l}\text { Signatory } \\
\text { tribe(s) }\end{array}$ & $\begin{array}{l}\text { Treaty } \\
\text { signing date }\end{array}$ & $\begin{array}{l}\text { Kappler } \\
\text { page } \\
\text { number }\end{array}$ & $\begin{array}{l}\text { Statutes at } \\
\text { Large or an } \\
\text { alternative } \\
\text { source }\end{array}$ & Case title & U.S. reports \\
\hline 338 & & $\begin{array}{l}29 \text { September } \\
1865\end{array}$ & 878 & $\begin{array}{l}14 \text { Stat. } \\
687\end{array}$ & Thomas v. Gay (1898) & $\begin{array}{l}169 \text { U.S. } \\
264,269(16)\end{array}$ \\
\hline 338 & & $\begin{array}{l}29 \text { September } \\
1865\end{array}$ & 878 & $\begin{array}{l}14 \text { Stat. } \\
687\end{array}$ & $\begin{array}{l}\text { Stewart v. United } \\
\text { States }(1907)\end{array}$ & $\begin{array}{l}206 \text { U.S. } \\
185,187(16)\end{array}$ \\
\hline 343 & $\begin{array}{l}\text { Comanche; } \\
\text { Kiowa }\end{array}$ & $\begin{array}{l}18 \text { October } \\
1865\end{array}$ & 892 & $\begin{array}{l}14 \text { Stat. } \\
717\end{array}$ & $\begin{array}{l}\text { Cook v. United States } \\
\text { (1891) }\end{array}$ & $\begin{array}{l}138 \text { U.S. } \\
157,176\end{array}$ \\
\hline 350 & Sioux: Oglala & $\begin{array}{l}28 \text { October } \\
1865\end{array}$ & 906 & $\begin{array}{l}14 \text { Stat. } \\
747\end{array}$ & $\begin{array}{l}\text { Leighton v. United } \\
\text { States }(1896)\end{array}$ & $\begin{array}{l}161 \text { U.S. } \\
291,292\end{array}$ \\
\hline 352 & Seminole & $\begin{array}{l}21 \text { March } \\
1866\end{array}$ & 910 & $\begin{array}{l}14 \text { Stat. } \\
755\end{array}$ & $\begin{array}{l}\text { Atlantic and Pacific } \\
\text { Railroad Co. v. } \\
\text { Mingus (1897) }\end{array}$ & $\begin{array}{l}165 \text { U.S. } \\
413,440\end{array}$ \\
\hline 352 & & $\begin{array}{l}21 \text { March } \\
1866\end{array}$ & 910 & $\begin{array}{l}14 \text { Stat. } \\
755\end{array}$ & $\begin{array}{l}\text { United States v. } \\
\text { Choctaw Nation } \\
(1900)\end{array}$ & $\begin{array}{l}179 \text { U.S. } \\
494,494\end{array}$ \\
\hline 352 & & $\begin{array}{l}21 \text { March } \\
1866\end{array}$ & 910 & $\begin{array}{l}14 \text { Stat. } \\
755\end{array}$ & $\begin{array}{l}\text { Heckman v. United } \\
\text { States (1912) }\end{array}$ & $\begin{array}{l}224 \text { U.S. } \\
413,420+\end{array}$ \\
\hline 352 & & $\begin{array}{l}21 \text { March } \\
1866\end{array}$ & 910 & $\begin{array}{l}14 \text { Stat. } \\
755\end{array}$ & $\begin{array}{l}\text { Goat v. United States } \\
\text { (1912) }\end{array}$ & $\begin{array}{l}224 \text { U.S. } \\
458,461\end{array}$ \\
\hline 352 & & $\begin{array}{l}21 \text { March } \\
1866\end{array}$ & 910 & $\begin{array}{l}14 \text { Stat. } \\
755\end{array}$ & $\begin{array}{l}\text { Woodward v. De } \\
\text { Graffenried (1915) }\end{array}$ & $\begin{array}{l}238 \text { U.S. } \\
284,294\end{array}$ \\
\hline 352 & & $\begin{array}{l}21 \text { March } \\
1866\end{array}$ & 910 & $\begin{array}{l}14 \text { Stat. } \\
755\end{array}$ & $\begin{array}{l}\text { Oklahoma Tax } \\
\text { Commission v. United } \\
\text { States (1943) }\end{array}$ & $\begin{array}{l}319 \text { U.S. } \\
598,617\end{array}$ \\
\hline 352 & & $\begin{array}{l}21 \text { March } \\
1866\end{array}$ & 910 & $\begin{array}{l}14 \text { Stat. } \\
755\end{array}$ & $\begin{array}{l}\text { Cherokee Nation v. } \\
\text { Journeycake (1894) }\end{array}$ & $\begin{array}{l}155 \text { U.S. } \\
196,214(3)\end{array}$ \\
\hline 352 & & $\begin{array}{l}21 \text { March } \\
1866\end{array}$ & 910 & $\begin{array}{l}14 \text { Stat. } \\
755\end{array}$ & $\begin{array}{l}\text { United States v. } \\
\text { Seminole Nation } \\
(1937)\end{array}$ & $\begin{array}{l}299 \text { U.S. } \\
417,426(3)\end{array}$ \\
\hline 352 & & $\begin{array}{l}21 \text { March } \\
1866\end{array}$ & 910 & $\begin{array}{l}14 \text { Stat. } \\
755\end{array}$ & $\begin{array}{l}\text { Seminole Nation } v . \\
\text { United States (1942) }\end{array}$ & $\begin{array}{l}316 \text { U.S. } \\
286,287(3)\end{array}$ \\
\hline 352 & & $\begin{array}{l}21 \text { March } \\
1866\end{array}$ & 910 & $\begin{array}{l}14 \text { Stat. } \\
755\end{array}$ & $\begin{array}{l}\text { Seminole Nation } v . \\
\text { United States }(1942)\end{array}$ & $\begin{array}{l}316 \text { U.S. } \\
310,310(3)\end{array}$ \\
\hline 352 & & $\begin{array}{l}21 \text { March } \\
1866\end{array}$ & 910 & $\begin{array}{l}14 \text { Stat. } \\
755\end{array}$ & $\begin{array}{l}\text { Creek Nation v. } \\
\text { United States (1943) }\end{array}$ & $\begin{array}{l}318 \text { U.S. } \\
629,631(5)\end{array}$ \\
\hline 352 & & $\begin{array}{l}21 \text { March } \\
1866\end{array}$ & 910 & $\begin{array}{l}14 \text { Stat. } \\
755\end{array}$ & $\begin{array}{l}\text { Seminole Nation } v . \\
\text { United States }(1942)\end{array}$ & $\begin{array}{l}316 \text { U.S. } \\
286,287(6)\end{array}$ \\
\hline 352 & & $\begin{array}{l}21 \text { March } \\
1866\end{array}$ & 910 & $\begin{array}{l}14 \text { Stat. } \\
755\end{array}$ & $\begin{array}{l}\text { United States v. } \\
\text { Dann }(1985)\end{array}$ & $\begin{array}{l}470 \text { U.S. } \\
39,48(6)\end{array}$ \\
\hline 352 & & $\begin{array}{l}21 \text { March } \\
1866\end{array}$ & 910 & $\begin{array}{l}14 \text { Stat. } \\
755\end{array}$ & $\begin{array}{l}\text { Seminole Nation } v . \\
\text { United States }(1942)\end{array}$ & $\begin{array}{l}316 \text { U.S. } \\
286,286(8)\end{array}$ \\
\hline 353 & Potawatomi & $\begin{array}{l}29 \text { March } \\
1866\end{array}$ & 916 & $\begin{array}{l}14 \text { Stat. } \\
763\end{array}$ & Elk v. Wilkins (1884) & $\begin{array}{l}112 \text { U.S. } \\
94,100\end{array}$ \\
\hline 354 & $\begin{array}{l}\text { Chippewa: } \\
\text { Bois Forte }\end{array}$ & 7 April 1866 & 916 & $\begin{array}{l}14 \text { Stat. } \\
765\end{array}$ & $\begin{array}{l}\text { Mullen v. United } \\
\text { States (1912) }\end{array}$ & $\begin{array}{l}224 \text { U.S. } \\
448,451+\end{array}$ \\
\hline
\end{tabular}


Table 1 (continued)

\begin{tabular}{|c|c|c|c|c|c|c|}
\hline $\begin{array}{l}\text { Ratified } \\
\text { treaty } \\
\text { number }\end{array}$ & $\begin{array}{l}\text { Signatory } \\
\text { tribe(s) }\end{array}$ & $\begin{array}{l}\text { Treaty } \\
\text { signing date }\end{array}$ & $\begin{array}{l}\text { Kappler } \\
\text { page } \\
\text { number }\end{array}$ & $\begin{array}{l}\text { Statutes at } \\
\text { Large or an } \\
\text { alternative } \\
\text { source }\end{array}$ & Case title & U.S. reports \\
\hline 354 & & 7 April 1866 & 916 & $\begin{array}{l}14 \text { Stat. } \\
765\end{array}$ & $\begin{array}{l}\text { Chippewa Indians of } \\
\text { Minnesota v. United } \\
\text { States (1937) }\end{array}$ & $\begin{array}{l}301 \text { U.S. } \\
358,361\end{array}$ \\
\hline 355 & $\begin{array}{l}\text { Choctaw; } \\
\text { Chickasaw }\end{array}$ & 28 April 1866 & 918 & $\begin{array}{l}14 \text { Stat. } \\
769\end{array}$ & $\begin{array}{l}\text { Choctaw Nation v. } \\
\text { United States (1886) }\end{array}$ & $\begin{array}{l}119 \text { U.S. } \\
1,3\end{array}$ \\
\hline 355 & & 28 April 1866 & 918 & $\begin{array}{l}14 \text { Stat. } \\
769\end{array}$ & $\begin{array}{l}\text { Cherokee Nation v. } \\
\text { Journeycake (1894) }\end{array}$ & $\begin{array}{l}155 \text { U.S. } \\
196,214\end{array}$ \\
\hline 355 & & 28 April 1866 & 918 & $\begin{array}{l}14 \text { Stat. } \\
769\end{array}$ & $\begin{array}{l}\text { Gilfillian v. McKee } \\
\text { (1895) }\end{array}$ & $\begin{array}{l}159 \text { U.S. } \\
303,308\end{array}$ \\
\hline 355 & & 28 April 1866 & 918 & $\begin{array}{l}14 \text { Stat. } \\
769\end{array}$ & $\begin{array}{l}\text { McKee v. Latrobe } \\
\text { (1895) }\end{array}$ & $\begin{array}{l}159 \text { U.S. } \\
327,328\end{array}$ \\
\hline 355 & & 28 April 1866 & 918 & $\begin{array}{l}14 \text { Stat. } \\
769\end{array}$ & $\begin{array}{l}\text { Atlantic and Pacific } \\
\text { Railroad Co. v. } \\
\text { Mingus (1897) }\end{array}$ & $\begin{array}{l}165 \text { U.S. } \\
413,440\end{array}$ \\
\hline 355 & & 28 April 1866 & 918 & $\begin{array}{l}14 \text { Stat. } \\
769\end{array}$ & $\begin{array}{l}\text { Lone Wolf v. } \\
\text { Hitchcock (1903) }\end{array}$ & $\begin{array}{l}187 \text { U.S. } \\
553,557\end{array}$ \\
\hline 355 & & 28 April 1866 & 918 & $\begin{array}{l}14 \text { Stat. } \\
769\end{array}$ & $\begin{array}{l}\text { Heckman v. United } \\
\text { States (1912) }\end{array}$ & $\begin{array}{l}224 \text { U.S. } \\
413,420+\end{array}$ \\
\hline 355 & & 28 April 1866 & 918 & $\begin{array}{l}14 \text { Stat. } \\
769\end{array}$ & $\begin{array}{l}\text { Mullen v. United } \\
\text { States (1912) }\end{array}$ & $\begin{array}{l}224 \text { U.S. } \\
448,451\end{array}$ \\
\hline 355 & & 28 April 1866 & 918 & $\begin{array}{l}14 \text { Stat. } \\
769\end{array}$ & $\begin{array}{l}\text { Woodward v. De } \\
\text { Graffenried (1915) }\end{array}$ & $\begin{array}{l}238 \text { U.S. } \\
284,294\end{array}$ \\
\hline 355 & & 28 April 1866 & 918 & $\begin{array}{l}14 \text { Stat. } \\
769\end{array}$ & $\begin{array}{l}\text { Choctaw Nation of } \\
\text { Indians } v \text {. United } \\
\text { States }(1943)\end{array}$ & $\begin{array}{l}318 \text { U.S. } \\
423,423\end{array}$ \\
\hline 355 & & 28 April 1866 & 918 & $\begin{array}{l}14 \text { Stat. } \\
769\end{array}$ & $\begin{array}{l}\text { United States v. John } \\
\text { (1978) }\end{array}$ & $\begin{array}{l}437 \text { U.S. } \\
634,643\end{array}$ \\
\hline 355 & & 28 April 1866 & 918 & $\begin{array}{l}14 \text { Stat. } \\
769\end{array}$ & $\begin{array}{l}\text { United States v. } \\
\text { Choctaw Nation } \\
\text { (1900) }\end{array}$ & $\begin{array}{l}179 \text { U.S. } \\
494,526(1)\end{array}$ \\
\hline 355 & & 28 April 1866 & 918 & $\begin{array}{l}14 \text { Stat. } \\
769\end{array}$ & $\begin{array}{l}\text { United States v. } \\
\text { Choctaw Nation } \\
\text { (1900) }\end{array}$ & $\begin{array}{l}179 \text { U.S. } \\
494,527(2)\end{array}$ \\
\hline 355 & & 28 April 1866 & 918 & $\begin{array}{l}14 \text { Stat. } \\
769\end{array}$ & $\begin{array}{l}\text { United States v. } \\
\text { Choctaw Nation } \\
\text { (1904) }\end{array}$ & $\begin{array}{l}193 \text { U.S. } \\
115,117(2)\end{array}$ \\
\hline 355 & & 28 April 1866 & 918 & $\begin{array}{l}14 \text { Stat. } \\
769\end{array}$ & $\begin{array}{l}\text { Lucas v. United States } \\
\text { (1896) }\end{array}$ & $\begin{array}{l}163 \text { U.S. } \\
612,613(3)\end{array}$ \\
\hline 355 & & 28 April 1866 & 918 & $\begin{array}{l}14 \text { Stat. } \\
769\end{array}$ & $\begin{array}{l}\text { United States v. } \\
\text { Choctaw Nation } \\
(1900)\end{array}$ & $\begin{array}{l}179 \text { U.S. } \\
494,527(3)\end{array}$ \\
\hline 355 & & 28 April 1866 & 918 & $\begin{array}{l}14 \text { Stat. } \\
769\end{array}$ & $\begin{array}{l}\text { United States v. } \\
\text { Choctaw Nation } \\
\text { (1904) }\end{array}$ & $\begin{array}{l}193 \text { U.S. } \\
115,115(3)\end{array}$ \\
\hline
\end{tabular}


Table 1 (continued)

\begin{tabular}{|c|c|c|c|c|c|c|}
\hline $\begin{array}{l}\text { Ratified } \\
\text { treaty } \\
\text { number }\end{array}$ & $\begin{array}{l}\text { Signatory } \\
\text { tribe(s) }\end{array}$ & $\begin{array}{l}\text { Treaty } \\
\text { signing date }\end{array}$ & $\begin{array}{l}\text { Kappler } \\
\text { page } \\
\text { number }\end{array}$ & $\begin{array}{l}\text { Statutes at } \\
\text { Large or an } \\
\text { alternative } \\
\text { source }\end{array}$ & Case title & U.S. reports \\
\hline 355 & & 28 April 1866 & 918 & $\begin{array}{l}14 \text { Stat. } \\
769\end{array}$ & $\begin{array}{l}\text { Choctaw Nation of } \\
\text { Indians } v \text {. United } \\
\text { States }(1943)\end{array}$ & $\begin{array}{l}318 \text { U.S. } \\
423,424(3)\end{array}$ \\
\hline 355 & & 28 April 1866 & 918 & $\begin{array}{l}14 \text { Stat. } \\
769\end{array}$ & $\begin{array}{l}\text { United States v. } \\
\text { Choctaw Nation } \\
(1900)\end{array}$ & $\begin{array}{l}179 \text { U.S. } \\
494,528(4)\end{array}$ \\
\hline 355 & & 28 April 1866 & 918 & $\begin{array}{l}14 \text { Stat. } \\
769\end{array}$ & $\begin{array}{l}\text { Morris v. Hitchcock } \\
\text { (1904) }\end{array}$ & $\begin{array}{l}194 \text { U.S. } \\
384,389(8)\end{array}$ \\
\hline 355 & & 28 April 1866 & 918 & $\begin{array}{l}14 \text { Stat. } \\
769\end{array}$ & $\begin{array}{l}\text { Lucas v. United States } \\
\text { (1896) }\end{array}$ & $\begin{array}{l}163 \text { U.S. } \\
612,612(8.8)\end{array}$ \\
\hline 355 & & 28 April 1866 & 918 & $\begin{array}{l}14 \text { Stat. } \\
769\end{array}$ & $\begin{array}{l}\text { Mullen v. United } \\
\text { States }(1912)\end{array}$ & $\begin{array}{l}224 \text { U.S. } \\
448,451(10)\end{array}$ \\
\hline 355 & & 28 April 1866 & 918 & $\begin{array}{l}14 \text { Stat. } \\
769\end{array}$ & $\begin{array}{l}\text { Fleming v. McCurtain } \\
\text { (1909) }\end{array}$ & $\begin{array}{l}215 \text { U.S. 56, } \\
62(11-36)\end{array}$ \\
\hline 355 & & 28 April 1866 & 918 & $\begin{array}{l}14 \text { Stat. } \\
769\end{array}$ & $\begin{array}{l}\text { Missouri, Kansas and } \\
\text { Texas Railway Co. v. } \\
\text { United States (1914) }\end{array}$ & $\begin{array}{l}235 \text { U.S. } \\
37,40(11)\end{array}$ \\
\hline 355 & & 28 April 1866 & 918 & $\begin{array}{l}14 \text { Stat. } \\
769\end{array}$ & $\begin{array}{l}\text { Johnson v. Riddle } \\
\text { (1916) }\end{array}$ & $\begin{array}{l}240 \text { U.S. } \\
467,476(11)\end{array}$ \\
\hline 355 & & 28 April 1866 & 918 & $\begin{array}{l}14 \text { Stat. } \\
769\end{array}$ & $\begin{array}{l}\text { United States v. } \\
\text { Choctaw Nation } \\
(1900)\end{array}$ & $\begin{array}{l}179 \text { U.S. } \\
494,528(30)\end{array}$ \\
\hline 355 & & 28 April 1866 & 918 & $\begin{array}{l}14 \text { Stat. } \\
769\end{array}$ & $\begin{array}{l}\text { Westmoreland v. } \\
\text { United States (1895) }\end{array}$ & $\begin{array}{l}155 \text { U.S. } \\
545,546(38)\end{array}$ \\
\hline 355 & & 28 April 1866 & 918 & $\begin{array}{l}14 \text { Stat. } \\
769\end{array}$ & Roff v. Burney (1897) & $\begin{array}{l}168 \text { U.S. } \\
218,220(38)\end{array}$ \\
\hline 355 & & 28 April 1866 & 918 & $\begin{array}{l}14 \text { Stat. } \\
769\end{array}$ & $\begin{array}{l}\text { United States v. } \\
\text { Choctaw Nation } \\
(1900)\end{array}$ & $\begin{array}{l}179 \text { U.S. } \\
494,528(43)\end{array}$ \\
\hline 355 & & 28 April 1866 & 918 & $\begin{array}{l}14 \text { Stat. } \\
769\end{array}$ & $\begin{array}{l}\text { United States v. } \\
\text { Choctaw Nation } \\
(1900)\end{array}$ & $\begin{array}{l}179 \text { U.S. } \\
494,530(46)\end{array}$ \\
\hline 355 & & 28 April 1866 & 918 & $\begin{array}{l}14 \text { Stat. } \\
769\end{array}$ & $\begin{array}{l}\text { Choctaw Nation of } \\
\text { Indians v. United } \\
\text { States }(1943)\end{array}$ & $\begin{array}{l}318 \text { U.S. } \\
423,425(46)\end{array}$ \\
\hline 355 & & 28 April 1866 & 918 & $\begin{array}{l}14 \text { Stat. } \\
769\end{array}$ & $\begin{array}{l}\text { Wright v. Tebbitts } \\
(1876)\end{array}$ & $\begin{array}{l}91 \text { U.S. } \\
252,252(49)\end{array}$ \\
\hline 355 & & 28 April 1866 & 918 & $\begin{array}{l}14 \text { Stat. } \\
769\end{array}$ & $\begin{array}{l}\text { United States v. } \\
\text { Choctaw Nation } \\
(1900)\end{array}$ & $\begin{array}{l}179 \text { U.S. } \\
494,530(51)\end{array}$ \\
\hline 356 & Creek & 14 June 1866 & 931 & $\begin{array}{l}14 \text { Stat. } \\
785\end{array}$ & $\begin{array}{l}\text { Cherokee Nation v. } \\
\text { Journeycake (1894) }\end{array}$ & $\begin{array}{l}155 \text { U.S. } \\
196,214\end{array}$ \\
\hline
\end{tabular}


Table 1 (continued)

\begin{tabular}{|c|c|c|c|c|c|c|}
\hline $\begin{array}{l}\text { Ratified } \\
\text { treaty } \\
\text { number }\end{array}$ & $\begin{array}{l}\text { Signatory } \\
\text { tribe(s) }\end{array}$ & $\begin{array}{l}\text { Treaty } \\
\text { signing date }\end{array}$ & $\begin{array}{l}\text { Kappler } \\
\text { page } \\
\text { number }\end{array}$ & $\begin{array}{l}\text { Statutes at } \\
\text { Large or an } \\
\text { alternative } \\
\text { source }\end{array}$ & Case title & U.S. reports \\
\hline 356 & & 14 June 1866 & 931 & $\begin{array}{l}14 \text { Stat. } \\
785\end{array}$ & $\begin{array}{l}\text { Atlantic and Pacific } \\
\text { Railroad Co. v. } \\
\text { Mingus (1897) }\end{array}$ & $\begin{array}{l}165 \text { U.S. } \\
413,440\end{array}$ \\
\hline 356 & & 14 June 1866 & 931 & $\begin{array}{l}14 \text { Stat. } \\
785\end{array}$ & $\begin{array}{l}\text { Missouri, Kansas and } \\
\text { Texas Railway Co. v. } \\
\text { United States (1914) }\end{array}$ & $\begin{array}{l}235 \text { U.S. } \\
37,40\end{array}$ \\
\hline 356 & & 14 June 1866 & 931 & $\begin{array}{l}14 \text { Stat. } \\
785\end{array}$ & $\begin{array}{l}\text { Woodward v. De } \\
\text { Graffenried (1915) }\end{array}$ & $\begin{array}{l}238 \text { U.S. } \\
284,294\end{array}$ \\
\hline 356 & & 14 June 1866 & 931 & $\begin{array}{l}14 \text { Stat. } \\
785\end{array}$ & $\begin{array}{l}\text { Seminole Nation v. } \\
\text { United States }(1942)\end{array}$ & $\begin{array}{l}316 \text { U.S. } \\
310,311\end{array}$ \\
\hline 356 & & 14 June 1866 & 931 & $\begin{array}{l}14 \text { Stat. } \\
785\end{array}$ & $\begin{array}{l}\text { Oklahoma Tax } \\
\text { Commission v. United } \\
\text { States (1943) }\end{array}$ & $\begin{array}{l}319 \text { U.S. } \\
598,617\end{array}$ \\
\hline 356 & & 14 June 1866 & 931 & $\begin{array}{l}14 \text { Stat. } \\
785\end{array}$ & $\begin{array}{l}\text { Creek Nation v. } \\
\text { United States (1943) }\end{array}$ & $\begin{array}{l}318 \text { U.S. } \\
629,641(1)\end{array}$ \\
\hline 356 & & 14 June 1866 & 931 & $\begin{array}{l}14 \text { Stat. } \\
785\end{array}$ & $\begin{array}{l}\text { United States v. } \\
\text { Choctaw Nation } \\
\text { (1900) }\end{array}$ & $\begin{array}{l}179 \text { U.S. } \\
494,540(3)\end{array}$ \\
\hline 356 & & 14 June 1866 & 931 & $\begin{array}{l}14 \text { Stat. } \\
785\end{array}$ & $\begin{array}{l}\text { United States v. Creek } \\
\text { Nation (1935) }\end{array}$ & $\begin{array}{l}295 \text { U.S. } \\
103,105(3)\end{array}$ \\
\hline 356 & & 14 June 1866 & 931 & $\begin{array}{l}14 \text { Stat. } \\
785\end{array}$ & $\begin{array}{l}\text { Noble v. Oklahoma } \\
\text { City (1936) }\end{array}$ & $\begin{array}{l}297 \text { U.S. } \\
481,482(3)\end{array}$ \\
\hline 356 & & 14 June 1866 & 931 & $\begin{array}{l}14 \text { Stat. } \\
785\end{array}$ & $\begin{array}{l}\text { United States v. Creek } \\
\text { Nation (1935) }\end{array}$ & $\begin{array}{l}295 \text { U.S. } \\
103,105(8)\end{array}$ \\
\hline 356 & & 14 June 1866 & 931 & $\begin{array}{l}14 \text { Stat. } \\
785\end{array}$ & $\begin{array}{l}\text { Turner v. United } \\
\text { States (1919) }\end{array}$ & $\begin{array}{l}248 \text { U.S. } \\
354,355(10)\end{array}$ \\
\hline 357 & Delaware & 4 July 1866 & 937 & $\begin{array}{l}14 \text { Stat. } \\
793\end{array}$ & Elkv. Wilkins (1884) & $\begin{array}{l}112 \text { U.S. } \\
94,103\end{array}$ \\
\hline 357 & & 4 July 1866 & 937 & $\begin{array}{l}14 \text { Stat. } \\
793\end{array}$ & $\begin{array}{l}\text { Atlantic and Pacific } \\
\text { Railroad Co. v. } \\
\text { Mingus (1897) }\end{array}$ & $\begin{array}{l}165 \text { U.S. } \\
413,440\end{array}$ \\
\hline 357 & & 4 July 1866 & 937 & $\begin{array}{l}14 \text { Stat. } \\
793\end{array}$ & $\begin{array}{l}\text { United States v. Union } \\
\text { Pacific Railway Co. } \\
\text { (1897) }\end{array}$ & $\begin{array}{l}168 \text { U.S. } \\
505,512\end{array}$ \\
\hline 357 & & 4 July 1866 & 937 & $\begin{array}{l}14 \text { Stat. } \\
793\end{array}$ & $\begin{array}{l}\text { Kindred v. Union } \\
\text { Pacific Railroad Co. } \\
\text { (1912) }\end{array}$ & $\begin{array}{l}225 \text { U.S. } \\
582,593\end{array}$ \\
\hline 357 & & 4 July 1866 & 937 & $\begin{array}{l}14 \text { Stat. } \\
793\end{array}$ & $\begin{array}{l}\text { Delaware Tribal } \\
\text { Business Committee v. } \\
\text { Weeks (1977) }\end{array}$ & $\begin{array}{l}430 \text { U.S. } \\
73,77\end{array}$ \\
\hline 357 & & 4 July 1866 & 937 & $\begin{array}{l}14 \text { Stat. } \\
793\end{array}$ & $\begin{array}{l}\text { United States v. Union } \\
\text { Pacific Railway Co. } \\
\text { (1897) }\end{array}$ & $\begin{array}{l}168 \text { U.S. } \\
505,509(1)\end{array}$ \\
\hline
\end{tabular}


Table 1 (continued)

\begin{tabular}{|c|c|c|c|c|c|c|}
\hline $\begin{array}{l}\text { Ratified } \\
\text { treaty } \\
\text { number }\end{array}$ & $\begin{array}{l}\text { Signatory } \\
\text { tribe(s) }\end{array}$ & $\begin{array}{l}\text { Treaty } \\
\text { signing date }\end{array}$ & $\begin{array}{l}\text { Kappler } \\
\text { page } \\
\text { number }\end{array}$ & $\begin{array}{l}\text { Statutes at } \\
\text { Large or an } \\
\text { alternative } \\
\text { source }\end{array}$ & Case title & U.S. reports \\
\hline 357 & & 4 July 1866 & 937 & $\begin{array}{l}14 \text { Stat. } \\
793\end{array}$ & $\begin{array}{l}\text { Delaware Tribal } \\
\text { Business Committee v. } \\
\text { Weeks (1977) }\end{array}$ & $\begin{array}{l}430 \text { U.S. } \\
73,78(3)\end{array}$ \\
\hline 357 & & 4 July 1866 & 937 & $\begin{array}{l}14 \text { Stat. } \\
793\end{array}$ & $\begin{array}{l}\text { Delaware Indians } v \text {. } \\
\text { Cherokee Nation } \\
\text { (1904) }\end{array}$ & $\begin{array}{l}193 \text { U.S. } \\
127,133(4)\end{array}$ \\
\hline 357 & & 4 July 1866 & 937 & $\begin{array}{l}14 \text { Stat. } \\
793\end{array}$ & $\begin{array}{l}\text { Delaware Tribal } \\
\text { Business Committee v. } \\
\text { Weeks (1977) }\end{array}$ & $\begin{array}{l}430 \text { U.S. } \\
73,78(9)\end{array}$ \\
\hline 358 & Cherokee & 19 July 1866 & 942 & $\begin{array}{l}14 \text { Stat. } \\
799\end{array}$ & Holden v. Joy (1872) & $\begin{array}{l}84 \text { U.S. } \\
211,217\end{array}$ \\
\hline 358 & & 19 July 1866 & 942 & $\begin{array}{l}14 \text { Stat. } \\
799\end{array}$ & $\begin{array}{l}\text { Cherokee Nation v. } \\
\text { Southern Kansas } \\
\text { Railway Co. (1890) }\end{array}$ & $\begin{array}{l}135 \text { U.S. } \\
641,654\end{array}$ \\
\hline 358 & & 19 July 1866 & 942 & $\begin{array}{l}14 \text { Stat. } \\
799\end{array}$ & $\begin{array}{l}\text { Smith v. United States } \\
\text { (1894) }\end{array}$ & $\begin{array}{l}151 \text { U.S. } \\
50,53\end{array}$ \\
\hline 358 & & 19 July 1866 & 942 & $\begin{array}{l}14 \text { Stat. } \\
799\end{array}$ & $\begin{array}{l}\text { Atlantic and Pacific } \\
\text { Railroad Co. v. } \\
\text { Mingus (1897) }\end{array}$ & $\begin{array}{l}165 \text { U.S. } \\
413,440\end{array}$ \\
\hline 358 & & 19 July 1866 & 942 & $\begin{array}{l}14 \text { Stat. } \\
799\end{array}$ & Thomas v. Gay (1898) & $\begin{array}{l}169 \text { U.S. } \\
264,269\end{array}$ \\
\hline 358 & & 19 July 1866 & 942 & $\begin{array}{l}14 \text { Stat. } \\
799\end{array}$ & $\begin{array}{l}\text { Stephens v. Cherokee } \\
\text { Nation (1899) }\end{array}$ & $\begin{array}{l}174 \text { U.S. } \\
445,485\end{array}$ \\
\hline 358 & & 19 July 1866 & 942 & $\begin{array}{l}14 \text { Stat. } \\
799\end{array}$ & $\begin{array}{l}\text { Cherokee Nation v. } \\
\text { Hitchcock (1902) }\end{array}$ & $\begin{array}{l}187 \text { U.S. } \\
294,297\end{array}$ \\
\hline 358 & & 19 July 1866 & 942 & $\begin{array}{l}14 \text { Stat. } \\
799\end{array}$ & $\begin{array}{l}\text { United States v. } \\
\text { Cherokee Nation } \\
\text { (1906) }\end{array}$ & $\begin{array}{l}202 \text { U.S. } \\
101,107\end{array}$ \\
\hline 358 & & 19 July 1866 & 942 & $\begin{array}{l}14 \text { Stat. } \\
799\end{array}$ & $\begin{array}{l}\text { Cherokee Nation and } \\
\text { United States v. } \\
\text { Whitmire (1912) }\end{array}$ & $\begin{array}{l}223 \text { U.S. } \\
108,108\end{array}$ \\
\hline 358 & & 19 July 1866 & 942 & $\begin{array}{l}14 \text { Stat. } \\
799\end{array}$ & $\begin{array}{l}\text { Heckman v. United } \\
\text { States }(1912)\end{array}$ & $\begin{array}{l}224 \text { U.S. } \\
413,431\end{array}$ \\
\hline 358 & & 19 July 1866 & 942 & $\begin{array}{l}14 \text { Stat. } \\
799\end{array}$ & $\begin{array}{l}\text { Woodward v. De } \\
\text { Graffenried (1915) }\end{array}$ & $\begin{array}{l}238 \text { U.S. } \\
284,294\end{array}$ \\
\hline 358 & & 19 July 1866 & 942 & $\begin{array}{l}14 \text { Stat. } \\
799\end{array}$ & $\begin{array}{l}\text { Brewer-Elliott Oil and } \\
\text { Gas Co. v. United } \\
\text { States (1922) }\end{array}$ & $\begin{array}{l}260 \text { U.S. } \\
77,81\end{array}$ \\
\hline 358 & & 19 July 1866 & 942 & $\begin{array}{l}14 \text { Stat. } \\
799\end{array}$ & $\begin{array}{l}\text { Cherokee Nation v. } \\
\text { United States (1926) }\end{array}$ & $\begin{array}{l}270 \text { U.S. } \\
476,480\end{array}$ \\
\hline 358 & & 19 July 1866 & 942 & $\begin{array}{l}14 \text { Stat. } \\
799\end{array}$ & $\begin{array}{l}\text { United States v. } \\
\text { Mason (1973) }\end{array}$ & $\begin{array}{l}412 \text { U.S. } \\
391,392\end{array}$ \\
\hline 358 & & 19 July 1866 & 942 & $\begin{array}{l}14 \text { Stat. } \\
799\end{array}$ & Holden v. Joy (1872) & $\begin{array}{l}84 \text { U.S. } \\
211,248(1)\end{array}$ \\
\hline
\end{tabular}


Table 1 (continued)

\begin{tabular}{|c|c|c|c|c|c|c|}
\hline $\begin{array}{l}\text { Ratified } \\
\text { treaty } \\
\text { number }\end{array}$ & $\begin{array}{l}\text { Signatory } \\
\text { tribe(s) }\end{array}$ & $\begin{array}{l}\text { Treaty } \\
\text { signing date }\end{array}$ & $\begin{array}{l}\text { Kappler } \\
\text { page } \\
\text { number }\end{array}$ & $\begin{array}{l}\text { Statutes at } \\
\text { Large or an } \\
\text { alternative } \\
\text { source }\end{array}$ & Case title & U.S. reports \\
\hline 358 & & 19 July 1866 & 942 & $\begin{array}{l}14 \text { Stat. } \\
799\end{array}$ & $\begin{array}{l}\text { United States ex rel. } \\
\text { Lowe v. Fisher (1912) }\end{array}$ & $\begin{array}{l}223 \text { U.S. } \\
95,98(3)\end{array}$ \\
\hline 358 & & 19 July 1866 & 942 & $\begin{array}{l}14 \text { Stat. } \\
799\end{array}$ & In re Mayfield (1891) & $\begin{array}{l}141 \text { U.S. } \\
107,113(4)\end{array}$ \\
\hline 358 & & 19 July 1866 & 942 & $\begin{array}{l}14 \text { Stat. } \\
799\end{array}$ & In re Mayfield (1891) & $\begin{array}{l}141 \text { U.S. } \\
107,112(7)\end{array}$ \\
\hline 358 & & 19 July 1866 & 942 & $\begin{array}{l}14 \text { Stat. } \\
799\end{array}$ & $\begin{array}{l}\text { Cherokee Nation v. } \\
\text { Journeycake (1894) }\end{array}$ & $\begin{array}{l}155 \text { U.S. } \\
196,217(9)\end{array}$ \\
\hline 358 & & 19 July 1866 & 942 & $\begin{array}{l}14 \text { Stat. } \\
799\end{array}$ & $\begin{array}{l}\text { Alberty v. United } \\
\text { States (1896) }\end{array}$ & $\begin{array}{l}162 \text { U.S. } \\
499,500(9)\end{array}$ \\
\hline 358 & & 19 July 1866 & 942 & $\begin{array}{l}14 \text { Stat. } \\
799\end{array}$ & $\begin{array}{l}\text { Stephens v. Cherokee } \\
\text { Nation (1899) }\end{array}$ & $\begin{array}{l}174 \text { U.S. } \\
445,462(9)\end{array}$ \\
\hline 358 & & 19 July 1866 & 942 & $\begin{array}{l}14 \text { Stat. } \\
799\end{array}$ & $\begin{array}{l}\text { Blackfeather v. United } \\
\text { States (1903) }\end{array}$ & $\begin{array}{l}190 \text { U.S. } \\
368,373(9)\end{array}$ \\
\hline 358 & & 19 July 1866 & 942 & $\begin{array}{l}14 \text { Stat. } \\
799\end{array}$ & $\begin{array}{l}\text { United States ex rel. } \\
\text { Lowe v. Fisher (1912) }\end{array}$ & $\begin{array}{l}223 \text { U.S. } \\
95,95(9)\end{array}$ \\
\hline 358 & & 19 July 1866 & 942 & $\begin{array}{l}14 \text { Stat. } \\
799\end{array}$ & $\begin{array}{l}\text { Cherokee Nation and } \\
\text { United States v. } \\
\text { Whitmire (1912) }\end{array}$ & $\begin{array}{l}223 \text { U.S. } \\
108,113(9)\end{array}$ \\
\hline 358 & & 19 July 1866 & 942 & $\begin{array}{l}14 \text { Stat. } \\
799\end{array}$ & $\begin{array}{l}\text { Cherokee Tobacco } \\
\text { (1871) }\end{array}$ & $\begin{array}{l}78 \text { U.S. } \\
616,616(10)\end{array}$ \\
\hline 358 & & 19 July 1866 & 942 & $\begin{array}{l}14 \text { Stat. } \\
799\end{array}$ & Holden v. Joy (1872) & $\begin{array}{l}84 \text { U.S. 211, } \\
217(12.1)\end{array}$ \\
\hline 358 & & 19 July 1866 & 942 & $\begin{array}{l}14 \text { Stat. } \\
799\end{array}$ & In re Mayfield (1891) & $\begin{array}{l}141 \text { U.S. } \\
107,112(13)\end{array}$ \\
\hline 358 & & 19 July 1866 & 942 & $\begin{array}{l}14 \text { Stat. } \\
799\end{array}$ & $\begin{array}{l}\text { Alberty v. United } \\
\text { States }(1896)\end{array}$ & $\begin{array}{l}162 \text { U.S. } \\
499,502(13)\end{array}$ \\
\hline 358 & & 19 July 1866 & 942 & $\begin{array}{l}14 \text { Stat. } \\
799\end{array}$ & $\begin{array}{l}\text { Talton v. Mayes } \\
\text { (1896) }\end{array}$ & $\begin{array}{l}163 \text { U.S. } \\
376,380(13)\end{array}$ \\
\hline 358 & & 19 July 1866 & 942 & $\begin{array}{l}14 \text { Stat. } \\
799\end{array}$ & $\begin{array}{l}\text { Cherokee Nation v. } \\
\text { Journeycake (1894) }\end{array}$ & $\begin{array}{l}155 \text { U.S. } \\
196,196(15)\end{array}$ \\
\hline 358 & & 19 July 1866 & 942 & $\begin{array}{l}14 \text { Stat. } \\
799\end{array}$ & $\begin{array}{l}\text { Cherokee Nation v. } \\
\text { Blackfeather (1894) }\end{array}$ & $\begin{array}{l}155 \text { U.S. } \\
218,219(15)\end{array}$ \\
\hline 358 & & 19 July 1866 & 942 & $\begin{array}{l}14 \text { Stat. } \\
799\end{array}$ & $\begin{array}{l}\text { Blackfeather v. United } \\
\text { States (1903) }\end{array}$ & $\begin{array}{l}190 \text { U.S. } \\
368,373(15)\end{array}$ \\
\hline 358 & & 19 July 1866 & 942 & $\begin{array}{l}14 \text { Stat. } \\
799\end{array}$ & $\begin{array}{l}\text { Delaware Indians } v \text {. } \\
\text { Cherokee Nation } \\
\text { (1904) }\end{array}$ & $\begin{array}{l}193 \text { U.S. } \\
127,132(15)\end{array}$ \\
\hline 358 & & 19 July 1866 & 942 & $\begin{array}{l}14 \text { Stat. } \\
799\end{array}$ & $\begin{array}{l}\text { Cherokee } \\
\text { Intermarriage Cases } \\
\text { (1906) }\end{array}$ & $\begin{array}{l}203 \text { U.S. } \\
76,87(15)\end{array}$ \\
\hline 358 & & 19 July 1866 & 942 & $\begin{array}{l}14 \text { Stat. } \\
799\end{array}$ & $\begin{array}{l}\text { Cherokee Nation v. } \\
\text { Journeycake (1894) }\end{array}$ & $\begin{array}{l}155 \text { U.S. } \\
196,205(16)\end{array}$ \\
\hline
\end{tabular}


Table 1 (continued)

\begin{tabular}{|c|c|c|c|c|c|c|}
\hline $\begin{array}{l}\text { Ratified } \\
\text { treaty } \\
\text { number }\end{array}$ & $\begin{array}{l}\text { Signatory } \\
\text { tribe(s) }\end{array}$ & $\begin{array}{l}\text { Treaty } \\
\text { signing date }\end{array}$ & $\begin{array}{l}\text { Kappler } \\
\text { page } \\
\text { number }\end{array}$ & $\begin{array}{l}\text { Statutes at } \\
\text { Large or an } \\
\text { alternative } \\
\text { source }\end{array}$ & Case title & U.S. reports \\
\hline 358 & & 19 July 1866 & 942 & $\begin{array}{l}14 \text { Stat. } \\
799\end{array}$ & $\begin{array}{l}\text { Delaware Indians } v . \\
\text { Cherokee Nation } \\
\text { (1904) }\end{array}$ & $\begin{array}{l}193 \text { U.S. } \\
127,136(16)\end{array}$ \\
\hline 358 & & 19 July 1866 & 942 & $\begin{array}{l}14 \text { Stat. } \\
799\end{array}$ & $\begin{array}{l}\text { Missouri, Kansas and } \\
\text { Texas Railway Co. v. } \\
\text { United States (1914) }\end{array}$ & $\begin{array}{l}235 \text { U.S. } \\
37,40(16)\end{array}$ \\
\hline 358 & & 19 July 1866 & 942 & $\begin{array}{l}14 \text { Stat. } \\
799\end{array}$ & $\begin{array}{l}\text { Brewer-Elliott Oil and } \\
\text { Gas Co. v. United } \\
\text { States (1922) }\end{array}$ & $\begin{array}{l}260 \text { U.S. } \\
77,82(16)\end{array}$ \\
\hline 358 & & 19 July 1866 & 942 & $\begin{array}{l}14 \text { Stat. } \\
799\end{array}$ & Holden v. Joy (1872) & $\begin{array}{l}84 \text { U.S. } \\
211,211(17)\end{array}$ \\
\hline 358 & & 19 July 1866 & 942 & $\begin{array}{l}14 \text { Stat. } \\
799\end{array}$ & $\begin{array}{l}\text { Cherokee Nation v. } \\
\text { Journeycake (1894) }\end{array}$ & $\begin{array}{l}155 \text { U.S. } \\
196,203(17)\end{array}$ \\
\hline 358 & & 19 July 1866 & 942 & $\begin{array}{l}14 \text { Stat. } \\
799\end{array}$ & $\begin{array}{l}\text { West v. Oklahoma Tax } \\
\text { Commission }(1948)\end{array}$ & $\begin{array}{l}334 \text { U.S. } \\
717,720(17)\end{array}$ \\
\hline 358 & & 19 July 1866 & 942 & $\begin{array}{l}14 \text { Stat. } \\
799\end{array}$ & $\begin{array}{l}\text { Cherokee Nation v. } \\
\text { Journeycake (1894) }\end{array}$ & $\begin{array}{l}155 \text { U.S. } \\
196,199(20)\end{array}$ \\
\hline 358 & & 19 July 1866 & 942 & $\begin{array}{l}14 \text { Stat. } \\
799\end{array}$ & $\begin{array}{l}\text { Delaware Indians } v \text {. } \\
\text { Cherokee Nation } \\
\text { (1904) }\end{array}$ & $\begin{array}{l}193 \text { U.S. } \\
127,143(20)\end{array}$ \\
\hline 358 & & 19 July 1866 & 942 & $\begin{array}{l}14 \text { Stat. } \\
799\end{array}$ & $\begin{array}{l}\text { Cherokee } \\
\text { Intermarriage Cases } \\
\text { (1906) }\end{array}$ & $\begin{array}{l}203 \text { U.S. } \\
76,81(20)\end{array}$ \\
\hline 358 & & 19 July 1866 & 942 & $\begin{array}{l}14 \text { Stat. } \\
799\end{array}$ & $\begin{array}{l}\text { Cherokee Trust Funds } \\
\text { (1886) }\end{array}$ & $\begin{array}{l}117 \text { U.S. } \\
288,302(23)\end{array}$ \\
\hline 358 & & 19 July 1866 & 942 & $\begin{array}{l}14 \text { Stat. } \\
799\end{array}$ & $\begin{array}{l}\text { Cherokee Nation v. } \\
\text { Journeycake (1894) }\end{array}$ & $\begin{array}{l}155 \text { U.S. } \\
196,202(23)\end{array}$ \\
\hline 358 & & 19 July 1866 & 942 & $\begin{array}{l}14 \text { Stat. } \\
799\end{array}$ & $\begin{array}{l}\text { Delaware Indians v. } \\
\text { Cherokee Nation } \\
\text { (1904) }\end{array}$ & $\begin{array}{l}193 \text { U.S. } \\
127,132(23)\end{array}$ \\
\hline 358 & & 19 July 1866 & 942 & $\begin{array}{l}14 \text { Stat. } \\
799\end{array}$ & $\begin{array}{l}\text { Cherokee Nation v. } \\
\text { United States (1926) }\end{array}$ & $\begin{array}{l}270 \text { U.S. } \\
476,477(23)\end{array}$ \\
\hline 358 & & 19 July 1866 & 942 & $\begin{array}{l}14 \text { Stat. } \\
799\end{array}$ & Holden v. Joy (1872) & $\begin{array}{l}84 \text { U.S. } \\
211,217(28)\end{array}$ \\
\hline 358 & & 19 July 1866 & 942 & $\begin{array}{l}14 \text { Stat. } \\
799\end{array}$ & Holden v. Joy (1872) & $\begin{array}{l}84 \text { U.S. } \\
211,217(29)\end{array}$ \\
\hline 358 & & 19 July 1866 & 942 & $\begin{array}{l}14 \text { Stat. } \\
799\end{array}$ & Holden v. Joy (1872) & $\begin{array}{l}84 \text { U.S. } \\
211,218(30)\end{array}$ \\
\hline 359 & $\begin{array}{l}\text { Sac: } \\
\text { Mississippi; } \\
\text { Fox: } \\
\text { Mississippi }\end{array}$ & $\begin{array}{l}18 \text { February } \\
1867\end{array}$ & 951 & $\begin{array}{l}15 \text { Stat. } \\
495\end{array}$ & $\begin{array}{l}\text { Sac and Fox Indians } \\
\text { of the Mississippi in } \\
\text { Iowa v. Sac and Fox } \\
\text { Indians of the } \\
\text { Mississippi in } \\
\text { Oklahoma (1911) }\end{array}$ & $\begin{array}{l}220 \text { U.S. } \\
481,484\end{array}$ \\
\hline
\end{tabular}


Table 1 (continued)

\begin{tabular}{|c|c|c|c|c|c|c|}
\hline $\begin{array}{l}\text { Ratified } \\
\text { treaty } \\
\text { number }\end{array}$ & $\begin{array}{l}\text { Signatory } \\
\text { tribe(s) }\end{array}$ & $\begin{array}{l}\text { Treaty } \\
\text { signing date }\end{array}$ & $\begin{array}{l}\text { Kappler } \\
\text { page } \\
\text { number }\end{array}$ & $\begin{array}{l}\text { Statutes at } \\
\text { Large or an } \\
\text { alternative } \\
\text { source }\end{array}$ & Case title & U.S. reports \\
\hline 359 & & $\begin{array}{l}18 \text { February } \\
1867\end{array}$ & 951 & $\begin{array}{l}15 \text { Stat. } \\
495\end{array}$ & $\begin{array}{l}\text { United States v. Creek } \\
\text { Nation (1935) }\end{array}$ & $\begin{array}{l}295 \text { U.S. } \\
103,103(6)\end{array}$ \\
\hline 359 & & $\begin{array}{l}18 \text { February } \\
1867\end{array}$ & 951 & $\begin{array}{l}15 \text { Stat. } \\
495\end{array}$ & $\begin{array}{l}\text { Pennock v. } \\
\text { Commissioners } \\
\text { (1881) }\end{array}$ & $\begin{array}{l}103 \text { U.S. } \\
44,44(17)\end{array}$ \\
\hline 359 & & $\begin{array}{l}18 \text { February } \\
1867\end{array}$ & 951 & $\begin{array}{l}15 \text { Stat. } \\
495\end{array}$ & $\begin{array}{l}\text { Pennock } v . \\
\text { Commissioners } \\
(1881)\end{array}$ & $\begin{array}{l}103 \text { U.S. } \\
44,48(18)\end{array}$ \\
\hline 359 & & $\begin{array}{l}18 \text { February } \\
1867\end{array}$ & 951 & $\begin{array}{l}15 \text { Stat. } \\
495\end{array}$ & $\begin{array}{l}\text { Sac and Fox Indians } \\
\text { of the Mississippi in } \\
\text { Iowa } v \text {. Sac and Fox } \\
\text { Indians of the } \\
\text { Mississippi in } \\
\text { Oklahoma (1911) }\end{array}$ & $\begin{array}{l}220 \text { U.S. } \\
481,484(21)\end{array}$ \\
\hline 360 & $\begin{array}{l}\text { Sioux: } \\
\text { Sisseton and } \\
\text { Wahpeton }\end{array}$ & $\begin{array}{l}19 \text { February } \\
1867\end{array}$ & 956 & $\begin{array}{l}15 \text { Stat. } \\
505\end{array}$ & $\begin{array}{l}\text { Buttz v. Northern } \\
\text { Pacific Railroad Co. } \\
\text { (1886) }\end{array}$ & $\begin{array}{l}119 \text { U.S. } \\
55,68\end{array}$ \\
\hline 360 & & $\begin{array}{l}19 \text { February } \\
1867\end{array}$ & 956 & $\begin{array}{l}15 \text { Stat. } \\
505\end{array}$ & $\begin{array}{l}\text { United States v. } \\
\text { Sisseton and } \\
\text { Wahpeton Bands of } \\
\text { Sioux Indians (1908) }\end{array}$ & $\begin{array}{l}208 \text { U.S. } \\
561,564\end{array}$ \\
\hline 360 & & $\begin{array}{l}19 \text { February } \\
1867\end{array}$ & 956 & $\begin{array}{l}15 \text { Stat. } \\
505\end{array}$ & $\begin{array}{l}\text { De Coteau v. District } \\
\text { County Court for the } \\
\text { 10th Judicial District } \\
\text { (1975) }\end{array}$ & $\begin{array}{l}420 \text { U.S. } \\
425,425\end{array}$ \\
\hline 360 & & $\begin{array}{l}19 \text { February } \\
1867\end{array}$ & 956 & $\begin{array}{l}15 \text { Stat. } \\
505\end{array}$ & $\begin{array}{l}\text { Buttz v. Northern } \\
\text { Pacific Railroad Co. } \\
\text { (1886) }\end{array}$ & $\begin{array}{l}119 \text { U.S. } \\
58(2)\end{array}$ \\
\hline 360 & & $\begin{array}{l}19 \text { February } \\
1867\end{array}$ & 956 & $\begin{array}{l}15 \text { Stat. } \\
505\end{array}$ & $\begin{array}{l}\text { United States v. } \\
\text { Sisseton and } \\
\text { Wahpeton Bands of } \\
\text { Sioux Indians (1908) }\end{array}$ & $\begin{array}{l}208 \text { U.S. } \\
561,567(2)\end{array}$ \\
\hline 360 & & $\begin{array}{l}19 \text { February } \\
1867\end{array}$ & 956 & $\begin{array}{l}15 \text { Stat. } \\
505\end{array}$ & $\begin{array}{l}\text { Sisseton and } \\
\text { Wahpeton Bands of } \\
\text { Sioux Indians v. } \\
\text { United States (1928) }\end{array}$ & $\begin{array}{l}277 \text { U.S. } \\
424,431(2)\end{array}$ \\
\hline 360 & & $\begin{array}{l}19 \text { February } \\
1867\end{array}$ & 956 & $\begin{array}{l}15 \text { Stat. } \\
505\end{array}$ & $\begin{array}{l}\text { Buttz v. Northern } \\
\text { Pacific Railroad Co. } \\
\text { (1886) }\end{array}$ & $\begin{array}{l}119 \text { U.S. } \\
55,59(3)\end{array}$ \\
\hline 360 & & $\begin{array}{l}19 \text { February } \\
1867\end{array}$ & 956 & $\begin{array}{l}15 \text { Stat. } \\
505\end{array}$ & $\begin{array}{l}\text { United States v. } \\
\text { Sisseton and } \\
\text { Wahpeton Bands of } \\
\text { Sioux Indians (1908) }\end{array}$ & $\begin{array}{l}208 \text { U.S. } \\
561,567(3)\end{array}$ \\
\hline
\end{tabular}


Table 1 (continued)

\begin{tabular}{|c|c|c|c|c|c|c|}
\hline $\begin{array}{l}\text { Ratified } \\
\text { treaty } \\
\text { number }\end{array}$ & $\begin{array}{l}\text { Signatory } \\
\text { tribe(s) }\end{array}$ & $\begin{array}{l}\text { Treaty } \\
\text { signing date }\end{array}$ & $\begin{array}{l}\text { Kappler } \\
\text { page } \\
\text { number }\end{array}$ & $\begin{array}{l}\text { Statutes at } \\
\text { Large or an } \\
\text { alternative } \\
\text { source }\end{array}$ & Case title & U.S. reports \\
\hline 360 & & $\begin{array}{l}19 \text { February } \\
1867\end{array}$ & 956 & $\begin{array}{l}15 \text { Stat. } \\
505\end{array}$ & $\begin{array}{l}\text { De Coteau v. District } \\
\text { County Court for the } \\
\text { 10th Judicial District } \\
(1975)\end{array}$ & $\begin{array}{l}420 \text { U.S. } \\
425,443(3)\end{array}$ \\
\hline 360 & & $\begin{array}{l}19 \text { February } \\
1867\end{array}$ & 956 & $\begin{array}{l}15 \text { Stat. } \\
505\end{array}$ & $\begin{array}{l}\text { Buttz v. Northern } \\
\text { Pacific Railroad Co. } \\
\text { (1886) }\end{array}$ & $\begin{array}{l}119 \text { U.S. } \\
55,59(4)\end{array}$ \\
\hline 360 & & $\begin{array}{l}19 \text { February } \\
1867\end{array}$ & 956 & $\begin{array}{l}15 \text { Stat. } \\
505\end{array}$ & $\begin{array}{l}\text { United States v. } \\
\text { Sisseton and } \\
\text { Wahpeton Bands of } \\
\text { Sioux Indians (1908) }\end{array}$ & $\begin{array}{l}208 \text { U.S. } \\
561,567(4)\end{array}$ \\
\hline 360 & & $\begin{array}{l}19 \text { February } \\
1867\end{array}$ & 956 & $\begin{array}{l}15 \text { Stat. } \\
505\end{array}$ & $\begin{array}{l}\text { United States v. } \\
\text { Sisseton and } \\
\text { Wahpeton Bands of } \\
\text { Sioux Indians (1908) }\end{array}$ & $\begin{array}{l}208 \text { U.S. } \\
561,567(6)\end{array}$ \\
\hline 360 & & $\begin{array}{l}19 \text { February } \\
1867\end{array}$ & 956 & $\begin{array}{l}15 \text { Stat. } \\
505\end{array}$ & $\begin{array}{l}\text { Buttz v. Northern } \\
\text { Pacific Railroad Co. } \\
\text { (1886) }\end{array}$ & $\begin{array}{l}119 \text { U.S. } \\
55,60(8)\end{array}$ \\
\hline 360 & & $\begin{array}{l}19 \text { February } \\
1867\end{array}$ & 956 & $\begin{array}{l}15 \text { Stat. } \\
505\end{array}$ & $\begin{array}{l}\text { Buttz v. Northern } \\
\text { Pacific Railroad Co. } \\
\text { (1886) }\end{array}$ & $\begin{array}{l}119 \text { U.S. } \\
55,60(9)\end{array}$ \\
\hline 360 & & $\begin{array}{l}19 \text { February } \\
1867\end{array}$ & 956 & $\begin{array}{l}15 \text { Stat. } \\
505\end{array}$ & $\begin{array}{l}\text { Buttz v. Northern } \\
\text { Pacific Railroad Co. } \\
\text { (1886) }\end{array}$ & $\begin{array}{l}119 \text { U.S. } \\
55,60(10)\end{array}$ \\
\hline 360 & & $\begin{array}{l}19 \text { February } \\
1867\end{array}$ & 956 & $\begin{array}{l}15 \text { Stat. } \\
505\end{array}$ & $\begin{array}{l}\text { De Coteau v. District } \\
\text { County Court for the } \\
\text { 10th Judicial District } \\
\text { (1975) }\end{array}$ & $\begin{array}{l}420 \text { U.S. } \\
425,461(10)\end{array}$ \\
\hline 361 & $\begin{array}{l}\text { Seneca; Mixed } \\
\text { Seneca; } \\
\text { Shawnee; } \\
\text { Quapaw; } \\
\text { Peoria; } \\
\text { Kaskaskia; } \\
\text { Wea; } \\
\text { Piankashaw; } \\
\text { Miami; Ottawa: } \\
\text { Blanchard's } \\
\text { Fork; Ottawa: } \\
\text { Roche de } \\
\text { Boeuf; Wyandot }\end{array}$ & $\begin{array}{l}23 \text { February } \\
1867\end{array}$ & 960 & $\begin{array}{l}15 \text { Stat. } \\
513\end{array}$ & Elk v. Wilkins (1884) & $\begin{array}{l}112 \text { U.S. } \\
94,103\end{array}$ \\
\hline 361 & & $\begin{array}{l}23 \text { February } \\
1867\end{array}$ & 960 & $\begin{array}{l}15 \text { Stat. } \\
513\end{array}$ & $\begin{array}{l}\text { Wiggan v. Conolly } \\
\text { (1896) }\end{array}$ & $\begin{array}{l}163 \text { U.S. } \\
56,56\end{array}$ \\
\hline
\end{tabular}


Table 1 (continued)

\begin{tabular}{|c|c|c|c|c|c|c|}
\hline $\begin{array}{l}\text { Ratified } \\
\text { treaty } \\
\text { number }\end{array}$ & $\begin{array}{l}\text { Signatory } \\
\text { tribe(s) }\end{array}$ & $\begin{array}{l}\text { Treaty } \\
\text { signing date }\end{array}$ & $\begin{array}{l}\text { Kappler } \\
\text { page } \\
\text { number }\end{array}$ & $\begin{array}{l}\text { Statutes at } \\
\text { Large or an } \\
\text { alternative } \\
\text { source }\end{array}$ & Case title & U.S. reports \\
\hline 361 & & $\begin{array}{l}23 \text { February } \\
1867\end{array}$ & 960 & $\begin{array}{l}15 \text { Stat. } \\
513\end{array}$ & $\begin{array}{l}\text { Bowling and Miami } \\
\text { Investment Co. v. } \\
\text { United States (1914) }\end{array}$ & $\begin{array}{l}233 \text { U.S. } \\
528,533\end{array}$ \\
\hline 361 & & $\begin{array}{l}23 \text { February } \\
1867\end{array}$ & 960 & $\begin{array}{l}15 \text { Stat. } \\
513\end{array}$ & $\begin{array}{l}\text { Wiggan v. Conolly } \\
\text { (1896) }\end{array}$ & $\begin{array}{l}163 \text { U.S. } \\
56,58(3)\end{array}$ \\
\hline 361 & & $\begin{array}{l}23 \text { February } \\
1867\end{array}$ & 960 & $\begin{array}{l}15 \text { Stat. } \\
513\end{array}$ & $\begin{array}{l}\text { Conley v. Ballinger } \\
\text { (1910) }\end{array}$ & $\begin{array}{l}216 \text { U.S. } \\
84,89(13)\end{array}$ \\
\hline 361 & & $\begin{array}{l}23 \text { February } \\
1867\end{array}$ & 960 & $\begin{array}{l}15 \text { Stat. } \\
513\end{array}$ & $\begin{array}{l}\text { Schrimpscher v. } \\
\text { Stockton (1902) }\end{array}$ & $\begin{array}{l}183 \text { U.S. } \\
290,292(15)\end{array}$ \\
\hline 361 & & $\begin{array}{l}23 \text { February } \\
1867\end{array}$ & 960 & $\begin{array}{l}15 \text { Stat. } \\
513\end{array}$ & $\begin{array}{l}\text { Wiggan v. Conolly } \\
\text { (1896) }\end{array}$ & $\begin{array}{l}163 \text { U.S. } \\
56,62(16)\end{array}$ \\
\hline 361 & & $\begin{array}{l}23 \text { February } \\
1867\end{array}$ & 960 & $\begin{array}{l}15 \text { Stat. } \\
513\end{array}$ & $\begin{array}{l}\text { Wiggan v. Conolly } \\
\text { (1896) }\end{array}$ & $\begin{array}{l}163 \text { U.S. } \\
56,62(17)\end{array}$ \\
\hline 362 & Potawatomi & $\begin{array}{l}27 \text { February } \\
1867\end{array}$ & 970 & $\begin{array}{l}15 \text { Stat. } \\
531\end{array}$ & Elk v. Wilkins (1884) & $\begin{array}{l}112 \text { U.S. } \\
94,103\end{array}$ \\
\hline 362 & & $\begin{array}{l}27 \text { February } \\
1867\end{array}$ & 970 & $\begin{array}{l}15 \text { Stat. } \\
531\end{array}$ & $\begin{array}{l}\text { United States v. } \\
\text { Navarre (1899) }\end{array}$ & $\begin{array}{l}173 \text { U.S. } \\
77,77\end{array}$ \\
\hline 362 & & $\begin{array}{l}27 \text { February } \\
1867\end{array}$ & 970 & $\begin{array}{l}15 \text { Stat. } \\
531\end{array}$ & $\begin{array}{l}\text { Kindred v. Union } \\
\text { Pacific Railroad Co. } \\
\text { (1912) }\end{array}$ & $\begin{array}{l}225 \text { U.S. } \\
582,589+\end{array}$ \\
\hline 362 & & $\begin{array}{l}27 \text { February } \\
1867\end{array}$ & 970 & $\begin{array}{l}15 \text { Stat. } \\
531\end{array}$ & $\begin{array}{l}\text { United States v. Chase } \\
\text { (1917) }\end{array}$ & $\begin{array}{l}245 \text { U.S. } \\
89,95\end{array}$ \\
\hline 362 & & $\begin{array}{l}27 \text { February } \\
1867\end{array}$ & 970 & $\begin{array}{l}15 \text { Stat. } \\
531\end{array}$ & $\begin{array}{l}\text { Seminole Nation v. } \\
\text { United States (1942) }\end{array}$ & $\begin{array}{l}316 \text { U.S. } \\
310,312(1)\end{array}$ \\
\hline 362 & & $\begin{array}{l}27 \text { February } \\
1867\end{array}$ & 970 & $\begin{array}{l}15 \text { Stat. } \\
531\end{array}$ & $\begin{array}{l}\text { United States v. } \\
\text { Navarre (1899) }\end{array}$ & $\begin{array}{l}173 \text { U.S. } \\
77,78(10)\end{array}$ \\
\hline 363 & $\begin{array}{l}\text { Chippewa: } \\
\text { Mississippi }\end{array}$ & $\begin{array}{l}19 \text { March } \\
1867\end{array}$ & 974 & $\begin{array}{l}16 \text { Stat. } \\
719\end{array}$ & $\begin{array}{l}\text { Jacobs v. Prichard } \\
\text { (1912) }\end{array}$ & $\begin{array}{l}223 \text { U.S. } \\
200,216\end{array}$ \\
\hline 363 & & $\begin{array}{l}19 \text { March } \\
1867\end{array}$ & 974 & $\begin{array}{l}16 \text { Stat. } \\
719\end{array}$ & $\begin{array}{l}\text { United States v. Mille } \\
\text { Lac Band of } \\
\text { Chippewa Indians } \\
\text { (1913) }\end{array}$ & $\begin{array}{l}229 \text { U.S. } \\
498,501\end{array}$ \\
\hline 363 & & $\begin{array}{l}19 \text { March } \\
1867\end{array}$ & 974 & $\begin{array}{l}16 \text { Stat. } \\
719\end{array}$ & $\begin{array}{l}\text { United States v. First } \\
\text { National Bank (1914) }\end{array}$ & $\begin{array}{l}234 \text { U.S. } \\
245,246\end{array}$ \\
\hline 363 & & $\begin{array}{l}19 \text { March } \\
1867\end{array}$ & 974 & $\begin{array}{l}16 \text { Stat. } \\
719\end{array}$ & $\begin{array}{l}\text { Johnson v. Gearlds } \\
\text { (1914) }\end{array}$ & $\begin{array}{l}234 \text { U.S. } \\
422,422\end{array}$ \\
\hline 363 & & $\begin{array}{l}19 \text { March } \\
1867\end{array}$ & 974 & $\begin{array}{l}16 \text { Stat. } \\
719\end{array}$ & $\begin{array}{l}\text { United States v. } \\
\text { Waller (1917) }\end{array}$ & $\begin{array}{l}243 \text { U.S. } \\
452,460\end{array}$ \\
\hline 363 & & $\begin{array}{l}19 \text { March } \\
1867\end{array}$ & 974 & $\begin{array}{l}16 \text { Stat. } \\
719\end{array}$ & $\begin{array}{l}\text { United States } v . \\
\text { Minnesota }(1926)\end{array}$ & $\begin{array}{l}270 \text { U.S. } \\
181,197\end{array}$ \\
\hline 363 & & $\begin{array}{l}19 \text { March } \\
1867\end{array}$ & 974 & $\begin{array}{l}16 \text { Stat. } \\
719\end{array}$ & $\begin{array}{l}\text { Wilbur v. United } \\
\text { States }(1930)\end{array}$ & $\begin{array}{l}281 \text { U.S. } \\
206,208\end{array}$ \\
\hline 363 & & $\begin{array}{l}19 \text { March } \\
1867\end{array}$ & 974 & $\begin{array}{l}16 \text { Stat. } \\
719\end{array}$ & $\begin{array}{l}\text { Chippewa Indians of } \\
\text { Minnesota v. United } \\
\text { States (1937) }\end{array}$ & $\begin{array}{l}301 \text { U.S. } \\
358,361\end{array}$ \\
\hline
\end{tabular}


Table 1 (continued)

\begin{tabular}{|c|c|c|c|c|c|c|}
\hline $\begin{array}{l}\text { Ratified } \\
\text { treaty } \\
\text { number }\end{array}$ & $\begin{array}{l}\text { Signatory } \\
\text { tribe(s) }\end{array}$ & $\begin{array}{l}\text { Treaty } \\
\text { signing date }\end{array}$ & $\begin{array}{l}\text { Kappler } \\
\text { page } \\
\text { number }\end{array}$ & $\begin{array}{l}\text { Statutes at } \\
\text { Large or an } \\
\text { alternative } \\
\text { source }\end{array}$ & Case title & U.S. reports \\
\hline 363 & & $\begin{array}{l}19 \text { March } \\
1867\end{array}$ & 974 & $\begin{array}{l}16 \text { Stat. } \\
719\end{array}$ & $\begin{array}{l}\text { United States } v . \\
\text { Minnesota }(1926)\end{array}$ & $\begin{array}{l}270 \text { U.S. } \\
181,197(1)\end{array}$ \\
\hline 363 & & $\begin{array}{l}19 \text { March } \\
1867\end{array}$ & 974 & $\begin{array}{l}16 \text { Stat. } \\
719\end{array}$ & $\begin{array}{l}\text { United States } v . \\
\text { Minnesota }(1926)\end{array}$ & $\begin{array}{l}270 \text { U.S. } \\
181,197(2)\end{array}$ \\
\hline 363 & & $\begin{array}{l}19 \text { March } \\
1867\end{array}$ & 974 & $\begin{array}{l}16 \text { Stat. } \\
719\end{array}$ & $\begin{array}{l}\text { United States v. First } \\
\text { National Bank (1914) }\end{array}$ & $\begin{array}{l}234 \text { U.S. } \\
245,250(4)\end{array}$ \\
\hline 363 & & $\begin{array}{l}19 \text { March } \\
1867\end{array}$ & 974 & $\begin{array}{l}16 \text { Stat. } \\
719\end{array}$ & $\begin{array}{l}\text { Fairbanks v. United } \\
\text { States (1912) }\end{array}$ & $\begin{array}{l}223 \text { U.S. } \\
215,217(7)+\end{array}$ \\
\hline 364 & $\begin{array}{l}\text { Kiowa; } \\
\text { Comanche }\end{array}$ & $\begin{array}{l}21 \text { October } \\
1867\end{array}$ & 977 & $\begin{array}{l}15 \text { Stat. } \\
581\end{array}$ & $\begin{array}{l}\text { Cook v. United States } \\
\text { (1891) }\end{array}$ & $\begin{array}{l}138 \text { U.S. } \\
157,176\end{array}$ \\
\hline 364 & & $\begin{array}{l}21 \text { October } \\
1867\end{array}$ & 977 & $\begin{array}{l}15 \text { Stat. } \\
581\end{array}$ & $\begin{array}{l}\text { United States v. Texas } \\
(1896)\end{array}$ & $\begin{array}{l}162 \text { U.S. } \\
1,63\end{array}$ \\
\hline 364 & & $\begin{array}{l}21 \text { October } \\
1867\end{array}$ & 977 & $\begin{array}{l}15 \text { Stat. } \\
581\end{array}$ & $\begin{array}{l}\text { United States v. } \\
\text { Andrews (1900) }\end{array}$ & $\begin{array}{l}179 \text { U.S. } \\
96,97\end{array}$ \\
\hline 364 & & $\begin{array}{l}21 \text { October } \\
1867\end{array}$ & 977 & $\begin{array}{l}15 \text { Stat. } \\
581\end{array}$ & $\begin{array}{l}\text { United States v. } \\
\text { Rowell (1917) }\end{array}$ & $\begin{array}{l}243 \text { U.S. } \\
464,466\end{array}$ \\
\hline 364 & & $\begin{array}{l}21 \text { October } \\
1867\end{array}$ & 977 & $\begin{array}{l}15 \text { Stat. } \\
581\end{array}$ & $\begin{array}{l}\text { Oklahoma v. Texas } \\
\text { (1922) }\end{array}$ & $\begin{array}{l}258 \text { U.S. } \\
574,575\end{array}$ \\
\hline 364 & & $\begin{array}{l}21 \text { October } \\
1867\end{array}$ & 977 & $\begin{array}{l}15 \text { Stat. } \\
581\end{array}$ & $\begin{array}{l}\text { United States v. Sioux } \\
\text { Nation of Indians } \\
(1980)\end{array}$ & $\begin{array}{l}448 \text { U.S. } \\
371,410\end{array}$ \\
\hline 364 & & $\begin{array}{l}21 \text { October } \\
1867\end{array}$ & 977 & $\begin{array}{l}15 \text { Stat. } \\
581\end{array}$ & $\begin{array}{l}\text { United States } v \text {. } \\
\text { Andrews (1900) }\end{array}$ & $\begin{array}{l}179 \text { U.S. } \\
96,97(2)\end{array}$ \\
\hline 364 & & $\begin{array}{l}21 \text { October } \\
1867\end{array}$ & 977 & $\begin{array}{l}15 \text { Stat. } \\
581\end{array}$ & $\begin{array}{l}\text { Lone Wolf v. } \\
\text { Hitchcock (1903) }\end{array}$ & $\begin{array}{l}187 \text { U.S. } \\
553,554(3)\end{array}$ \\
\hline 364 & & $\begin{array}{l}21 \text { October } \\
1867\end{array}$ & 977 & $\begin{array}{l}15 \text { Stat. } \\
581\end{array}$ & $\begin{array}{l}\text { Lone Wolf v. } \\
\text { Hitchcock (1903) }\end{array}$ & $\begin{array}{l}187 \text { U.S. } \\
553,554(6)\end{array}$ \\
\hline 364 & & $\begin{array}{l}21 \text { October } \\
1867\end{array}$ & 977 & $\begin{array}{l}15 \text { Stat. } \\
581\end{array}$ & $\begin{array}{l}\text { United States v. } \\
\text { Andrews (1900) }\end{array}$ & $\begin{array}{l}179 \text { U.S. } \\
96,98(11)\end{array}$ \\
\hline 364 & & $\begin{array}{l}21 \text { October } \\
1867\end{array}$ & 977 & $\begin{array}{l}15 \text { Stat. } \\
581\end{array}$ & $\begin{array}{l}\text { United States } v \text {. } \\
\text { Andrews (1900) }\end{array}$ & $\begin{array}{l}179 \text { U.S. } \\
96,98(11.3)\end{array}$ \\
\hline 364 & & $\begin{array}{l}21 \text { October } \\
1867\end{array}$ & 977 & $\begin{array}{l}15 \text { Stat. } \\
581\end{array}$ & $\begin{array}{l}\text { United States } v \text {. } \\
\text { Andrews (1900) }\end{array}$ & $\begin{array}{l}179 \text { U.S. } \\
96,98(11.6)\end{array}$ \\
\hline 364 & & $\begin{array}{l}21 \text { October } \\
1867\end{array}$ & 977 & $\begin{array}{l}15 \text { Stat. } \\
581\end{array}$ & $\begin{array}{l}\text { Lone Wolf v. } \\
\text { Hitchcock (1903) }\end{array}$ & $\begin{array}{l}187 \text { U.S. } \\
553,553(12)\end{array}$ \\
\hline 365 & $\begin{array}{l}\text { Kiowa; } \\
\text { Comanche; } \\
\text { Apache: } \\
\text { Plains }\end{array}$ & $\begin{array}{l}21 \text { October } \\
1867\end{array}$ & 982 & $\begin{array}{l}15 \text { Stat. } \\
589\end{array}$ & $\begin{array}{l}\text { Lone Wolf v. } \\
\text { Hitchcock (1903) }\end{array}$ & $\begin{array}{l}187 \text { U.S. } \\
553,554\end{array}$ \\
\hline 366 & $\begin{array}{l}\text { Cheyenne; } \\
\text { Arapaho }\end{array}$ & $\begin{array}{l}28 \text { October } \\
1867\end{array}$ & 984 & $\begin{array}{l}15 \text { Stat. } \\
593\end{array}$ & $\begin{array}{l}\text { Metlakatla Indian } \\
\text { Community v. Egan } \\
\text { (1962) }\end{array}$ & $\begin{array}{l}369 \text { U.S. } \\
45,52\end{array}$ \\
\hline
\end{tabular}


Table 1 (continued)

\begin{tabular}{|c|c|c|c|c|c|c|}
\hline $\begin{array}{l}\text { Ratified } \\
\text { treaty } \\
\text { number }\end{array}$ & $\begin{array}{l}\text { Signatory } \\
\text { tribe(s) }\end{array}$ & $\begin{array}{l}\text { Treaty } \\
\text { signing date }\end{array}$ & $\begin{array}{l}\text { Kappler } \\
\text { page } \\
\text { number }\end{array}$ & $\begin{array}{l}\text { Statutes at } \\
\text { Large or an } \\
\text { alternative } \\
\text { source }\end{array}$ & Case title & U.S. reports \\
\hline 366 & & $\begin{array}{l}28 \text { October } \\
1867\end{array}$ & 984 & $\begin{array}{l}15 \text { Stat. } \\
593\end{array}$ & $\begin{array}{l}\text { Metlakatla Indian } \\
\text { Community v. Egan } \\
(1962)\end{array}$ & $\begin{array}{l}369 \text { U.S. } \\
45,52(2)\end{array}$ \\
\hline 367 & $\begin{array}{l}\text { Ute: } \\
\text { Tabeguache, } \\
\text { Muache, } \\
\text { Capote, } \\
\text { Wiminuche, } \\
\text { Yampa, } \\
\text { Grand River, } \\
\text { and Uintah }\end{array}$ & 2 March 1868 & 990 & $\begin{array}{l}15 \text { Stat. } \\
619\end{array}$ & $\begin{array}{l}\text { United States v. Santa } \\
\text { Fe Pacific Railroad } \\
\text { Co. (1941) }\end{array}$ & $\begin{array}{l}314 \text { U.S. } \\
339,346\end{array}$ \\
\hline 367 & & 2 March 1868 & 990 & $\begin{array}{l}15 \text { Stat. } \\
619\end{array}$ & $\begin{array}{l}\text { Confederated Bands } \\
\text { of Ute Indians v. } \\
\text { United States (1947) }\end{array}$ & $\begin{array}{l}330 \text { U.S. } \\
169,172\end{array}$ \\
\hline 367 & & 2 March 1868 & 990 & $\begin{array}{l}15 \text { Stat. } \\
619\end{array}$ & $\begin{array}{l}\text { United States } v \text {. } \\
\text { Southern Ute Tribe } \\
\text { (1971) }\end{array}$ & $\begin{array}{l}402 \text { U.S. } \\
159,162\end{array}$ \\
\hline 367 & & 2 March 1868 & 990 & $\begin{array}{l}15 \text { Stat. } \\
619\end{array}$ & $\begin{array}{l}\text { United States v. } \\
\text { McBratney (1882) }\end{array}$ & $\begin{array}{l}104 \text { U.S. } \\
621,622(2)\end{array}$ \\
\hline 367 & & 2 March 1868 & 990 & $\begin{array}{l}15 \text { Stat. } \\
619\end{array}$ & $\begin{array}{l}\text { Kendall v. San Juan } \\
\text { Silver Mining Co. } \\
\text { (1892) }\end{array}$ & $\begin{array}{l}144 \text { U.S. } \\
658,663(2)\end{array}$ \\
\hline 367 & & 2 March 1868 & 990 & $\begin{array}{l}15 \text { Stat. } \\
619\end{array}$ & $\begin{array}{l}\text { Thurston v. United } \\
\text { States (1914) }\end{array}$ & $\begin{array}{l}232 \text { U.S. } \\
469,477(5)\end{array}$ \\
\hline 367 & & 2 March 1868 & 990 & $\begin{array}{l}15 \text { Stat. } \\
619\end{array}$ & $\begin{array}{l}\text { United States v. } \\
\text { McBratney (1882) }\end{array}$ & $\begin{array}{l}104 \text { U.S. } \\
621,622(6)\end{array}$ \\
\hline 367 & & 2 March 1868 & 990 & $\begin{array}{l}15 \text { Stat. } \\
619\end{array}$ & $\begin{array}{l}\text { Thurston v. United } \\
\text { States (1914) }\end{array}$ & $\begin{array}{l}232 \text { U.S. } \\
469,477(6)\end{array}$ \\
\hline 367 & & 2 March 1868 & 990 & $\begin{array}{l}15 \text { Stat. } \\
619\end{array}$ & $\begin{array}{l}\text { United States v. } \\
\text { McBratney (1882) }\end{array}$ & $\begin{array}{l}104 \text { U.S. } \\
621,622(7)\end{array}$ \\
\hline 368 & Cherokee & 27 April 1868 & 996 & $\begin{array}{l}16 \text { Stat. } \\
727\end{array}$ & Holden v. Joy (1872) & $\begin{array}{l}84 \text { U.S. } \\
211,219\end{array}$ \\
\hline 368 & & 27 April 1868 & 996 & $\begin{array}{l}16 \text { Stat. } \\
727\end{array}$ & $\begin{array}{l}\text { United States v. } \\
\text { Cherokee Nation } \\
\text { (1906) }\end{array}$ & $\begin{array}{l}202 \text { U.S. } \\
101,107\end{array}$ \\
\hline 369 & $\begin{array}{l}\text { Sioux: Brule, } \\
\text { Oglala, } \\
\text { Miniconjou, } \\
\text { Yanktonai, } \\
\text { Hunkpapa, } \\
\text { Blackfeet, } \\
\text { Cuthead, Two } \\
\text { Kettle, Sans } \\
\text { Arcs and Santee; } \\
\text { Arapaho }\end{array}$ & 29 April 1868 & 998 & $\begin{array}{l}15 \text { Stat. } \\
635\end{array}$ & $\begin{array}{l}\text { Ex parte Crow Dog } \\
(1883)\end{array}$ & $\begin{array}{l}109 \text { U.S. } \\
556,556\end{array}$ \\
\hline
\end{tabular}


Table 1 (continued)

\begin{tabular}{|c|c|c|c|c|c|c|}
\hline $\begin{array}{l}\text { Ratified } \\
\text { treaty } \\
\text { number }\end{array}$ & $\begin{array}{l}\text { Signatory } \\
\text { tribe(s) }\end{array}$ & $\begin{array}{l}\text { Treaty } \\
\text { signing date }\end{array}$ & $\begin{array}{l}\text { Kappler } \\
\text { page } \\
\text { number }\end{array}$ & $\begin{array}{l}\text { Statutes at } \\
\text { Large or an } \\
\text { alternative } \\
\text { source }\end{array}$ & Case title & U.S. reports \\
\hline 369 & & 29 April 1868 & 998 & $\begin{array}{l}15 \text { Stat. } \\
635\end{array}$ & Felix v. Patrick (1892) & $\begin{array}{l}145 \text { U.S. } \\
317,331\end{array}$ \\
\hline 369 & & 29 April 1868 & 998 & $\begin{array}{l}15 \text { Stat. } \\
635\end{array}$ & $\begin{array}{l}\text { Donnelly v. United } \\
\text { States }(1913)\end{array}$ & $\begin{array}{l}228 \text { U.S. } \\
243,270\end{array}$ \\
\hline 369 & & 29 April 1868 & 998 & $\begin{array}{l}15 \text { Stat. } \\
635\end{array}$ & $\begin{array}{l}\text { Sioux Tribe of Indians } \\
\text { v. United States (1942) }\end{array}$ & $\begin{array}{l}316 \text { U.S. } \\
317,318\end{array}$ \\
\hline 369 & & 29 April 1868 & 998 & $\begin{array}{l}15 \text { Stat. } \\
635\end{array}$ & $\begin{array}{l}\text { Rosebud Sioux Tribe v. } \\
\text { Kneip (1977) }\end{array}$ & $\begin{array}{l}430 \text { U.S. } \\
584,589\end{array}$ \\
\hline 369 & & 29 April 1868 & 998 & $\begin{array}{l}15 \text { Stat. } \\
635\end{array}$ & $\begin{array}{l}\text { United States v. Sioux } \\
\text { Nation of Indians } \\
(1980)\end{array}$ & $\begin{array}{l}448 \text { U.S. } \\
371,374\end{array}$ \\
\hline 369 & & 29 April 1868 & 998 & $\begin{array}{l}15 \text { Stat. } \\
635\end{array}$ & $\begin{array}{l}\text { Montana } v . \text { United } \\
\text { States }(1981)\end{array}$ & $\begin{array}{l}450 \text { U.S. } \\
544,575\end{array}$ \\
\hline 369 & & 29 April 1868 & 998 & $\begin{array}{l}15 \text { Stat. } \\
635\end{array}$ & $\begin{array}{l}\text { South Dakota v. } \\
\text { Bourland (1993) }\end{array}$ & $\begin{array}{l}508 \text { U.S. } \\
679,682\end{array}$ \\
\hline 369 & & 29 April 1868 & 998 & $\begin{array}{l}15 \text { Stat. } \\
635\end{array}$ & $\begin{array}{l}\text { Ex parte Crow Dog } \\
(1883)\end{array}$ & $\begin{array}{l}109 \text { U.S. } \\
556,556(1)\end{array}$ \\
\hline 369 & & 29 April 1868 & 998 & $\begin{array}{l}15 \text { Stat. } \\
635\end{array}$ & $\begin{array}{l}\text { Leighton v. United } \\
\text { States }(1896)\end{array}$ & $\begin{array}{l}161 \text { U.S. } \\
291,295(1)\end{array}$ \\
\hline 369 & & 29 April 1868 & 998 & $\begin{array}{l}15 \text { Stat. } \\
635\end{array}$ & $\begin{array}{l}\text { Ex parte Crow Dog } \\
(1883)\end{array}$ & $\begin{array}{l}109 \text { U.S. } \\
556,559(2)\end{array}$ \\
\hline 369 & & 29 April 1868 & 998 & $\begin{array}{l}15 \text { Stat. } \\
635\end{array}$ & $\begin{array}{l}\text { Noonan v. Caledonia } \\
\text { Mining Co. (1887) }\end{array}$ & $\begin{array}{l}121 \text { U.S. } \\
393,400(2)\end{array}$ \\
\hline 369 & & 29 April 1868 & 998 & $\begin{array}{l}15 \text { Stat. } \\
635\end{array}$ & $\begin{array}{l}\text { Sioux Tribe of Indians } \\
\text { v. United States (1942) }\end{array}$ & $\begin{array}{l}316 \text { U.S. } \\
317,318(2)\end{array}$ \\
\hline 369 & & 29 April 1868 & 998 & $\begin{array}{l}15 \text { Stat. } \\
635\end{array}$ & $\begin{array}{l}\text { United States v. Sioux } \\
\text { Nation of Indians } \\
(1980)\end{array}$ & $\begin{array}{l}448 \text { U.S. } \\
371,374(2)\end{array}$ \\
\hline 369 & & 29 April 1868 & 998 & $\begin{array}{l}15 \text { Stat. } \\
635\end{array}$ & $\begin{array}{l}\text { South Dakota v. } \\
\text { Bourland (1993) }\end{array}$ & $\begin{array}{l}508 \text { U.S. } \\
679,682(2)\end{array}$ \\
\hline 369 & & 29 April 1868 & 998 & $\begin{array}{l}15 \text { Stat. } \\
635\end{array}$ & $\begin{array}{l}\text { Ex parte Crow Dog } \\
(1883)\end{array}$ & $\begin{array}{l}109 \text { U.S. } \\
556,564(5)\end{array}$ \\
\hline 369 & & 29 April 1868 & 998 & $\begin{array}{l}15 \text { Stat. } \\
635\end{array}$ & Elk v. Wilkins (1884) & $\begin{array}{l}112 \text { U.S. } \\
94,103(6)\end{array}$ \\
\hline 369 & & 29 April 1868 & 998 & $\begin{array}{l}15 \text { Stat. } \\
635\end{array}$ & Felix v. Patrick (1892) & $\begin{array}{l}145 \text { U.S. } \\
317,317(6)\end{array}$ \\
\hline 369 & & 29 April 1868 & 998 & $\begin{array}{l}15 \text { Stat. } \\
635\end{array}$ & $\begin{array}{l}\text { Quick Bear v. Leupp } \\
\text { (1908) }\end{array}$ & $\begin{array}{l}210 \text { U.S. } \\
50,51(7)\end{array}$ \\
\hline 369 & & 29 April 1868 & 998 & $\begin{array}{l}15 \text { Stat. } \\
635\end{array}$ & $\begin{array}{l}\text { Rosebud Sioux Tribe } \\
\text { v. Kneip (1977) }\end{array}$ & $\begin{array}{l}430 \text { U.S. } \\
584,589(12)\end{array}$ \\
\hline 369 & & 29 April 1868 & 998 & $\begin{array}{l}15 \text { Stat. } \\
635\end{array}$ & $\begin{array}{l}\text { United States v. Sioux } \\
\text { Nation of Indians } \\
(1980)\end{array}$ & $\begin{array}{l}448 \text { U.S. } \\
371,376(12)\end{array}$ \\
\hline
\end{tabular}


Table 1 (continued)

\begin{tabular}{|c|c|c|c|c|c|c|}
\hline $\begin{array}{l}\text { Ratified } \\
\text { treaty } \\
\text { number }\end{array}$ & $\begin{array}{l}\text { Signatory } \\
\text { tribe(s) }\end{array}$ & $\begin{array}{l}\text { Treaty } \\
\text { signing date }\end{array}$ & $\begin{array}{l}\text { Kappler } \\
\text { page } \\
\text { number }\end{array}$ & $\begin{array}{l}\text { Statutes at } \\
\text { Large or an } \\
\text { alternative } \\
\text { source }\end{array}$ & Case title & U.S. reports \\
\hline 370 & Crow & 7 May 1868 & 1008 & $\begin{array}{l}15 \text { Stat. } \\
649\end{array}$ & $\begin{array}{l}\text { Draper v. United } \\
\text { States }(1896)\end{array}$ & $\begin{array}{l}164 \text { U.S. } \\
240,242\end{array}$ \\
\hline 370 & & 7 May 1868 & 1008 & $\begin{array}{l}15 \text { Stat. } \\
649\end{array}$ & $\begin{array}{l}\text { United States v. } \\
\text { Northern Pacific } \\
\text { Railway Co. }(1940)\end{array}$ & $\begin{array}{l}311 \text { U.S. } \\
317,352\end{array}$ \\
\hline 370 & & 7 May 1868 & 1008 & $\begin{array}{l}15 \text { Stat. } \\
649\end{array}$ & $\begin{array}{l}\text { Metlakatla Indian } \\
\text { Community v. Egan } \\
\text { (1962) }\end{array}$ & $\begin{array}{l}369 \text { U.S. } \\
45,52\end{array}$ \\
\hline 370 & & 7 May 1868 & 1008 & $\begin{array}{l}15 \text { Stat. } \\
649\end{array}$ & $\begin{array}{l}\text { Montana v. United } \\
\text { States }(1981)\end{array}$ & $\begin{array}{l}450 \text { U.S. } \\
544,548\end{array}$ \\
\hline 370 & & 7 May 1868 & 1008 & $\begin{array}{l}15 \text { Stat. } \\
649\end{array}$ & $\begin{array}{l}\text { South Dakota v. } \\
\text { Bourland (1993) }\end{array}$ & $\begin{array}{l}508 \text { U.S. } \\
679,688\end{array}$ \\
\hline 370 & & 7 May 1868 & 1008 & $\begin{array}{l}15 \text { Stat. } \\
649\end{array}$ & $\begin{array}{l}\text { Atkinson Trading Co. } v . \\
\text { Shirley (2001) }\end{array}$ & $\begin{array}{l}532 \text { U.S. } \\
645,650\end{array}$ \\
\hline 370 & & 7 May 1868 & 1008 & $\begin{array}{l}15 \text { Stat. } \\
649\end{array}$ & $\begin{array}{l}\text { Metlakatla Indian } \\
\text { Community v. Egan } \\
\text { (1962) }\end{array}$ & $\begin{array}{l}369 \text { U.S. } \\
45,52(2)\end{array}$ \\
\hline 370 & & 7 May 1868 & 1008 & $\begin{array}{l}15 \text { Stat. } \\
649\end{array}$ & $\begin{array}{l}\text { Montana v. United } \\
\text { States }(1981)\end{array}$ & $\begin{array}{l}450 \text { U.S. } \\
544,548(2)\end{array}$ \\
\hline 370 & & 7 May 1868 & 1008 & $\begin{array}{l}15 \text { Stat. } \\
649\end{array}$ & $\begin{array}{l}\text { Idaho v. United States } \\
\text { (2001) }\end{array}$ & $\begin{array}{l}533 \text { U.S. } \\
262,287(2)\end{array}$ \\
\hline 370 & & 7 May 1868 & 1008 & $\begin{array}{l}15 \text { Stat. } \\
649\end{array}$ & $\begin{array}{l}\text { Montana v. United } \\
\text { States (1981) }\end{array}$ & $\begin{array}{l}450 \text { U.S. } \\
544,558(4)\end{array}$ \\
\hline 370 & & 7 May 1868 & 1008 & $\begin{array}{l}15 \text { Stat. } \\
649\end{array}$ & $\begin{array}{l}\text { United States v. } \\
\text { Powers (1939) }\end{array}$ & $\begin{array}{l}305 \text { U.S. } \\
527,529(6)\end{array}$ \\
\hline 370 & & 7 May 1868 & 1008 & $\begin{array}{l}15 \text { Stat. } \\
649\end{array}$ & $\begin{array}{l}\text { Montana v. United } \\
\text { States }(1981)\end{array}$ & $\begin{array}{l}450 \text { U.S. } \\
544,572(6)\end{array}$ \\
\hline 370 & & 7 May 1868 & 1008 & $\begin{array}{l}15 \text { Stat. } \\
649\end{array}$ & $\begin{array}{l}\text { Montana v. United } \\
\text { States (1981) }\end{array}$ & $\begin{array}{l}450 \text { U.S. } \\
544,572(8)\end{array}$ \\
\hline 370 & & 7 May 1868 & 1008 & $\begin{array}{l}15 \text { Stat. } \\
649\end{array}$ & $\begin{array}{l}\text { Montana v. United } \\
\text { States (1981) }\end{array}$ & $\begin{array}{l}450 \text { U.S. } \\
544,572(9)\end{array}$ \\
\hline 371 & $\begin{array}{l}\text { Cheyenne: } \\
\text { Northern; } \\
\text { Arapaho: } \\
\text { Northern }\end{array}$ & 10 May 1868 & 1012 & $\begin{array}{l}15 \text { Stat. } \\
655\end{array}$ & $\begin{array}{l}\text { Fisher v. District } \\
\text { Court of 16th Judicial } \\
\text { District (1976) }\end{array}$ & $\begin{array}{l}424 \text { U.S. } \\
382,386\end{array}$ \\
\hline 372 & Navajo & 1 June 1868 & 1015 & $\begin{array}{l}15 \text { Stat. } \\
667\end{array}$ & $\begin{array}{l}\text { United States v. Santa } \\
\text { Fe Pacific Railroad } \\
\text { Co. (1941) }\end{array}$ & $\begin{array}{l}314 \text { U.S. } \\
339,346\end{array}$ \\
\hline 372 & & 1 June 1868 & 1015 & $\begin{array}{l}15 \text { Stat. } \\
667\end{array}$ & Williams v. Lee (1959) & $\begin{array}{l}358 \text { U.S. } \\
217,217\end{array}$ \\
\hline 372 & & 1 June 1868 & 1015 & $\begin{array}{l}15 \text { Stat. } \\
667\end{array}$ & $\begin{array}{l}\text { Metlakatla Indian } \\
\text { Community v. Egan } \\
\text { (1962) }\end{array}$ & $\begin{array}{l}369 \text { U.S. } \\
45,52\end{array}$ \\
\hline
\end{tabular}


Table 1 (continued)

\begin{tabular}{|c|c|c|c|c|c|c|}
\hline $\begin{array}{l}\text { Ratified } \\
\text { treaty } \\
\text { number }\end{array}$ & $\begin{array}{l}\text { Signatory } \\
\text { tribe(s) }\end{array}$ & $\begin{array}{l}\text { Treaty } \\
\text { signing date }\end{array}$ & $\begin{array}{l}\text { Kappler } \\
\text { page } \\
\text { number }\end{array}$ & $\begin{array}{l}\text { Statutes at } \\
\text { Large or an } \\
\text { alternative } \\
\text { source }\end{array}$ & Case title & U.S. reports \\
\hline 372 & & 1 June 1868 & 1015 & $\begin{array}{l}15 \text { Stat. } \\
667\end{array}$ & $\begin{array}{l}\text { Warren Trading Post } \\
\text { Co. v. Arizona Tax } \\
\text { Commission }(1965)\end{array}$ & $\begin{array}{l}380 \text { U.S. } \\
686\end{array}$ \\
\hline 372 & & 1 June 1868 & 1015 & $\begin{array}{l}15 \text { Stat. } \\
667\end{array}$ & $\begin{array}{l}\text { McClanahan v. } \\
\text { Arizona Tax } \\
\text { Commission (1973) }\end{array}$ & $\begin{array}{l}411 \text { U.S. } \\
164,174\end{array}$ \\
\hline 372 & & 1 June 1868 & 1015 & $\begin{array}{l}15 \text { Stat. } \\
667\end{array}$ & $\begin{array}{l}\text { Moe v. Confederated } \\
\text { Salish and Kootenai } \\
\text { Tribes of Flathead } \\
\text { Reservation (1976) }\end{array}$ & $\begin{array}{l}425 \text { U.S. } \\
463,475\end{array}$ \\
\hline 372 & & 1 June 1868 & 1015 & $\begin{array}{l}15 \text { Stat. } \\
667\end{array}$ & $\begin{array}{l}\text { United States v. } \\
\text { Wheeler (1978) }\end{array}$ & $\begin{array}{l}435 \text { U.S. } \\
313,324\end{array}$ \\
\hline 372 & & 1 June 1868 & 1015 & $\begin{array}{l}15 \text { Stat. } \\
667\end{array}$ & $\begin{array}{l}\text { Atkinson Trading Co. } v \text {. } \\
\text { Shirley (2001) }\end{array}$ & $\begin{array}{l}532 \text { U.S. } \\
645,647+\end{array}$ \\
\hline 372 & & 1 June 1868 & 1015 & $\begin{array}{l}15 \text { Stat. } \\
667\end{array}$ & $\begin{array}{l}\text { Nevada v. Hicks } \\
(2001)\end{array}$ & $\begin{array}{l}533 \text { U.S. } \\
353,361\end{array}$ \\
\hline 372 & & 1 June 1868 & 1015 & $\begin{array}{l}15 \text { Stat. } \\
667\end{array}$ & $\begin{array}{l}\text { Metlakatla Indian } \\
\text { Community v. Egan } \\
\text { (1962) }\end{array}$ & $\begin{array}{l}369 \text { U.S. } \\
45,52(2)\end{array}$ \\
\hline 372 & & 1 June 1868 & 1015 & $\begin{array}{l}15 \text { Stat. } \\
667\end{array}$ & $\begin{array}{l}\text { Ramah Navajo School } \\
\text { Board, Inc. v. Bureau } \\
\text { of Revenue (1982) }\end{array}$ & $\begin{array}{l}458 \text { U.S. } \\
832,839(6)\end{array}$ \\
\hline 373 & $\begin{array}{l}\text { Shoshone: } \\
\text { Eastern; } \\
\text { Bannock }\end{array}$ & 3 July 1868 & 1020 & $\begin{array}{l}15 \text { Stat. } \\
673\end{array}$ & $\begin{array}{l}\text { Utah and Northern } \\
\text { Railway v. Fisher } \\
(1885)\end{array}$ & $\begin{array}{l}116 \text { U.S. } \\
28,29\end{array}$ \\
\hline 373 & & 3 July 1868 & 1020 & $\begin{array}{l}15 \text { Stat. } \\
673\end{array}$ & $\begin{array}{l}\text { Marks v. United } \\
\text { States (1896) }\end{array}$ & $\begin{array}{l}161 \text { U.S. } \\
297,299\end{array}$ \\
\hline 373 & & 3 July 1868 & 1020 & $\begin{array}{l}15 \text { Stat. } \\
673\end{array}$ & $\begin{array}{l}\text { Shoshone Tribe of } \\
\text { Indians v. United } \\
\text { States (1937) }\end{array}$ & $\begin{array}{l}299 \text { U.S. } \\
476,476\end{array}$ \\
\hline 373 & & 3 July 1868 & 1020 & $\begin{array}{l}15 \text { Stat. } \\
673\end{array}$ & $\begin{array}{l}\text { United States v. } \\
\text { Shoshone Tribe of } \\
\text { Indians (1938) }\end{array}$ & $\begin{array}{l}304 \text { U.S. } \\
111,113\end{array}$ \\
\hline 373 & & 3 July 1868 & 1020 & $\begin{array}{l}15 \text { Stat. } \\
673\end{array}$ & $\begin{array}{l}\text { Northwestern Bands } \\
\text { of Shoshone Indians v. } \\
\text { United States (1945) }\end{array}$ & $\begin{array}{l}324 \text { U.S. } \\
335,338\end{array}$ \\
\hline 373 & & 3 July 1868 & 1020 & $\begin{array}{l}15 \text { Stat. } \\
673\end{array}$ & $\begin{array}{l}\text { United States v. } \\
\text { Mazurie (1975) }\end{array}$ & $\begin{array}{l}419 \text { U.S. } \\
544,546\end{array}$ \\
\hline 373 & & 3 July 1868 & 1020 & $\begin{array}{l}15 \text { Stat. } \\
673\end{array}$ & $\begin{array}{l}\text { Ward v. Race Horse } \\
\text { (1896) }\end{array}$ & $\begin{array}{l}163 \text { U.S. } \\
504,509(1)\end{array}$ \\
\hline 373 & & 3 July 1868 & 1020 & $\begin{array}{l}15 \text { Stat. } \\
673\end{array}$ & $\begin{array}{l}\text { Harkness v. Hyde } \\
\text { (1879) }\end{array}$ & $\begin{array}{l}98 \text { U.S. } \\
476,477(2)\end{array}$ \\
\hline 373 & & 3 July 1868 & 1020 & $\begin{array}{l}15 \text { Stat. } \\
673\end{array}$ & $\begin{array}{l}\text { Ward v. Race Horse } \\
\text { (1896) }\end{array}$ & $\begin{array}{l}163 \text { U.S. } \\
504,505(2)\end{array}$ \\
\hline
\end{tabular}


Table 1 (continued)

\begin{tabular}{|c|c|c|c|c|c|c|}
\hline $\begin{array}{l}\text { Ratified } \\
\text { treaty } \\
\text { number }\end{array}$ & $\begin{array}{l}\text { Signatory } \\
\text { tribe(s) }\end{array}$ & $\begin{array}{l}\text { Treaty } \\
\text { signing date }\end{array}$ & $\begin{array}{l}\text { Kappler } \\
\text { page } \\
\text { number }\end{array}$ & $\begin{array}{l}\text { Statutes at } \\
\text { Large or an } \\
\text { alternative } \\
\text { source }\end{array}$ & Case title & U.S. reports \\
\hline 373 & & 3 July 1868 & 1020 & $\begin{array}{l}15 \text { Stat. } \\
673\end{array}$ & $\begin{array}{l}\text { Shoshone Tribe of } \\
\text { Indians v. United } \\
\text { States (1937) }\end{array}$ & $\begin{array}{l}299 \text { U.S. } \\
476,486(2)\end{array}$ \\
\hline 373 & & 3 July 1868 & 1020 & $\begin{array}{l}15 \text { Stat. } \\
673\end{array}$ & $\begin{array}{l}\text { Northwestern Bands } \\
\text { of Shoshone Indians v. } \\
\text { United States 1945) }\end{array}$ & $\begin{array}{l}324 \text { U.S. } \\
335,338(2)\end{array}$ \\
\hline 373 & & 3 July 1868 & 1020 & $\begin{array}{l}15 \text { Stat. } \\
673\end{array}$ & $\begin{array}{l}\text { Nevada v. Hicks } \\
\text { (2001) }\end{array}$ & $\begin{array}{l}533 \text { U.S. } \\
353,363(2)\end{array}$ \\
\hline 373 & & 3 July 1868 & 1020 & $\begin{array}{l}15 \text { Stat. } \\
673\end{array}$ & $\begin{array}{l}\text { Ward v. Race Horse } \\
\text { (1896) }\end{array}$ & $\begin{array}{l}163 \text { U.S. } \\
504,505(4)\end{array}$ \\
\hline 373 & & 3 July 1868 & 1020 & $\begin{array}{l}15 \text { Stat. } \\
673\end{array}$ & Coyle v. Smith (1911) & $\begin{array}{l}221 \text { U.S. } \\
559,576(4)\end{array}$ \\
\hline 999 & $\begin{array}{l}\text { Sioux; } \\
\text { Cheyenne; } \\
\text { Arapaho; } \\
\text { Crow; } \\
\text { Assiniboin; } \\
\text { Gros Ventre; } \\
\text { Mandan; } \\
\text { Arikara }\end{array}$ & $\begin{array}{l}17 \text { September } \\
1851\end{array}$ & 594 & $\begin{array}{l}11 \text { Stat. } \\
749\end{array}$ & $\begin{array}{l}\text { British-American Oil } \\
\text { Producing Co. v. } \\
\text { Board of Equalization } \\
\text { (1936) }\end{array}$ & $\begin{array}{l}299 \text { U.S. } \\
159,1162\end{array}$ \\
\hline 999 & & $\begin{array}{l}17 \text { September } \\
1851\end{array}$ & 594 & $\begin{array}{l}11 \text { Stat. } \\
749\end{array}$ & $\begin{array}{l}\text { Northwestern Bands } \\
\text { of Shoshone Indians v. } \\
\text { United States (1945) }\end{array}$ & $\begin{array}{l}324 \text { U.S. } \\
335,349\end{array}$ \\
\hline 999 & & $\begin{array}{l}17 \text { September } \\
1851\end{array}$ & 594 & $\begin{array}{l}11 \text { Stat. } \\
749\end{array}$ & $\begin{array}{l}\text { United States v. Sioux } \\
\text { Nation of Indians } \\
(1980)\end{array}$ & $\begin{array}{l}448 \text { U.S. } \\
371,374\end{array}$ \\
\hline 999 & & $\begin{array}{l}17 \text { September } \\
1851\end{array}$ & 594 & $\begin{array}{l}11 \text { Stat. } \\
749\end{array}$ & $\begin{array}{l}\text { Montana v. United } \\
\text { States }(1981)\end{array}$ & $\begin{array}{l}450 \text { U.S. } \\
544,548\end{array}$ \\
\hline
\end{tabular}

in Table 1, to federally recognized treaties in 70 Supreme Court opinions decided after 1940.

This examination covers all Supreme Court sessions through the 2000-2001 term (i.e., the opinions contained in U.S. Reports through volume number 533). The volumes of Shepard's Federal Statute Citations ${ }^{12}$ were employed, by using each treaty's Statutes at Large reference, ${ }^{13}$ to identify cases before the Court. Further, each Statutes at Large citation was re-examined with the full LexisNexis on-line database to identify any case(s) other than those reported in Shepard's Federal Statute Citations. References to an additional 34 treaties, cited in 39 instances, were found in this latter manner. These specific entries are indicated in Table 1 by a plus sign ("+") after the U.S. Reports citation for the case. ${ }^{14}$ 
Table 1 is an aggregate of the following:

- The ratified treaty number, assigned by the Department of State, of each of the 209 treaties that has appeared before the Supreme Court through the 2000-2001 term;

- The name(s) of the participating tribe(s), with an expansion of the "etc." found in the titles of many treaties in Kappler's work into a complete list of parties. For example, ratified treaty number 23 is the Treaty with the Wyandot, etc., 1795 (Kappler, 1971, pp. 39-45) and the entry for this document in Table 1 identifies as signatories the Wyandot as well as the Delaware, Shawnee, Ottawa, Chippewa, Potawatomi, Miami, Eel River, Wea, Kickapoo, Piankashaw, and Kaskaskia;

- The signing date of the treaty, taken from each treaty's entry in volume 2 of Kappler's Indian Affairs: Laws and Treaties (1971);

- The treaty page number, according to Kappler's data;

- The Statutes at Large, or an alternate, citation for that treaty; ${ }^{15}$

- The case title and year of the Supreme Court decision ${ }^{16}$ that referred to that specific treaty; and

- The U.S. Reports citation of the opinion of that case. Individual article numbers are enclosed in parentheses. U.S. Reports volume number in ascending decision year order arranges the cases within each treaty. Cases (if any) that refer to the preamble or to specific article numbers ${ }^{17}$ follow general citations to the same treaty. For instance, within this table, Pam-To-Pee v. United States (148 U.S. 691 [1893]), Cherokee Nation v. Blackfeather (155 U.S. 218 [1894]), and Jones v. Meehan (175 U.S. 1 [1899]) are sequentially ordered and cite Article 4 in ratified treaty number 23, the Treaty with the Wyandot, etc., 1795 (Kappler, 1971, pp. 39-45). These three entries follow five general citations to the treaty by cases decided between 1829 and 1937.

Table 2 is a case title index to these Indian treaties. Both principal entries and reverse titles have been included. This table is an inventory of case-specific collections of ratified treaty numbers that identifies the instrument(s) cited in each action before the Court. Those citations from the LexisNexis examination maintain the plus sign as an identifier of that source. As a model, there are five entries associated with Lone Wolf v. Hitchcock (187 U.S. 553 [1903]). Two of these entries identify single, general citations to each of ratified treaty numbers 355 and 365, and three records account for specific citations to Articles 3, 6, and 12 of ratified treaty number $364 .^{18}$

For those treaties, or components of treaties, cited more than once within a case, a number sign ("\#") follows the ratified treaty number indicator. For example, Minnesota v. Mille Lacs Band of Chippewa Indians (526 U.S. 172 [1999]) cited each of ratified treaty number 223, 242, and 275-in whole or in part-more than once. Each of these citations in Table 2 thus has the added indicator (e.g., "275(2)\#"). Note, also, that reference was made for the first time before the Supreme Court to three treaties during this case (Bernholz, 2002). The three documents are ratified treaty numbers 227, 228, and $249,{ }^{19}$ and there are six citation entries in Table 1 for these instruments. 
Table 2

A case title index to Indian treaties, identified by Department of State Ratified Treaty Number, which have been cited in the opinions of the U.S. Supreme Court

\begin{tabular}{|c|c|c|c|c|c|c|c|c|c|}
\hline Case title & Cited & Ratified & Treaty & Number(s) & & & & & \\
\hline Alberty v. United States (1896) & $358(9)$ & $358(13)$ & & & & & & & \\
\hline $\begin{array}{l}\text { Alcea Band of Tillamooks, } \\
\text { United States v. (1946) }\end{array}$ & 324 & & & & & & & & \\
\hline $\begin{array}{l}\text { Algoma Lumber Co., United States v. } \\
\text { (1939) }\end{array}$ & 332 & & & & & & & & \\
\hline Allain, Papasan v. (1986) & $173+$ & & & & & & & & \\
\hline Amos, Winton v. (1921) & 160 & $160(3)$ & $160(14)$ & $160(19)$ & & & & & \\
\hline Andrews, United States v. (1900) & 364 & $364(2)$ & $364(11)$ & $364(11.3)$ & $364(11.6)$ & & & & \\
\hline $\begin{array}{l}\text { Arizona Tax Commission, McClanahan v. } \\
\quad \text { (1973) }\end{array}$ & 372 & & & & & & & & \\
\hline $\begin{array}{l}\text { Arizona Tax Commission, } \\
\quad \text { Warren Trading Post Co. v. (1965) }\end{array}$ & 8 & $8(5)$ & 372 & & & & & & \\
\hline Arkansas, Oklahoma v. (1985) & 152 & & & & & & & & \\
\hline Arkansas v. Mississippi (1919) & $152(1)$ & & & & & & & & \\
\hline Arredondo, United States v. (1832) & 23 & & & & & & & & \\
\hline Ashley, Cunningham v. (1853) & 96 & 123 & & & & & & & \\
\hline Atkinson Trading Co. v. Shirley (2001) & 290 & 370 & $372+$ & & & & & & \\
\hline $\begin{array}{l}\text { Atlantic and Pacific Railroad Co. v. } \\
\text { Mingus (1897) }\end{array}$ & $160(4)$ & $167(14)$ & $199(5)$ & $248(1)$ & 352 & 355 & 356 & 357 & 358 \\
\hline Ayres v. Carver (1855) & 173 & 191 & & & & & & & \\
\hline Ball v. Halsell (1896) & $248(5)$ & & & & & & & & \\
\hline Ballinger, Conley v. (1910) & $285(1)$ & $285(2)$ & $361(13)$ & & & & & & \\
\hline Ballinger v. United States (1910) & 160 & & & & & & & & \\
\hline $\begin{array}{l}\text { Bardon v. Northern Pacific Railroad Co. } \\
\text { (1892) }\end{array}$ & 126 & & & & & & & & \\
\hline Barney v. Keokuk (1877) & 121 & & & & & & & & \\
\hline $\begin{array}{l}\text { Becker, New York ex rel. Kennedy v. } \\
\quad \text { (1916) }\end{array}$ & 27 & 290 & & & & & & & \\
\hline Beecher v. Wetherby (1877) & 139 & 161 & 253 & 253(8) & 269 & $269(2)$ & & & \\
\hline Best v. Polk (1873) & 173 & 191 & 191(6) & & & & & & \\
\hline Blackfeather, Cherokee Nation v. (1894) & $23(4)$ & $90(4)$ & 268 & $268(3)$ & $358(15)$ & & & & \\
\hline Blackfeather, United States v. (1894) & 143 & $143(2)$ & $164(2)$ & 164(4) & $164(5)$ & $164(7)$ & $164(11)$ & $164(13)$ & $268(8)$ \\
\hline
\end{tabular}


Blackfeather v. United States (1903)

Blacksmith, Fellows v. (1857)

Board of County Commissioners v.

United States (1939)

Board of Equalization, British-American

Oil Producing Co. v. (1936)

Bourland, South Dakota v. (1993)

Bowling and Miami Investment Co. v.

United States (1914)

Boyd v. Nebraska (1892)

Brendale v. Confederated Tribes and Bands of the Yakima Indian Nation (1989)

Brewer-Elliott Oil and Gas Co. v. United States (1922)

Brindle, United States v. (1884)

British-American Oil Producing Co. $v$ Board of Equalization (1936)

Brooks, Marsh v. (1850)

Brooks, Marsh v. (1852)

Brooks, United States v. (1850)

Browder, Preston v. (1816)

Brown, Fee v. (1896)

Bryan v. Itasca County (1976)

Budzisz v. Illinois Steel Co. (1898)

Burcham, Crews v. (1862)

Bureau of Revenue, Ramah Navajo

School Board, Inc. v. (1982)

Burney, Roff v. (1897)

Buttz v. Northern Pacific Railroad

$$
\text { Co. (1886) }
$$

Caldwell, Robinson v. (1897)

Caledonia Mining Co., Noonan v

(1887)

Campbell, Starr v. (1908)
268(11) $268(14) \quad 358(9) \quad 358(15)$

$230 \quad 230(10) \quad 230(15) \quad 241$

241(1) 241(2) 241(3) 241(4)

241(5) 241(7)

318

999

$369 \quad 369(2) \quad 370$

$101+\quad 178 \quad 180$

273

$274+$

361

160(14) 199(12)

290

$358 \quad 358(16)$

$299 \quad 999$

$\begin{array}{llll}88 & 106 & 121 & 121(1)\end{array}$

$\begin{array}{llll}43 & 55 & 121 & 121(1)\end{array}$

$197 \quad 197(1)$

$18 \quad 29$

$275 \quad 275(1) \quad 275(2) \quad 275(2.1-2.6) \quad 275(3) \quad 275(7)$

287

16

179

253

177

372(6)

292(7) 355(38)

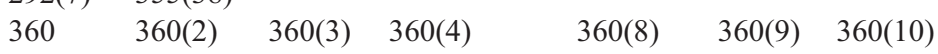

291

$369(2)$

$275(3)$ 
Table 2 (continued)

\begin{tabular}{|c|c|c|c|c|c|c|c|c|c|c|}
\hline Case title & Cited & Ratified & Treaty & Number(s) & & & & & & \\
\hline Cannon, White v. (1868) & 197 & & & & & & & & & \\
\hline Capoeman, Squire v. (1956) & 294 & $294(2)$ & & & & & & & & \\
\hline Carpenter, United States v. (1884) & 307 & & & & & & & & & \\
\hline Carr, Doolan v. (1888) & 191 & & & & & & & & & \\
\hline Carver, Ayres v. (1855) & 173 & 191 & & & & & & & & \\
\hline Celestine, United States v. (1909) & $266(6)$ & 281 & $283(3)$ & $283(7)$ & & & & & & \\
\hline Chandler, Spalding v. (1896) & 110 & $110(1)$ & $110(3)$ & 201 & 297 & & & & & \\
\hline $\begin{array}{l}\text { Charles W. Cox, Ltd., Pigeon River } \\
\text { Improvement, Slide and Boom Co.v. } \\
\text { (1934) }\end{array}$ & $275(2.5)$ & & & & & & & & & \\
\hline Chase, United States v. (1917) & 318 & $334(4)$ & 362 & & & & & & & \\
\hline Chase v. United States (1921) & 266 & 334 & & & & & & & & \\
\hline Cherokee Intermarriage Cases (1906) & 199(5) & $248(1)$ & $248(4)$ & $358(15)$ & $358(20)$ & & & & & \\
\hline $\begin{array}{l}\text { Cherokee Nation, Delaware Indians } v \text {. } \\
\text { (1904) }\end{array}$ & $357(4)$ & $358(15)$ & $358(16)$ & $358(20)$ & $358(23)$ & & & & & \\
\hline Cherokee Nation, Stephens v. (1899) & $160(14)$ & 199(5) & 248 & $248(1)$ & 358 & $358(9)$ & & & & \\
\hline Cherokee Nation, United States v. (1906) & $\begin{array}{l}18 \\
368\end{array}$ & 89 & 106 & 152 & 199 & $199(1)$ & 248 & $248(4)$ & 248(11) & 358 \\
\hline Cherokee Nation v. Blackfeather (1894) & $23(4)$ & $90(4)$ & 268 & $268(3)$ & $358(15)$ & & & & & \\
\hline \multirow[t]{4}{*}{ Cherokee Nation v. Georgia (1831) } & 8 & $8(6)$ & 11 & $11(3)$ & 11(4) & 11(5) & $11(6)$ & 11(9) & $11(12)$ & 18 \\
\hline & $18(2)$ & $18(4)$ & $18(7)$ & $18(8)$ & $18(11)$ & $18(14)$ & $18(16)$ & 20 & 29 & 40 \\
\hline & 42 & 48 & 49 & 53 & 76 & 77 & 89 & $89(5)$ & $89(8)$ & $106(\mathrm{P})$ \\
\hline & $106(5)$ & 152 & & & & & & & & \\
\hline Cherokee Nation v. Hitchcock (1902) & $152(2)$ & 182(1) & 199 & 199(2) & 199(3) & $199(5)$ & $248(1)$ & 358 & & \\
\hline \multirow[t]{2}{*}{ Cherokee Nation v. Journeycake (1894) } & $152(2)$ & 182 & 199(3) & $352(3)$ & 355 & 356 & $358(9)$ & $358(15)$ & $358(16)$ & $358(17)$ \\
\hline & $358(20)$ & $358(23)$ & & & & & & & & \\
\hline $\begin{array}{l}\text { Cherokee Nation v. Southern Kansas } \\
\text { Railway Co. (1890) }\end{array}$ & 11 & 29 & 49 & 182 & 199 & 248 & 358 & & & \\
\hline Cherokee Nation v. United States (1926) & 89 & 106 & 152 & 182 & 199 & 248 & 358 & $358(23)$ & & \\
\hline $\begin{array}{l}\text { Cherokee Nation and United States v. } \\
\text { Whitmire (1912) }\end{array}$ & 358 & $358(9)$ & & & & & & & & \\
\hline Cherokee Tobacco (1871) & $358(10)$ & & & & & & & & & \\
\hline
\end{tabular}




$\begin{array}{llllllllll}11 & 11(9) & 18 & 18(1) & 20 & 29 & 48 & 89 & 106 & 152 \\ 182 & 199 & 199(2) & 199(8) & 199(12) & 199(15) & 248 & 248(1) & 248(4) & 248(9) \\ 248(10) & 358(23) & & & & & & & & \end{array}$

Chicago, Williams v. (1917)

23

Chickasaw Nation, Oklahoma Tax $\quad 160 \quad 220+$

Commission v. (1995)

Chippewa Indians of Minnesota $v$

United States (1937)

Choctaw Nation, Heirs of Garland v. (1921)

Choctaw Nation, United States v. (1900)

Choctaw Nation, United States v. (1904)

Choctaw Nation v. Oklahoma (1970)

Choctaw Nation v. United States (1886)

Choctaw Nation of Indians $v$.

United States (1943)

Christy, Seneca Nation v. (1896)

Clairmont v. United States (1912)

Clark v. Smith (1839)

Clark, Kinney v. (1844)

Clark, Libby v. (1886)

Coffee v. Groover (1887)

Coleman, Verden v. (1862)

Commissioners, Pennockv. (1881)

Confederated Bands and Tribes of the

$160 \quad 220+$

$\begin{array}{llllllllll}23 & 45 & 54 & 109 & 110 & 111 & 117 & 139 & 145 & 148 \\ 207 & 219 & 242 & 250 & 251 & 275 & 287 & 327 & 327(6) & 330 \\ 331 & 354 & 363 & & & & & & & \\ 292 & & & & & & & & & \\ & & & & & & & & & \\ 96(2) & 115 & 115(2) & 160(2) & 160(3) & 160(4) & 220 & 292 & 292(1) & 292(2) \\ 292(3) & 292(4) & 292(5) & 292(6) & 292(7) & 292(8) & 292(9) & 292(10) & 352 & 355(1) \\ 355(2) & 355(3) & 355(4) & 355(30) & 355(43) & 355(46) & 355(51) & 356(3) & & \\ 173 & 292 & 355(2) & 355(3) & & & & & & \\ 11 & 12 & 18(7) & 29 & 31 & 48 & 89 & 89(5) & 106 & 115(2) \\ 124 & 152 & 160(4) & 160(18) & 182 & 199 & 199(2) & 220+ & 292 & \\ 115 & 115(2) & 115(4) & 124 & 124(7) & 160 & 160(3) & 160(14) & 160(15) & 160(16) \\ 160(18) & 160(19) & 160(20) & 292 & 292(11) & 292(12) & 292(13) & 292(14) & 355 & \\ 355 & 355(3) & 355(46) & & & & & & & \end{array}$$$
21
$$$$
295
$$$$
105
$$$$
\begin{array}{llllllll}
7 & 11(4) & 12(3) & 13(3) & 13(4) & 18 & 105 & 106(1)
\end{array}
$$$$
162+\quad 320 \quad 320(1) \quad 320(3) \quad 320(7)
$$$$
32 \quad 50 \quad 61
$$$$
243 \quad 243(2)+\quad 312 \quad 312(10) \quad 359(17) \quad 359(18)
$$

Yakima Indian Nation, Washington $v$. (1979)

Confederated Bands of Ute Indians $v$. 
Confederated Salish and Kootenai Tribes $295 \quad 372$

of Flathead Reservation, Moe v. (1976)

Confederated Tribes and Bands of the

Yakima Indian Nation, Brendale v.

$$
\text { (1989) }
$$

Confederated Tribes and Bands of the Yakima Indian Nation, County of Yakima v. (1992)

Confederated Tribes of the Colville Indian Reservation, Washington $v$ (1980)

Conley v. Ballinger (1910)

Conolly, Wiggan v. (1896)

Cook, Missouri, Kansas and Texas Railway Co. v. (1896)

Cook, United States v. (1874)

Cook v. United States (1891)

County of Oneida, Oneida Indian Nation v. (1974)

County of Oneida v. Oneida Indian Nation (1985)

County of Yakima v. Confederated Tribes and Bands of the Yakima Indian Nation (1992)

Coxe, United States use of Mackey v. (1856)

Coy v. Mason (1855)

Coyle v. Smith (1911)

Creek Nation, United States v. (1935)

Creek Nation v. United States (1943)

Crews v. Burcham (1862)

Crommelin, Minter v. (1856)

290

$257(9)+290+$

$283 \quad 286 \quad 290$

285(1) 285(2) 361(13)

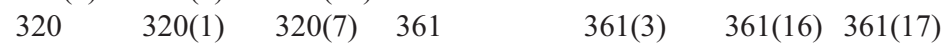

$161 \quad 161(1)$

$152 \quad 262 \quad 343 \quad 364$

$9 \quad 16 \quad 21$

$\begin{array}{llll}9 & 16 & 21 & 21(2)\end{array}$

21(7)

28

230

$230(2)$

$257(9)+290+$

$199(5)$

121

373(4)

$183(2) \quad 183(3) \quad 356(3) \quad 356(8)$

Crow Dog. See Ex parte Crow Dog (1883)

356(1) 
Cutler. See New York ex rel. Cutler v. Dibble (1859)

Dann, United States v. (1985)

De Coteau v. District County Court for the 10th Judicial District (1975)

De Graffenried, Woodward v. (1915)

Delaware Indians v. Cherokee Nation (1904)

Delaware Tribal Business Committee v. Weeks (1977)

Dept. of Game, Puyallup Tribe v. (1968)

Dept. of Game, Puyallup Tribe, Inc. v. (1977)

Dept. of Game v. Puyallup Tribe (1973)

Des Moines Valley Railroad Co.,

Dubuque and Sioux City

Railroad Co. v. (1883)

Dibble, New York ex rel. Cutler v. (1859)

Dick v. United States (1908)

Dion, United States v. (1986)

District County Court for the 10th

Judicial District, De Coteau v. (1975)

District Court of 16th Judicial District,

Fisher v. (1976)

Doe ex. dem. Mann v. Wilson (1860)

Donnelly v. United States (1913)

352(6)

$360 \quad 360(3) \quad 360(10)$

144(6) $\quad 167(12) \quad 167(14) \quad 183(3)$

303(4) 303(15) 352

355

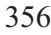

358

$357(4) \quad 358(15) \quad 358(16) \quad 358(20)$

$358(23)$

$\begin{array}{lllllll}103 & 158 & 267 & 314(4) & 357 & 357(3) & 357(9)\end{array}$

$281 \quad 281(2) \quad 281(3) \quad 281(6) \quad 290$

$281 \quad 281(2) \quad 281(3)$

281

Doolan v. Carr (1888)

Draper v. United States (1896)

Dubuque and Sioux City Railroad Co. v.

Des Moines Valley Railroad Co. (1883)

Dunbar v. Green (1905)

Duncan, Witherspoon v. (1867)

$$
281(2) \quad 281(3)
$$

Eastern Cherokees. See In re Eastern Cherokees (1911) 


\begin{tabular}{|c|c|c|c|c|c|c|c|c|c|c|}
\hline Case title & Cited & Ratified & Treaty & Number(s) & & & & & & \\
\hline Egan, Kake v. (1962) & 152 & & & & & & & & & \\
\hline \multirow{2}{*}{$\begin{array}{l}\text { Egan, Metlakatla Indian Community v. } \\
\quad(1962)\end{array}$} & 143 & 152 & 221 & 230 & $230(2)$ & 243 & 294 & 366 & $366(2)$ & 370 \\
\hline & $370(2)$ & 372 & $372(2)$ & & & & & & & \\
\hline \multirow[t]{2}{*}{ Elkv. Wilkins (1884) } & 89 & 115 & 124 & 160 & 199 & 254 & 285 & 301 & 318 & 320 \\
\hline & 321 & 353 & 357 & 361 & 362 & $369(6)$ & & & & \\
\hline Elwood v. Flannigan (1882) & $177(3)$ & & & & & & & & & \\
\hline Ex parte Crow Dog (1883) & 11 & 369 & $369(1)$ & $369(2)$ & $369(5)$ & & & & & \\
\hline Ex parte Taylor $(1852)$ & 199 & & & & & & & & & \\
\hline Fairbanks v. United States (1912) & $363(7)+$ & & & & & & & & & \\
\hline Faulkner, Hegler v. (1894) & 159 & & & & & & & & & \\
\hline $\begin{array}{l}\text { Federal Power Commission v. } \\
\quad \text { Oregon }(1955)\end{array}$ & 293 & 293(1) & & & & & & & & \\
\hline $\begin{array}{l}\text { Federal Power Commission v. } \\
\quad \text { Tuscarora Indian Nation (1960) }\end{array}$ & 9 & 16 & 19 & 21 & $21(3)$ & $21(6)$ & 22 & 27 & 230 & $230(14)$ \\
\hline Fee v. Brown (1896) & 275 & $275(1)$ & $275(2)$ & $275(2.1-2.6)$ & $275(3)$ & $275(7)$ & & & & \\
\hline Felix v. Patrick (1892) & 159 & 369 & $369(6)$ & & & & & & & \\
\hline Fellows v. Blacksmith (1857) & 230 & $230(10)$ & $230(15)$ & 241 & 241(1) & $241(2)$ & 241(3) & 241(4) & $241(5)$ & $241(7)$ \\
\hline $\begin{array}{l}\text { First National Bank, United States } v . \\
\quad(1914)\end{array}$ & $223(3)$ & $242(4)$ & $250(4)$ & 275 & $287(6)$ & 363 & $363(4)$ & & & \\
\hline $\begin{array}{l}\text { Fisher, United States ex rel. Lowe v. } \\
\text { (1912) }\end{array}$ & $358(3)$ & $358(9)$ & & & & & & & & \\
\hline $\begin{array}{l}\text { Fisher, Utah and Northern Railway v. } \\
\quad(1885)\end{array}$ & 373 & & & & & & & & & \\
\hline $\begin{array}{l}\text { Fisher v. District Court of 16th } \\
\quad \text { Judicial District (1976) }\end{array}$ & 371 & & & & & & & & & \\
\hline Flannigan, Elwood v. (1882) & $177(3)$ & & & & & & & & & \\
\hline Fleming v. McCurtain (1909) & $115(2)$ & $160(2)$ & $160(4)$ & $160(5)$ & $160(18)$ & 220 & 292 & $355(11-36)$ & & \\
\hline $\begin{array}{l}\text { Forty-Three Gallons of Whiskey, } \\
\text { United States v. (1876) }\end{array}$ & $287+$ & 327 & $327(7)$ & & & & & & & \\
\hline $\begin{array}{l}\text { Forty-Three Gallons of Whiskey, } \\
\text { United States v. (1883) }\end{array}$ & $327(7)$ & & & & & & & & & \\
\hline Francis v. Francis (1906) & 109 & $162+$ & & & & & & & & \\
\hline Frost v. Wenie (1895) & 126 & 338 & $338(1)$ & $338(2)$ & $338(16)$ & & & & & \\
\hline
\end{tabular}


Gaines, Hale v. (1860)

Gaines v. Nicholson (1850)

Gay, Thomas v. (1898)

Gearlds, Johnson v. (1914)

Georgia, Cherokee Nation v. (1831)

Georgia, Worcester v. (1832)

Gilfillian v. McKee (1895)

Gilpin v. United States (1921)

Goat v. United States (1912)

Goudy v. Meath (1906)

Green Bay Co., Pumpelly v. (1872)

Green, Dunbar v. (1905)

Groover, Coffee v. (1887)

Halbert v. United States (1931)

Hale v. Gaines (1860)

Halsell, Ball v. (1896)

Hand, Tyler v. (1849)

Harkness v. Hyde (1879)

Heckman v. United States (1912)

Heff. See In re Heff (1905)

Hegler v. Faulkner (1894)

Heirs of Garland v. Choctaw Nation

$$
\text { (1921) }
$$

Henderson v. Tennessee (1850)

Henshaw, Walker v. (1873)

Hicks, Nevada v. (2001)

Hitchcock, Cherokee Nation v. (1902)

Hitchcock, Lone Wolf v. (1903)

Hitchcock, Minnesota v. (1902)
$55+$

160

152

287

$18(2)$

42

106(5)

$8 \quad 11 \quad 11(1)$

18(1) $\quad 18(2) \quad 18(3) \quad 18(4)$

$\begin{array}{llll}29 & 42 & 48 & 49\end{array}$

$292-355$

$266 \quad 266(1) \quad 266(6) \quad 334$

$168 \quad 183(4) \quad 185 \quad 244$

266(6) $281 \quad 285$

169

268

32

50

61

294

$55+$

248(5)

$160 \quad 160(19)$

373(2)

$11 \quad 18$

$248-292+\quad 89-106$

$303+\quad 352+$

$115+$

$288(8)$

$\begin{array}{llll}307 & 322(1) & 331(1) & 363\end{array}$

$11(4) \quad 11(5) \quad 11(6) \quad 11(9)$

$18(11) \quad 18(14) \quad 18(16) \quad 20$

$\begin{array}{llllll}76 & 77 & 89 & 89(5) & 89(8) & 106(\mathrm{P})\end{array}$

11(3) $\quad 11(4) \quad 11(5)$

$18(5) \quad 18(6) \quad 18(7)$

$11(6)$

53

$76 \quad 77$

$334(4)$

$303 \quad 352$

159

292

89

$89(8)$

106

143

152

152(2)

164(2)

164(10) 240

$164 \quad 199(5) \quad 292(7)$

240(14) 268

$268(5)$

285

285(9)

11(7) 18

$89 \quad 106$

$355 \quad 364(3) \quad 364(6) \quad 364(12)$

199(3) $\quad 199(5) \quad 248(1) \quad 358$

365

327 


\begin{tabular}{|c|c|c|c|c|c|c|c|c|c|c|}
\hline Case title & Cited & Ratified & Treaty & Number(s) & & & & & & \\
\hline Hitchcock, Morris v. (1904) & 292(7) & 292(14) & $355(8)$ & & & & & & & \\
\hline Hitchcock, Oregon v. (1906) & 332 & & & & & & & & & \\
\hline Hitchcock, Wisconsin v. (1906) & $242(2)$ & $242(3)$ & $242(4)$ & $275(1)$ & $275(2)$ & $275(3)$ & & & & \\
\hline \multirow[t]{3}{*}{ Holden v. Joy (1872) } & 89 & 106 & 126 & 152 & 182 & 199 & 199(1) & $199(2)$ & 199(3) & $199(4)$ \\
\hline & 199(11) & 199(13) & 199(17) & 199(18) & 358 & $358(1)$ & $358(12.1)$ & $358(17)$ & $358(28)$ & $358(29)$ \\
\hline & $358(30)$ & 368 & & & & & & & & \\
\hline Holliday, United States v. (1866) & 298 & & & & & & & & & \\
\hline Holt State Bank, United States v. (1926) & 275 & 287 & 327 & & & & & & & \\
\hline Hyde, Harkness v. (1879) & $373(2)$ & & & & & & & & & \\
\hline Hy-Yu-Tse-Mil-Kin v. Smith (1904) & 289 & & & & & & & & & \\
\hline Idaho v. United States (2001) & 290 & $370(2)$ & & & & & & & & \\
\hline Illinois Steel Co., Budzisz v. (1898) & 161 & 179 & 253 & & & & & & & \\
\hline In re Eastern Cherokees (1911) & 199 & 248 & $248(9)$ & & & & & & & \\
\hline In re Heff (1905) & 318 & $321(3)$ & & & & & & & & \\
\hline In re Mayfield (1891) & $358(4)$ & $358(7)$ & $358(13)$ & & & & & & & \\
\hline Iowa, Missouri v. (1849) & 55 & 71 & 121 & 121(1) & $127(1)$ & 159 & 211 & 215 & 217 & \\
\hline Irvine, Sims v. (1799) & 7 & & & & & & & & & \\
\hline Itasca County, Bryan v. (1976) & 287 & & & & & & & & & \\
\hline $\begin{array}{l}\text { J.S. Stearns Lumber Co., United States v. } \\
\text { (1918) }\end{array}$ & 242 & 275 & $275(3)$ & & & & & & & \\
\hline Jacobs v. Prichard (1912) & $266(6)$ & 363 & & & & & & & & \\
\hline Jaffree, Wallace v. (1985) & 38 & & & & & & & & & \\
\hline Jenks, Patterson v. (1829) & $17(4)$ & & & & & & & & & \\
\hline Jicarilla Apache Tribe, Merrion v. (1982) & $199(5)$ & 292(7) & $303(15)$ & & & & & & & \\
\hline \multirow[t]{2}{*}{ John, United States v. (1978) } & 12 & 31 & 35 & 39 & 51 & 85 & 115 & 124 & 160 & $160(\mathrm{P})$ \\
\hline & 292 & 355 & & & & & & & & \\
\hline Johnson v. Gearlds (1914) & 287 & $287(1)$ & $287(2)$ & $287(7)$ & $288(8)$ & 307 & $322(1)$ & $331(1)$ & 363 & \\
\hline Johnson v. Riddle (1916) & 160 & 220 & 292 & $355(11)$ & & & & & & \\
\hline \multirow[t]{3}{*}{ Jones v. Meehan (1899) } & $10(2)$ & $11(4)$ & $15(3)$ & $23(4)$ & $23(5)$ & $127(6)$ & $127(11)$ & $155(4)$ & 160 & 172 \\
\hline & $177(1)$ & $177(2)$ & $177(3)$ & $191(5)$ & $191(6)$ & 268 & $320(3)$ & $320(7)$ & $327(2)$ & $327(3)$ \\
\hline & $327(5)$ & $327(8)$ & $327(9)$ & 331 & & & & & & \\
\hline Jones, Mescalero Apache Tribe v. (1973) & 261 & $261(10)$ & & & & & & & & \\
\hline Journeycake, Cherokee Nation v. (1894) & $152(2)$ & 182 & $199(3)$ & $352(3)$ & 355 & 356 & $358(9)$ & $358(15)$ & $358(16)$ & $358(17)$ \\
\hline
\end{tabular}




\begin{tabular}{|c|c|c|c|c|c|c|c|c|c|}
\hline 89 & 106 & 126 & 152 & 182 & 199 & $199(1)$ & $199(2)$ & 199(3) & $199(4)$ \\
\hline $199(11)$ & $199(13)$ & $199(17)$ & $199(18)$ & 358 & $358(1)$ & $358(12.1)$ & $358(17)$ & $358(28)$ & $358(29)$ \\
\hline $358(30)$ & 368 & & & & & & & & \\
\hline \multicolumn{10}{|l|}{152} \\
\hline 211 & 211(1) & & & & & & & & \\
\hline $90(15)$ & 143 & 164 & $164(10)$ & 268 & $268(11)$ & 273 & $273(10)$ & $273(11)$ & 274 \\
\hline $274(2)$ & 274(9) & $274(11)$ & & & & & & & \\
\hline \multicolumn{10}{|l|}{$367(2)$} \\
\hline \multicolumn{10}{|l|}{$248(5)$} \\
\hline \multicolumn{10}{|l|}{121} \\
\hline $10+$ & $15+$ & $23+$ & $90+$ & $97+$ & $103+$ & 158 & $267(11)$ & $267(12)$ & 314 \\
\hline $314(3)$ & 357 & $362+$ & & & & & & & \\
\hline 7 & $11(4)$ & $12(3)$ & $13(3)$ & $13(4)$ & 18 & 105 & $106(1)$ & & \\
\hline 292 & 332 & $332(1)$ & & & & & & & \\
\hline \multicolumn{10}{|l|}{332} \\
\hline 290 & 332 & & & & & & & & \\
\hline 369 & $369(12)$ & & & & & & & & \\
\hline 106 & $167(1)$ & $167(2)$ & $167(3)$ & $167(4)$ & $167(5)$ & $167(6)$ & $167(15)$ & & \\
\hline 160 & 292 & & & & & & & & \\
\hline 253 & $269+\#$ & & & & & & & & \\
\hline \multicolumn{10}{|l|}{355} \\
\hline 126 & $126(2)$ & $338 \#$ & $338(2)$ & & & & & & \\
\hline 11 & 18 & 372 & & & & & & & \\
\hline 350 & $369(1)$ & & & & & & & & \\
\hline $11(4)$ & $18(4)$ & 20 & $20(2)$ & 29 & $29(2)$ & $29(3)$ & $29(4)$ & $29(5)$ & \\
\hline $126(6)$ & $126(7)$ & $253(5)$ & $338(2)$ & $369(7)$ & & & & & \\
\hline $162+$ & 320 & $320(1)$ & $320(3)$ & $320(7)$ & & & & & \\
\hline
\end{tabular}

Kake v. Egan (1962)

Kansas, Missouri v. (1909)

Kansas Indians (1867)

Kendall v. San Juan Silver Mining Co. (1892)

Kendall v. United States (1869)

Kennedy. See New York ex rel.

Kennedy v. Becker (1916)

Keokuk, Barney v. (1877)

Kindred v. Union Pacific Railroad Co.

(1912)

Kinney v. Clark (1844)

Klamath and Moadoc Tribes of

Indians v. United States (1935)

Klamath and Moadoc Tribes,

United States v. (1938)

Klamath Indian Tribe, Oregon Dept. of

Fish and Wildlife v. (1985)

Kneip, Rosebud Sioux Tribe v. (1977)

Ladiga v. Roland (1844)

Lamon, McKee v. (1895)

Lane, Wisconsin v. (1918)

Latrobe, McKee v. (1895)

Leavenworth, Lawrence and Galveston

Railroad Co. v. United States (1876)

Lee, Williams v. (1959)

Leighton v. United States (1896)

Lessee of Lattimer v. Poteet (1840)

Leupp, Ouick Bear v. (1908)

Libby v. Clark (1886) 


\begin{tabular}{|c|c|c|c|c|c|c|c|c|}
\hline Case title & Cited & Ratified & Treaty & Number(s) & & & & \\
\hline Lomax, Pickering v. (1892) & $155(4)$ & & & & & & & \\
\hline Lomax v. Pickering (1899) & $155(4)$ & & & & & & & \\
\hline Lone Wolf v. Hitchcock (1903) & 355 & $364(3)$ & $364(6)$ & $364(12)$ & 365 & & & \\
\hline \multicolumn{9}{|l|}{$\begin{array}{l}\text { Lowe. See United States ex rel. } \\
\text { Lowe v. Fisher (1912) }\end{array}$} \\
\hline Lucas v. United States (1896) & $355(3)$ & $355(8.8)$ & & & & & & \\
\hline Lykins v. McGrath (1902) & 273 & & & & & & & \\
\hline \multicolumn{9}{|l|}{$\begin{array}{l}\text { Mackey. See United States use of } \\
\text { Mackey v. Coxe (1856) }\end{array}$} \\
\hline Maney v. Porter (1845) & $160(14)$ & & & & & & & \\
\hline $\begin{array}{l}\text { Marchie Tiger v. Western Investment Co. } \\
\text { (1911) }\end{array}$ & 183 & & & & & & & \\
\hline Marks v. United States (1896) & 373 & & & & & & & \\
\hline Marsh v. Brooks (1850) & 88 & 106 & 121 & 121(1) & & & & \\
\hline Marsh v. Brooks (1852) & 43 & 55 & 121 & 121(1) & & & & \\
\hline M'Arthur, Reynolds v. (1829) & 23 & & & & & & & \\
\hline Martin, New York ex rel. Ray v. (1946) & 21 & $21(7)$ & & & & & & \\
\hline Mason, Coy v. (1855) & 121 & & & & & & & \\
\hline Mason, United States v. (1973) & 358 & & & & & & & \\
\hline Massachusetts v. New York (1926) & 21 & $21(3)$ & & & & & & \\
\hline Mayes, Talton v. (1896) & $199(5)$ & $358(13)$ & & & & & & \\
\hline \multicolumn{9}{|l|}{ Mayfield. See In re Mayfield (1891) } \\
\hline Mazurie, United States v. (1975) & 373 & & & & & & & \\
\hline McBratney, United States v. (1882) & $367(2)$ & $367(6)$ & $367(7)$ & & & & & \\
\hline $\begin{array}{l}\text { McClanahan v. Arizona Tax } \\
\text { Commission (1973) }\end{array}$ & 372 & & & & & & & \\
\hline McCurtain, Fleming v. (1909) & $115(2)$ & $160(2)$ & $160(4)$ & $160(5)$ & $160(18)$ & 220 & 292 & $355(11-36)$ \\
\hline McGrath, Lykins v. (1902) & 273 & & & & & & & \\
\hline McKee v. Lamon (1895) & 160 & 292 & & & & & & \\
\hline McKee v. Latrobe (1895) & 355 & & & & & & & \\
\hline McKee, Gilfillian v. (1895) & 292 & 355 & & & & & & \\
\hline McLaughlin, United States v. (1888) & 126 & & & & & & & \\
\hline M'Clung's Lessee, Meigs v. (1815) & $48(2)$ & & & & & & & \\
\hline Meath, Goudy v. (1906) & $266(6)$ & 281 & 285 & & & & & \\
\hline
\end{tabular}


Meehan, Jones v. (1899)

Meigs v. M'Clung's Lessee (1815)

Menominee Tribe of Indians $v$. United States (1968)

Merrion v. Jicarilla Apache Tribe (1982)

Mescalero Apache Tribe,

New Mexico v. (1983)

Mescalero Apache Tribe $v$. Jones (1973)

Metlakatla Indian Community

v. Egan (1962)

Mille Lac Band of Chippewa Indians, United States v. (1913)

Mille Lacs Band of Chippewa

Indians, Minnesota v. (1999)

Mingus, Atlantic and Pacific Railroad Co. v. (1897)

Minnesota, Stearns v. (1900)

Minnesota, United States v. (1926)

Minnesota v. Hitchcock (1902)

Minnesota v. Mille Lacs Band of

Chippewa Indians (1999)

Minnesota v. United States (1939)

Minter v. Crommelin (1856)

Mississippi, Arkansas v. (1919)

Missouri, Kansas and Texas

Railway Co. v. Cook (1896)

$\begin{array}{llllllllll}10(2) & 11(4) & 15(3) & 23(4) & 23(5) & 127(6) & 127(11) & 155(4) & 160 & 172 \\ 177(1) & 177(2) & 177(3) & 191(5) & 191(6) & 268 & 320(3) & 320(7) & 327(2) & 327(3) \\ 327(5) & 327(8) & 327(9) & 331 & & & & & \\ 48(2) & & & & & & & & \\ 12(3) & 14(6) & 15(3) & 23(5) & 198(4) & 253 & 269 & \end{array}$

199(5) 292(7) 303(15)

261

$261 \quad 261(10)$

$143 \quad 152 \quad 22$

370(2) $\quad 372 \quad 372(2)$

$287 \quad 322(1) \quad 322(2) \quad 322(4)$

230(2) $243 \quad 294 \quad 366$

322(12) $331 \quad 331(1) \quad 331(2)$

$366(2) \quad 370$

27\# 219(6)\# 221(1)\# 223\#

223(1)\# 223(2)\# 223(3)\# 223(4)\#

242\# 242(2)\# 242(6)\# 249\#

287(11) 290(3)\# 297\# 297(1)+

$352-355-356$

357

$331(12) \quad 363$

223(5)\# 225

$249(4)+275 \#$

332\#

160(4) 167(14) 199(5) 248(1)

(1)

268

322(1)

$322(2) \quad 322(12) \quad 331$

331(1) 331(2)

$\begin{array}{lllll}363 & 363(1) & 363(2) & & \\ 110 & 161 & 253(2) & 269(1) & 327\end{array}$

27\# 219(6)\# 221(1)\# 223\#

225(1) 225(2)\# 227(2)+ 228(3)\#

275(2)\# 275(11)\# 287\# 287(1)\#

223(1)\# 223(2)\# 223(3)\# 223(4)\# 223(5)\# 225

242\# 242(2)\# 242(6)\# 249\# $249(4)+275 \#$

287(11) 290(3)\# 297\# 297(1)+ 332\#

61

152(1)

338

(continued on next page) 


\begin{tabular}{|c|c|c|c|c|c|c|c|c|c|c|}
\hline Case title & Cited & Ratified & Treaty & Number(s) & & & & & & \\
\hline $\begin{array}{l}\text { Missouri, Kansas and Texas Railway } \\
\text { Co. v. Roberts (1894) }\end{array}$ & 126 & 338 & & & & & & & & \\
\hline $\begin{array}{l}\text { Missouri, Kansas and Texas Railway } \\
\text { Co. v. United States (1914) }\end{array}$ & $355(11)$ & 356 & $358(16)$ & & & & & & & \\
\hline Missouri v. Iowa (1849) & 55 & 71 & 121 & 121(1) & $127(1)$ & 159 & 211 & 215 & 217 & \\
\hline Missouri v. Kansas (1909) & 211 & 211(1) & & & & & & & & \\
\hline Missouri v. Nebraska (1904) & 127 & & & & & & & & & \\
\hline Mitchell, United States v. (1980) & 294 & & & & & & & & & \\
\hline Mitchell, United States v. (1983) & 294 & & & & & & & & & \\
\hline $\begin{array}{l}\text { Moe v. Confederated Salish and } \\
\text { Kootenai Tribes of Flathead } \\
\text { Reservation (1976) }\end{array}$ & 295 & 372 & & & & & & & & \\
\hline Montana v. United States (1981) & $\begin{array}{l}160 \\
370(8)\end{array}$ & $\begin{array}{l}275+ \\
370(9)\end{array}$ & $\begin{array}{l}281(2) \\
999\end{array}$ & 281(3) & 287 & 369 & 370 & $370(2)$ & $370(4)$ & $370(6)$ \\
\hline Morris v. Hitchcock (1904) & 292(7) & $292(14)$ & $355(8)$ & & & & & & & \\
\hline Morrison, United States v. (1916) & $242(2)$ & 253 & 269 & 275 & 301 & & & & & \\
\hline Mullen v. Pickens (1919) & 177 & 327 & & & & & & & & \\
\hline Mullen v. United States (1912) & 12 & 115 & 160 & 220 & 292 & $354+$ & 355 & $355(10)$ & & \\
\hline Myrick v. Thompson (1879) & $159(9)$ & & & & & & & & & \\
\hline $\begin{array}{l}\text { Nadeau v. Union Pacific } \\
\text { Railroad Co. (1920) }\end{array}$ & 247 & $247(4)$ & 318 & $318(5)$ & & & & & & \\
\hline $\begin{array}{l}\text { Nashville, Chattanooga and St. Louis } \\
\text { Railway Co., United States v. (1886) }\end{array}$ & 173 & $173(1)$ & $173(11)$ & 191(11) & $260(2)$ & $260(5)$ & & & & \\
\hline Navarre, United States v. (1899) & 362 & $362(10)$ & & & & & & & & \\
\hline Nebraska, Boyd v. (1892) & $160(14)$ & $199(12)$ & & & & & & & & \\
\hline Nebraska, Missouri v. (1904) & 127 & & & & & & & & & \\
\hline Nevada v. Hicks (2001) & 152 & 164 & 199(5) & 292(7) & $303(15)$ & 372 & $373(2)$ & & & \\
\hline $\begin{array}{l}\text { New Mexico v. Mescalero Apache } \\
\text { Tribe (1983) }\end{array}$ & 261 & & & & & & & & & \\
\hline New York, Massachusetts v. (1926) & 21 & 21(3) & & & & & & & & \\
\hline New York ex rel. Cutler v. Dibble (1859) & 241 & & & & & & & & & \\
\hline New York ex rel. Kennedy v. Becker & 27 & 290 & & & & & & & & \\
\hline
\end{tabular}




\begin{tabular}{|c|c|c|c|c|c|c|c|c|c|c|}
\hline New York ex rel. Ray v. Martin (1946) & 21 & $21(7)$ & & & & & & & & \\
\hline New York Indians (1867) & 9 & 16 & 21 & $21(3)$ & 27 & 33 & $230(10)$ & 241 & & \\
\hline \multirow[t]{3}{*}{ New York Indians v. United States (1898) } & 148 & 161 & 161(1) & 230 & $230(1)$ & $230(2)$ & $230(3)$ & $230(4)$ & $230(5)$ & $230(6)$ \\
\hline & $230(9)$ & $230(10)$ & $230(12)$ & $230(13)$ & $230(14)$ & $230(15)$ & 232 & 241 & 254 & 301 \\
\hline & 302 & 305 & & & & & & & & \\
\hline New York Indians, United States v. (1899) & 230 & $230(2)$ & & & & & & & & \\
\hline Nicholson, Gaines v. (1850) & 160 & & & & & & & & & \\
\hline Noble, United States v. (1915) & 186 & & & & & & & & & \\
\hline Noble v. Oklahoma City (1936) & $167(12)$ & 183 & 292 & 303 & $303(2)$ & $356(3)$ & & & & \\
\hline Noonan v. Caledonia Mining Co. (1887) & $369(2)$ & & & & & & & & & \\
\hline $\begin{array}{l}\text { Northern Pacific Railroad Co., Bardon v. } \\
\text { (1892) }\end{array}$ & 126 & & & & & & & & & \\
\hline $\begin{array}{l}\text { Northern Pacific Railroad Co., Buttz v. } \\
\text { (1886) }\end{array}$ & 360 & $360(2)$ & $360(3)$ & $360(4)$ & $360(8)$ & $360(9)$ & $360(10)$ & & & \\
\hline $\begin{array}{l}\text { Northern Pacific Railroad Co., } \\
\quad \text { Prentice v. (1894) }\end{array}$ & $275(2.6)$ & & & & & & & & & \\
\hline $\begin{array}{l}\text { Northern Pacific Railway Co. v. } \\
\text { United States (1913) }\end{array}$ & 290 & $290(1)$ & $290(2)$ & & & & & & & \\
\hline $\begin{array}{l}\text { Northern Pacific Railway Co., } \\
\text { United States v. (1940) }\end{array}$ & 299 & 370 & & & & & & & & \\
\hline \multirow{2}{*}{$\begin{array}{l}\text { Northwestern Bands of Shoshone } \\
\text { Indians v. United States (1945) }\end{array}$} & 18 & 324 & $324(2)$ & $324(3)$ & $324(4)$ & 325 & $325(1)$ & $325(2)$ & $325(3)$ & $325(4)$ \\
\hline & 326 & 329 & 373 & $373(2)$ & 999 & & & & & \\
\hline Oklahoma v. Arkansas (1985) & 152 & & & & & & & & & \\
\hline Oklahoma v. Texas (1922) & 364 & & & & & & & & & \\
\hline Oklahoma v. Texas (1926) & $292+$ & 292(1) & & & & & & & & \\
\hline \multirow[t]{2}{*}{ Oklahoma, Choctaw Nation v. (1970) } & 11 & 12 & $18(7)$ & 29 & 31 & 48 & 89 & $89(5)$ & 106 & $115(2)$ \\
\hline & 124 & 152 & $160(4)$ & $160(18)$ & 182 & 199 & $199(2)$ & $220+$ & 292 & \\
\hline Oklahoma City, Noble v. (1936) & $167(12)$ & 183 & 292 & 303 & $303(2)$ & $356(3)$ & & & & \\
\hline $\begin{array}{l}\text { Oklahoma Gas and Electric Co., } \\
\text { United States v. (1943) }\end{array}$ & 174 & 272 & 321 & & & & & & & \\
\hline $\begin{array}{l}\text { Oklahoma Tax Commission v. } \\
\text { Chickasaw Nation (1995) }\end{array}$ & 160 & $220+$ & & & & & & & & \\
\hline $\begin{array}{l}\text { Oklahoma Tax Commission v. Sac } \\
\text { and Fox Nation (1993) }\end{array}$ & $15+$ & & & & & & & & & \\
\hline
\end{tabular}


Table 2 (continued)

\begin{tabular}{|c|c|c|c|c|c|c|c|c|c|c|}
\hline Case title & Cited & Ratified & Treaty & Number(s) & & & & & & \\
\hline $\begin{array}{l}\text { Oklahoma Tax Commission v. } \\
\text { United States (1943) }\end{array}$ & $167(14)$ & $303(4)$ & 352 & 356 & & & & & & \\
\hline $\begin{array}{l}\text { Oklahoma Tax Commission, West } v \text {. } \\
\text { (1948) }\end{array}$ & $338(2)$ & $358(17)$ & & & & & & & & \\
\hline \multirow[t]{2}{*}{ Old Settlers, United States v. (1893) } & 11 & 89 & 106 & 152 & $152(2)$ & $152(4)$ & $152(8)$ & 182 & 199 & 199(1) \\
\hline & $199(2)$ & $199(8)$ & 199(10) & $199(12)$ & $199(15)$ & 248 & $248(3)$ & $248(4)$ & $248(5)$ & $248(11)$ \\
\hline Oliphant v. Suquamish Indian Tribe (1978) & $8(4)$ & $12(4)$ & 14(3) & 43 & $160(4)$ & 265 & 266 & 283 & 283(9) & $328(6)$ \\
\hline Olson, Rice v. (1945) & $334+$ & 335 & & & & & & & & \\
\hline Omaha Indian Tribe, Wilson v. (1979) & 266 & 334 & & & & & & & & \\
\hline $\begin{array}{l}\text { Omaha Tribe of Indians, } \\
\text { United States v. }(1920)\end{array}$ & 266 & $266(1)$ & 266(4) & $266(5)$ & $266(7)$ & $334(2)$ & & & & \\
\hline $\begin{array}{l}\text { Oneida Indian Nation, County of } \\
\text { Oneida v. (1985) }\end{array}$ & 9 & 16 & 21 & $21(2)$ & $21(7)$ & 28 & 230 & $230(2)$ & & \\
\hline $\begin{array}{l}\text { Oneida Indian Nation v. County of } \\
\text { Oneida (1974) }\end{array}$ & 9 & 16 & 21 & & & & & & & \\
\hline $\begin{array}{l}\text { Oregon Dept. of Fish and Wildlife v. } \\
\text { Klamath Indian Tribe (1985) }\end{array}$ & 290 & 332 & & & & & & & & \\
\hline $\begin{array}{l}\text { Oregon, Federal Power Commission v. } \\
\text { (1955) }\end{array}$ & 293 & 293(1) & & & & & & & & \\
\hline Oregon v. Hitchcock (1906) & 332 & & & & & & & & & \\
\hline $\begin{array}{l}\text { Paine Lumber Co., United States v. } \\
\text { (1907) }\end{array}$ & 301 & $301(11)$ & & & & & & & & \\
\hline \multirow[t]{2}{*}{ Pam-To-Pee v. United States (1893) } & $23(4)$ & $57(3)$ & $101(3)$ & $117(4)$ & $146(3)$ & $154(2)$ & 155 & $155(2)$ & $172(3)$ & $175(3)$ \\
\hline & 189 & $189(3)$ & $247 \#$ & & & & & & & \\
\hline Papasan v. Allain (1986) & $173+$ & & & & & & & & & \\
\hline Patrick, Felix v. (1892) & 159 & 369 & $369(6)$ & & & & & & & \\
\hline Patterson v. Jenks (1829) & $17(4)$ & & & & & & & & & \\
\hline Payne, United States v. (1924) & $266(6)$ & 294 & $294(2)$ & $294(5)$ & $294(6)$ & & & & & \\
\hline Pennock v. Commissioners (1881) & 243 & $243(2)+$ & 312 & $312(10)$ & $359(17)$ & $359(18)$ & & & & \\
\hline $\begin{array}{l}\text { Peoria Tribe of Indians } v . \\
\text { United States (1968) }\end{array}$ & 164 & 273 & 273(4) & 273(7) & & & & & & \\
\hline Perrin v. United States (1914) & 307 & $307(17)$ & $327(7)$ & & & & & & & \\
\hline Pickens, Mullen v. (1919) & 177 & 327 & & & & & & & & \\
\hline
\end{tabular}


Pigeon River Improvement, Slide

and Boom Co. v. Charles W.

Cox, Ltd. (1934)

Pintard, Thredgill v. (1851)

Polk, Best v. (1873)

Porter, Maney v. (1845)

Poteet, Lessee of Lattimer v. (1840)

Powers, United States v. (1939)

Prentice v. Northern Pacific

$$
\text { Railroad Co. (1894) }
$$

Prentice v. Stearns (1885)

Preston v. Browder (1816)

Prichard, Jacobs v. (1912)

Pronovost v. United States (1914)

Pumpelly v. Green Bay Co. (1872)

Puyallup Tribe, Dept. of Game v. (1973)

Puyallup Tribe v. Dept. of Game (1968)

Puyallup Tribe, Inc. v. Dept. of Game (1977)

Quick Bear v. Leupp (1908)

Race Horse, Ward v. (1896)

160(14)

11(4)

$18(4)$

20

20(2)

29

29(2) 29(3)

29(4)

29(5)

275(2.6)

275(2.6)

$18 \quad 29$

266(6) 363

295(2)

169

281

$281 \quad 281(2) \quad 281(3) \quad 281(6) \quad 290$

281

$\begin{array}{lllll}126(6) & 126(7) & 253(5) & 338(2) & 369(7)\end{array}$

Ramah Navajo School Board, Inc. v. $372(6)$

Bureau of Revenue (1982)

Ray. See New York ex rel. Ray v.

Martin (1946)

Reid, Webster v. (1851)

Reily, United States v. (1933)

Repentigny, United States v. (1867)

Reynolds v. M'Arthur (1829)

Rice v. Olson (1945)

Riddle, Johnson v. (1916)

Roberts, Missouri, Kansas and

373(1) $373(2) \quad 373(4)$

Texas Railway Co. v. (1894)

$\begin{array}{llll}121 & 121(1) & & \\ 174 & 272 & 321 & 321(10) \\ 110 & & & \\ 23 & & & \\ 334+ & 335 & & \\ 160 & 220 & 292 & 355(11) \\ 126 & 338 & & \end{array}$




\begin{tabular}{|c|c|c|c|c|c|c|c|c|c|}
\hline Case title & Cited & Ratified & Treaty & Number(s) & & & & & \\
\hline Robinson v. Caldwell (1897) & 291 & & & & & & & & \\
\hline Roff v. Burney (1897) & $292(7)$ & $355(38)$ & & & & & & & \\
\hline Rogers, United States v. (1846) & 199(5) & & & & & & & & \\
\hline Roland, Ladiga v. (1844) & 106 & $167(1)$ & $167(2)$ & $167(3)$ & $167(4)$ & $167(5)$ & $167(6)$ & $167(15)$ & \\
\hline Rosebud Sioux Tribe v. Kneip (1977) & 369 & $369(12)$ & & & & & & & \\
\hline Rowell, United States v. (1917) & 364 & & & & & & & & \\
\hline $\begin{array}{l}\text { Sac and Fox Indians of the Mississippi } \\
\text { in Iowa v. Sac and Fox Indians of } \\
\text { the Mississippi in Oklahoma (1911) }\end{array}$ & 43 & 225 & 243 & $243(4)$ & 312 & $312(6)$ & $312(7)$ & 359 & $359(21)$ \\
\hline $\begin{array}{l}\text { Sac and Fox Indians of the Mississippi } \\
\text { in Oklahoma, Sac and Fox Indians of } \\
\text { the Mississippi in Iowa v. (1911) }\end{array}$ & 43 & 225 & 243 & $243(4)$ & 312 & $312(6)$ & $312(7)$ & 359 & $359(21)$ \\
\hline $\begin{array}{l}\text { Sac and Fox Nation, Oklahoma Tax } \\
\text { Commission v. (1993) }\end{array}$ & $15+$ & & & & & & & & \\
\hline $\begin{array}{l}\text { San Juan Silver Mining Co., } \\
\text { Kendall v. (1892) }\end{array}$ & $367(2)$ & & & & & & & & \\
\hline Sandford, Scott v. (1857) & $160(14)$ & 199(12) & & & & & & & \\
\hline $\begin{array}{l}\text { Santa Fe Pacific Railroad Co., } \\
\text { United States v. (1941) }\end{array}$ & 261 & 328 & 367 & 372 & & & & & \\
\hline Schrimpscher v. Stockton (1902) & $285(1)$ & $285(2)$ & $285(3)$ & $285(4)$ & $361(15)$ & & & & \\
\hline Scott v. Sandford (1857) & $160(14)$ & $199(12)$ & & & & & & & \\
\hline Seminole Nation, United States v. (1937) & $303(8)$ & $352(3)$ & & & & & & & \\
\hline Seminole Nation v. United States (1942) & $303(8)$ & 352(3)\# & $352(6)$ & $352(8)$ & 356 & $362(1)$ & & & \\
\hline Seneca Nation v. Christy (1896) & 21 & & & & & & & & \\
\hline Seufert Bros. Co. v. United States (1919) & 290 & 290(3) & 293 & & & & & & \\
\hline Shirley, Atkinson Trading Co. v. (2001) & 290 & 370 & $372+$ & & & & & & \\
\hline $\begin{array}{l}\text { Shoshone Tribe of Indians, } \\
\text { United States v. (1938) }\end{array}$ & 324 & 373 & & & & & & & \\
\hline $\begin{array}{l}\text { Shoshone Tribe of Indians v. } \\
\text { United States (1937) }\end{array}$ & 373 & $373(2)$ & & & & & & & \\
\hline Sims v. Irvine (1799) & 7 & & & & & & & & \\
\hline Sioux Nation of Indians, & 160 & 364 & 369 & $369(2)$ & $369(12)$ & 999 & & & \\
\hline
\end{tabular}


Sioux Tribe of Indians v.

United States (1942)

Sisseton and Wahpeton Bands of Sioux Indians, United States v. (1908)

Sisseton and Wahpeton Bands of Sioux Indians v. United States (1928)

Sloan v. United States (1904)

Smith, Clark v. (1839)

Smith, Coyle v. (1911)

Smith, Hy-Yu-Tse-Mil-Kin v. (1904)

Smith v. Stevens (1870)

Smith v. United States (1894)

South Dakota v. Bourland (1993)

South Dakota v. Yankton Sioux Tribe (1998)

Southern Kansas Railway Co.,

Cherokee Nation v. (1890)

Southern Ute Tribe, United States $v$. (1971)

Spalding v. Chandler (1896)

Squire v. Capoeman (1956)

Starr v. Campbell (1908)

Stearns, Prentice v. (1885)

Stearns v. Minnesota (1900)

Stephens v. Cherokee Nation (1899)

Stevens, Smith v. (1870)

Stewart v. United States (1907)

Stockton, Schrimpscher v. (1902)

Stone, United States v. (1865)

Suquamish Indian Tribe, Oliphant $v$. (1978)

Sutton, United States v. (1909)

Talton v. Mayes (1896)

Taylor. See Ex parte Taylor (1852)

Tebbitts, Wright v. (1876)

\begin{tabular}{|c|c|c|c|c|c|c|c|c|c|}
\hline 369 & $369(2)$ & & & & & & & & \\
\hline 258 & $309(6)$ & 360 & $360(2)$ & $360(3)$ & $360(4)$ & $360(6)$ & & & \\
\hline $258(3)$ & 259 & 308 & $360(2)$ & & & & & & \\
\hline $159(10)$ & $266(6)$ & $334(4)$ & & & & & & & \\
\hline 105 & & & & & & & & & \\
\hline 373(4) & & & & & & & & & \\
\hline 289 & & & & & & & & & \\
\hline 127 & $127(6)$ & $127(11)$ & & & & & & & \\
\hline 358 & & & & & & & & & \\
\hline 369 & $369(2)$ & 370 & & & & & & & \\
\hline 307 & $307(1)$ & $307(4)$ & $307(10)$ & $307(11)$ & & & & & \\
\hline 11 & 29 & 49 & 182 & 199 & 248 & 358 & & & \\
\hline 328 & 367 & & & & & & & & \\
\hline 110 & $110(1)$ & $110(3)$ & 201 & 297 & & & & & \\
\hline 294 & 294(2) & & & & & & & & \\
\hline $275(3)$ & & & & & & & & & \\
\hline $275(2.6)$ & & & & & & & & & \\
\hline 268 & & & & & & & & & \\
\hline $160(14)$ & $199(5)$ & 248 & $248(1)$ & 358 & $358(9)$ & & & & \\
\hline 127 & $127(6)$ & $127(11)$ & & & & & & & \\
\hline $338(1)$ & $338(2)$ & $338(13)$ & $338(16)$ & & & & & & \\
\hline $285(1)$ & $285(2)$ & $285(3)$ & $285(4)$ & $361(15)$ & & & & & \\
\hline 103 & 158 & 267 & 314 & & & & & & \\
\hline $8(4)$ & $12(4)$ & $14(3)$ & 43 & $160(4)$ & 265 & 266 & 283 & 283(9) & $328(6)$ \\
\hline $266(6)$ & 290(2) & $290(4)$ & & & & & & & \\
\hline $199(5)$ & $358(13)$ & & & & & & & & \\
\hline $355(49$ & & & & & & & & & \\
\hline
\end{tabular}


Table 2 (continued)

\begin{tabular}{|c|c|c|c|c|c|c|c|c|c|c|}
\hline Case title & Cited & Ratified & Treaty & Number(s) & & & & & & \\
\hline $\begin{array}{l}\text { Tee-Hit-Ton Indians v. United States } \\
\text { (1955) }\end{array}$ & 332 & & & & & & & & & \\
\hline Tennessee, Henderson v. (1850) & 89 & $89(8)$ & 106 & & & & & & & \\
\hline Texas, Oklahoma v. (1922) & 364 & & & & & & & & & \\
\hline Texas, Oklahoma v. (1926) & $292+$ & $292(1)$ & & & & & & & & \\
\hline Texas, United States v. (1896) & 282 & 292 & 364 & & & & & & & \\
\hline Thomas, United States v. (1894) & $242(1)$ & $242(2)$ & $242(5)$ & $242(7)$ & 275 & & & & & \\
\hline Thomas v. Gay (1898) & 152 & 199 & 338 & $338(16)$ & 358 & & & & & \\
\hline Thompson, Myrick v. (1879) & $159(9)$ & & & & & & & & & \\
\hline Thredgill v. Pintard (1851) & 96 & & & & & & & & & \\
\hline Thurston v. United States (1914) & $328(6)$ & $367(5)$ & $367(6)$ & & & & & & & \\
\hline Tulee v. Washington (1942) & 290 & $290(3)$ & & & & & & & & \\
\hline Turner v. United States (1919) & $356(10)$ & & & & & & & & & \\
\hline $\begin{array}{l}\text { Tuscarora Indian Nation, Federal } \\
\text { Power Commission v. (1960) }\end{array}$ & 9 & 16 & 19 & 21 & $21(3)$ & $21(6)$ & 22 & 27 & 230 & $230(14)$ \\
\hline Tyler v. Hand (1849) & 160 & $160(19)$ & & & & & & & & \\
\hline $\begin{array}{l}\text { Union Pacific Railroad Co., } \\
\text { Kindred v. (1912) }\end{array}$ & $\begin{array}{l}10+ \\
314(3)\end{array}$ & $\begin{array}{l}15+ \\
357\end{array}$ & $\begin{array}{l}23+ \\
362+\end{array}$ & $90+$ & $97+$ & $103+$ & 158 & $267(11)$ & $267(12)$ & 314 \\
\hline $\begin{array}{l}\text { Union Pacific Railroad Co., } \\
\text { Nadeau v. (1920) }\end{array}$ & 247 & $247(4)$ & 318 & $318(5)$ & & & & & & \\
\hline $\begin{array}{l}\text { Union Pacific Railway Co., } \\
\text { United States v. (1897) }\end{array}$ & 158 & 267 & $267(11)$ & $267(12)$ & 314 & $314(2)$ & $314(3)$ & 317 & 357 & $357(1)$ \\
\hline United States, Alberty v. (1896) & $358(9)$ & $358(13)$ & & & & & & & & \\
\hline United States, Ballinger v. (1910) & 160 & & & & & & & & & \\
\hline United States, Blackfeather v. (1903) & $268(11)$ & $268(14)$ & $358(9)$ & $358(15)$ & & & & & & \\
\hline $\begin{array}{l}\text { United States, Board of County } \\
\text { Commissioners v. (1939) }\end{array}$ & 318 & & & & & & & & & \\
\hline $\begin{array}{l}\text { United States, Bowling and Miami } \\
\text { Investment Co. v. (1914) }\end{array}$ & $101+$ & 178 & 180 & 273 & $274+$ & 361 & & & & \\
\hline $\begin{array}{l}\text { United States, Brewer-Elliott Oil and } \\
\text { Gas Co.v. (1922) }\end{array}$ & 358 & $358(16)$ & & & & & & & & \\
\hline
\end{tabular}


United States, Chase v. (1921)

$266 \quad 334$

United States, Cherokee Nation v.

(1926)

United States, Chippewa Indians of Minnesota v. (1937)

United States, Choctaw Nation of

Indians v. (1943)

United States, Choctaw Nation v. (1886)

United States, Clairmont v. (1912)

United States, Confederated Bands of

Ute Indians v. (1947)

United States, Cook v. (1891)

United States, Creek Nation v. (1943)

United States, Dick v. (1908)

United States, Donnelly v. (1913)

United States, Draper v. (1896)

United States, Fairbanks v. (1912)

United States, Gilpin v. (1921)

United States, Goat v. (1912)

United States, Halbert v. (1931)

United States, Heckman v. (1912)

United States, Idaho v. (2001)

United States, Kendall v. (1869)

United States, Klamath and Moadoc Tribes of Indians v. (1935)

United States, Leavenworth, Lawrence

and Galveston Railroad Co. v. (1876)

United States, Leighton v. (1896)

United States, Lucas v. (1896)

United States, Marks v. (1896)

United States, Menominee Tribe of

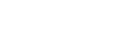

06

152

182

$110 \quad 111$

117

$\begin{array}{llll}207 & 219 & 242 & 250\end{array}$

251

275

287

139

$331 \quad 354 \quad 363$

$355 \quad 355(3) \quad 355(46)$

$115 \quad 115(2) \quad 115(4) \quad 124$

160(18) $\quad 160(19) \quad 160(20) \quad 292$

295

367

$\begin{array}{llll}152 & 262 & 343 & 364\end{array}$

191(3) 352(5) 356(1)

$327 \quad 327(7)$

369

370

$363(7)+$

$266 \quad 266(1) \quad 266(6) \quad 334$

$\begin{array}{llll}168 & 183(4) & 185 & 244\end{array}$

$\begin{array}{llllll}124(7) & 160 & 160(3) & 160(14) & 160(15) & 160(16) \\ 292(11) & 292(12) & 292(13) & 292(14) & 355 & \end{array}$

$145 \quad 148$

294

2

$\begin{array}{llll}248 & 292+ & 89 & 106 \\ 293+ & 352+\end{array}$


Table 2 (continued)

\begin{tabular}{|c|c|c|c|c|c|c|c|c|c|c|}
\hline Case title & Cited & Ratified & Treaty & Number(s) & & & & & & \\
\hline United States, Minnesota v. (1939) & 275 & $275(3)$ & & & & & & & & \\
\hline $\begin{array}{l}\text { United States, Missouri, Kansas and } \\
\text { Texas Railway Co. v. (1914) }\end{array}$ & $355(11)$ & 356 & $358(16)$ & & & & & & & \\
\hline United States, Montana v. (1981) & $\begin{array}{l}160 \\
370(8)\end{array}$ & $\begin{array}{l}275+ \\
370(9)\end{array}$ & $\begin{array}{l}281(2) \\
999\end{array}$ & $281(3)$ & 287 & 369 & 370 & $370(2)$ & $370(4)$ & $370(6)$ \\
\hline United States, Mullen v. (1912) & 12 & 115 & 160 & 220 & 292 & $354+$ & 355 & $355(10)$ & & \\
\hline \multirow{2}{*}{$\begin{array}{l}\text { United States, New York Indians v. } \\
\text { (1898) }\end{array}$} & 148 & 161 & $161(1)$ & 230 & $230(1)$ & $230(2)$ & $230(3)$ & $230(4)$ & $230(5)$ & $230(6)$ \\
\hline & $\begin{array}{l}230(9) \\
302\end{array}$ & $\begin{array}{l}230(10) \\
305\end{array}$ & $230(12)$ & $230(13)$ & $230(14)$ & $230(15)$ & 232 & 241 & 254 & 301 \\
\hline $\begin{array}{l}\text { United States, Northern Pacific } \\
\text { Railway Co. v. (1913) }\end{array}$ & 290 & $290(1)$ & $290(2)$ & & & & & & & \\
\hline United States, Northwestern Bands & 18 & 324 & $324(2)$ & $324(3)$ & $324(4)$ & 325 & $325(1)$ & $325(2)$ & $325(3)$ & $325(4)$ \\
\hline of Shoshone Indians v. (1945) & 326 & 329 & 373 & $373(2)$ & 999 & & & & & \\
\hline $\begin{array}{l}\text { United States, Oklahoma Tax } \\
\text { Commission v. (1943) }\end{array}$ & $167(14)$ & $303(4)$ & 352 & 356 & & & & & & \\
\hline \multirow[t]{2}{*}{ United States, Pam-To-Pee v. (1893) } & $23(4)$ & $57(3)$ & $101(3)$ & $117(4)$ & $146(3)$ & $154(2)$ & 155 & $155(2)$ & $172(3)$ & $175(3)$ \\
\hline & 189 & $189(3)$ & $247 \#$ & & & & & & & \\
\hline $\begin{array}{l}\text { United States, Peoria Tribe of } \\
\text { Indians v. (1968) }\end{array}$ & 164 & 273 & 273(4) & $273(7)$ & & & & & & \\
\hline United States, Perrin v. (1914) & 307 & $307(17)$ & $327(7)$ & & & & & & & \\
\hline United States, Pronovost v. (1914) & $295(2)$ & & & & & & & & & \\
\hline United States, Seminole Nation v. (1942) & $303(8)$ & 352(3)\# & $352(6)$ & $352(8)$ & 356 & $362(1)$ & & & & \\
\hline $\begin{array}{l}\text { United States, Seufert Bros. } \\
\text { Co. v. (1919) }\end{array}$ & 290 & $290(3)$ & 293 & & & & & & & \\
\hline $\begin{array}{l}\text { United States, Shoshone Tribe of } \\
\text { Indians v. (1937) }\end{array}$ & 373 & $373(2)$ & & & & & & & & \\
\hline $\begin{array}{l}\text { United States, Sioux Tribe of Indians v. } \\
\text { (1942) }\end{array}$ & 369 & $369(2)$ & & & & & & & & \\
\hline $\begin{array}{l}\text { United States, Sisseton and Wahpeton } \\
\text { Bands of Sioux Indians v. (1928) }\end{array}$ & $258(3)$ & 259 & 308 & $360(2)$ & & & & & & \\
\hline United States, Sloan v. (1904) & $159(10)$ & $266(6)$ & $334(4)$ & & & & & & & \\
\hline United States, Smith v. (1894) & 358 & & & & & & & & & \\
\hline United States, Stewart v. (1907) & $338(1)$ & $338(2)$ & $338(13)$ & $338(16)$ & & & & & & \\
\hline
\end{tabular}


United States, Tee-Hit-Ton Indians v. (1955)

United States, Thurston v. (1914)

United States, Turner v. (1919)

United States, Westmoreland v. (1895)

United States, Wilbur v. (1930)

United States, Yankton Sioux Tribe v. (1926)

United States ex rel. Lowe v. Fisher (1912)

United States use of Mackey v. Coxe (1856)

United States v. Alcea Band of Tillamooks (1946)

United States v. Algoma Lumber Co. (1939)

United States v. Andrews (1900)

United States v. Arredondo (1832)

United States v. Blackfeather (1894)

United States v. Brindle (1884)

United States v. Brooks (1850)

United States v. Carpenter (1884)

United States v. Celestine (1909)

United States v. Chase (1917)

United States v. Cherokee Nation (1906)

United States v. Choctaw Nation (1900)

United States v. Choctaw Nation (1904)

United States v. Cook (1874)

United States v. Creek Nation (1935)

United States v. Dann (1985)

United States v. Dion (1986)
332

328(6) $367(5) \quad 367(6)$

$356(10)$

$355(38)$

$307 \quad 307(8)$

$358(3) \quad 358(9)$

199(5)

324

332

$\begin{array}{llllllllll}364 & 364(2) & 364(11) & 364(11.3) & 364(11.6) & & & & \\ 23 & & & & & & & & \\ 143 & 143(2) & 164(2) & 164(4) & 164(5) & 164(7) & 164(11) & 164(13) & 268(8) & \\ 267 & 267(1) & 267(2) & 267(3) & 273 & 273(2) & & & \\ 197 & 197(1) & & & & & & & \\ 307 & & & & & & & & & \\ 266(6) & 281 & 283(3) & 283(7) & & & & & & \\ 318 & 334(4) & 362 & & & & & & \\ 18 & 89 & 106 & 152 & 199 & 199(1) & 248 & 248(4) & 248(11) & 358 \\ 368 & & & & & & & & & \\ 96(2) & 115 & 115(2) & 160(2) & 160(3) & 160(4) & 220 & 292 & 292(1) & 292(2) \\ 292(3) & 292(4) & 292(5) & 292(6) & 292(7) & 292(8) & 292(9) & 292(10) & 352 & 355(1) \\ 355(2) & 355(3) & 355(4) & 355(30) & 355(43) & 355(46) & 355(51) & 356(3) & & \\ 173 & 292 & 355(2) & 355(3) & & & & & & \\ 161 & 161(1) & & & & & & & & \\ 183(2) & 183(3) & 356(3) & 356(8) & 359(6) & & & & & \\ 352(6) & & & & & & & & \\ 307 & & & & & & & & \end{array}$

(continued on next page) 


\begin{tabular}{|c|c|c|c|c|c|c|c|c|c|c|}
\hline Case title & Cited & Ratified & Treaty & Number(s) & & & & & & \\
\hline $\begin{array}{l}\text { United States v. First National Bank } \\
\text { (1914) }\end{array}$ & $223(3)$ & $242(4)$ & $250(4)$ & 275 & $287(6)$ & 363 & $363(4)$ & & & \\
\hline $\begin{array}{l}\text { United States v. Forty-Three Gallons } \\
\text { of Whiskey (1876) }\end{array}$ & $287+$ & 327 & $327(7)$ & & & & & & & \\
\hline $\begin{array}{l}\text { United States v. Forty-Three Gallons } \\
\text { of Whiskey (1883) }\end{array}$ & $327(7)$ & & & & & & & & & \\
\hline United States v. Holliday (1866) & 298 & & & & & & & & & \\
\hline United States v. Holt State Bank (1926) & 275 & 287 & 327 & & & & & & & \\
\hline $\begin{array}{l}\text { United States v. J.S. Stearns Lumber } \\
\text { Co. (1918) }\end{array}$ & 242 & 275 & $275(3)$ & & & & & & & \\
\hline \multirow[t]{2}{*}{ United States v. John (1978) } & 12 & 31 & 35 & 39 & 51 & 85 & 115 & 124 & 160 & $160(\mathrm{P})$ \\
\hline & 292 & 355 & & & & & & & & \\
\hline $\begin{array}{l}\text { United States v. Klamath and Moadoc } \\
\text { Tribes (1938) }\end{array}$ & 332 & & & & & & & & & \\
\hline United States v. Mason (1973) & 358 & & & & & & & & & \\
\hline United States v. Mazurie (1975) & 373 & & & & & & & & & \\
\hline United States v. McBratney (1882) & $367(2)$ & $367(6)$ & $367(7)$ & & & & & & & \\
\hline United States v. McLaughlin (1888) & 126 & & & & & & & & & \\
\hline $\begin{array}{l}\text { United States v. Mille Lac Band of } \\
\text { Chippewa Indians (1913) }\end{array}$ & 287 & $322(1)$ & $322(2)$ & $322(4)$ & $322(12)$ & 331 & $331(1)$ & $331(2)$ & $331(12)$ & 363 \\
\hline \multirow[t]{2}{*}{ United States v. Minnesota (1926) } & 223(1) & 287 & $287(1)$ & $287(2)$ & $322(1)$ & $322(2)$ & $322(12)$ & 331 & $331(1)$ & $331(2)$ \\
\hline & 363 & $363(1)$ & $363(2)$ & & & & & & & \\
\hline United States v. Mitchell (1980) & 294 & & & & & & & & & \\
\hline United States v. Mitchell (1983) & 294 & & & & & & & & & \\
\hline United States v. Morrison (1916) & $242(2)$ & 253 & 269 & 275 & 301 & & & & & \\
\hline $\begin{array}{l}\text { United States v. Nashville, Chattanooga } \\
\text { and St. Louis Railway Co. (1886) }\end{array}$ & 173 & 173(1) & $173(11)$ & 191(11) & $260(2)$ & $260(5)$ & & & & \\
\hline United States v. Navarre (1899) & 362 & $362(10)$ & & & & & & & & \\
\hline United States v. New York Indians (1899) & 230 & $230(2)$ & & & & & & & & \\
\hline United States v. Noble (1915) & 186 & & & & & & & & & \\
\hline $\begin{array}{l}\text { United States v. Northern Pacific } \\
\text { Railway Co. }(1940)\end{array}$ & 299 & 370 & & & & & & & & \\
\hline $\begin{array}{l}\text { United States v. Oklahoma Gas and } \\
\text { Electric Co. (1943) }\end{array}$ & 174 & 272 & 321 & & & & & & & \\
\hline
\end{tabular}




\begin{tabular}{|c|c|c|c|c|c|c|c|c|c|c|}
\hline United States v. Old Settlers (1893) & 11 & 89 & 106 & 152 & $152(2)$ & $152(4)$ & $152(8)$ & 182 & 199 & $199(1)$ \\
\hline & 199(2) & 199(8) & 199(10) & 199(12) & 199(15) & 248 & $248(3)$ & $248(4)$ & $248(5)$ & $248(11)$ \\
\hline $\begin{array}{l}\text { United States v. Omaha Tribe of Indians } \\
\text { (1920) }\end{array}$ & 266 & $266(1)$ & $266(4)$ & $266(5)$ & $266(7)$ & $334(2)$ & & & & \\
\hline United States v. Paine Lumber Co. (1907) & 301 & $301(11)$ & & & & & & & & \\
\hline United States v. Payne (1924) & $266(6)$ & 294 & $294(2)$ & $294(5)$ & $294(6)$ & & & & & \\
\hline United States v. Powers (1939) & $370(6)$ & & & & & & & & & \\
\hline United States v. Reily (1933) & 174 & 272 & 321 & $321(10)$ & & & & & & \\
\hline United States v. Repentigny (1867) & 110 & & & & & & & & & \\
\hline United States v. Rogers (1846) & $199(5)$ & & & & & & & & & \\
\hline United States v. Rowell (1917) & 364 & & & & & & & & & \\
\hline $\begin{array}{l}\text { United States v. Santa Fe Pacific } \\
\text { Railroad Co. (1941) }\end{array}$ & 261 & 328 & 367 & 372 & & & & & & \\
\hline United States v. Seminole Nation (1937) & $303(8)$ & $352(3)$ & & & & & & & & \\
\hline $\begin{array}{l}\text { United States v. Shoshone Tribe of } \\
\text { Indians (1938) }\end{array}$ & 324 & 373 & & & & & & & & \\
\hline $\begin{array}{l}\text { United States v. Sioux Nation of } \\
\text { Indians (1980) }\end{array}$ & 160 & 364 & 369 & $369(2)$ & $369(12)$ & 999 & & & & \\
\hline $\begin{array}{l}\text { United States v. Sisseton and Wahpeton } \\
\text { Bands of Sioux Indians (1908) }\end{array}$ & 258 & $309(6)$ & 360 & $360(2)$ & $360(3)$ & $360(4)$ & $360(6)$ & & & \\
\hline $\begin{array}{l}\text { United States v. Southern Ute Tribe } \\
\text { (1971) }\end{array}$ & 328 & 367 & & & & & & & & \\
\hline United States v. Stone (1865) & 103 & 158 & 267 & 314 & & & & & & \\
\hline United States v. Sutton (1909) & $266(6)$ & $290(2)$ & $290(4)$ & & & & & & & \\
\hline United States v. Texas (1896) & 282 & 292 & 364 & & & & & & & \\
\hline United States v. Thomas (1894) & $242(1)$ & $242(2)$ & $242(5)$ & $242(7)$ & 275 & & & & & \\
\hline $\begin{array}{l}\text { United States v. Union Pacific } \\
\text { Railway Co. (1897) }\end{array}$ & 158 & 267 & $267(11)$ & $267(12)$ & 314 & $314(2)$ & $314(3)$ & 317 & 357 & $357(1)$ \\
\hline United States v. Waller (1917) & $250+$ & 363 & & & & & & & & \\
\hline United States v. Wheeler (1978) & 255 & 372 & & & & & & & & \\
\hline United States v. Winans (1905) & 290 & $290(1)$ & $290(2)$ & $290(3)$ & $290(10)$ & & & & & \\
\hline $\begin{array}{l}\text { Utah and Northern Railway v. } \\
\text { Fisher (1885) }\end{array}$ & 373 & & & & & & & & & \\
\hline Verden v. Coleman (1862) & 175 & & & & & & & & & \\
\hline Walker v. Henshaw (1873) & 143 & $164(2)$ & $164(10)$ & 240 & $240(14)$ & 268 & $268(5)$ & 285 & $285(9)$ & \\
\hline
\end{tabular}


Table 2 (continued)

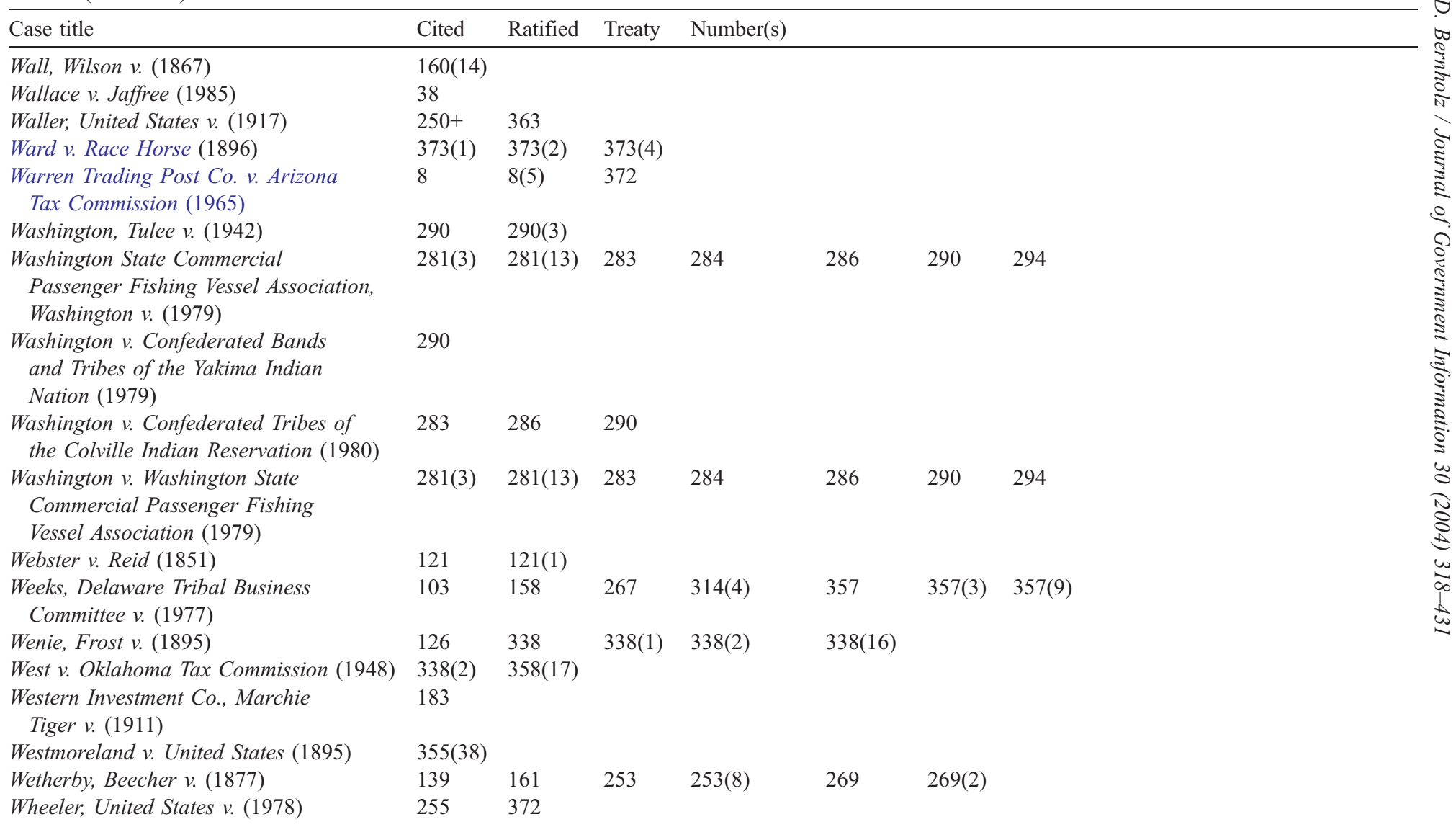


White v. Cannon (1868)

Whitmire, Cherokee Nation and United

States v. (1912)

Wiggan v. Conolly (1896)

Wilbur v. United States (1930)

Wilkins, Elk v. (1884)

Williams v. Chicago (1917)

Williams v. Lee (1959)

Wilson v. Omaha Indian Tribe (1979)

Wilson v. Wall (1867)

Wilson, Doe ex. dem. Mann v. (1860)

Winans, United States v. (1905)

Winton v. Amos (1921)

Wisconsin v. Hitchcock (1906)

Wisconsin v. Lane (1918)

Witherspoon v. Duncan (1867)

Woodward v. De Graffenried (1915)

Worcester v. Georgia (1832)

Wright v. Tebbitts (1876)

Yankton Sioux Tribe v. United States (1926)

Yankton Sioux Tribe, South Dakota v.
197

358

$358(9)$

$\begin{array}{lllllll}320 & 320(1) & 320(7) & 361 & 361(3) & 361(16) & 361(17)\end{array}$

$109 \quad 110 \quad 145 \quad 223$

$89-115-124-160$

$\begin{array}{llll}321 & 353 & 357 & 361\end{array}$

242

$287 \quad 322$

$\begin{array}{llll}199 & 254 & 285 & 301\end{array}$

301

331

363

$11 \quad 18 \quad 372$

$266 \quad 334$

$160(14)$

$177(3)$

$290 \quad 290(1) \quad 290(2) \quad 290(3) \quad 290(10)$

$160 \quad 160(3) \quad 160(14) \quad 160(19)$

242(2) 242(3) 242(4) 275(1) 275(2) 275(3)

$253 \quad 269+\#$

$152(2)$

$144(6) \quad 167(12)$

$18(1) \quad 18(1)$

$29 \quad 42$

$355(49)$

$307 \quad 307(8)$

$307 \quad 307(1) \quad 307(4) \quad 307(10) \quad 307(11)$

(1998)

Both principal entries and reverse case titles have been included. 


\section{Acknowledgment}

I thank Francis Paul Prucha, S.J., for his constructive comments regarding this article.

\section{Notes}

1. See Report of the Special Committee to Investigate the Indian Problem of the State of New York (1889, pp. 237-241, 244-249) for the text of these two transactions.

2. The foundation of the Handbook consists of a massive, 46-volume collection of case law, federal statutes and opinions, and rulings entitled Statutory Compilation of the Indian Law Survey (Cohen, 1940). Feldman (1986, p. 479) called Cohen's Handbook "the first synthesis of that field." A later edition, titled Felix Cohen's Handbook of Federal Indian Law, was published in 1982 by an editorial board composed of many prominent Indian law specialists. The publication attempted to enhance the original 1942 version with legislative and case law examples through March 1981.

3. As a clear demonstration of the continuity of federal Indian law, Williams v. Lee was cited in the recent Nevada v. Hicks (533 U.S. 353 [2001]) case as a cross-reference comparing the Treaty with the Navajo, 1868 with the Treaty with the Western Cherokee, 1828 (Kappler, 1971, pp. 1015-1020 and 288-292, respectively).

4. The attached tables indicate that 51 citations to 30 Indian treaties appeared in the opinions of 10 of the selected Supreme Court proceedings. These 10, in chronological order, are United States v. Rogers (45 U.S. 567 [1846]), Cherokee Tobacco (78 U.S. 616 [1871]), Cherokee Nation v. Southern Kansas Railway Co. (135 U.S. 641 [1890]), Ward v. Race Horse (163 U.S. 504 [1896]), Lone Wolf v. Hitchcock (187 U.S. 553 [1903]), Northwestern Bands of Shoshone Indians v. United States (324 U.S. 335 [1945]), Tee-Hit-Ton Indians v. United States (348 U.S. 272 [1955]), Oliphant v. Suquamish Indian Tribe (435 U.S. 191 [1978]), United States v. Sioux Nation of Indians (448 U.S. 371 [1980]), and County of Yakima v. Confederated Tribes and Bands of Yakima Indian Nation (502 U.S. 251 [1992]). The remaining five cases from Wilkins's list that do not have citations to treaty documents in their opinions are Johnson v. M'Intosh (21 U.S. 543 [1823]), United States v. Kagama (118 U.S. 375 [1886]), United States v. Nice (241 U.S. 591 [1916]), Lyng v. Northwest Indian Cemetery Protective Association (485 U.S. 439 [1988]), and Department of Human Resources Employment Division v. Smith (494 U.S. 872 [1990]).

5. With specific regard to rights discussed in treaties, the court concluded in United States v. Winans (198 U.S. 371, 381 [1905]) that a "treaty [is] not a grant of rights to the Indians, but a grant of rights from them-a reservation of those not granted." This "reserved rights doctrine" maintains that any right not explicitly extinguished by treaty or by federal statute is reserved or secured to the tribe.

6. Minnesota v. Mille Lacs Band of Chippewa Indians (526 U.S. 172 [1999]) revolved around certain rights assured by the United States in Article 5 of the Treaty with the Chippewa, 1837 (Kappler, 1971, pp. 491-493), which stated: "The privilege of hunting, fishing, and gathering the wild rice, upon the lands, the rivers and the lakes included in the territory ceded, is guaranteed to the Indians, during the pleasure of the President of the United States." A particularly clear image of the aspects of this case may be found in McClurken (2000).

7. Note that the U.S. Court of Claims ruled that, although never formally proclaimed or given a ratified treaty number by the Department of State, the Treaty of Fort Laramie with the Sioux, etc., 1851 "is binding upon the parties" (Roy v. United States, 45 Ct. Cl. 177, 177 [1910]). An additional entry point at the fictitious "999" ratified treaty number has been assigned to this treaty.

8. The remaining 85 treaties have appeared in the opinions of the lower federal court system (Bernholz, 2003).

9. The five elements were "Tribal Index of Materials on Indian Law" (Cohen, 1942, pp. 457-484), "Annotated Table of Statutes and Treaties" (pp. 485-608), "Table of Federal Cases" (pp. 609-627), "Table of Interior Department Rulings" (pp. 628-635), and "Table of Attorney General’s Opinions” (pp. 636-637).

10. The three cases, attached by a footnote to entry "7 Stat. 13" in Cohen's table on p. 499, are Labadie v. United States (6 Okla. 400 [1897]), United States v. Boylan (265 F. 165 [1920]), and Worcester v. Georgia (31 U.S. 515 [1832]). Only the last one of these appeared before the Supreme Court. 
11. The presence of Cherokee Nation v. Georgia in Table 1, as a case that cited the Treaty with the Delaware, 1778, suggests that Cohen's strategy for case inclusion in the Handbook may have been more stringent than the approach used for this note. The pertinent text in Cherokee Nation for inclusion in this note reads, "In the treaty of 1804 with the Delaware Indians, they are denominated the 'Delaware tribe of Indians'...And in a previous treaty with the same people in the year 1778, they are designated by the name of 'the Delaware nation." (30 U.S. 1, 65; emphasis added). This finding leads to the possibility that other cases, absent from the Handbook list, are now included in Table 1 as part of the suite of relevant cases before the Supreme Court.

12. Volume 6 of the 8th edition of Shepard's Federal Statute Citations (1996) covers volumes 1-504 of United States Reports. Volume 4 of Shepard's Federal Statute Citations: Statute Edition Supplement, 1996-2001 (2001) covers volumes 505 through a portion of volume 530 of this reporter. Cumulative soft covered issues that update the bound permanent volumes completed the examination through volume number 533. I thank Matthew Cheney of LexisNexis for his continued interest in, and support of, my research.

13. Volumes of Statutes at Large are now available on the Library of Congress's Century of Lawmaking for a New Nation page at http://memory.loc.gov/ammem/amlaw/lwsl.html. The texts of all but three treaties in Table 1 are available at this site. Two treaties (ratified treaty numbers 19 and 28) are in volume 1 of the American State Papers: Indian Affairs, which is also accessible at the Library of Congress (http://memory.loc.gov/ammem/amlaw/lwsp.html). The sole remaining document is the last of the seven preRevolutionary War treaties acknowledged by the Department of State (i.e., ratified treaty number 7), and this may be found in O'Callaghan (1857, pp. 111-137).

14. The first marked example from LexisNexis occurs for ratified treaty number 10, the Treaty with the Wyandot, etc., 1785 (Kappler, 1971, pp. 6-8), that was cited by Kindred v. Union Pacific Railroad Co. (225 U.S. 582 [1912]). This single case created seven extra entries in these tables (i.e., citation(s) for each of ratified treaty numbers $10,15,23,90,97,103$, and 362).

15. There are three special cases for treaty identification. None has a Statutes at Large entry, but all were recognized by the Department of State and hence have a ratified treaty number. One treaty is a pre-Revolutionary War document, and the other two appear only in the American State Papers: Indian Affairs. The three are ratified treaty number 7, the Treaty of Fort Stanwix, or The Grant from the Six Nations to the King and Agreement of Boundary Line-Six Nations, Shawnee, Delaware, Mingoes of Ohio, 1768 (O'Callaghan, 1857, pp. 111-137; abbreviated in Table 1 as NY 8, 111); ratified treaty number 19, the Treaty with the Five Nations, 1792 (American State Papers: Indian Affairs, 1998, p. 232; abbreviated in Table 1 as ASP: IA 1, 232); and ratified treaty 28, the Treaty with the Oneida, 1798 (p. 641; abbreviated in Table 1 as ASP: IA 1, 641).

16. The Bluebook's (2000, p. 66) Rule 10.5, "Date or Year," indicates "Dates of United States Supreme Court cases, which usually are not given in the official reports before 108 U.S., may be found in Lawyers' Edition beginning with the December 1854 Term." The 2001 Lawyers' Edition Quick Case Table was used, therefore, to confirm the correct date of each Supreme Court case. The Bluebook's Rules 10.2.1, "Case Names in Textual Sentences," and 10.2.2, "Case Names in Citations" (pp. 57-62), were followed throughout, except in those situations where clarification was considered appropriate. For example, each of ratified treaty numbers 43,225 , 243, 312, and 359 was cited in Sac and Fox Indians v. Sac and Fox Indians. For a clearer representation, that case appears in the tables as Sac and Fox Indians of the Mississippi in Iowa v. Sac and Fox Indians of the Mississippi in Oklahoma (220 U.S. 481 [1911]).

17. There is a single citation to the preamble of each of ratified treaty numbers 106 and 160 , and each is indicated by the symbol "(P)." Section(s) under a specific Article within a treaty are designated by a decimal point. For example, there are two special cases within Table 1 where ranges of sections or articles are defined. One of the entries for ratified treaty number 275-Fee v. Brown (162 U.S. 602 [1896]) — cites several individual Articles (number 1, 2, 3, and 7) of the Treaty with the Chippewa, 1854 (Kappler, 1971, pp. 648-652), as well as to sections $1-6$ of Article 2. These six sections are indicated in the table by the notation "(2.1-2.6)." In a similar manner, Fleming v. McCurtain (215 U.S. 56 [1909]) cites Articles 11-36 (the treaty consists of 51 articles) of ratified treaty number 355, the Treaty with the Choctaw and Chickasaw, 1866 (Kappler, 1971, pp. 918-931). In all other entries in the table, there is either no, or a single, article or article section specified. 
18. These three treaties are, respectively, the Treaty with the Choctaw and Chickasaw, 1866; the Treaty with the Kiowa, Comanche, and Apache, 1867; and the Treaty with the Kiowa and Comanche, 1867 (Kappler, 1971, pp. 918-931, 982-984, and 977-982). Article 12 contains the particularized procedural promise (Duthu, 2000, p. 167) from the third treaty that was discussed at length in these proceedings: "No treaty for the cession of any portion or part of the reservation herein described, which may be held in common, shall be of any validity or force as against the said Indians, unless executed and signed by at least three-fourths of all the adult male Indians occupying the same" (p. 981). Blue Clark (1999a) has commented upon the Lone Wolf case.

19. The three instruments are the Treaty with the Sauk and Foxes, 1837; the Treaty with the Winnebago, 1837; and the Treaty with the Winnebago, 1846 (Kappler, 1971, pp. 497-498, 498-500, and 565-567).

\section{References}

American State Papers: Indian Affairs: Vol. 1 (1998). Buffalo, NY: William S. Hein and Co., Reprint. Atkinson Trading Co. v. Shirley, 532 U.S. 645, (2001).

Bernholz, C. D. (2001). The absent American Indian treaties: A guide to treaties never referenced at the federal court level. Journal of Government Information, 28, 171-178.

Bernholz, C. D. (2002). The absent American Indian treaties: An update. Journal of Government Information, 29, 39-41.

Bernholz, C. D. (2003). American Indian Treaties and the lower federal courts: A guide to treaty citations from opinions of the lower federal court system, Manuscript in preparation.

Cherokee Nation v. Blackfeather, 155 U.S. 218 (1894).

Cherokee Nation v. Georgia, 30 U.S. 1 (1831).

Cherokee Nation v. Southern Kansas Railway Co., 135 U.S. 641 (1890).

Cherokee Tobacco, 78 U.S. 616 (1871).

Clark, B. (1987). Indian Title in Canada. Toronto, Ontario: Carswell.

Clark, B. (1990). Native Liberty, Crown Sovereignty: The Existing Aboriginal Right of Self-Government in Canada. Montreal, Quebec: McGill-Queen's University Press.

Clark, B. (1999a). Lone Wolf v. Hitchcock: Treaty Rights and Indian Law at the End of the Nineteenth Century. Lincoln: University of Nebraska Press.

Clark, B. (1999b). Justice in Paradise. Montreal, Quebec: McGill-Queen's University Press.

Cohen, F. S. (Ed.) (1940). Statutory Compilation of the Indian Law Survey: A Compendium of Federal Laws and Treaties Relating to Indians. Washington, DC: Government Printing Office.

Cohen, F. S. (1942). Handbook of Federal Indian Law. Washington, DC: Government Printing Office.

Cohen, F. S. (1982). Felix S. Cohen's Handbook of Federal Indian Law. Charlottesville, VA: Michie.

County of Oneida v. Oneida Indian Nation, 470 U.S. 226 (1985).

County of Yakima v. Confederated Tribes and Bands of Yakima Indian Nation, 502 U.S. 251 (1992).

Department of Human Resources Employment Division v. Smith, 494 U.S. 872 (1990).

Duthu, N. B. (2000). Incorporative discourse in federal Indian law: Negotiating tribal sovereignty through the lens of Native American literature. Harvard Human Rights Journal, 13, 141-189.

Fee v. Brown, 162 U.S. 602 (1896).

Feldman, S. M. (1986). Felix S. Cohen and his jurisprudence: Reflections on federal Indian law. Buffalo Law Review, 35, 479-525.

Fleming v. McCurtain, 215 U.S. 56 (1909).

Idaho v. United States, 533 U.S. 262, (2001).

Johnson v. M'Intosh, 21 U.S. 543 (1823).

Jones v. Meehan, 175 U.S. 1 (1899).

Kappler, C. J. (1971). Indian Affairs: Laws and Treaties: Vol. 2. Treaties. New York: AMS Press.

Kindred v. Union Pacific Railroad Co., 225 U.S. 582 (1912).

Labadie v. United States, 6 Okla. 400 (1897). 
2001 Lawyers' Edition Quick Case Table (2001). Charlottesville, VA: LexisNexis.

Lone Wolf v. Hitchcock, 187 U.S. 553 (1903).

Lyng v. Northwest Indian Cemetery Protective Association, 485 U.S. 439 (1988).

Mazurek, J. P., Wrend, J., Smith, C. (Eds.) (1998). American Indian Law Deskbook: Conference of Western Attorneys General (2nd ed.). Niwot: University Press of Colorado.

McClurken, J. M. (2000). Fish in the Lakes, Wild Rice, and Game in Abundance: Testimony on Behalf of Mille Lacs Ojibwe Hunting and Fishing Rights. East Lansing, MI: Michigan State University Press.

Minnesota v. Mille Lacs Band of Chippewa Indians, 526 U.S. 172 (1999).

Nevada v. Hicks, 533 U.S. 353, (2001).

Northwestern Bands of Shoshone Indians v. United States, 324 U.S. 335 (1945).

O'Callaghan, E. B. (Ed.) (1857). Documents Relative to the Colonial History of the State of New York, Vol. 8. Albany, NY: Weed, Parsons, and Co.

Oliphant v. Suquamish Indian Tribe, 435 U.S. 191 (1978).

Pam-To-Pee v. United States, 148 U.S. 691 (1893).

Prucha, F. P. (1994). American Indian Treaties: The History of a Political Anomaly. Berkeley, CA: University of California Press.

Report of Special Committee to Investigate the Indian Problem of the State of New York (1889). Albany, NY: Troy Press.

Roy v. United States, 45 Ct. Cl. 177 (1910).

Sac and Fox Indians of the Mississippi in Iowa v. Sac and Fox Indians of the Mississippi in Oklahoma and the United States, 220 U.S. 481 (1911).

Shepard's Federal Statute Citations: Vol. 6 (8th ed.) (1996). Colorado Springs, CO: Shepard's/McGraw-Hill.

Shepard's Federal Statute Citations: Statute Edition Supplement, 1996-2001: Vol. 4 (2001). Colorado Springs, CO: Lexis.

Tee-Hit-Ton Indians v. United States, 348 U.S. 272 (1955).

The Bluebook: A Uniform System of Citation (17th ed.) (2000). Cambridge, MA: Harvard Law Review Association.

United States v. Boylan, 265 F. 165 (1920).

United States v. Kagama, 118 U.S. 375 (1886).

United States v. Nice, 241 U.S. 591 (1916).

United States v. Rogers, 45 U.S. 567 (1846).

United States v. Sioux Nation of Indians, 448 U.S. 371 (1980).

United States v. Winans, 198 U.S. 371 (1905).

Ward v. Race Horse, 163 U.S. 504 (1896).

Warren Trading Post Co. v. Arizona Tax Commission, 380 U.S. 685 (1965).

Wilkins, D. E. (1997). American Indian Sovereignty and the U.S. Supreme Court: The Masking of Justice. Austin, TX: University of Texas Press.

Wilkinson, C. F. (1987). American Indians, Time, and the Law: Native Societies in a Modern Constitutional Democracy. New Haven, CT: Yale University Press.

Williams v. Lee, 358 U.S. 217 (1959).

Worcester v. Georgia, 31 U.S. 515 (1832). 